DENIS KENHITI SUZUKI

VERTICALIZAÇÃO DE ATERROS SANITÁRIOS POR MEIO DE REFORÇO COM GEOGRELHAS E DIQUES PERIFÉRICOS ALTEADOS PELO MÉTODO DE MONTANTE

SÃO PAULO

2012 
DENIS KENHITI SUZUKI

\title{
VERTICALIZAÇÃO DE ATERROS SANITÁRIOS POR MEIO DE REFORÇO COM GEOGRELHAS E DIQUES PERIFÉRICOS
} ALTEADOS PELO MÉTODO DE MONTANTE

\author{
Dissertação apresentada à Escola \\ Politécnica da Universidade de São \\ Paulo para obtenção do título de Mestre \\ em Engenharia
}

Área de Concentração:

Engenharia Geotécnica

Orientadora: Profa. Livre-Docente Maria Eugenia Gimenez Boscov

SÃO PAULO

2012 
Este exemplar foi revisado e alterado em relação à versão original, sob responsabilidade única do autor e com a anuência de seu orientador.

São Paulo, 22 de novembro de 2012.

Assinatura do autor

Assinatura do orientador

FICHA CATALOGRÁFICA

Suzuki, Denis Kenhiti

Verticalização de aterros sanitários por meio de reforço com geogrelhas e diques periféricos alteados pelo método de montante / D.K. Suzuki. -- ed.rev. -- São Paulo, 2012.

$165 \mathrm{p}$.

Dissertação (Mestrado) - Escola Politécnica da Universidade de São Paulo. Departamento de Engenharia de Estruturas e Geotécnica.

1. Aterros sanitários 2. Resíduos urbanos 3. Taludes 4. Estabilidade estrutural 5 . Geossintéticos 6 . Geometria e modelagem computacional I. Universidade de São Paulo. Escola Politécnica. Departamento de Engenharia de Estruturas e Geotécnica II. t. 


\section{DEDICATÓRIA}

Aos meus pais, Lidia lamasaqui Suzuki e Célio Yukihiro Suzuki, que sempre acreditaram na minha capacidade, me transmitiram todos os valores da vida e viveram uma vida de sacrifícios para me proporcionar a educação que me possibilitou chegar até aqui. 


\section{AGRADECIMENTOS}

Primeiramente, a Deus por sempre iluminar meu caminho e me dar força para concluir mais uma etapa em minha vida.

A professora Maria Eugênia Boscov, que acreditou na minha capacidade, e me orientou com paciência, dedicação e carinho ao longo de todo o desenvolvimento deste trabalho.

A todos os professores da Engenharia Geotécnica da EPUSP, pelo conhecimento e experiências transmitidas, que me ajudaram na minha formação profissional.

Aos meus irmãos, Daniel, Dayana e Magno, pela presença, por acreditarem em mim e pelos quais tanto me esforço.

A minha querida e amada esposa, Elke Cristina Hirata, pela compreensão das minhas ausências e por todo amor dado a que muito me orgulho.

Ao meu filho, Victor, cuja sua vinda me trouxe alegria e felicidade imensa, que me ajudou a concluir este trabalho.

Aos meus sogros, Cleide e Inácio, e todos os meus familiares que apoiaram, torceram e acompanharam o desenvolvimento da dissertação e desta etapa de minha vida.

Ao meu grande amigo, Lucio Barcelos Rodrigues, pelo companheirismo, apoio e presença constante em toda minha trajetória na engenharia até os dias atuais.

A Cristina Schmidt, da Huesker, pela idéia inicial do tema e pelo fornecimento dos dados técnicos das geogrelhas.

Aos meus amigos da Moretti Engenharia, Atilio, Geraldo e Fabian que me apresentaram à engenharia geotécnica de forma prática e que contribuíram consideravelmente na minha formação técnica.

Ao meu amigo Ivo Teixeira pela parceria no dia a dia e pelo apoio no desenvolvimento dos trabalhos técnicos.

A todos outros que direta ou indiretamente contribuíram para o desenvolvimento desta pesquisa. 
"Seu tempo é limitado. Por isso, não perca tempo em viver a vida de outra pessoa. Não se prenda pelo dogma que nada mais é do que viver pelos resultados das ideias de outras pessoas."

Steve Jobs 


\section{RESUMO}

Este trabalho apresenta resultados de análises de estabilidade por métodos de equilíbrio limite e análises tensão-deformação para um aterro sanitário de grande porte reforçado com geossintéticos e alteado com diques periféricos sucessivos segundo o método de montante de barragens de rejeitos, visando a aumentar sua capacidade de armazenamento. Os valores dos parâmetros de resistência elásticos e elasto-plásticos dos materiais foram definidos com base na bibliografia, privilegiando-se os obtidos em campo. Os parâmetros dos reforços geossintéticos (geogrelhas) foram obtidos dos catálogos técnicos de empresa fabricante de geogrelhas. Nas análises equilíbrio-limite verificou-se também a influência das pressões neutras nos fatores de segurança por meio da variação do parâmetro de pressão $r_{u}$ de 0 a 0,3 . Os resultados dos métodos de equilíbrio limite mostraram que a construção de diques periféricos sucessivos não aumenta significativamente o fator de segurança do aterro para qualquer altura e a de diques reforçados aumentao para alturas até $30 \mathrm{~m}$. Por outro lado, o reforço dentro do maciço aumenta consideravelmente o fator de segurança para qualquer altura do aterro. As pressões neutras no maciço podem reduzir significativamente o fator de segurança, em até $25 \%$ para as configurações propostas. $O$ fator de segurança 1,5 é atingido para $r_{u}=$ 0,2 , para as alturas de até $30 \mathrm{~m}$ nas configurações com reforço no interior do maciço sanitário. As análises tensão-deformação mostraram que as deformações são principalmente verticais, sendo que as horizontais representam até $30 \%$ das totais. As deformações verticais máximas foram de $4 \%$, valor muito inferior aos encontrados na bibliografia em aterros monitorados (10 a 40\%), provavelmente porque as contribuições da decomposição da matéria orgânica e do "creep" ao longo do tempo superam o efeito do peso próprio do maciço. A análise conjunta das duas metodologias mostra que os fatores de segurança obtidos nas análises tensãodeformação são muito próximos aos obtidos nas análises equilíbrio-limite para $r_{u}$ $=0,1$; que o uso de reforços no interior do maciço sanitário proporciona um aumento no fator de segurança da ordem de $30 \%$, o que justifica a continuação deste estudo focalizando aspectos práticos construtivos e operacionais; e que a configuração em diques sucessivos e maciço sanitário reforçado mostrou-se, dentre as alternativas estudadas, a mais eficiente e eficaz para a configuração de aterro estudada, uma 
vez que permitiu obter o fator de segurança desejado sem a necessidade de reforço dos diques de solos. 


\begin{abstract}
This paper presents results of stability analysis by limit-equilibrium methods and stress-strain analysis for a large sanitary landfill reinforced with geosynthetics and raising with perimeters soil dikes according to the method used in tailing dams in order to increase their ability to storage. The values of strength parameters, elastic and elasto-plastic materials were defined based on the literature, privileging those obtained in the field. The parameters of geosynthetic reinforcements (geogrids) were obtained from the catalogs of technical manufacturer of geogrid. The analyzes limitequilibrium were verified also the influence of the factors of safety pore pressures by varying the parameter pressure $r_{u} 0$ to 0.3 . The results of limit-equilibrium methods showed that the construction of dikes successive peripheral does not significantly increase the safety factor of the landfill for any height and the use of reinforced dikes increases it to heights up to $30 \mathrm{~m}$. Moreover, the reinforcement into the mass increases substantially the safety factor for any height of the landfill. The pore pressures in mass can significantly reduce the safety factor in up to $25 \%$ for the proposed configurations. The safety factor of 1.5 is achieved for $r_{u}=0.2$, for heights up to $30 \mathrm{~m}$ with enhanced settings inside the massive sanitary. The stress-strain analyzes showed that the deformations are mainly vertical and the horizontal represent up to $30 \%$ of the total. The maximum vertical deformations were $4 \%$, value that is much lower than those described in the bibliography for landfill sites monitored (10-40\%), probably because the contributions of organic matter decomposition and "creep" over time outweigh the effect of self-weight of the massif. The joint analysis of the both methods show that safety factors obtained in the stress-strain analyzes are very near the limit-equilibrium analyses for $r_{u}=0.1$, that the use of solid reinforcement inside the landfill provides a factor increase in security of the order of $30 \%$, its which justifies the continuation of this study focusing on practical aspects of construction and operational and that the configuration in successive dikes and massive sanitary reinforced proved to be, among the alternatives studied, the most efficient and effective configuration of landfill studied, since it allowed to obtain the desired safety factor without the need to strengthen the soil dikes.
\end{abstract}




\section{LISTA DE TABELAS}

Tabela 2.1 - Composição do resíduos sólidos urbanos em diferente cidades (dados de Manassero et al. 1997, Carvalho 1999 e Boscov 2008) ...................................19

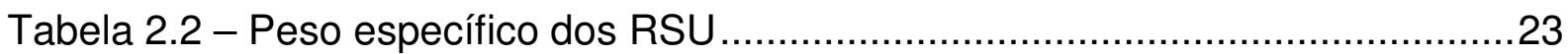

Tabela 2.3 - Revisão dos métodos para medir o comportamento cisalhamento do

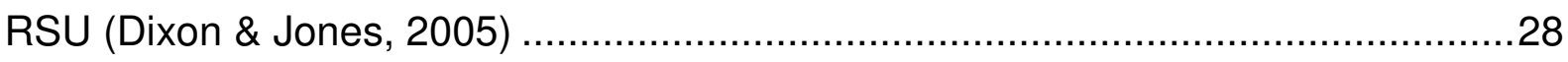

Tabela 2.4 - Resumo dos parâmetros de resistência dos RSU ..............................35

Tabela 2.5 - Recalques em maciços sanitários ..............................................41

Tabela 2.6 - Coeficiente de empuxo no repouso e coeficiente de Poisson ..............54

Tabela 2.7- Parâmetros para caracterização do lixiviado (Tchobanoglous et al., 1993)

Tabela 2.8 - Variação dos parâmetros dos lixiviados em função da idade do aterro (Gomes, 2008)

Tabela 2.9 - Variação da composição do lixiviado gerado em aterros brasileiros (Souto \& Povinelli, 2007) 60

Tabela 2.10 - Valores típicos para o índice de rigidez relativa (Ehrlich \& Becker,

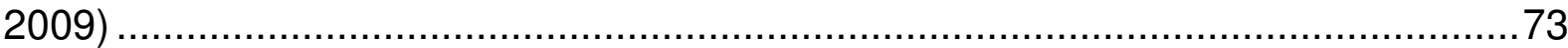

Tabela 2.11 - Fator de fluência para diferentes tipos de polímero.........................87

Tabela 2.12 - Fatores de redução para dano mecânico ......................................87

Tabela 2.13 - Fatores de redução por degradação ambiental, para geossintéticos

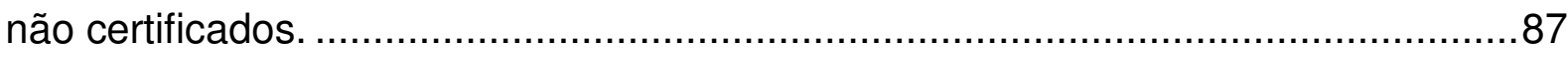

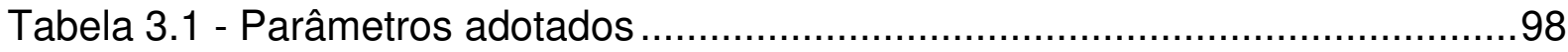

Tabela 3.2 - Parâmetros adotados para solos e RSU........................................104

Tabela 3.3 - Parâmetros adotados para a camada granular (interface estrutural) .104

Tabela 3.4 - Parâmetros de resistência das geogrelhas ................................... 105

Tabela 4.1 - Resumo dos resultados obtidos nas análises equilíbrio-limite. ..........128

Tabela 4.2 - Resumo dos resultados obtidos nas análises tensão-deformação.....145 


\section{LISTA DE ILUSTRAÇÕES}

Figura 2.1 - Detalhe dos elementos da malha utilizando representação discreta (Silva, 1998)

Figura 2.2- Classificação do RSU usando o diagrama triangular (Grisolia et al., 1995)

Figura 2.3 - Teor de umidade de resíduos sólidos urbanos (Carvalho, 1999) 21

Figura 2.4 - Variação da temperatura do RSU com a profundidade, Aterro de Muribeca, Recife (Mariano \& Jucá, 1998) 26

Figura 2.5 - Envoltórias de resistência de RSU correspondentes a diferentes níveis de deslocamentos obtidas em ensaios de cisalhamento direto (Stark et al., 2009) ..29 Figura 2.6 - Envoltórias de resistência de RSU para diferentes níveis de deformação axial obtidas em ensaios de compressão triaxial. (Stark et al., 2009) .

Figura 2.7 - Parâmetros de resistência para quatro níveis de deformação $(\gamma=7000$ $\mathrm{N} / \mathrm{m}^{3}$ ) (Ribeiro, 2007) 30

Figura 2.8 - Envoltórias de resistência de RSU obtidas por três autores para tensões normais até $300 \mathrm{kPa}$ (Ribeiro, 2007).

Figura 2.9 - Envoltórias de resistência obtidas por diversos autores para tensões normais até $1800 \mathrm{kPa}$ (Stark et al., 2009).

Figura 2.10 - Envoltórias de resistência para tensões normais efetivas menores que 500KPa (Stark et al., 2009)

Figura 2.11 - Equipamento para ensaios de resistência à tração desenvolvido por Kolsch (1993) .38

Figura 2.12 - Resistência à tração de RSU (Kolsch, 1995) 38

Figura 2.13 - Fatores que afetam a compressibilidade dos resíduos sólidos urbanos (Grisolia et al., 1993 apud Marques, 2001) 40

Figura 2.14 - Recalque total e anual de RSU (Gandolla et al., 1994). 42

Figura 2.15 - Medidas de recalques de superfície de diferentes aterros (König \& Jessberger, 1997)

Figura 2.16 - Resultados obtidos de ensaios de compressão confinada para resíduos do Canadá (Landva \& Clark, 1990 apud Carvalho, 1999) 
Figura 2.17 - Variação de módulo de deformação com a tensão vertical obtidos para diferentes resíduos sólidos urbanos (modificado de Knochenmus et al., 1998 apud Carvalho, 1999)

Figura 2.18 - Módulo de elasticidade $\mathrm{x}$ deformação axial para amostras com peso específico de $14 \mathrm{kN} / \mathrm{m}^{3}$ e $12 \mathrm{kN} / \mathrm{m}^{3}$, respectivamente (Carvalho, 1999) 46

Figura 2.19 - Comparação entre os módulos de elasticidade obtidos de ensaios em compressão confinada e de ensaios triaxiais a $20 \%$ de deformação axial (Carvalho, 1999) 46

Figura 2.20 - Módulos de deformabilidade secante em função da tensão octaédrica (Gomes, 2008)

Figura 2.21 - Módulos de deformabilidade não confinados do aterro de Sto Tirso (Gomes, 2008) .48

Figura 2.22 - Variação dos valores de $\mathrm{K}_{0}$ com o aumento do nível de tensa 49

Figura 2.23 - Coeficientes de Poisson obtidos por Matasovic \& Kavazanjian (1998)

Figura 2.24 - Medidas de $\mathrm{K}_{0}$ em RSU (Dixon et al. (2004)).

Figura 2.25 - Coeficientes de Poisson determinados a partir dos ensaios triaxiais em função da deformação axial .53

Figura 2.26 - Resumo de valores de $v$ e $\mathrm{K}_{0}$ determinados in situ em função da profundidade (Zeccos, 2005). .54

Figura 2.27 - Fatores que influenciam a produção de biogás 56

Figura 2.28 - Efeito do reforço na resistência ao cisalhamento (Abramento, 1998)..62 Figura 2.29 - Custos de construção, por área de face, em função da altura de muro, para várias soluções de contenção, conforme Elias et al. (2001) .63

Figura 2.30 - Talude reforçado por geossintéticos com comprimento variável (Azambuja e Strauss, 1999) .64

Figura 2.31 - Tipos de geogrelhas: (a) extrudada unidirecional; (b) extrudada bidirecional; (c) soldada; (d) tecida. 66

Figura 2.32 - Resistência mobilizada em função da deformação para diferentes tipos de geogrelha (Huesker, 2010). 68

Figura 2.33 - Mecanismos de interação típicos em estruturas de solo reforçado (Palmeira, 1999). .69 
Figura 2.34 - Esquema de geometria de uma geogrelha com os esforços envolvidos (Palmeira, 1999) .70

Figura 2.35 - Aderência entre grelha e solo: (a) mecanismos de interação e (b) definição da análise (Jewell, 1996) 70

Figura 2.36 - Mecanismos de ruptura interna em uma estrutura de solo reforçado (Milligan \& Palmeira, 1987 apud Becker, 2006) .71

Figura 2.37 - Tensões ( $\sigma$ e T) e deformações $(\varepsilon)$ no solo e no reforço (Ehrlich, 1994).

Figura 2.38 - Curva de compatibilidade solo-reforço (modificada de Jewell, 1990) ..75 Figura 2.39 - Curva de compatibilidade solo-reforço (Ehrlich, 2004)......................75 Figura 2.40 - Degradação termo-oxidativa em geotêxteis não tecidos em polipropileno e em poliéster (Santos et al., 2002 modificado por Pinto, 2005) .........78 Figura 2.41 - Efeito de soluções ácidas em geotêxteis não tecidos em PP e PET (Santos et al., 2002 modificado por Pinto, 2005). .78

Figura 2.42 - Efeito de soluções alcalinas em geotêxteis não tecidos em PP e PET (Santos et al., 2002 modificado por Pinto, 2005)...

Figura 2.43 - Efeito da temperatura na resistência à tração (adaptado de Pilarczyk, 2000 apud Pinto 2005)

Figura 2.44 - Configuração de um muro de solo reforçado, segundo Steward, Willianson e Mohney (1977) apud Ehrlich \& Becker (2009) . .89

Figura 2.45 - Variação da razão $K / K a$ em função da profundidade, para muros de solo reforçado (Elias, Christopher e Berg (2001) apud Ehrlich \& Becker (2009)......91 Figura 2.46 - Equilíbrio interno da massa de solo reforçado, segundo Ehrlich e Mitchell (1994) apud Ehrlich \& Becker (2009). .92

Figura 2.47 - Aplicações típicas de geossintéticos em aterros de resíduo (Koerner, 1994) . .93

Figura 3.1 - Método de montante de construção de barragens de rejeitos (Boscov, 2008)

Figura 3.2 - Ilustração das disposição dos reforços nas estruturas. 97

Figura 3.3 - Configurações estudadas: (a) Dique de solo ou aterro de resíduos de seção trapezoidal; (b) Aterro de resíduos com bermas de equilíbrio; (c) Dique de partida e aterro com bermas; (d) Dique de partida reforçado e aterro com bermas; (e) Diques sucessivos; (f) Diques sucessivos reforçados; (g) Aterro com diques 
sucessivos e reforço entre camadas de resíduos; (h) Aterro com diques sucessivos reforçado e reforço entre camadas de resíduos.................................................100

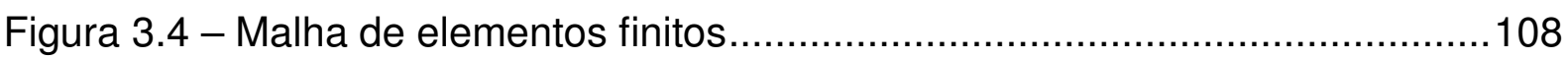

Figura 3.5 - Deslocamentos horizontais absolutos .........................................109

Figura 3.6 - Deslocamentos verticais absolutos ............................................109

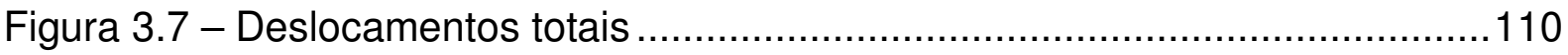

Figura 3.8 - Máxima tensão de cisalhamento (com contorno da superfície

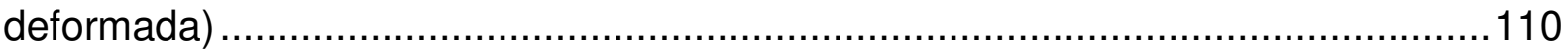

Figura 4.1- Fatores de segurança para aterro de resíduos com altura de $6 \mathrm{~m}$. .......112

Figura 4.2 - Fatores de segurança para aterro de resíduos com altura de $15 \mathrm{~m} . \ldots . .113$

Figura 4.3 - Fatores de segurança para aterro de resíduos com altura de 30m......113

Figura 4.4 - Variação do fator de segurança com a altura e inclinação do aterro de

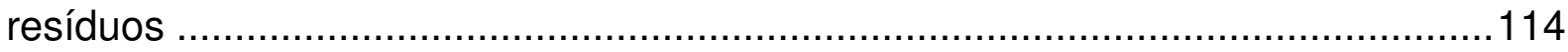

Figura 4.5 - Fatores de segurança para dique de solo com $5 \mathrm{~m}$.........................115

Figura 4.6 - Fatores de segurança para dique de solo com $6 \mathrm{~m}$...........................115

Figura 4.7 - Fatores de segurança para dique de solo com $7 \mathrm{~m}$. ..........................116

Figura 4.8 - Comparação entre fatores de segurança para dique de solo e aterro de resíduos com mesma altura ........................................................................116

Figura 4.9 - Fatores de segurança para a configuração de aterro com bermas .....118 Figura 4.10 - Fatores de segurança para a configuração do aterro com dique de partida e bermas ...........................................................................................119

Figura 4.11 - Fatores de segurança para a configuração do aterro com dique de partida reforçado e bermas.

Figura 4.12 - Fatores de segurança para a configuração do aterro com diques sucessivos.

Figura 4.13 - Fatores de segurança para a configuração do aterro com diques sucessivos reforçados...... 121

Figura 4.14 - Variação da superfície de ruptura com o alteamento do aterro. 121

Figura 4.15 - Fatores de segurança para a configuração de diques sucessivos e maciço reforçado 122

Figura 4.16 - Contribuição do reforço na estabilidade do aterro............................123

Figura 4.17 - Forças atuantes em uma das lamelas do circulo de ruptura .............123 
Figura 4.18 - Fatores de segurança para a configuração do aterro com diques sucessivos reforçados e com reforços no interior do maciço sanitário. 124

Figura 4.19 - Fatores de segurança das configurações analisadas para $r_{u}=0 \ldots \ldots .125$

Figura 4.20 - Fatores de segurança das configurações analisadas para $r_{u}=0,1 \ldots 125$

Figura 4.21 - Fatores de segurança das configurações analisadas para $r_{u}=0,2 \ldots .126$

Figura 4.22 - Fatores de segurança das configurações analisadas para $r_{u}=0,3 \ldots 126$

Figura 4.23 - Fatores de segurança para configuração em diques sucessivos.......129 Figura 4.24 - Comparação entre os fatores de segurança obtidos nas análises tensão-deformação e equilíbrio limite. 130

Figura 4.25 - Deformações máximas obtidas para configuração em diques sucessivos.

Figura 4.26 - Deslocamentos máximos obtidos para configuração em diques sucessivos 131

Figura 4.27 - Fatores de segurança para configuração em diques sucessivos reforçados 132

Figura 4.28 - Variação da zona plastificada com o alteamento do aterro. 133 Figura 4.29 - Comparação entre as configurações sem reforço e com as análises equilíbrio limite 133

Figura 4.30 - Deformações máximas para configuração em diques sucessivos reforçados 134

Figura 4.31 - Deslocamentos máximos para a configuração em diques sucessivos reforçados 134

Figura 4.32 - Fatores de segurança obtidos em cada estágio de alteamento para configuração de diques sucessivos e maciço reforçado 135

Figura 4.33 - Fatores de segurança corrigidos em cada estágio de alteamento para configuração de diques sucessivos e maciço reforçado 136

Figura 4.34 - Comparação entre os resultados das análises tensão-deformação e equilíbrio limite para configuração de diques sucessivos e maciço sanitário reforçado

Figura 4.35 - Deformações para configuração em diques sucessivos e maciço reforçado

Figura 4.36 - Deslocamentos para configuração em diques sucessivos e maciço reforçado 138 
Figura 4.37 - Fatores de segurança obtidos para cada etapa de alteamento para configuração de diques sucessivos reforçados e maciço reforçado. 139

Figura 4.38 - Comparação entre os resultados das análises tensão-deformação e equilíbrio limite para configuração de diques sucessivos com e sem reforço e maciço sanitário reforçado. 139

Figura 4.39 - Deslocamentos obtidos para as configurações sem e com reforço nos diques e maciço reforçado 140

Figura 4.40 - Deformações obtidas para as configurações sem e com reforço nos diques e maciço reforçado

Figura 4.41 - Comparação dos resultados obtidos nas análises tensão-deformação para as configurações estudadas.

Figura 4.42 - Comparação entre fatores de segurança com e sem interface estrutural no reforço geossintético 142

Figura 4.43 - Deslocamentos máximos obtidos nas análises com interface estrutural 143

Figura 4.44 - Deformações máximas obtidas nas análises com interface estrutural 143

Figura 4.45 - Comparação entre os valores de deslocamento com e sem interface estrutural 144

Figura 4.46 - Comparação entre os valores de deformação com e sem interface estrutural 144 


\section{LISTA DE ABREVIATURAS E SIGLAS}

$\begin{array}{ll}\text { AR } & \text { Aramida } \\ \text { ABNT } & \text { Associação Brasileira de Normas Técnicas } \\ \text { CPT } & \text { Cone Penetration Test } \\ \text { CU } & \text { Consolidated Undrained } \\ \text { FR } & \text { Fator de Redução Total } \\ \text { FS } & \text { Fator de Segurança } \\ \text { GCE } & \text { Geogrelha Extrudada } \\ \text { GCL } & \text { Geosynthetic Clay Liner } \\ \text { GGB } & \text { Geogrelha Soldada } \\ \text { GGW } & \text { Geogrelha Tecida } \\ \text { IBGE } & \text { Instituto Brasileiro de Geografia e Estatística } \\ \text { IPT } & \text { Instituto de Pesquisas Tecnológicas } \\ \text { MEF } & \text { Método dos Elementos Finitos } \\ \text { PEAD } & \text { Polietileno de Alta Densidade } \\ \text { PET } & \text { Poliéster } \\ \text { PP } & \text { Polipropileno } \\ \text { PVA } & \text { Álcool de Polivinila } \\ \text { RSU } & \text { Resíduos Sólidos Urbanos } \\ \text { SPT } & \text { Standart Penetration Test } \\ \text { USEPA } & \text { United States Environmental Protection Agency } \\ \text { UV } & \text { Ultravioleta } \\ \end{array}$




\section{LISTA DE SÍMBOLOS}

a

$\alpha$

c

$c^{\prime}$

$C_{e}$

$C_{d}$

D

$\delta$

E

Es

$\varepsilon r$

$\varepsilon x$

$f a$

fcr

fe

$\phi$

$\phi^{\prime}$

$f m$

fmr

$F S a$

$F S g$
Adesão da interface solo-geossintético

Coeficiente de correção de temperatura

Coesão

Coesão efetiva

Temperatura do ensaio

Temperaturao dentro do solo ou do resíduo

Módulo de compressão confinada

Ângulo de atrito da interface solo-geossintético.

Módulo de deformabilidade

Módulo de deformabilidade secante

Alongamento máximo na ruptura

Deformação horizontal

Fator de redução parcial para danos químicos e ambientais

Fator de redução parcial para fluência à tração

Fator de redução

Ângulo de atrito

Ângulo de atrito efetivo

Fator de redução parcial para incertezas estatísticas na determinação da resistência do geossintético.

Fator de redução parcial para danos mecânicos de instalação

Fator de segurança ao arrancamento

Fator de segurança global da estrutura

Peso específico do solo

Peso específico do material sobrejacente 
Altura de material sobrejacente

Jr Módulo de rigidez à tração

$k \quad$ Coeficiente de empuxo

K Coeficiente de permeabilidade

K Módulo inicial tangente do solo do modelo hiperbólico

$K_{0} \quad$ Coeficiente de empuxo no repouso

ka Coeficiente de empuxo ativo

Le Comprimento de ancoragem

$v \quad$ Coeficiente de Poisson

$\mathrm{Pa} \quad$ Pressão atmosférica

$r_{u} \quad$ Parâmetro de pressão neutra $r_{u}$

Si I I lndice de rigidez relativa

Sh Espaçamento horizontal dos reforços

$\sigma 1 \quad$ Tensão principal maior

$\sigma^{\prime} x \quad$ Tensão horizontal efetiva

ooct Tensão octaédrica

ov Tensão vertical

Sv $\quad$ Espaçamento vertical dos reforços

$\sigma^{\prime} z(z) \quad$ Tensão vertical na profundidade $z$

Ta Resistência a tração disponível no reforço (admissível)

$T(z) \quad$ Força de tração na profundidade $\mathrm{z}$, medida a partir da crista

$t_{d} \quad$ Tempo de projeto = vida útil da estrutura

Td Resistência à tração de projeto do geossintético

$t_{d c o r r} \quad$ Vida útil corrigida

$t_{e} \quad$ Tempo de duração do ensaio

Tmax Resistência a tração do reforço 
Largura do geossintético

Pressão neutra / Pressão neutra

Z

Profundidade

$\zeta$

Ângulo de forças de tração interno tensão normal como coesão 


\section{SUMÁRIO}

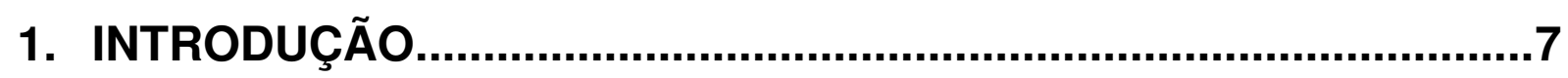

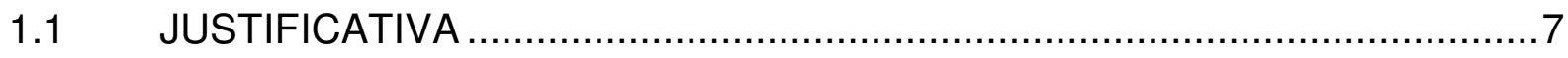

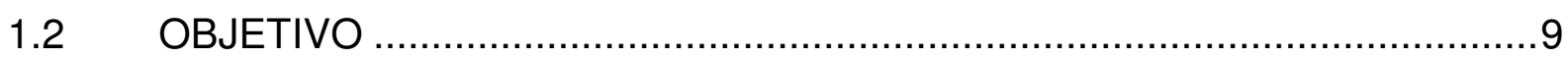

2. REVISÃO BIBLIOGRÁFICA.....................................................11

2.1 ESTABILIDADE DE TALUDES DE ATERROS SANITÁRIOS ....................11

2.1.1 Análise das tensões e deformações por métodos numéricos........................11

2.1.2 Influência da geração de lixiviados e gases na estabilidade dos aterros......13

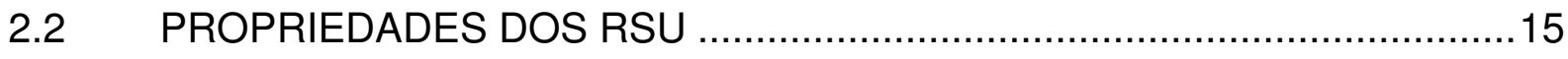

2.2.1 Classificação dos resíduos sólidos urbanos .............................................16

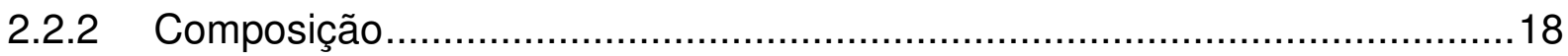

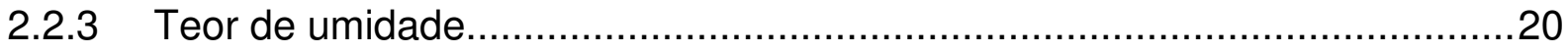

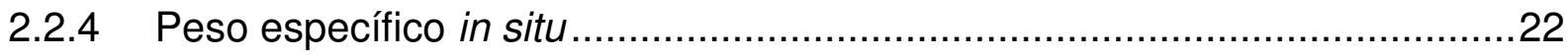

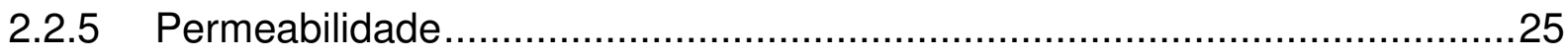

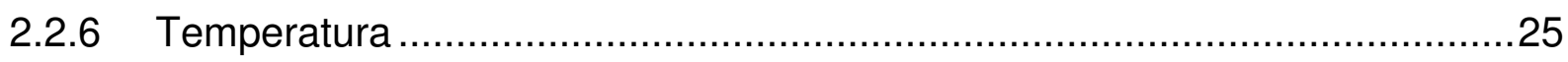

2.2.7 Parâmetros de resistência de RSU.........................................................26

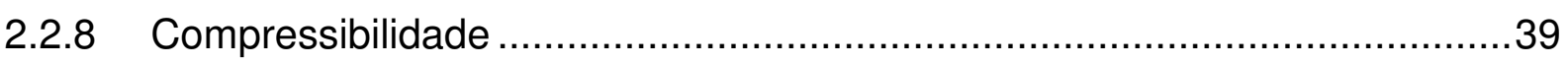

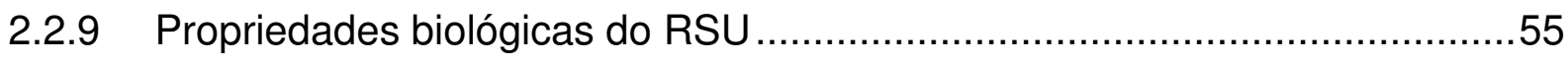

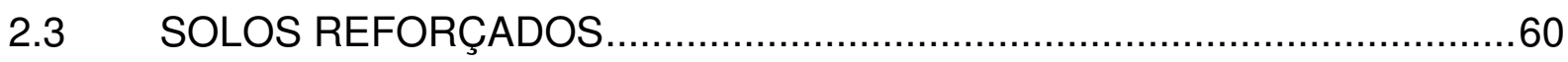

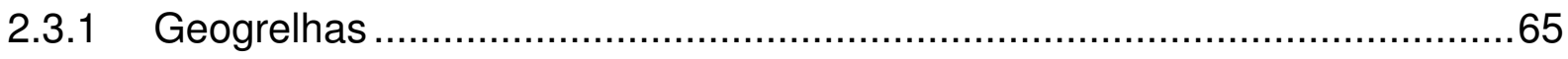

2.3.2 Mecanismos de interação solo-reforço ......................................................68

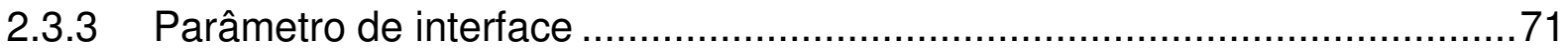

2.3.4 Compatibilidade de deformações ............................................................73

2.3.5 Durabilidade e degradação físico-química dos geossintéticos .....................76

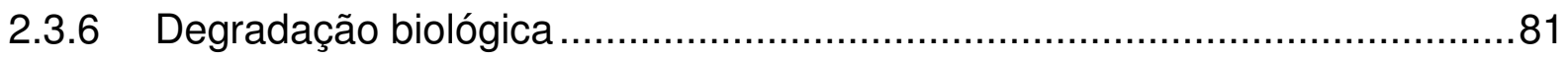

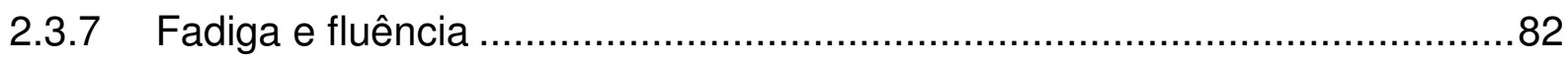




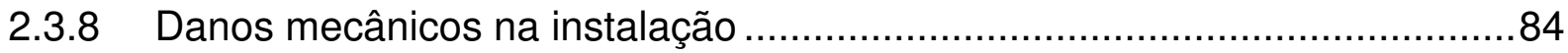

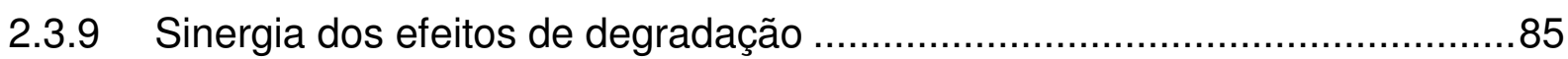

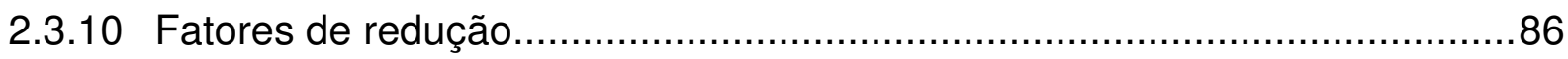

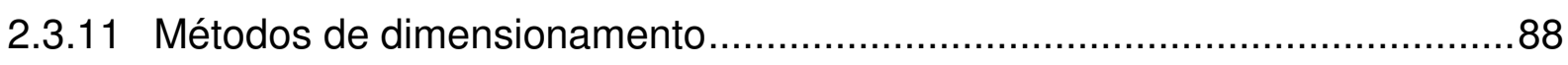

2.4 GEOSSINTÉTICOS EM ATERROS DE RSU …......................................92

3. MATERIAIS E MÉTODOS...........................................................96

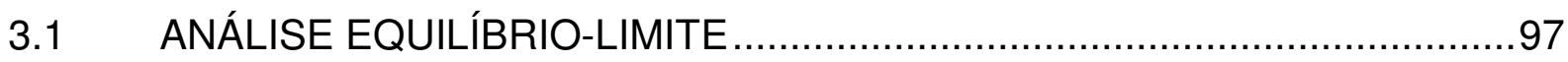

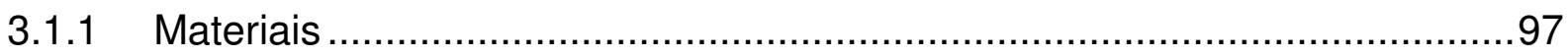

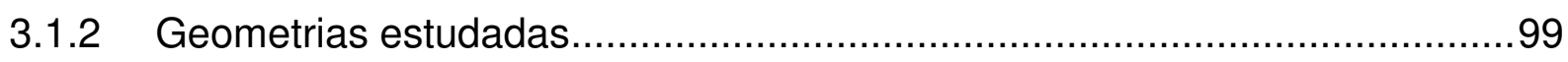

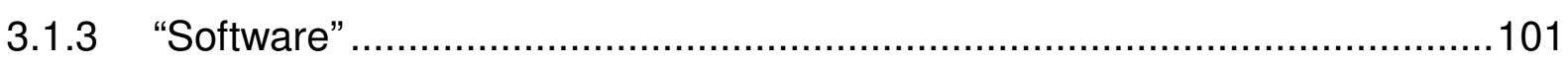

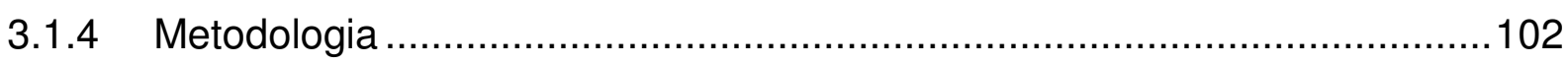

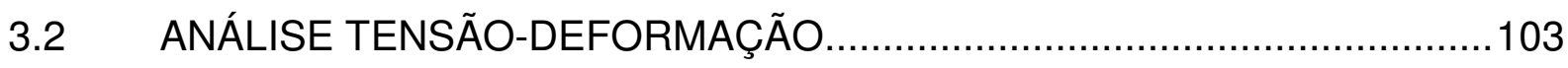

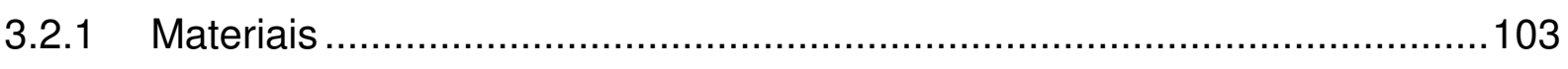

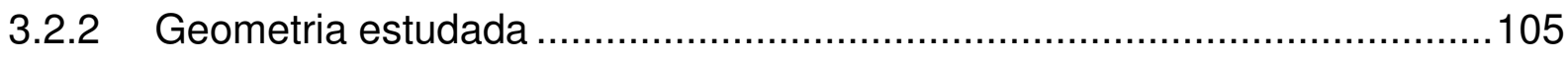

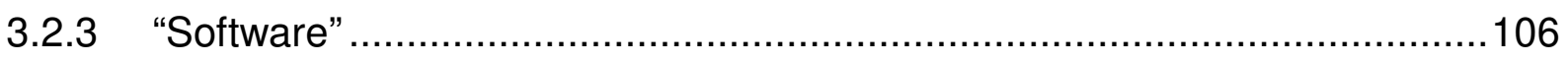

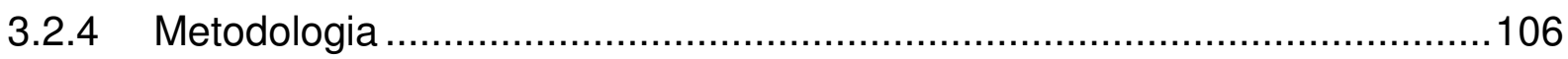

4. APRESENTAÇÃO E ANÁLISE DOS RESULTADOS ...................112

4.1 ANÁLISE DE ESTABILIDADE POR MÉTODOS DE EQUILÍBRIO LIMITE112

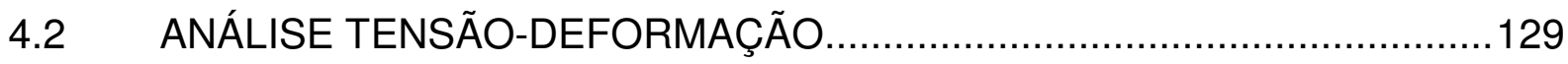

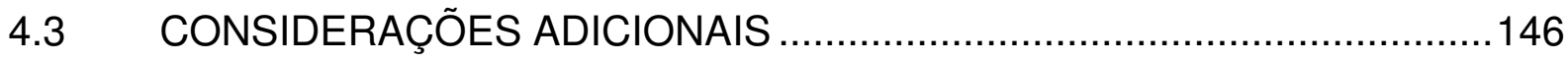

5. CONCLUSÕES.....................................................................148

6. SUGESTÕES PARA PESQUISAS FUTURAS .............................151

7. REFERÊNCIAS BIBLIOGRÁFICAS.......................................152 


\section{INTRODUÇÃO}

\subsection{JUSTIFICATIVA}

A população brasileira cresceu de 51,9 milhões de habitantes em 1950 para 169,8 milhões em 2000. No mesmo período, a população urbana passou de $36,16 \%$ para $81,23 \%$ (IBGE, 2010a e b). Como o crescimento populacional ocorreu de forma desordenada, os impactos ambientais resultantes da disposição de resíduos passaram a ter maior magnitude.

Durante boa parte do século $X X$, os resíduos sólidos urbanos (RSU) não eram considerados um problema público sério; bastava coletá-los e afastá-los dos centros urbanos para os chamados lixões. Porém, a ocupação de áreas cada vez maiores e o aumento da diversidade e quantidade dos resíduos gerados resultaram em uma demanda para disposição ambientalmente adequada, surgindo o conceito de aterro sanitário. $O$ aterro sanitário pode ser definido como uma forma de disposição de resíduos sólidos urbanos no solo que, fundamentada em critérios de engenharia e normas operacionais, permite o confinamento seguro, garantindo o controle de poluição ambiental e proteção à saúde pública, minimizando impactos ambientais (IPT, 2000).

A geração de resíduos sólidos urbanos no Brasil é de $0,74 \mathrm{Kg} / \mathrm{dia}$ por habitante, variando entre 0,47 e $0,70 \mathrm{Kg} /$ (hab.dia) nas cidades com até 200.000 habitantes, e entre 0,80 e $1,20 \mathrm{Kg} /$ (hab.dia) nas cidades com mais de 200.000 habitantes (Ministério das Cidades, 2003). Em 2008, das $259.547 .000 \mathrm{~kg}$ de lixo coletados diariamente no Brasil, $64 \%$ eram dispostas em aterros sanitários, $16 \%$ em aterros controlados e $18 \%$ em lixões; por outro lado, apenas $28 \%$ dos municípios dispunham seus resíduos em aterros sanitários, enquanto 53\% ainda utilizavam lixões (IBGE, 2010c), o que mostra a carência de aterros sanitários no Brasil.

Os aterros sanitários tendem a ser cada vez maiores, devido ao crescimento contínuo das grandes cidades e ao surgimento de consórcios entre pequenos municípios com a finalidade de dividir os custos de implantação e operação. Devido à dificuldade de encontrar locais disponíveis no meio urbano em distâncias 
economicamente viáveis, esses aterros de grande porte tendem à verticalização, evidenciando a importância da garantia da estabilidade da massa de resíduos.

A estabilidade dos taludes do maciço sanitário é assegurada por configurações que resultem em fatores de segurança (FS) da ordem de 1,5, calculados pelos métodos de equilíbrio limite desenvolvidos para a análise de estabilidade de taludes de solos. Esses métodos pressupõem material com comportamento rígido-plástico e utilizam os parâmetros de resistência ao cisalhamento relativos à envoltória de MohrCoulomb. No entanto, nos ensaios de compressão triaxial realizados em amostras de RSU, a tensão desviadora cresce com a deformação axial (Manassero et al., 1996; Vilar et al., 2006), sem se verificar a existência de valor de pico ou de assíntota que caracterize a ruptura do material. Mesmo assim, procura-se associar os parâmetros de resistência ao cisalhamento da envoltória de Mohr-Coulomb aos $\mathrm{RSU}$, os quais são materiais de comportamento reológico muito diferente. Os parâmetros de resistência dos RSU para projeto, geralmente, são obtidos na literatura, por retroanálise de rupturas existentes, ensaios ou ainda com base na experiência do projetista.

A prática de projeto e construção de aterros sanitários no Brasil, tendo em vista o fator de segurança especificado e os parâmetros de resistência geralmente adotados no meio técnico para os RSU nacionais, resulta em aterros construídos com bermas de cerca de $5 \mathrm{~m}$ de altura, com taludes intermediários de cerca de $1,5 \mathrm{H}: 1 \mathrm{~V}$ de declividade. Uma possibilidade para aumentar a declividade do maciço é a inserção de geogrelhas, a exemplo dos taludes de solo reforçados. Contudo, novas propostas de configuração para a geometria dos taludes são dificilmente aceitas pelos órgãos licenciadores, devido à dificuldade de prever o comportamento real do maciço e à falta de conhecimento das interações dos resíduos sólidos urbanos com outros materiais.

O avanço dos programas computacionais para análise da estabilidade de taludes torna-os uma ferramenta muito utilizada. No entanto, os métodos de equilíbrio-limite não levam em consideração as deformações e interações entre os materiais envolvidos; os RSU, por outro lado, são materiais muito deformáveis, mesmo se comparados a argilas moles. O meio técnico ainda carece de pesquisas que permitam compreender melhor a estabilidade dos taludes sob o ponto de vista das 
deformações, deslocamentos e interações entre o maciço sanitário e reforços geossintéticos.

Este trabalho apresenta o estudo de uma nova proposta para a verticalização de aterros sanitários, por meio da utilização de reforços geossintéticos, que faz uso de ferramentas computacionais de análise numérica para avaliar o fator de segurança por métodos de equilíbrio-limite e o comportamento tensão-deformação do maciço. Representa a primeira etapa de avaliação da viabilidade técnica desta solução, à qual deve seguir o estudo das interações químicas entre os resíduos e os geossintéticos, do efeito dos recalques de longo prazo dos resíduos nos reforços e dos aspectos construtivos e operacionais.

\subsection{OBJETIVO}

Este trabalho tem por objetivo principal avaliar a verticalização de aterros sanitários por meio da construção por alteamentos sucessivos com diques periféricos de solo reforçado, a exemplo do método de montante de barragens de rejeitos de mineração, e do reforço da massa de resíduos por geogrelhas, investigando o fator de segurança do maciço e os níveis de deformação dos materiais envolvidos (massa de resíduos e reforços geossintéticos). Neste caso, a ideia de verticalização tem por objetivo aumentar a altura do aterro sanitário e não promover a inclinação dos taludes.

Os objetivos parciais podem ser resumidos em:

- Determinar o fator de segurança da configuração proposta por métodos de equilíbrio limite.

- Analisar a estabilidade do maciço sanitário na configuração proposta com base nos níveis de deformação dos materiais envolvidos.

- Estudar a interação entre o maciço sanitário e as geogrelhas utilizadas como reforço. 
- Comparar os resultados obtidos pelos métodos de equilíbrio-limite com os obtidos nas análises tensão-deformação. 


\section{REVISÃO BIBLIOGRÁFICA}

\subsection{ESTABILIDADE DE TALUDES DE ATERROS SANITÁRIOS}

\subsubsection{Análise das tensões e deformações por métodos numéricos}

Os aterros sanitários devem ser vistos como estruturas de engenharia, para as quais devem ser satisfeitas as exigências usuais de segurança, quanto à estabilidade, às deformações e às tensões impostas no solo de fundação.

A estabilidade de um maciço de solo ou de RSU pode ser realizada por meio da análise das tensões e deformações durante a construção e/ou operação, geralmente calculadas por programas computacionais que utilizam métodos numéricos tais como o método dos elementos finitos (MEF).

A análise de deformações é especialmente importante no caso de estruturas reforçadas, nas quais é importante verificar o desempenho de cada material e também do conjunto. Os métodos de equilíbrio limite não consideram explicitamente as deformações do solo, nem a interação que ocorre entre os elementos de reforço e o solo ou material adjacente. A utilização do MEF, que pode fornecer uma previsão mais realista das deformações, possibilita o estudo adequado de estruturas de solo reforçado (Azevedo et al. 1992). O conhecimento das deformações é importante para verificar não apenas se os esforços no reforço, calculados nas análises de estabilidade, é realmente mobilizada, como também para avaliar as condições de trabalho do aterro.

Azevedo et al. (1992) citam que existem duas maneiras de representar solos reforçados através do MEF. A primeira é chamada de representação composta, que utiliza um único elemento para representar o solo reforçado. A segunda é denominada representação discreta, em que se utilizam diferentes elementos para representar o solo e o reforço, com ou sem interface entre ambos (Figura 2.1). 


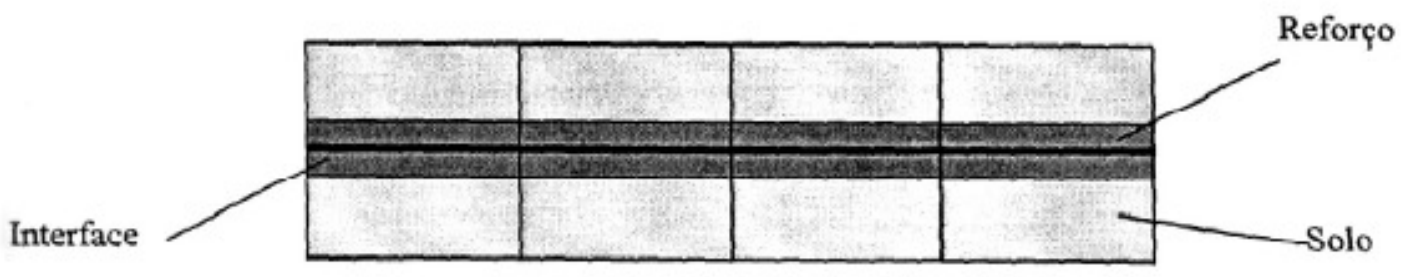

Figura 2.1 - Detalhe dos elementos da malha utilizando representação discreta (Silva, 1998)

Segundo Chang \& Forsyth $(1977)^{1}$ (apud Pedroso, 2000), a representação composta apresenta como vantagem a elaboração de uma malha mais simples de elementos finitos e, consequentemente, menor trabalho computacional. No entanto, apresenta como principais desvantagens a impossibilidade de modelar os deslocamentos relativos entre o solo e o reforço, a obtenção das tensões e deformações no reforço e a modelagem do processo construtivo.

A representação discreta do solo reforçado fornece diretamente informações a respeito das deformações e tensões nas interfaces, no reforço, entre as camadas de reforço e na massa de solo. Por isso, esta representação vem sendo cada vez mais utilizada, dada a facilidade proporcionada pelos programas computacionais e 0 avanço da capacidade de processamento dos computadores.

De acordo com Pedroso (2000), os programas de elementos finitos são, dentre todas as ferramentas disponíveis, as mais adequadas para prever os deslocamentos horizontais de estruturas de contenção reforçadas com geossintéticos. Karpurapu \& Bathurst (1995) mostraram que através de simulações numéricas é possível prever com boa precisão o comportamento de uma estrutura de contenção tanto para condições de trabalho quanto para a de colapso utilizando apenas os resultados de ensaios realizados no solo e no geossintético isoladamente.

Diversos autores têm estudado o efeito da rigidez do reforço, das características geométricas do aterro e da sequencia executiva nas deformações por meio de modelos numéricos baseados no MEF. Citam-se como exemplos: Azevedo et al. (1992) utilizaram elementos finitos no cálculo de estruturas de solo reforçado; Teixeira (2003) estudou a interação solo-geogrelha em testes de arrancamento e a

${ }^{1}$ Chang, J.C.; Forsyth, R.F. (1977). Finite Element Analysis and Design of Reinforced Earth Wall. Journal of the Geotechnical Engineering Division, ASCE, v.103, n. 7, p. 711 - 724. 
sua aplicação na análise e dimensionamento de maciços reforçados; Pedroso (2000) realizou análises numéricas para avaliar e comparar o comportamento de uma estrutura de solo reforçado para alguns tipos de solo, rigidez e arranjos dos reforços.

\subsubsection{Influência da geração de lixiviados e gases na estabilidade dos aterros}

A geração de percolados e gases, assim como a recirculação de lixiviado para acelerar o processo de degradação do lixo, tem relação direta com a estabilidade dos aterros sanitários, uma vez que tais fatores influem nos valores de pressão neutra dos RSU. Com o aumento das pressões neutras, diminuem as tensões efetivas dos RSU e, consequentemente, diminui o fator de segurança do aterro.

Segundo Boscov et al. (2011), uma importante questão de debate entre os projetistas de aterros sanitários é como considerar as pressões neutras nas análises de estabilidade. Pressões neutras são causadas pelo lixiviado e/ou biogás no interior da massa de lixo. A geração de biogás pode ser totalmente atribuída à biodegradação de matéria orgânica putrescível, enquanto a formação de lixiviado depende também do balanço hídrico pelo sistema de cobertura. Nas regiões de clima árido, por exemplo, onde a infiltração de águas pluviais pela cobertura é pequena e a biodegradação da matéria orgânica é desfavorecida pela falta de umidade, as pressões neutras dentro da massa de lixo podem ser desprezíveis. Entretanto, em climas úmidos associados a altas porcentagens de degradação de matéria orgânica, como na maioria dos aterros sanitários do Brasil, as pressões neutras podem chegar a 170kPa (Kaimoto e Cepollina, 1996).

Sistemas de drenagem externa e interna eficientes e divisão em células com sistemas intermediários de impermeabilização e drenagem dificultam a formação de uma região saturada contínua desde a base do aterro. É mais provável ocorrerem lençóis empoleirados de lixiviado e eventuais bolsões de gás (Coelho, 2001).

No entanto, os projetistas brasileiros usam frequentemente a hipótese de um nível piezométrico de lixiviado no interior da massa de solo. Esta hipótese é fácil de ser implementada, em termos de simulação numérica, nas análises de estabilidade de taludes, mas muito conservadora, resultando em valores de pressão neutra muito 
mais elevados do que aqueles que provavelmente ocorrerão. A consideração de um nível de lixiviado independente em cada célula é mais realista, mas complexa do ponto de vista da simulação numérica, visto que, geralmente, os softwares não permitem a representação de vários níveis d'água independentes.

Uma alternativa para a estimativa das pressões neutras na massa de resíduos é a interpolação de valores de pressão neutra a partir de dados de piezômetros de aterros monitorados. Esta é uma prática muito boa para monitorar a estabilidade do aterro ao longo do tempo, no entanto, na concepção de um novo aterro, esta prática assume que as distribuições de pressões neutras serão semelhantes ao conjunto de dados obtidos em um aterro sanitário já construído, enquanto as pressões neutras realmente dependem da composição dos RSU, clima, configuração e operação de cada aterro.

Alguns projetistas usam o parâmetro $r_{u}$ (Benvenuto e Cipriano, 2010), que é uma opção comum de entrada de dados de pressões neutras em modelos numéricos para solos. O parâmetro $r_{u}$ é dado pela equação (2.1).

$$
r_{u}=\frac{u}{\sigma 1} \approx \frac{u}{\sigma \mathrm{v}}=\frac{u}{\gamma_{B} H_{S}}
$$

Onde:

u - pressão neutra;

$\sigma_{1}-$ tensão normal principal maior

$\sigma_{v}-$ tensão normal vertical

$\gamma_{B}$ - Peso específico do material sobrejacente;

$\mathrm{H}_{\mathrm{s}}$ - Altura de material sobrejacente.

O parâmetro $r_{u}$ relaciona a pressão neutra com a tensão vertical imposta. De forma mais clara o parâmetro $r_{u}$ simula as condições de drenagem interna do aterro. Porém, enquanto existem valores de $r_{u}$ publicados para barragens de terra para as situações de final de construção, operação e estágios de rebaixamento do reservatório para solos brasileiros, valores de referência de $r_{u}$ para aterros de RSU ainda são escassos. 
Oliveira (2002) realizou análises de estabilidade paramétricas de um aterro sanitário variando o ângulo de atrito de $20^{\circ}$ a $35^{\circ}$ e calculando a coesão necessária para obter um fator de segurança mínimo de $F S=1,3$, para o valor de $r_{u}=0,2$. Os resultados mostram que, para um determinado ângulo de atrito, em função da inclinação dos taludes é necessário um incremento de coesão que pode chegar a mais de $200 \%$.

Borgatto (2006) também realizou análises de estabilidade por equilíbrio-limite para valores de $r_{u}$ variando entre 0 e 0,5, mantendo-se os valores de coesão e ângulo de atrito do material. Para uma das seções analisadas, com $r_{u}=0$ o fator de segurança obtido foi de $F S=1,72$; para $r_{u}=0,2$, o fator de segurança reduziu para $F S=1,44$ e, para $r_{u}=0,5$, o fator de segurança obtido foi de $F S=1,00$. Os resultados mostraram uma redução de cerca de $40 \%$ no fator de segurança em uma situação crítica de drenagem $\left(r_{u}=0,5\right)$ e de $30 \%$ para uma condição intermediária de excesso de pressão neutra $\left(r_{u}=0,2\right)$.

Boscov et al. (2011) analisaram a seção transversal típica de um aterro de grande porte, construído em uma sequencia de 7 células de $5 \mathrm{~m}$ de altura, que atingiu a altura final de $35 \mathrm{~m}$ com boas condições de estabilidade. As pressões neutras foram consideradas de três formas: nível freático único, níveis freáticos independentes em cada célula, que é possível representar com o software Geostudio, e fator de pressão neutra $r_{u}$ variando de 0 a 0,5. Adotando-se valores típicos de coesão, ângulo de atrito e peso específico de aterros sanitários brasileiros, verificou-se que os valores de $r_{u}$ entre 0,1 e 0,3 forneciam fatores de segurança semelhantes à representação de lençóis freáticos independentes.

\subsection{PROPRIEDADES DOS RSU}

Em geral, o projeto e a operação de aterros sanitários envolvem uma variedade de problemas geotécnicos, que para serem solucionados exigem o conhecimento adequado das propriedades físicas e mecânicas dos resíduos sólidos urbanos (peso especifico, resistência ao cisalhamento, permeabilidade, compressibilidade, dentre 
outras). A quantificação dessas propriedades é complexa devido ao fato de os RSU possuírem natureza e comportamento mecânico significativamente diferente dos solos, às dificuldades relacionadas ao tamanho e a obtenção de amostras representativas das condições in situ, às dificuldades quanto à técnica e procedimento de ensaio, bem como à mudança das propriedades do RSU com o tempo devido ao processo de degradação (Van Impe, 1998; Knochenmus et al. 1998; Manassero et al. 1996 e König \& Jessberger, 1997).

Assim como os solos naturais, os resíduos sólidos urbanos são meios multifásicos constituídos pelas fases sólida, líquida e gasosa. Num primeiro momento, tem-se o predomínio da parte sólida (os resíduos propriamente dito), após algum tempo, devido ao processo de biodegradação, surgem as fases líquida (chorume, percolado ou lixiviado) e gasosa (gás carbônico, gás metano e outros). Essas duas últimas fases estão relacionadas aos processos de decomposição dos resíduos ao longo do tempo, os quais estão diretamente associados ao teor de umidade, conteúdo orgânico e condições climáticas (Grisolia \& Nopoleoni, 1996; Cartier \& Baltdit, 1983). A fase sólida, por sua vez, apresenta diversos constituintes, os quais formam um arranjo poroso que pode estar ou não preenchido por lixiviado e/ou biogás e pode, ainda, estar em processo constante de decomposição física, química e biológica. Parece consenso geral que o ponto básico para a compreensão do comportamento dos maciços de RSU é o conhecimento das interações existentes entre as três fases e as alterações destas com o tempo, ou seja, sua biodegradabilidade.

\subsubsection{Classificação dos resíduos sólidos urbanos}

Os resíduos sólidos são classificados pela norma brasileira NBR-10004 "Resíduos Sólidos - Classificação." (ABNT, 2004), em:

1. Classe I-Perigosos: são aqueles que, em função de suas propriedades físicas, químicas ou infectocontagiosas, podem apresentar riscos à saúde publica, provocando ou acentuando, de forma significativa, um aumento de mortalidade ou incidências de doenças e/ou riscos ao meio ambiente, quando manuseados ou destinados de forma inadequada; ou ainda 
apresentar características patogênicas, de inflamabilidade, corrosividade, reatividade e toxidade.

2. Classe II - não perigosos.

- Classe IIA - Não inertes: não se enquadram nas classes I (perigosos) e IIB (Inertes). Podem ter propriedades como biodegradabilidade, combustibilidade ou solubilidade em água.

- Classe IIB - Inertes: quando amostrados de uma forma representativa e submetidos a um contato dinâmico e estático com água destilada ou deionizada, à temperatura ambiente, não apresentam nenhum de seus constituintes solubilizados em concentrações superiores aos padrões de potabilidade de água, excetuando-se aspectos de cor, turbidez, dureza e sabor.

Um resíduo sólido, para ser classificado, deve ser amostrado de acordo com a norma NBR-10007, "Amostragem dos resíduos sólidos" (ABNT, 2004), e submetido a ensaios de lixiviação e solubilização segundo as normas NBR-10005, "Procedimentos para obtenção de extrato lixiviado de resíduos sólidos" (ABNT, 2004), e NBR-10006, "Procedimentos para obtenção de extrato solubilizado de resíduos sólidos" (ABNT, 2004). Os resultados são comparados com os valores de referência estipulados na norma NBR-10004.

Os RSU são considerados resíduos Classe IIA. Grisolia et al. (1995) propuseram uma sistemática de classificação para os RSU usando um diagrama triangular formado por três classes de materiais, que são materiais inertes, materiais muito deformáveis e materiais orgânicos biodegradáveis. A partir da determinação da posição de cada amostra no diagrama, pode-se avaliar as propriedades mecânicas esperadas para o material. A Figura 2.2 apresenta o diagrama triangular proposto por Grisolia et al. (1995) para resíduos de diversos locais da Europa. 


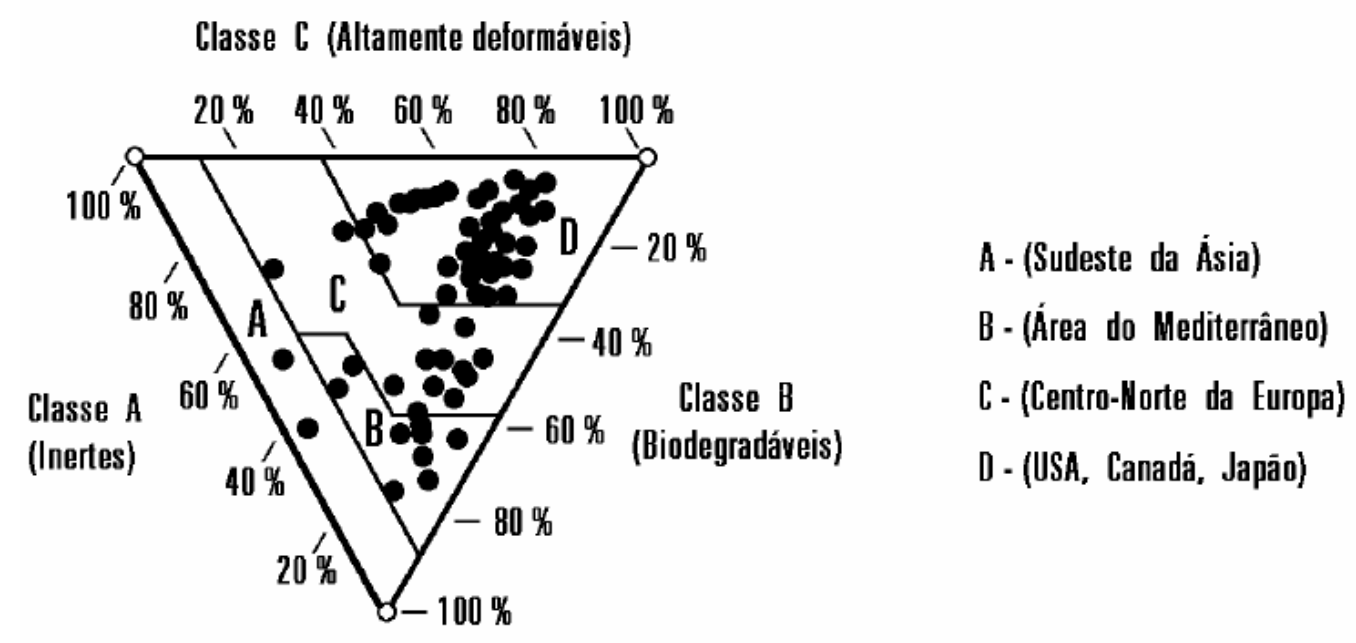

Figura 2.2- Classificação do RSU usando o diagrama triangular (Grisolia et al., 1995).

\subsubsection{Composição}

A composição do RSU é muito heterogênea, apresentando uma variação tanto da porcentagem de matéria orgânica putrescível como dos outros principais componentes do lixo, de uma região para outra. Relaciona-se ao local, em função dos hábitos da população, nível educacional, atividade econômica predominante, clima, desenvolvimento econômico, tecnológico, sanitário e cultura da região, práticas de reciclagem, incineração e aos hábitos de desperdícios da sociedade (Boscov, 2008; Cowland \& Koor, 1995; Cartier \& Baldit,1983), conforme exemplificado na Tabela 2.1 .

Um detalhe que se pode notar na Tabela 2.1 é que a quantidade de matéria orgânica presente no lixo é menor nos países desenvolvidos do que nos países subdesenvolvidos, com maior quantidade de papéis.

É importante mencionar que as modificações nesses fatores que interferem na composição do lixo, consequentemente, alteram as propriedades dos maciços sanitários, dificultando a avaliação das propriedades físicas e mecânicas dos RSU. 
Tabela 2.1 - Composição do resíduos sólidos urbanos em diferente cidades (dados de Manassero et al. 1997, Carvalho 1999 e Boscov 2008)

\begin{tabular}{|c|c|c|c|c|c|c|c|c|c|}
\hline Cidade/País & $\begin{array}{l}\text { Metal } \\
(\%)\end{array}$ & $\begin{array}{l}\text { Papel } \\
(\%)\end{array}$ & $\begin{array}{c}\text { Plástico } \\
\text { (\%) }\end{array}$ & $\begin{array}{c}\text { Borracha, } \\
\text { couro e } \\
\text { madeira } \\
(\%) \\
\end{array}$ & $\begin{array}{c}\text { Têxteis } \\
\text { (\%) }\end{array}$ & $\begin{array}{c}\text { Materiais } \\
\text { orgânicos } \\
\text { /putrescíveis } \\
\text { (\%) }\end{array}$ & $\begin{array}{l}\text { Vidro } \\
\text { (\%) }\end{array}$ & $\begin{array}{c}\text { Outros } \\
(\%)\end{array}$ & Fonte \\
\hline $\begin{array}{l}\text { Bangkok / } \\
\text { Tailândia }\end{array}$ & 1,0 & 25,0 & - & 7,0 & 3,0 & 44,0 & 1,0 & 19,0 & $\begin{array}{c}\text { Manassero et } \\
\text { al. } 1997\end{array}$ \\
\hline Pekin / China & 1,0 & 5,0 & 1,0 & 1,0 & - & 45,0 & 1,0 & 46,0 & $\begin{array}{c}\text { Manassero et } \\
\text { al. } 1997\end{array}$ \\
\hline $\begin{array}{l}\text { Nairobi / } \\
\text { Kenia }\end{array}$ & 3,0 & 12,0 & 5,0 & - & - & 74,0 & 4,0 & 2,0 & $\begin{array}{c}\text { Manassero et } \\
\text { al. } 1997\end{array}$ \\
\hline Hong Kong & 3,0 & 3,0 & - & 7,0 & 10,0 & 15,0 & 10,0 & 22,0 & $\begin{array}{c}\text { Manassero et } \\
\text { al. } 1997\end{array}$ \\
\hline $\begin{array}{c}\text { New York / } \\
\text { EUA }\end{array}$ & 5,0 & 22,0 & & 3,0 & & 20,0 & 6,0 & 46,0 & $\begin{array}{c}\text { Manassero et } \\
\text { al. } 1997\end{array}$ \\
\hline $\begin{array}{l}\text { Istanbul / } \\
\text { Turquia }\end{array}$ & 2,0 & 10,0 & 3,0 & 6,0 & 3,0 & 61,0 & 1,0 & 14,0 & $\begin{array}{c}\text { Manassero et } \\
\text { al. } 1997\end{array}$ \\
\hline $\begin{array}{l}\text { Atenas / } \\
\text { Grécia }\end{array}$ & 4,0 & 19,0 & 7,0 & 4,0 & & 59,0 & 2,0 & 5,0 & $\begin{array}{c}\text { Manassero et } \\
\text { al. } 1997\end{array}$ \\
\hline $\begin{array}{l}\text { Cochabamba } \\
\text { / Bolívia }\end{array}$ & 1,0 & 2,0 & 3,0 & 1,0 & & 71,0 & 1,0 & 21,0 & $\begin{array}{c}\text { Manassero et } \\
\text { al. } 1997\end{array}$ \\
\hline $\begin{array}{c}\text { Belo } \\
\text { Horizonte / } \\
\text { Brasil }\end{array}$ & 2,3 & 9,5 & 10,9 & 4,0 & & 61,6 & 2,9 & 8,8 & SMLU, 2003 \\
\hline Viçosa / Brasil & 1,6 & 14,2 & 8,5 & 1,3 & 2,2 & 65,1 & 1,1 & 6,1 & UFV, 1999 \\
\hline $\begin{array}{l}\text { Rio de Janeiro } \\
\text { / Brasil }\end{array}$ & 1,7 & 16,1 & 20,3 & 0,8 & 1,8 & 53,6 & 2,8 & 2,9 & Comlurb,2009 \\
\hline $\begin{array}{c}\text { São Paulo / } \\
\text { Brasil }\end{array}$ & 2 & 13 & 16 & - & & 58 & & 1* & $\begin{array}{c}\text { Limpurb, } \\
2003\end{array}$ \\
\hline $\begin{array}{c}\text { Maceió / } \\
\text { Brasil }\end{array}$ & 3 & 16 & 13 & - & & 50 & & 8* & UFA, 2004 \\
\hline
\end{tabular}

Assim como nos solos naturais, quanto maior a quantidade de um determinado componente presente nos resíduos, mais as características gerais do maciço se assemelharão às características desse componente; a quantidade de matéria orgânica putrescível é particularmente importante uma vez que influi no teor de umidade, na resistência ao cisalhamento do RSU, no desenvolvimento de pressões neutras no interior do maciço sanitário, na geração de chorume e gás, e na compressibilidade dos RSU (Boscov, 2008). 
A composição gravimétrica dos RSU é obtida através de processo de amostragem para seleção e mensuração dos componentes, determinando-se a relação entre o peso de cada componente presente na amostra e o peso da amostra total. As amostras devem ser representativas para que apresentem as mesmas características e propriedades da massa total. Jucá $(2012)^{2}$ ressalta a importância da determinação da composição volumétrica dos RSU, considerando-se que os diversos componentes têm densidades muito diferentes.

\subsubsection{Teor de umidade}

O teor de umidade do RSU depende da composição inicial do material, das condições climáticas locais, do processo de operação do aterro, da taxa de decomposição biológica, da capacidade e eficiência dos sistemas de coleta de lixiviado e do sistema de cobertura. Segundo Carvalho (1999), o teor de umidade pode variar significativamente entre um ponto e outro, tornando-se relevante a obtenção do perfil de umidade com a profundidade, o qual pode ser obtido através de sonda de nêutrons ou secagem de amostras representativas em estufa.

Segundo Knochenmus et al. (1998), o teor de umidade do RSU é basicamente o resultado de altas porcentagens de lixo orgânico (resíduos alimentares, de jardim e poda). Os componentes inorgânicos, tais como papéis e produtos plásticos, geralmente têm um teor de umidade abaixo de 10\%. Assim, o teor de umidade tende a aumentar como o aumento do conteúdo orgânico. Esse comportamento foi também observado por Landva \& Clark (1990) (apud Carvalho, 1999), para aterros do Canadá.

Por outro lado, a infiltração de água de chuva pela cobertura também é um fator que influencia o teor de umidade dentro do aterro, principalmente em regiões de alta pluviosidade e durante a fase de operação do aterro. De acordo com Coumoulos et al. (1995), o teor de umidade decresce com a profundidade, variando de $80 \%$ para

${ }_{3}^{2}$ Jucá, J.F.T. (2012). Comunicação pessoal. 
$5 \mathrm{~m}$ de profundidade, até cerca de $40 \%$ para a profundidade de $30 \mathrm{~m}$. A Figura 2.3 apresenta valores obtidos no aterro de Muribeca, em Recife, Brasil, confrontados com obtidos na literatura internacional. Nota-se que não há uma variação nítida do teor de umidade com a profundidade nos maciços sanitários, lembrando que diversos fatores podem interferir como a infiltração da água de chuva, condições de drenagem, composição dos resíduos, etc.

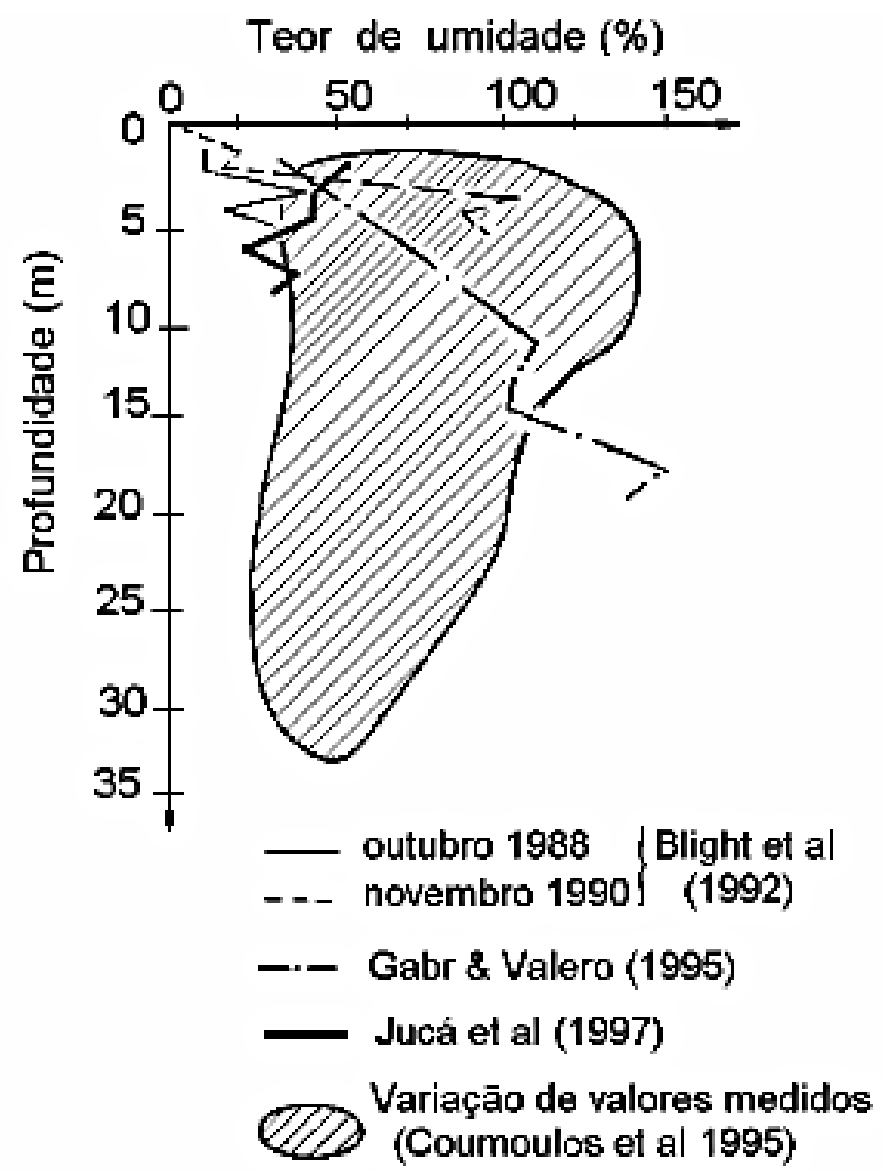

Figura 2.3 - Teor de umidade de resíduos sólidos urbanos (Carvalho, 1999)

Um problema para comparar teores de umidade obtidos de diferentes trabalhos é que geralmente falta norma específica para RSU. Se utilizadas normas de determinação de teor de umidade de solos, pode ocorrer a queima ou evaporação de outros componentes do lixo, além da água, a $105^{\circ} \mathrm{C} / 110^{\circ} \mathrm{C}$. 


\subsubsection{Peso específico in situ}

O peso específico in situ dos RSU aterrados é especialmente influenciado pela composição e umidade dos RSU, pelas camadas de cobertura diária, pela compactação, pelo peso das camadas sobrepostas, e pela decomposição e adensamento com o tempo (Cowland et al. 1993; Mitchell et al. 1995, Ling et al. 1998). Em aterros mais antigos, o peso específico aumenta com a profundidade (König \& Jessberger, 1997). Como os RSU são compostos de vários constituintes, o peso específico total médio depende do peso específico, porosidade, grau de saturação e porcentagem de cada componente.

Segundo Martins (2006), a influência da composição gravimétrica no peso específico pode ser confirmada pelo fato de resíduos com maior percentual de matéria orgânica putrescível apresentarem maior peso específico e resíduos com maior quantidade de papéis, papelão e plásticos possuírem menor peso específico. $O$ autor ainda afirma que, normalmente, populações de maior poder aquisitivo geram resíduos de menor peso específico, acontecendo o contrário com as populações de menor poder aquisitivo, devido ao maior percentual de matéria orgânica putrescível.

Na Tabela 2.2 são apresentados valores médios para o peso específico de resíduos sólidos urbanos determinados por diversos autores, incluindo valores de RSU brasileiros. 
Tabela 2.2 - Peso específico dos RSU

\begin{tabular}{|c|c|c|}
\hline Características dos resíduos & $\begin{array}{l}\text { Peso específico } \\
\qquad\left(\mathrm{N} / \mathrm{m}^{3}\right)\end{array}$ & Referência \\
\hline RSU não compactado & 2900 & \\
\hline RSU medianamente compactado & 4700 a 5900 & Schomaker $(1972)^{1}$ \\
\hline RSU bem compactado & 8800 & \\
\hline RSU pouco compactado & 5500 a 6900 & Sargunan et al. $(1986)^{1}$ \\
\hline RSU bem compactado & 6800 a 16200 & Landva e Clark (1986) ${ }^{1}$ \\
\hline RSU bem compactado & 5400 a 8000 & Watts e Charles (1990) ${ }^{1}$ \\
\hline RSU compactado & 6300 a 9400 & Oweis e Khera $(1990)^{1}$ \\
\hline RSU (sem relato sobre a compacidade dos materiais) & 15000 & Richardson e Reynolds (1991)1 \\
\hline RSU mal compactado & 3000 a 9000 & \\
\hline RSU medianamente compactado & 5000 a 8000 & Fasset et al. $(1994)^{1}$ \\
\hline RSU bem compactado & 9000 a 10500 & \\
\hline RSU (sem relato sobre a compacidade dos materiais) & 10000 a 15000 & Zonrberg et al. $(1999)^{1}$ \\
\hline $\begin{array}{l}\text { RSU (sem relato sobre a compacidade dos materiais) } \\
\text { Aterro a céu aberto (Paracambi/RJ) - cava }\end{array}$ & 13400 a 16500 & \\
\hline $\begin{array}{l}\text { RSU não compactado - Aterro a céu aberto (Paracambi/RJ) - } \\
\text { percâmetro }\end{array}$ & 9500 a 16400 & \\
\hline RSU compactado - Aterro controlado (Gramacho/RJ) - cava & 16800 a 19700 & Silveira $(2004)^{2}$ \\
\hline $\begin{array}{l}\text { RSU compactado - Aterro sanitário (Santo André e } \\
\text { Gramacho/RJ) - cava }\end{array}$ & 9100 a 10900 & \\
\hline $\begin{array}{l}\text { RSU compactado - Aterro sanitário (Santo André e } \\
\text { Gramacho/RJ) - percâmetro }\end{array}$ & 10000 a 10900 & \\
\hline RSU em condição drenada & 10000 & Benvenuto e Cunha (1991) ${ }^{3}$ \\
\hline RSU em condição saturada & 13000 & Benvenuto e cunna (1991) \\
\hline Resíduos recém-lançados & 7000 & Santos e Presa $(1995)^{3}$ \\
\hline Após a ocorrência de recalques & 10000 & \\
\hline Resíduos novos, não decompostos e pouco compactados & 5000 a 7000 & Kaimoto e Cepollina (1996) 3 \\
\hline Após compactação e ocorrência de recalques & 9000 a 13000 & \\
\hline Seção com 10 meses de alteamento & 10500 & Mahler e Iturri (1998) ${ }^{3}$ \\
\hline Resíduos soltos & 1500 a 3500 & \\
\hline Resíduos medianamente densos & 3500 a 6500 & Abreu $(2000)^{3}$ \\
\hline Resíduos densos & 6500 a 14000 & \\
\hline
\end{tabular}

Fontes: ${ }^{1}$ Martins, 2006; ${ }^{2}$ Silveira (2004), Boscov (2008)

As dificuldades frequentes em avaliar o peso específico dos RSU foram resumidas por Fassett et al. (1994): a separação da contribuição da cobertura de solo diária; a avaliação das mudanças no peso específico com o tempo e a profundidade; a maioria dos valores relatados reflete resíduos próximos ou na superfície; e a 
obtenção do teor de umidade. Acrescenta-se também a dificuldade de retirar amostras indeformadas e mesmo de determinar o volume in situ. Vale ressaltar a inexistência de ensaios normalizados para a determinação do peso específico dos RSU, o que constitui fonte adicional à variação desse parâmetro.

Dentre os vários métodos utilizados para determinação do peso específico in situ destaca-se como o mais simples a escavação de um poço ou trincheira, sendo feitas a pesagem do material e a determinação do volume por meio do preenchimento do poço, estando este devidamente impermeabilizado (Marques, 2001). No entanto, a determinação do volume de água para preenchimento da vala onde foi retirada a massa conhecida de RSU é muito problemática, dadas certas circunstâncias como: o alívio de tensões provocado pela retirada de material, que provoca movimentos laterais e de fundo em direção à abertura; movimentos de equipamentos pesados e pessoas na borda da cava, que também contribuem para a diminuição da mesma; dificuldades na preparação da cava, tendo em vistas as heterogeneidade dos resíduos e suas dimensões; dificuldades na colocação da manta plástica e sua adaptação à cava de forma a realmente ocupar as superfícies de todo o volume de resíduo escavado; dentre outras.

Kavazanjian et al. (1995), com base em dados de diversos aterros, propuseram um perfil de peso específico em função da profundidade, crescendo de cerca de 6000 $\mathrm{N} / \mathrm{m}^{3}$ na superfície até cerca de $13000 \mathrm{~N} / \mathrm{m}^{3}$ em profundidades próximas de $40 \mathrm{~m}$, a partir da qual fica constante. Analisando dados de campo em função da energia de compactação e presença de cobertura, Zeccos (2005) concluiu que o peso específico em aterros compactados com energia típica é de aproximadamente $10 \mathrm{kN} / \mathrm{m}^{3}$ nas camadas mais superficiais, tendendo ao valor de $13000 \mathrm{~N} / \mathrm{m}^{3} \mathrm{em}$ maiores profundidades, enquanto em aterros compactados com alta energia atinge mais de $15 \mathrm{kN} / \mathrm{m}^{3}$ e pouco varia em função da profundidade. Kavazanjian et al. (2006), a partir de dados de laboratório e campo, incluindo aqueles dos dois trabalhos anteriores, propuseram que para cada aterro existe uma equação hiperbólica que representa o perfil de peso específico.

Em relação à influência do peso específico na resistência dos RSU, diante de vários trabalhos publicados, destacando-se os de Carvalho (1999), Fucale e Jucá (2002) e Fucale (2005), entre outros, pode-se afirmar que resíduos com maior peso específico possuem maior resistência ao cisalhamento, demonstrando a grande 
importância de uma boa compactação dos resíduos durante a etapa de disposição final.

\subsubsection{Permeabilidade}

A permeabilidade dos RSU é um importante parâmetro de projeto e de operação de aterros sanitários, pois intervém no cálculo das vazões nos sistemas de drenagem e tratamento de lixiviado e gases, na análise dos recalques e nos estudos de estabilidade.

Dentre os fatores que influenciam a permeabilidade podem-se citar a composição do lixo, compactação e sobrecarga, com destaque para a idade dos resíduos.

O coeficiente de permeabilidade é normalmente avaliado por meio de ensaios de laboratório e ensaios in situ, executados em trincheiras e poços escavados de grande diâmetro ou em furos de sondagem.

Enquanto a literatura internacional mostra grande incidência de coeficientes de permeabilidade de RSU entre $10^{-6}$ e $10^{-4} \mathrm{~m} / \mathrm{s}$, valores obtidos para RSU brasileiros encontram-se na sua maioria entre $10^{-8}$ e $10^{-6} \mathrm{~m} / \mathrm{s}$ (Boscov, 2008). Tal diferença pode ser atribuída a maior presença de materiais putrescíveis presentes nos resíduos brasileiros.

\subsubsection{Temperatura}

Diferentemente dos solos, os resíduos sólidos urbanos apresentam uma variação significativa da temperatura ao longo da profundidade e do tempo, sendo este um dos indicadores das reações bioquímicas que ocorrem no interior da massa de lixo, devido à degradação da matéria orgânica. As reações exotérmicas de biodegradação podem levar a temperatura dos RSU até cerca de $70{ }^{\circ} \mathrm{C}$. Mariano e Jucá (1998) obtiveram valores de temperatura no aterro de Muribeca, Recife, apresentados na Figura 2.4. Observa-se uma maior variação de temperatura junto à 
superfície do aterro, onde os valores são cerca de 15 a $20^{\circ} \mathrm{C}$ menores do que em maiores profundidades, onde as temperaturas se situam em aproximadamente $55^{\circ} \mathrm{C}$. A temperatura dos resíduos sólidos urbanos torna-se um fator importante no projeto de aterros sanitários reforçados por geogrelhas, uma vez que a temperatura é um dos principais fatores que interferem nas propriedades dos reforços geossintéticos, como deformação, resistência à tração, fluência e durabilidade.

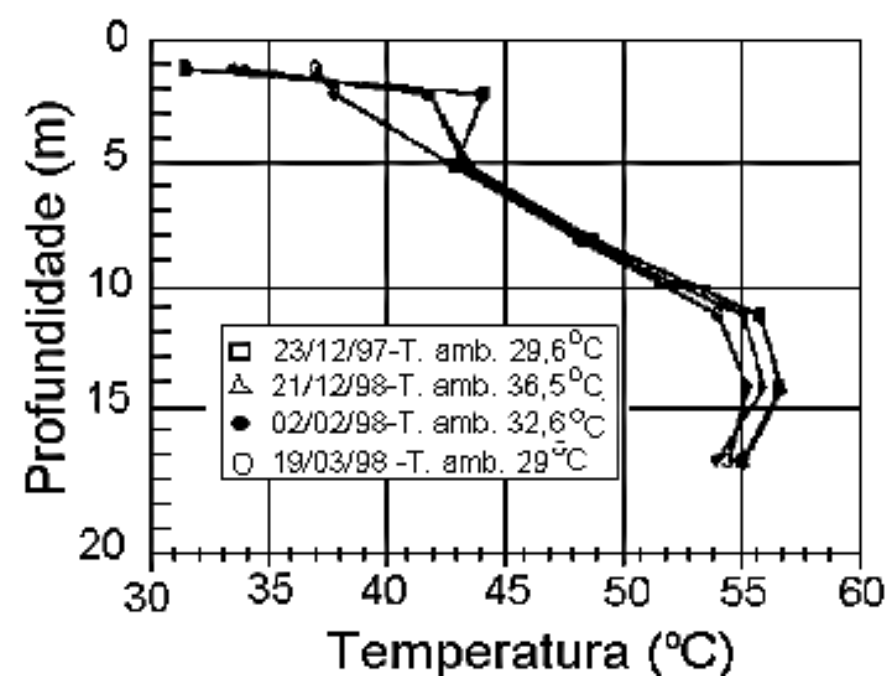

Figura 2.4 - Variação da temperatura do RSU com a profundidade, Aterro de Muribeca, Recife (Mariano \& Jucá, 1998)

\subsubsection{Parâmetros de resistência de RSU}

De acordo com Jessberger \& Kockel (1993), algumas propriedades mecânicas dos RSU, como resistência e deformabilidade, dependem da composição do resíduo e das propriedades mecânicas de seus constituintes, o que contribui para aumentar a variabilidade de resultados reportados. Stark et al. (2009), coletando dados obtidos por meio de retroanálises de ruptura em taludes de lixo e ensaios de laboratório, concluíram que a resistência ao cisalhamento do RSU é função de muitos fatores, como tipo de lixo, composição, compactação, cobertura diária, condições de umidade, idade, decomposição, sobrecarga etc.

Devido ao seu alto teor de matéria orgânica e sua estrutura fibrosa, os RSU se comportam mais como um solo orgânico fibroso do que como um solo inorgânico. 
Em consequência, os fatores que devem afetar os parâmetros de resistência dos resíduos são:

- Teor de matéria orgânica e fibras;

- Idade e grau de decomposição dos resíduos sólidos;

- Energia de compactação, composição e quantidade de solo de cobertura.

A resistência ao cisalhamento dos RSU tem sido determinada por meio de retroanálises de rupturas reais, ensaios in situ e ensaios de laboratório. Dixon \& Jones (2005) elaboraram um resumo das vantagens e desvantagens associadas aos métodos atualmente disponíveis para obtenção de informação sobre o comportamento da resistência dos RSU (

Tabela 2.3). Edincliler et al. (1996) declaram que a melhor metodologia para estudar propriedades mecânicas de resíduos sólidos é conduzir uma série de ensaios laboratoriais de grandes dimensões em conjunto com alguns ensaios de campo em grande escala.

Os parâmetros de resistência (ângulo de atrito e coesão) de solos são obtidos em laboratório geralmente por ensaios de cisalhamento direto e compressão triaxial. A partir das tensões de ruptura e das tensões confinantes determina-se a envoltória de resistência para uma determinada amostra de solo.

Contudo, não há ruptura definida nesses tipos de ensaio para os RSU, pois a resistência é crescente em função da deformação para os níveis de deformação usuais dos ensaios, como exemplificam as Figura 2.5 a Figura 2.7. A coesão e o ângulo de atrito dos RSU são especificados em função de uma tensão adotada como de ruptura, sendo o critério usual a tensão correspondente à máxima deformação aceitável.

Os níveis de deformação utilizados situam-se, geralmente, entre 10 e 20\% (Oweiss, $1993^{4}$ apud Zeccos, 2005; Oliveira, 2002; Azevedo et al., 2006; Campi, 2011). Esta faixa de valores é resultado da observação do comportamento de aterros sanitários

4 Oweiss I.S., 1993. Stability of landfills. Chapter 11 of Geotechnical Pratice for Waste Disposal, edited by D.E. Daniel, Chapman \& Hall. 
que tem demonstrado que a partir desses níveis de deformação a integridade e o bom desempenho dos aterros podem não estar garantidos.

Tabela 2.3 - Revisão dos métodos para medir o comportamento cisalhamento do RSU (Dixon \& Jones, 2005)

\begin{tabular}{|c|c|c|c|}
\hline Tipo & Método de medida & Comentários & Referências \\
\hline Campo & $\begin{array}{l}\text { Retroanálise de } \\
\text { rupturas de talude } \\
\text { Retroanálise de } \\
\text { experimentos de } \\
\text { talude cortado } \\
\text { Retroanálise de } \\
\text { taludes estáveis } \\
\text { existentes } \\
\text { Ensaio de } \\
\text { cisalhamento direto } \\
\text { de campo } \\
\text { SPT, CPT e ensaio de } \\
\text { palheta }\end{array}$ & $\begin{array}{l}\text { Informação adequada raramente disponível } \\
\text { (poro-pressão, forma e posição da superfície de } \\
\text { ruptura) } \\
\text { Grandes deformações observadas, mas sem } \\
\text { rupturas } \\
\text { A variável composição do RSU significa que a } \\
\text { experiência passada não é um caminho para } \\
\text { desempenho futuro } \\
\text { Dificuldades de execução e os resultados são } \\
\text { relacionados a baixos níveis de tensão } \\
\text { Não há relação clara entre a resitência à } \\
\text { penetração e a resitência ao cisalhamento dos } \\
\text { RSU. Poderia fornecer informação em materiais } \\
\text { degradados semelhantes a solos }\end{array}$ & $\begin{array}{l}\text { Koerner e Soong } \\
\text { (2000) } \\
\text { Singh e Murphy } \\
\text { (1990), Cowland et } \\
\text { al. (1993) } \\
\text { Gotteland et al. } \\
\text { (2002) } \\
\text { Jessberger e } \\
\text { Kockel (1993) }\end{array}$ \\
\hline \multirow{3}{*}{ Laboratório } & Compressão triaxial & $\begin{array}{l}\text { Amostras deformadas, resistências ao } \\
\text { cisalhamento de pico não obtidas devido à } \\
\text { compressão e densificação da amostra }\end{array}$ & $\begin{array}{l}\text { Jessberger (1994), } \\
\text { Grisolia et al. } \\
\text { (1995b) }\end{array}$ \\
\hline & Cisalhamento direto & $\begin{array}{l}\text { Exigência de grandes equipamentos, amostras } \\
\text { deformadas e grandes deslocamentos exigidos } \\
\text { para mobiliar a resistência ao cisalhamento de } \\
\text { pico }\end{array}$ & $\begin{array}{l}\text { Kolsch (1995)., } \\
\text { Gotteland et al. } \\
\text { (2001) }\end{array}$ \\
\hline & $\begin{array}{l}\text { Cisalhamento } \\
\text { simples }\end{array}$ & $\begin{array}{l}\text { Exigência de grandes equipamentos, amostras } \\
\text { deformadas e informação útil na rigidez cisalhante } \\
\text { (usado em análises sísmicas) }\end{array}$ & $\begin{array}{l}\text { Kavazanjian et al. } \\
\text { (1999) }\end{array}$ \\
\hline
\end{tabular}

Resultados obtidos por diferentes autores, Grisolia et al. (1995), Stark et al. (2000), Jessberger e Kockel (1993), mostram que resistência ao cisalhamento dos RSU estimada aumenta com o aumento da deformação ou deslocamento.

$\mathrm{Na}$ Figura 2.5 são apresentadas envoltórias de ruptura obtidas em ensaios de cisalhamento direto para diferentes níveis de deslocamento, enquanto a Figura 2.6 mostra resultados de ensaios de compressão triaxial com adensamento isotrópico para diferentes níveis de deformações axiais, obtidos por Stark et al. (2000). Observa-se que a resistência ao cisalhamento aumenta cerca de três vezes dependendo do deslocamento cisalhante ou da deformação aplicados. 


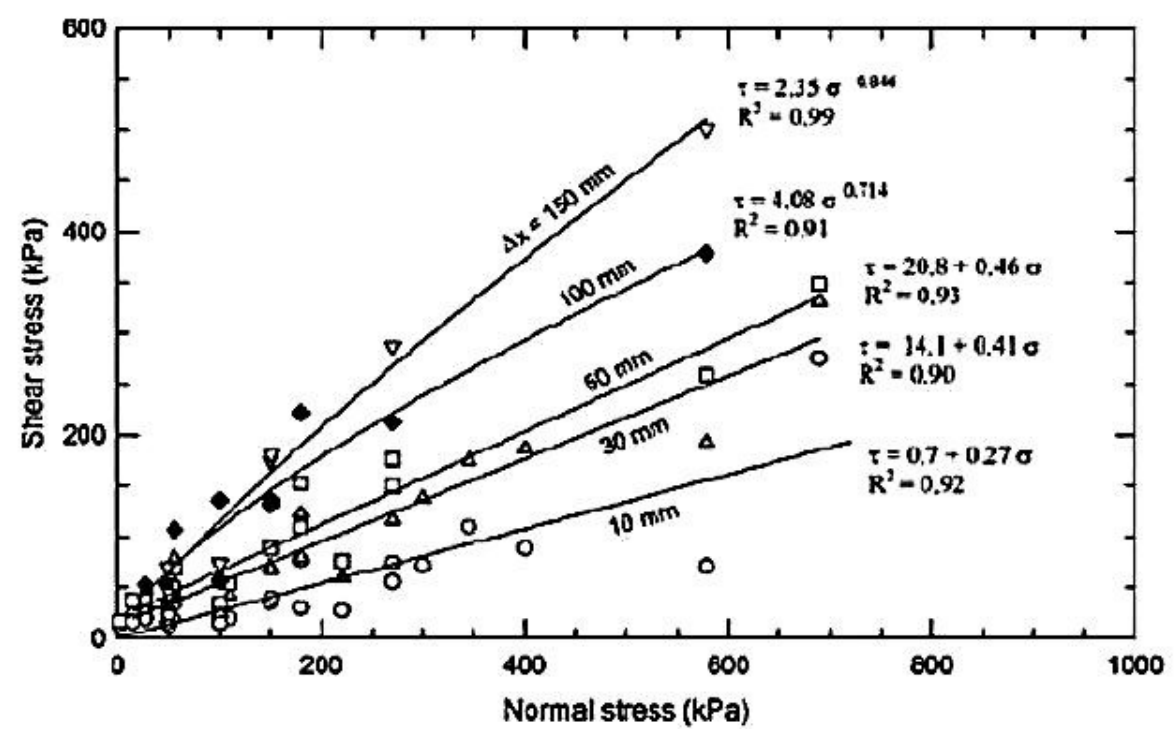

Figura 2.5 - Envoltórias de resistência de RSU correspondentes a diferentes níveis de deslocamentos obtidas em ensaios de cisalhamento direto (Stark et al., 2009)

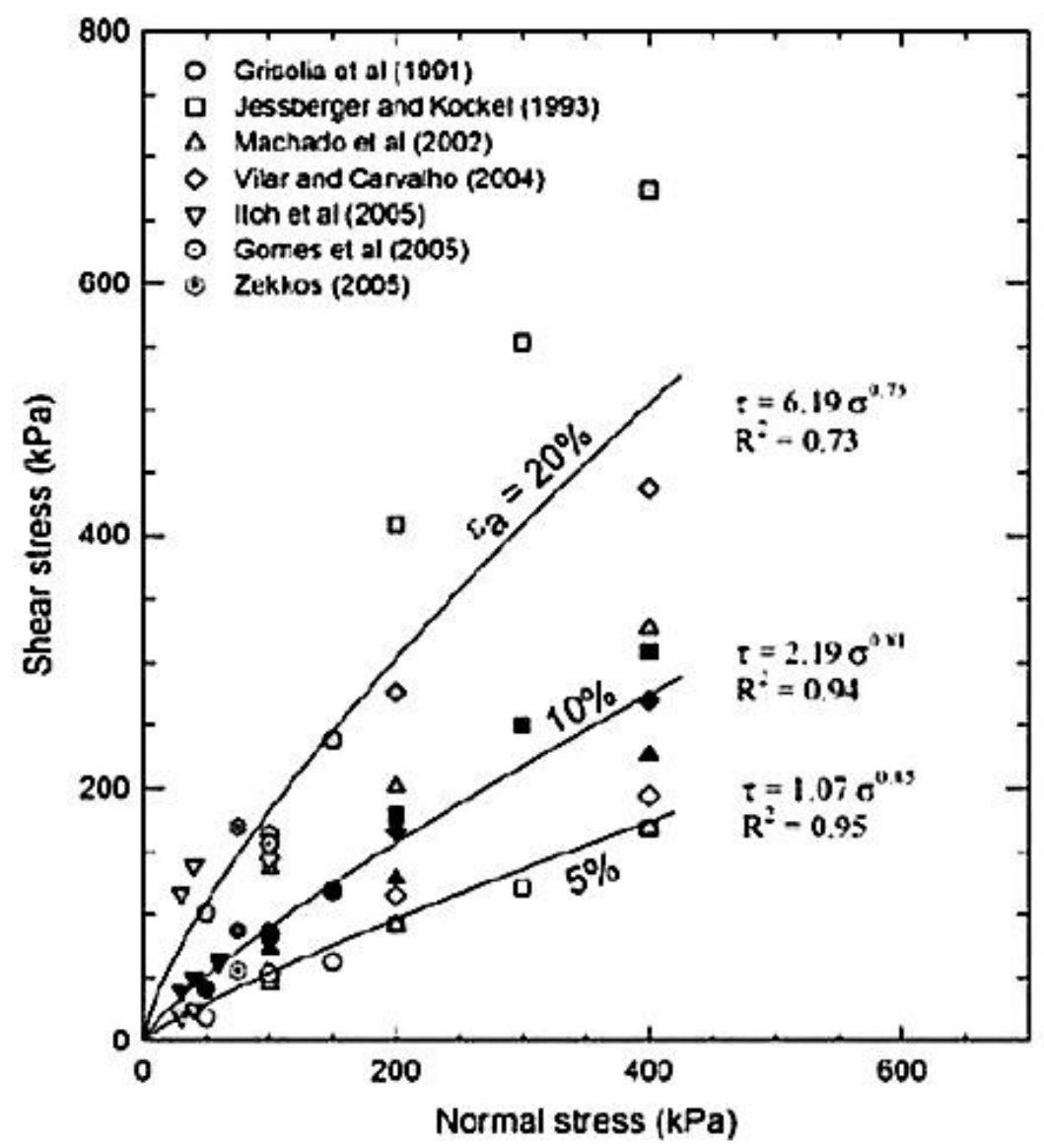

Figura 2.6 - Envoltórias de resistência de RSU para diferentes níveis de deformação axial obtidas em ensaios de compressão triaxial. (Stark et al., 2009) 
Ribeiro (2007) obteve parâmetros de resistência de RSU em ensaios de laboratório de grandes dimensões para diferentes níveis de deformação, variando de 10 a $20 \%$, para peso específico de $7000 \mathrm{~N} / \mathrm{m}^{3}$ e $5000 \mathrm{~N} / \mathrm{m}^{3}$. Na Figura 2.7 constam os resultados relativos a $\gamma=7000 \mathrm{~N} / \mathrm{m}^{3}$, que confirmam o aumento da coesão e ângulo de atrito conforme aumenta o nível de deformação.

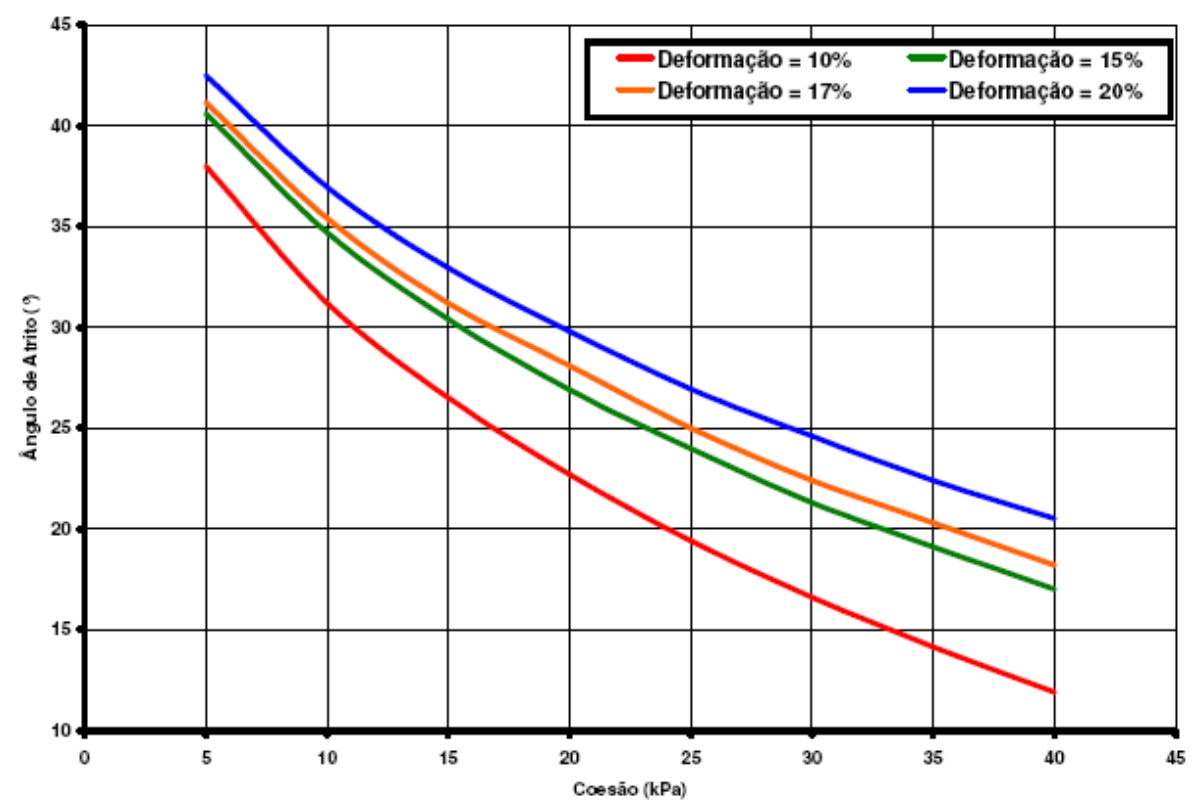

Figura 2.7 - Parâmetros de resistência para quatro níveis de deformação $\left(\gamma=7000 \mathrm{~N} / \mathrm{m}^{3}\right)$ (Ribeiro, 2007)

Segundo Ribeiro (2007), para resíduos com peso específico $\gamma=7 \mathrm{kN} / \mathrm{m}^{3}$, os valores recomendados por Azevedo (2005) ${ }^{5}$ (apud Ribeiro, 2007), $\mathrm{c}=10 \mathrm{kN} / \mathrm{m}^{2}$ e $\phi=28^{\circ}$, correspondem a uma deformação da ordem de 7\% (baixa para RSU) e estão a favor da segurança, pois para deformações entre 15 e $20 \%$, e coesão $c=10 \mathrm{kN} / \mathrm{m}^{2}$, o valor do ângulo de atrito $\phi$ é da ordem de $35^{\circ}$. Para resíduos com peso específico $\gamma=5 \mathrm{kN} / \mathrm{m}^{3}$, para $\mathrm{c}=10 \mathrm{kN} / \mathrm{m}^{2}$ e $\phi=28^{\circ}$, a deformação correspondente é $17 \%$, da ordem das que se evidenciam em aterros sanitários. $O$ autor considera que os valores recomendados por Azevedo (2005) ainda se mostram adequados, apesar de menos seguros quando os resíduos estão mais compactados.

${ }^{5}$ Azevedo, R.F. (2005). Notas de aula, disciplina CIV 639 - Projetos de Aterros Sanitários. Universidade Federal de Viçosa, Departamento de Engenharia Civil, Viçosa, 2005. 
Na Figura 2.8 é apresentada uma comparação entre as envoltórias de resistência propostas por três diferentes autores para tensões normais até $300 \mathrm{kPa}$. Stark et al. (2009) reuniram envoltórias para tensão normal efetiva até $1800 \mathrm{KPa}$ (Figura 2.9), no entanto os resultados se limitam em sua maioria a $400 \mathrm{KPa}$, o que os torna menos confiáveis para grandes aterros. Os resultados para tensões normais efetivas até $500 \mathrm{kPa}$ estão apresentados mais claramente na Figura 2.10. Os valores apresentados correspondem a deslocamentos cisalhantes menores ou iguais a $25 \mathrm{~mm}$ ou deformações cisalhantes ou axiais menores ou iguais a $10 \%$. Estes valores são compatíveis com o comportamento tensão-deformação na interface de geossintéticos e solos de fundação (Eid et al., 2000).

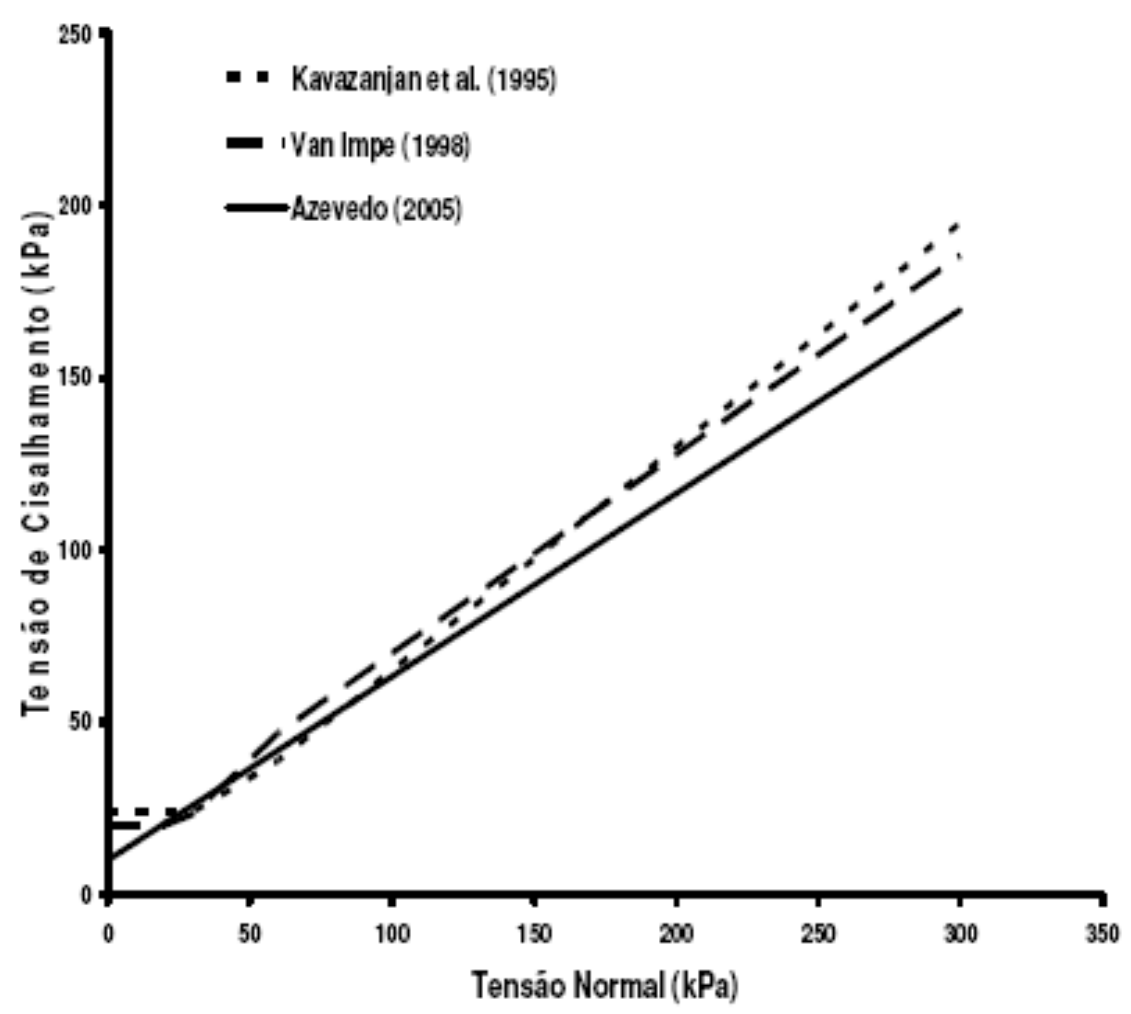

Figura 2.8 - Envoltórias de resistência de RSU obtidas por três autores para tensões normais até 300 kPa (Ribeiro, 2007) 


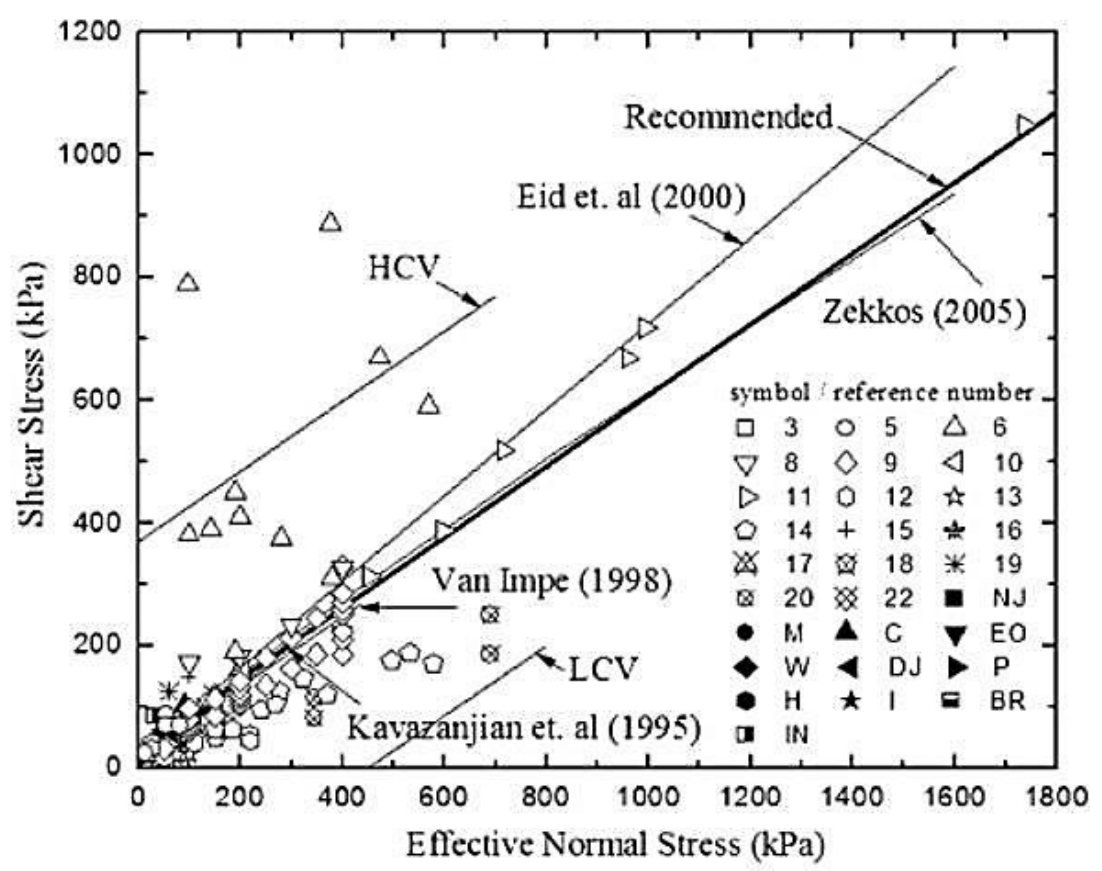

Figura 2.9 - Envoltórias de resistência obtidas por diversos autores para tensões normais até 1800 $\mathrm{kPa}$ (Stark et al., 2009)

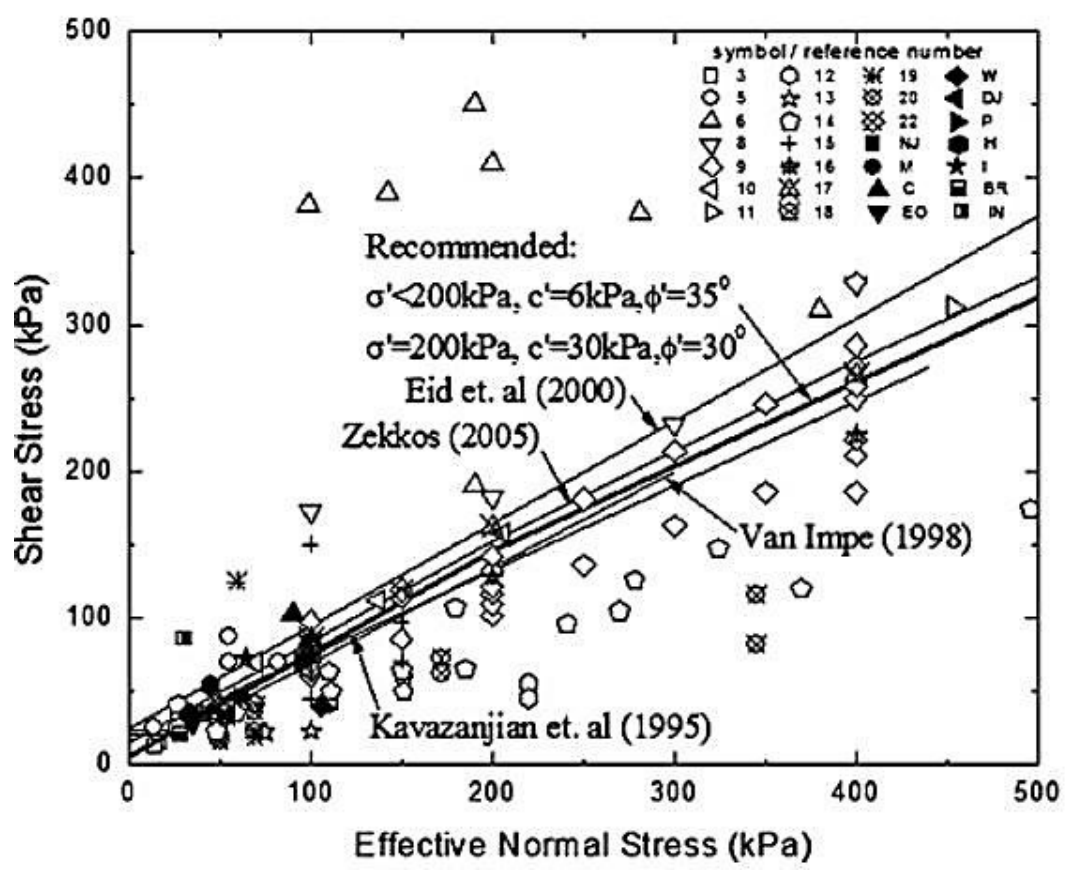

Figura 2.10 - Envoltórias de resistência para tensões normais efetivas menores que 500KPa (Stark et al., 2009) 
A estimativa dos parâmetros de resistência para os RSU no Brasil baseava-se inicialmente em revisões da literatura internacional, onde constam resultados de resíduos com características significativamente diferentes das dos resíduos brasileiros. Retroanálises realizadas a partir de uma ruptura de grandes proporções ocorrida em 1991 no Aterro Sanitário Bandeirantes constituíram um marco para a estimativa dos parâmetros utilizados nas análises de estabilidade (Boscov, 2008). Os valores de coesão e ângulo de atrito obtidos na ocasião considerando condições de pressões neutras críticas resultaram em, respectivamente, $13,5 \mathrm{kPa}$ e $22^{\circ}$ (Benvenuto e Cunha, 1991), que a partir de então se tornaram referência para projetos nacionais.

Desde então, projetistas e empreiteiros vêm acumulando informações baseados nesta e em outras rupturas, além de que pesquisas para estimar os parâmetros de resistência têm sido desenvolvidas em universidades brasileiras (Kaimoto e Cepollina, 1996; Azevedo et al., 2006; Vilar et al., 2006; Campi e Boscov, 2011; Ribeiro e Azevedo, 2008 etc.). Alguns exemplos são mostrados a seguir.

Azevedo et al. (2006) realizaram ensaios de placa em um lisímetro de grandes dimensões ( $1 \mathrm{~m}$ de diâmetro por 1,6 $\mathrm{m}$ de altura) para determinação dos parâmetros de resistência dos RSU pelas fórmulas de capacidade de carga de Terzaghi para fundações rasas em solo. A placa, feita de madeira, tinha $16 \mathrm{~cm}$ de diâmetro e 40 $\mathrm{cm}$ de altura. O material foi ensaiado com densidade de $5 \mathrm{kN} / \mathrm{m}^{3}$ e $7 \mathrm{kN} / \mathrm{m}^{3}$, equivalentes a resíduos recentes pouco compactados. Os carregamentos foram aplicados em 17 estágios de 24 horas. Os parâmetros de resistência obtidos foram significativamente menores do que sugere a literatura, enquanto os valores de deformações foram superiores aos obtidos em trabalhos semelhantes. Segundo os autores, em seu trabalho foram realizados ensaios sem alterar as características granulométricas dos RSU, ao passo que as pesquisas para definir o comportamento reológico dos resíduos geralmente utilizam material selecionado no qual se eliminam ou trituram as partículas de maiores dimensões, o que modifica substancialmente as características geomecânicas.

Em prosseguimento a esses ensaios, foram realizados ensaios de ruptura em um talude de lixo em laboratório, em caixa de madeira de $80 \mathrm{~cm} \times 8 \mathrm{~cm} \times 80 \mathrm{~cm}$, com parede lateral removível e aplicação de pressão por um pistão acoplado a uma sapata rígida, com os mesmos pesos específicos da série de ensaios anterior 
(Ribeiro, 2007; Ribeiro e Azevedo, 2008). A comparação entre as duas séries de ensaios levou à conclusão de que a adoção de valores de coesão $c=12 \mathrm{kPa} e$ ângulo de atrito $\phi=30^{\circ}$ são os mais adequados para serem usados em projetos de estabilidade de taludes.

Os estudos realizados por Machado et al. (2005) no aterro sanitário Metropolitano Centro-BA, para resíduos novos e com 4 anos de idade, não apresentaram variação significativa nos valores de tensão desviadora para baixos valores de tensão de confinamento. Para tensão de confinamento de $200 \mathrm{kPa}$, as tensões desviadoras para o resíduo com 4 anos de idade foram superiores às obtidas para o resíduo novo, o que foi atribuído à melhor ancoragem das "fibras" presentes no resíduo.

Ensaios de placa em um aterro sanitário de grande porte do Estado de São Paulo para determinação dos parâmetros de resistência por retroanálise seguindo a metodologia proposta por Azevedo et al. (2006) foram realizados por Campi e Boscov (2011) em RSU novos e bem compactados. A ruptura não ocorreu para os níveis de deformação possíveis de impor pelo sistema de carregamento adotado, desaconselhando esta metodologia para a determinação da coesão e ângulo de atrito in situ. Os resultados das deformações em função do tempo, entretanto, sugerem a necessidade de estudar novos modelos reológicos para representar o comportamento tensão-deformação e de ruptura dos RSU, mesmo para curto prazo. Modelos reológicos para RSU considerando efeitos de longo termo têm sido desenvolvidos na literatura (Machado et al., 2008; Machado et al., 2009; Reddy et al., 2011; Babu et al., 2010).

Na Tabela 2.4 é apresentado um quadro resumo com diversos parâmetros de resistência, obtidos por diferentes métodos (ensaios in-situ, retroanálises e ensaios de laboratório). 
Tabela 2.4 - Resumo dos parâmetros de resistência dos RSU

\begin{tabular}{|c|c|c|c|c|c|}
\hline \multirow[t]{2}{*}{ TIPO } & \multirow[t]{2}{*}{ FONTE } & \multicolumn{2}{|c|}{$\begin{array}{l}\text { PARÂMETROS DE } \\
\text { RESISTÊNCIA }\end{array}$} & \multirow[t]{2}{*}{ MÉTODO DE ENSAIO } & \multirow[t]{2}{*}{ OBSERVAÇÕES } \\
\hline & & $\mathrm{c}(\mathrm{kPa})$ & $\phi\left({ }^{\circ}\right)$ & & \\
\hline \multirow{10}{*}{$\begin{array}{l}? \\
\bar{n} \\
z\end{array}$} & \multirow{2}{*}{ Richardson e Reynolds (1991) ${ }^{\text {a) }}$} & \multirow{2}{*}{10} & \multirow{2}{*}{18 a 43} & \multirow{2}{*}{$\begin{array}{l}\text { Cisalhamento direto } \\
\text { de grande dimensão }\end{array}$} & $\gamma=15 \mathrm{KN} / \mathrm{m}^{3}$ \\
\hline & & & & & $\sigma_{\mathrm{n}}=14$ a $38 \mathrm{kPa}$ \\
\hline & Withiam et al. (1995) & 10 & 30 & $\begin{array}{l}\text { Cisalhamento direto } \\
\text { de grande dimensão }\end{array}$ & $\sigma_{\mathrm{n}}=0$ a $21 \mathrm{kPa}$ \\
\hline & Houston et al. (1995) & 5 & 33 a 35 & $\begin{array}{l}\text { Cisalhamento direto } \\
\text { de grande dimensão }\end{array}$ & $\begin{array}{l}\text { Determinados para } \\
\text { tensão de pico }\end{array}$ \\
\hline & \multirow{2}{*}{ Mazzucato et al. (1999) } & $22^{(1)}$ & 17 & \multirow{2}{*}{$\begin{array}{l}\text { Cisalhamento direto } \\
\text { de grande dimensão }\end{array}$} & (1) amostra reconstituída \\
\hline & & $24^{(2)}$ & 18 & & ${ }^{(2)}$ amostra indeformada \\
\hline & Gerber (1991) & 25 & 27 & $\begin{array}{l}\text { Cisalhamento direto } \\
\text { de grande dimensão }\end{array}$ & $\begin{array}{l}\text { Estudo de aterro } \\
\text { sanitário em Maine } \\
(\mathrm{EUA})\end{array}$ \\
\hline & Caicedo et al. (2002a) & 78 & 23 & $\begin{array}{l}\text { Cisalhamento direto } \\
\text { de grande dimensão }\end{array}$ & $\sigma_{\mathrm{n}}=6$ a $117 \mathrm{kPa}$ \\
\hline & \multirow{2}{*}{ Caicedo et al. (2002b) } & $36^{(3)}$ & 35 & \multirow{2}{*}{ Pressiômetro } & ${ }^{(3)}$ à superfície \\
\hline & & $72^{(4)}$ & 22 & & (4) à $8 m$ de profundidade \\
\hline \multirow{13}{*}{ 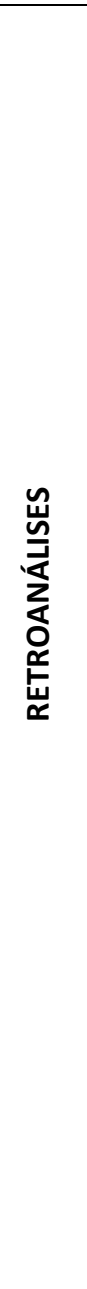 } & Oweiss $(1985)^{b)}$ & 0 & 26 & Prova de carga & $\begin{array}{l}\text { Limite inferior da } \\
\text { resistência, sem haver } \\
\text { ruptura, } \gamma \cong 7 \mathrm{KN} / \mathrm{m}^{3} ; \sigma_{\mathrm{n}} \\
\text { baixa }\end{array}$ \\
\hline & Singh e Murphy (1990) & $\begin{array}{l}75 a \\
110\end{array}$ & 25 a 36 & $\begin{array}{l}\text { Prova de carga e } \\
\text { observação do } \\
\text { comportamento de } \\
\text { vários aterros }\end{array}$ & Valores recomendados \\
\hline & Pagottto \& Rimoldi (1987) ${ }^{\text {a) }}$ & 29 & 22 & $\begin{array}{l}\text { Prova de carga em } \\
\text { placa }\end{array}$ & \\
\hline & Cowland et al. (1993) & 10 & 25 & $\begin{array}{l}\text { Taludes de trincheira } \\
\text { profunda }\end{array}$ & \\
\hline & Kavazanjian et al. (1995) & - & $25-34$ & - & $45 \mathrm{kPa}<\sigma<180 \mathrm{kPa}$ \\
\hline & Koda (1998) & 20 & 26 & $\begin{array}{l}\text { Escorregamento (A.S. } \\
\text { na Polônia) }\end{array}$ & RSU antigos \\
\hline & \multirow[t]{2}{*}{$\begin{array}{l}\text { Koda (1998) } \\
\text { Eid et al. (2000) }\end{array}$} & 150 & 20 & $\begin{array}{l}\text { Escorregamento (A.S. } \\
\text { na Polônia) } \\
\text { Escorregamento (A.S. } \\
\text { em Ohio) }\end{array}$ & RSU recentes \\
\hline & & 40 & 35 & & $\gamma=10,2 \mathrm{KN} / \mathrm{m}^{3}$ \\
\hline & Van Impe et al. (1996) & 20 & 0 & - & Sobrecarga $\leq 20 \mathrm{kPa}$ \\
\hline & \multirow{3}{*}{$\begin{array}{l}\text { Van Impe et al. (1996) } \\
\text { Benvenuto \& Cunha (1991) }\end{array}$} & 0 & 38 & - & $\begin{array}{l}\text { Sobrecarga de } 20 \text { a } 60 \\
\mathrm{kPa}\end{array}$ \\
\hline & & 20 & 30 & - & Sobrecarga > $60 \mathrm{kPa}$ \\
\hline & & 13,5 & 22 & $\begin{array}{c}\text { Escorregamento (A.S. } \\
\text { em São Paulo) }\end{array}$ & $\gamma=10$ a $13 \mathrm{KN} / \mathrm{m}^{3}$ \\
\hline & Landva \& Clark (1986) & 16 & 38 a 42 & $\begin{array}{l}\text { Cisalhamento direto } \\
\text { de grande dimensão }\end{array}$ & $\begin{array}{l}\text { Resíduos velhos (idade } \\
\text { não informada) }\end{array}$ \\
\hline
\end{tabular}


Tabela 2.4 - Resumo dos parâmetros de resistência dos RSU (continuação)

\begin{tabular}{|c|c|c|c|c|c|}
\hline \multirow[t]{2}{*}{ TIPO } & \multirow[t]{2}{*}{ FONTE } & \multicolumn{2}{|c|}{$\begin{array}{c}\text { PARÂMETROS } \\
\text { DE RESISTÊNCIA }\end{array}$} & \multirow{2}{*}{ MÉTODO DE ENSAIO } & \multirow[t]{2}{*}{ OBSERVAÇÕES } \\
\hline & & $c(k P a)$ & $\phi\left(^{0}\right)$ & & \\
\hline \multirow{20}{*}{ 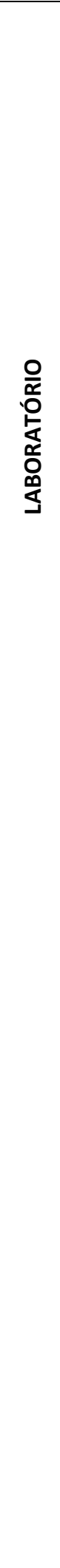 } & \multirow{4}{*}{$\begin{array}{l}\text { Landva \& Clark (1986) } \\
\text { Landva \& Clark (1990) }\end{array}$} & 16 & 33 & $\begin{array}{l}\text { Cisalhamento direto } \\
\text { de grande dimensão }\end{array}$ & $\begin{array}{l}\text { Resíduos velhos } \\
\text { decompostos por um } \\
\text { ano }\end{array}$ \\
\hline & & 23 & 24 & $\begin{array}{l}\text { Cisalhamento direto } \\
\text { de grande dimensão }\end{array}$ & Resíduo novo triturado \\
\hline & & 10 & 33 & $\begin{array}{l}\text { Cisalhamento direto } \\
\text { de grande dimensão }\end{array}$ & Resíduo madeireiro \\
\hline & & 19 a 22 & 24 a 39 & $\begin{array}{l}\text { Cisalhamento direto } \\
\text { de grande dimensão }\end{array}$ & $\sigma_{\mathrm{n}}=15 \mathrm{a} 480 \mathrm{kPa}$ \\
\hline & Jessberger \& Kockel (1991) b) & 22 & 17 & $\begin{array}{l}\text { Ensaio triaxial (grande } \\
\text { dimensão) } C D\end{array}$ & RSU antigos, $\varepsilon_{\mathrm{a}}=20 \%$ \\
\hline & Grisolia et al. (1991) & 10 & 17 & $\begin{array}{l}\text { Ensaio triaxial (grande } \\
\text { dimensão) } C D\end{array}$ & $\begin{array}{l}\text { RSU reconstituídos, } \varepsilon_{\mathrm{a}}= \\
20 \%\end{array}$ \\
\hline & \multirow{2}{*}{$\begin{array}{l}\text { Grisolia et al. (1991) } \\
\text { Howland \& Landva (1992) e) }\end{array}$} & 22 & 42 & \multirow{2}{*}{$\begin{array}{l}\text { Ensaio triaxial (grande } \\
\text { dimensão) CD } \\
\text { Cisalhamento direto }\end{array}$} & $\begin{array}{l}\text { RSU reconstituídos, } \varepsilon_{\mathrm{a}}= \\
35 \%\end{array}$ \\
\hline & & 17 & 33 & & $\begin{array}{l}\text { RSU com } 10 \text { a } 15 \text { anos; } \\
\sigma_{\mathrm{n}}<580 \mathrm{kPa}\end{array}$ \\
\hline & Bransl (1995) c) & 0 & 27 a 38 & Triaxiais & $\begin{array}{l}\text { Determinados para } \varepsilon_{\mathrm{a}} \text { de } \\
20 \%\end{array}$ \\
\hline & \multirow[b]{2}{*}{$\begin{array}{l}\text { Bransl (1995) } \\
\text { Kockel \& Jessberger (1995) }\end{array}$} & 0 & 36 a 42 & \multirow[b]{2}{*}{$\begin{array}{l}\text { Triaxiais } \\
\text { Triaxiais de grande } \\
\text { dimensão (CD) }\end{array}$} & \multirow{2}{*}{$\begin{array}{l}\text { Determinados para } \varepsilon_{\mathrm{a}} \text { de } \\
20 \% \\
\text { RSU com } 1 \text { a } 3 \text { anos; } \\
\text { determinados para } \varepsilon_{\mathrm{a}} \\
\text { máximo }\end{array}$} \\
\hline & & 41 a 51 & 42 a 49 & & \\
\hline & Gabr \& Valero (1995) & 16,8 & 34 & Triaxiais (CU) & $\begin{array}{l}\text { RSU antigos; } \gamma \mathrm{c}=7,4 \mathrm{a} \\
8,2 \mathrm{KN} / \mathrm{m}^{3} ; \varepsilon_{\mathrm{a}}=20 \%\end{array}$ \\
\hline & Grisolia \& Napoleoni (1996) & 0 & 22 & Triaxiais (CD) & $\begin{array}{l}\text { RSU reconstituídos, } \varepsilon_{\mathrm{a}}= \\
10 \text { a } 15 \%\end{array}$ \\
\hline & Carvalho (1999) & 27 a 60 & 17 a 29 & $\begin{array}{l}\text { Triaxiais de grande } \\
\text { dimensão (CD) }\end{array}$ & $\begin{array}{l}\text { RSU antigos, } \varnothing \text { e c } \\
\text { determinados para } \\
\text { deformações de } 20 \%\end{array}$ \\
\hline & Kavazanjian et al. (1995) & 24 & 0 & - & $\begin{array}{l}\text { Tensões normais } \\
\text { inferiores a } 30 \mathrm{kPa}\end{array}$ \\
\hline & $\begin{array}{l}\text { Kavazanjian et al. (1995) } \\
\text { Kavazanjian et al. (1999) }\end{array}$ & 0 & 33 & - & $\begin{array}{l}\text { Tensões normais } \\
\text { superiores a } 30 \mathrm{kPa}\end{array}$ \\
\hline & Caicedo et al. (2002b) & 45 & 14 & Triaxiais (CU) & $\begin{array}{l}\varnothing \text { e c determinados } \\
\text { para deformações de } \\
15 \%\end{array}$ \\
\hline & Caicedo et al. (2002b) & 25 & 24 & $\begin{array}{l}\text { Cisalhamento direto } \\
\text { de grande dimensão }\end{array}$ & - \\
\hline & Zeccos (2005) & 34 & 30 & $\begin{array}{l}\text { Cisalhamento direto } \\
\text { de grande dimensão }\end{array}$ & $\begin{array}{l}\sigma_{\mathrm{n}}=50 \text { a } 600 \mathrm{kPa} ; \\
\text { determinados para } \\
\text { deformações de } 55 \mathrm{~mm} \\
( \pm 18 \%)\end{array}$ \\
\hline & Zeccos (2005) & 0 & 39 & $\begin{array}{l}\text { Triaxiais de grande } \\
\text { dimensão (CD) }\end{array}$ & $\begin{array}{l}\varnothing \text { e c determinados para } \\
\text { deformações de } 5 \% \text { a } \\
\text { partir de } k=0,3\end{array}$ \\
\hline
\end{tabular}


Tabela 2.4 - Resumo dos parâmetros de resistência dos RSU (conclusão)

\begin{tabular}{|c|c|c|c|c|c|}
\hline \multirow[t]{2}{*}{ TIPO } & \multirow[t]{2}{*}{ FONTE } & \multicolumn{2}{|c|}{$\begin{array}{c}\text { PARÂMETROS } \\
\text { DE RESISTÊNCIA }\end{array}$} & \multirow[t]{2}{*}{ MÉTODO DE ENSAIO } & \multirow[t]{2}{*}{ OBSERVAÇÕES } \\
\hline & & $\mathrm{c}(\mathrm{kPa})$ & $\phi\left(^{\circ}\right)$ & & \\
\hline \multirow{6}{*}{ 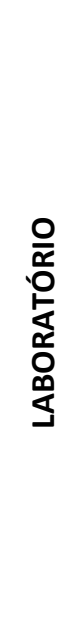 } & Ribeiro (2007) & 10 & 35 & $\begin{array}{l}\text { Prova de carga em } \\
\text { manilha de concreto }\end{array}$ & $\begin{array}{l}\varnothing \text { e c determinados para } \\
\text { deformações de entre } 15 \\
\text { e } 20 \% ; \gamma=7 \mathrm{kN} / \mathrm{m}^{3}\end{array}$ \\
\hline & \multirow[t]{2}{*}{$\begin{array}{l}\text { Ribeiro (2007) } \\
\text { Reddy et al. (2011) }\end{array}$} & 10 & 28 & $\begin{array}{l}\text { Prova de carga em } \\
\text { talude }\end{array}$ & $\begin{array}{l}\varnothing \text { e c determinados para } \\
\text { deformações de } 17 \% ; \gamma= \\
5 \mathrm{kN} / \mathrm{m}^{3}\end{array}$ \\
\hline & & 1 & 35 & Cisalhamento direto & RSU recentes \\
\hline & \multirow{3}{*}{ Reddy et al. (2011) } & 40 & 28 & \multirow[b]{2}{*}{$\begin{array}{l}\text { Cisalhamento direto } \\
\text { Triaxiais (CU) }\end{array}$} & RSU decompostos \\
\hline & & 21 & 8 & & $\begin{array}{l}\text { RSU recentes } \\
\text { (parâmetros totais), } \\
\text { deformação de } 15 \%\end{array}$ \\
\hline & & 57 & 5 & Triaxiais (CU) & $\begin{array}{l}\text { RSU decompostos } \\
\text { (parâmetros totais), } \\
\text { deformação de } 15 \%\end{array}$ \\
\hline
\end{tabular}

a) In Kavazanjian et al. (1995); ${ }^{\text {b) }}$ in Gonzalez (1995), ${ }^{\text {c) }}$ in Manassero et al. (1996); ${ }^{\text {d) }}$ in Carvalho (1999); ${ }^{\text {e) }}$ in Boscov (2006)

\subsubsection{Resistência a tração}

Visando avaliar a resistência a tração dos RSU, Kolsch (1993 e 1995) desenvolveu um equipamento de tração que permite ensaiar amostras de grandes dimensões $(3,0 \times 1,0 \times 1,5 \mathrm{~m})$.

O autor realizou ensaios em 4 tipo de amostras: RSUFO - resíduos frescos; RSUF resíduos frescos dos quais removeu componentes orgânicos; RSU1,5 - resíduos sujeitos a 18 meses de pré-tratamento em condições aeróbias; e RSU5 - resíduos diretos de um aterro com 5 anos de idade. A relação entre a resistência à tração e a tensão normal (linear) foi descrita pelo autor como ângulo de força de tração interno, $\zeta$ (de modo a adaptar os resultados a cálculos de estabilidade de taludes, adicionando $\zeta$ a $\phi$ ), e a parte independente da tensão normal, como coesão.

A Figura 2.11 ilustra o equipamento desenvolvido e, na Figura 2.12, os resultados obtidos, sendo possível verificar que as amostras de resíduos frescos apresentam maior resistência à tração $\left(\zeta=35^{\circ}\right)$ do que as mais antigas $\left(\zeta=14^{\circ}\right)$, o que segundo 0 autor estará associado à maior quantidade de elementos de maior dimensão. 
Segundo o autor, a diferença registrada entre as duas amostras de resíduos frescos se deve essencialmente às diferenças de teor em água ((WRSUFO=44\% e WRSUF $=32 \%$ ). Amostras com teor nulo em fibras apresentam valor de $\zeta$ igual a 0 . Kolsch verificou ainda que a resistência à tração não dependia da densidade das amostras, já que as amostras de resíduos antigos, apesar de terem $\gamma_{d}$ da ordem de 9 a $11 \mathrm{kN} / \mathrm{m}^{3}$, apresentaram menores forças de tração do que as de resíduos frescos, com $\gamma_{d}$ da ordem de 5 a $7 \mathrm{kN} / \mathrm{m}^{3}$.

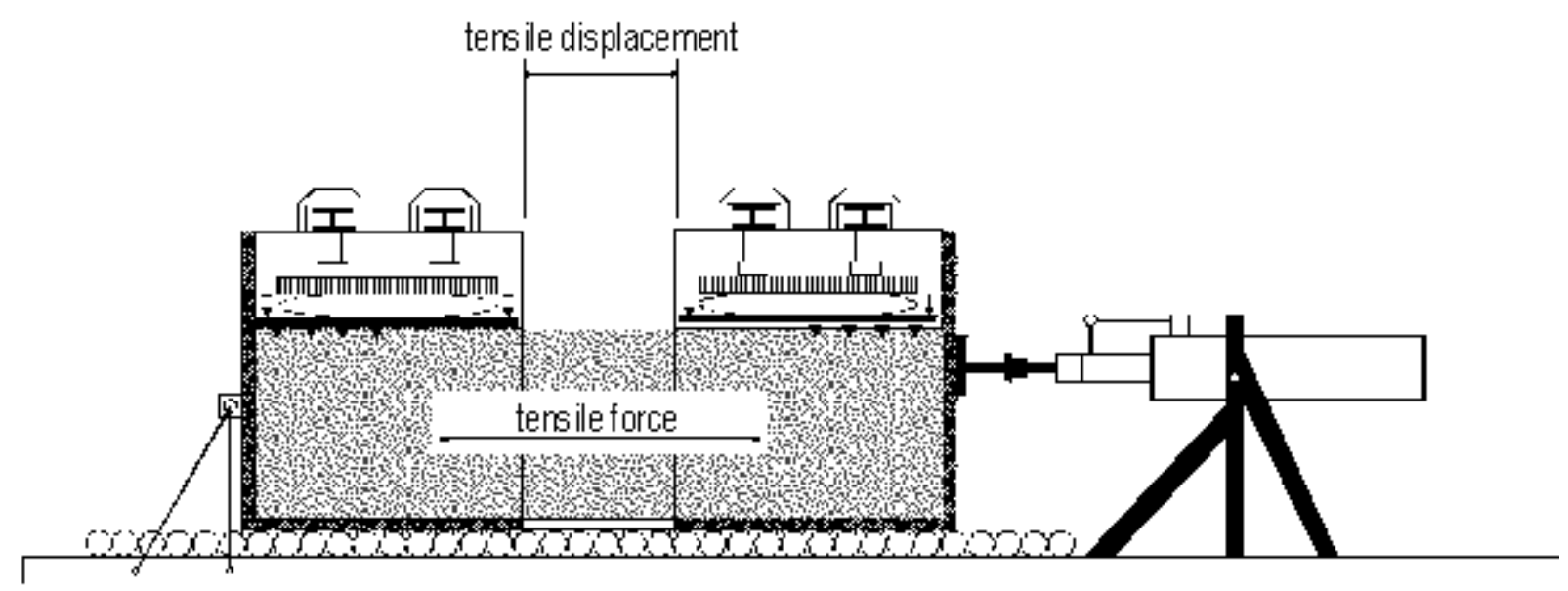

BACK

FRONT

Figura 2.11 - Equipamento para ensaios de resistência à tração desenvolvido por Kolsch (1993)
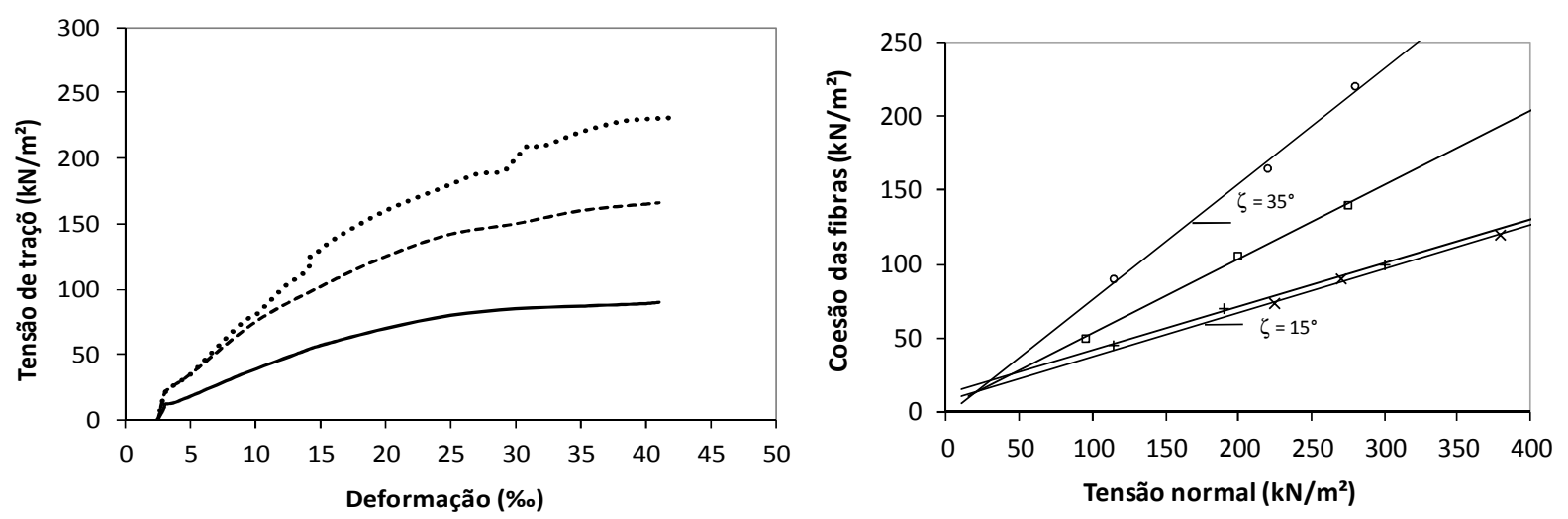

Figura 2.12 - Resistência à tração de RSU (Kolsch, 1995) 


\subsubsection{Compressibilidade}

Ao contrário dos maciços de solo compactado, os maciços de resíduos sólidos urbanos são constituídos por diferentes tipos de material, conforme descrito no item 2.2.2. Tal fato confere ao maciço de RSU características peculiares, tratando-se de um material poroso e heterogêneo cujas propriedades físicas e mecânicas são alteradas ao longo do tempo por fenômenos físicos, químicos e biológicos. Dentre as principais propriedades que sofrem alteração pode-se citar a compressibilidade dos RSU.

Por conta da variabilidade na composição dos RSU, os mecanismos que governam os recalques dos aterros sanitários são muitos e, em geral, complexos, pois além de cada material componente apresentar suas próprias características de compressibilidade, os processos de degradação que ocorrem ao longo do tempo resultam na formação de gases e chorume, com consequente redução de massa e de volume do resíduo depositado (Carvalho et al., 2000). A elevada compressibilidade dos aterros sanitários, apesar de ser problemática, prolonga a vida útil do aterro, possibilitando deposições adicionais (Edil et al., 1990).

A Figura 2.13 apresenta a inter-relação entre os diversos fatores que influenciam a compressibilidade dos resíduos sólidos urbanos, segundo Grisolia et al. (1993) ${ }^{6}$ (apud Marques, 2001).

${ }^{6}$ Grisolia, M.; Gasparini, A.; Saetti, G.F. (1993). Survey on Waste Compressibility. Proc., $4^{\text {th }}$ International Landfill Symposium - Sardinia 93, S. Margherita di Pula, Cagliarii, Italy, p.1447 - 1456. 


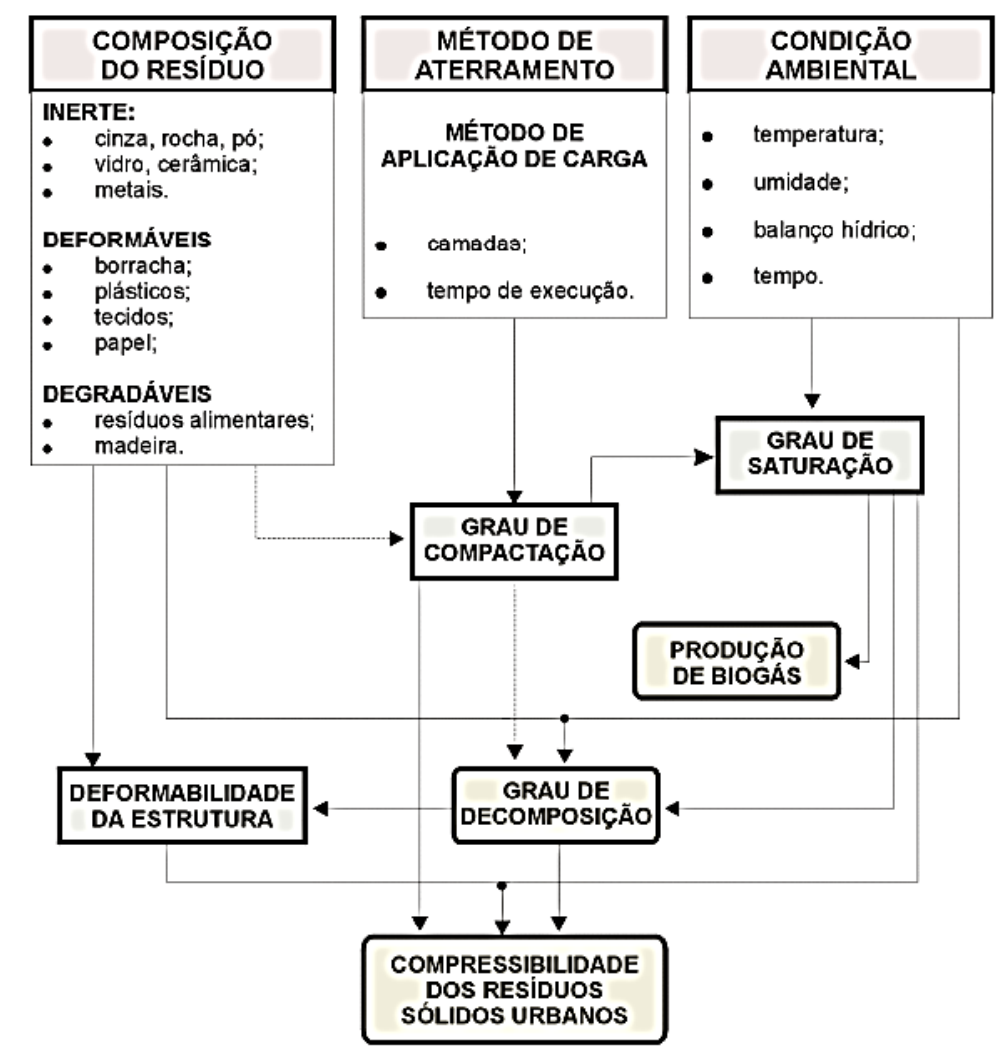

Figura 2.13 - Fatores que afetam a compressibilidade dos resíduos sólidos urbanos (Grisolia et al., 1993 apud Marques, 2001)

Segundo Wall \& Zeiss (1995) e Ouvry \& Page (2005), os recalques ocorrem essencialmente em três estágios:

1. Compressão inicial: ou mecânica, é o recalque que ocorre diretamente quando uma carga externa é aplicada ao aterro, geralmente associado à compressão imediata dos vazios e partículas devido a uma carga sobreposta.

2. Compressão primária: é a compressão devida à dissipação de pressões neutras nos vazios. Ocorre rapidamente, geralmente em até 30 dias após a aplicação da carga.

3. Compressão secundária: é o recalque que ocorre devido à deformação lenta (“creep") e à decomposição biológica.

Embora a compressão secundária inicie conjuntamente com a compressão primária, a magnitude maior da compressão primária no período inicial mascara os efeitos de compressão secundária.

O recalque de aterros sanitários pode ser atribuído a diferentes fenômenos (Manassero et al., 1996; Abreu, 2000; Carvalho et al., 2000): 
a) Compressão física do resíduo determinada pela distorção, flexão, esmagamento e reorientação de componentes;

b) Recalques determinados pela migração de partículas pequenas para os de maiores vazios;

c) Parcela devida ao adensamento propriamente dito (dissipação de pressões neutras, ocorre com a expulsão de líquidos e gases do interior do maciço e demanda certo tempo);

d) Parcela determinada por um colapso da estrutura resultante ou de alguns de seus componentes, graças a fenômenos de corrosão, oxidação e outros processos de degradação de componentes inorgânicos;

e) Parcela governada pela biodegradação dos componentes orgânicos;

f) Creep: deformação lenta sob carga constante em razão de fenômenos viscosos, tanto do esqueleto sólido, como de alguns componentes;

g) Interação dos mecanismos.

Os parâmetros de compressibilidade do RSU, geralmente, são determinados por meio de ensaios de laboratório, como o ensaio de compressão confinada de grandes dimensões; por meio de monitoramento in situ de recalques em aterro sanitário ou por ensaios de campo.

A magnitude dos recalques em maciços de RSU é muito elevada, quando comparados com maciços de solos. Na Tabela 2.5 são apresentados alguns valores de recalque em maciços sanitários.

Tabela 2.5 - Recalques em maciços sanitários

\begin{tabular}{lc}
\hline \multicolumn{1}{c}{ Autor } & Recalque relativo à espessura inicial \\
\hline Sowers (1973) & Da ordem de $30 \%$ \\
Wall e Zeiss (1995) & Entre $25 \%$ e $50 \%$ \\
Van Meerten et al. (1995) & Entre $10 \%$ e $25 \%$ \\
Coumoulos e Koryalos (1997) & Entre $20 \%$ e $25 \%$ \\
Abreu (2000) & Entre 10 e $30 \%$ \\
\hline
\end{tabular}

Fonte: Boscov (2008)

O maciço de RSU recalca sob peso próprio, entre 10 a $40 \%$ da altura original do aterro, e a maioria dos recalques ocorre nos primeiros anos após a disposição do resíduo (Carvalho 1999, Abreu 2000). Esse fato apontado por resultados de ensaios 
em colunas drenadas de grande diâmetro executados por Gandolla et al. (1994), conforme apresentado na Figura 2.14.

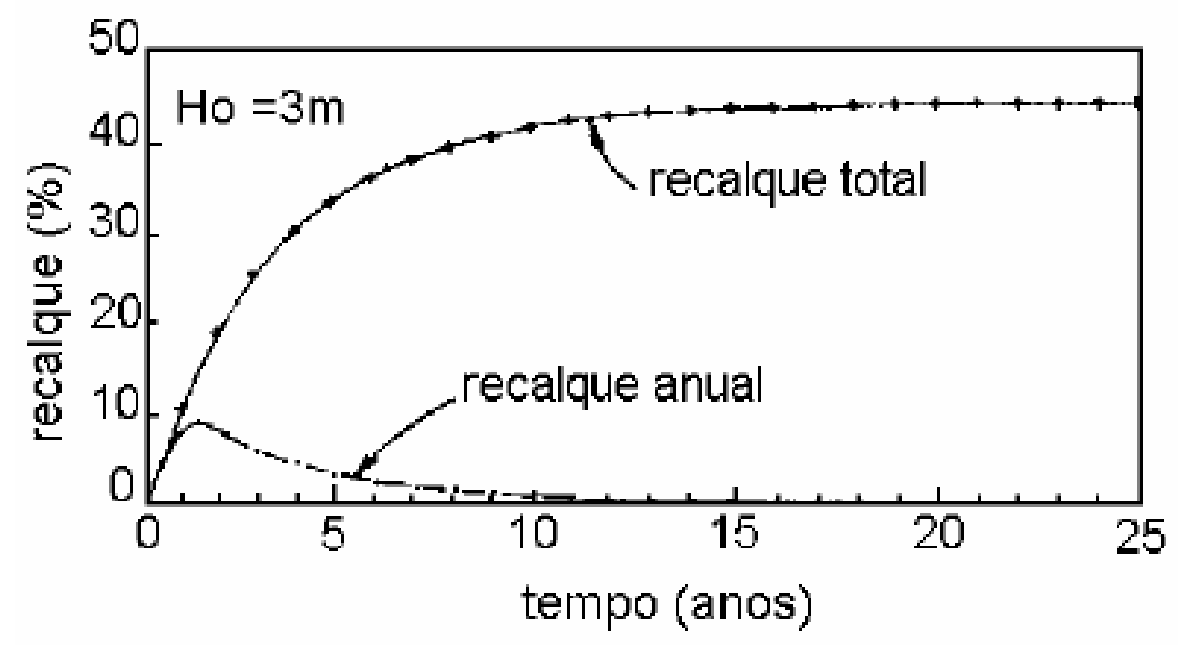

Figura 2.14 - Recalque total e anual de RSU (Gandolla et al., 1994)

Na Figura 2.15 são apresentados recalques de superfície de diversos aterros da Europa e América do Norte, com diferentes composições e idades, apresentados por König \& Jessberger (1997) ${ }^{7}$ (apud Carvalho, 1999), sendo que o tempo zero corresponde ao final do período de operação do aterro. É possível observar que em alguns casos a curva apresenta uma inflexão, cuja tendência é de diminuição das velocidades de recalque com possível estabilização, enquanto que em outros as curvas, mesmo após anos de monitoramento, não apresentam nenhuma mudança significativa em sua curvatura, com tendência de manutenção das velocidades e aumento dos valores de recalque.

\footnotetext{
${ }^{7}$ König, D., Jessberger, H.L. (1997). Waste Mechanics. Proc., 14th International Conference on Soil Mechanics and Foundation Engineering, Special Reporto f the TC5 Technical Committee on Waste Mechanics, Hamburg, Germany, 35-76.
} 


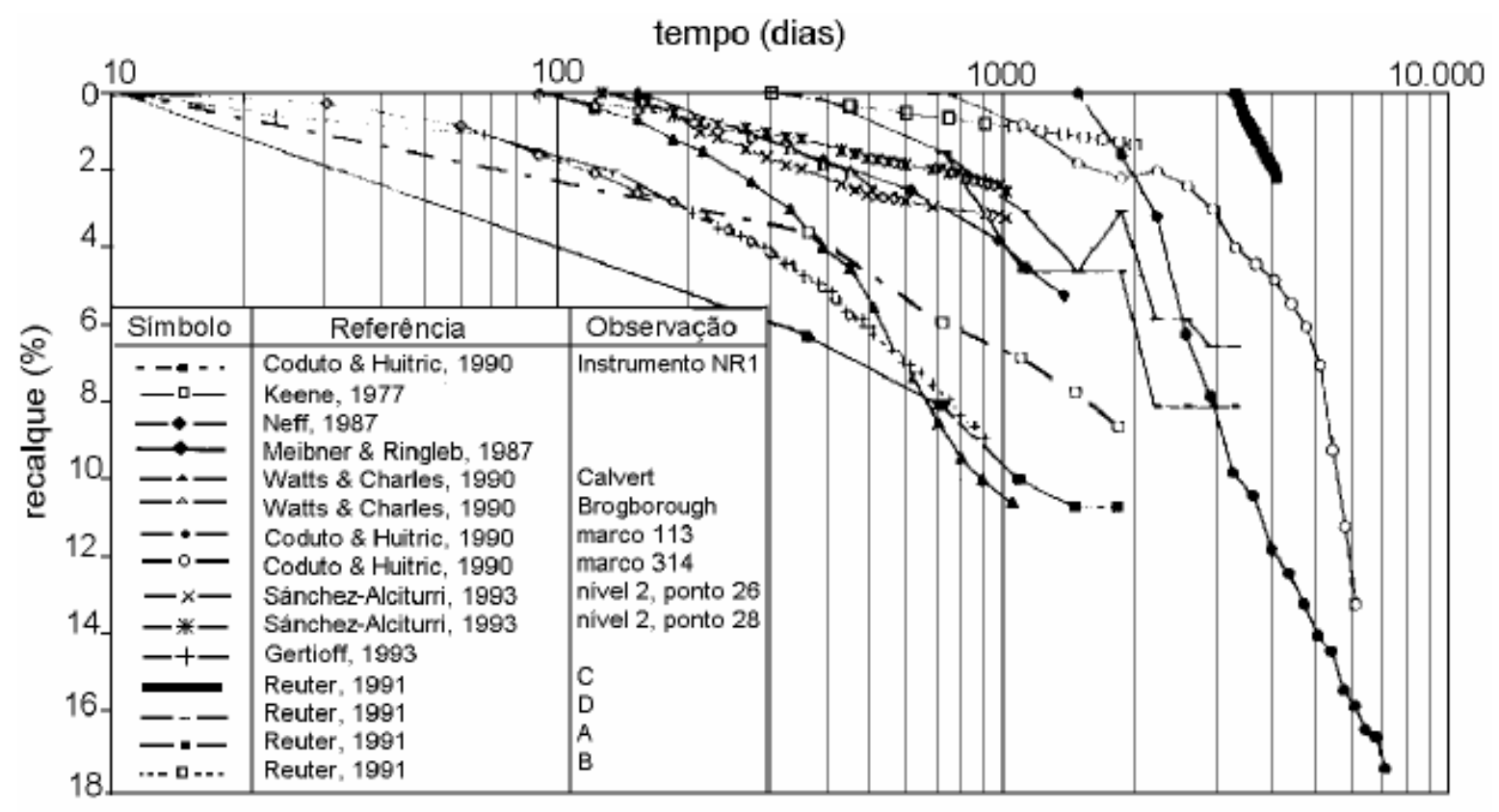

Figura 2.15 - Medidas de recalques de superfície de diferentes aterros (König \& Jessberger, 1997)

A avaliação da compressibilidade de resíduos sólidos urbanos antigos (idade desconhecida) de vários aterros do Canadá foi avaliada por Landva \& Clark (1990) ${ }^{8}$ (apud Carvalho, 1999) a partir de ensaios de compressão confinada em célula de grande dimensão (diâmetro de $0,45 \mathrm{~m}$ ); os resultados são apresentados na Figura 2.16. Os resultados mostram que para uma mesma pressão, a deformação é maior nos resíduos frescos triturados e com maior teor de matéria orgânica do que nos resíduos antigos.

${ }^{8}$ Landva, A.O.; Clark, J.I. (1990). Geotechnics of Waste Fill. Geotechnics of Waste Fills - Theory and Practice, ASTM STP 1070, Arvid Landva, G. David Knowles, editors, American Society for Testing and Materials, Philadelphia, 1990, p.86 - 103. 


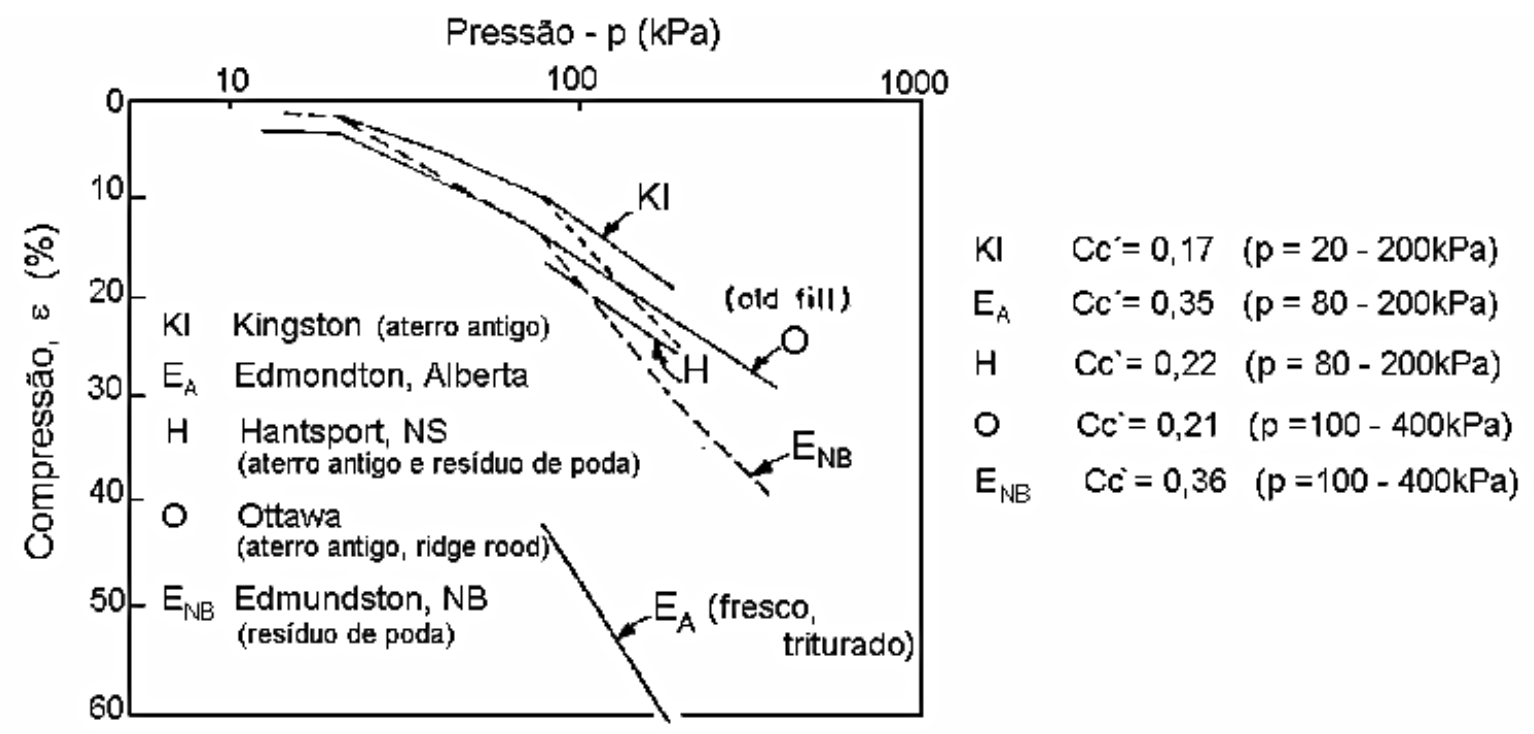

Figura 2.16 - Resultados obtidos de ensaios de compressão confinada para resíduos do Canadá (Landva \& Clark, 1990 apud Carvalho, 1999)

\subsubsection{Módulo de deformabilidade}

Embora o comportamento à deformabilidade dos resíduos não satisfaça os requisitos de material elástico, tem-se utilizado a Teoria da Elasticidade, particularmente o modelo elástico linear, para estimar recalques e tensões em maciços sanitários. Justifica-se esta simplificação por algumas constatações: até um determinado nível de tensões, existe certa proporcionalidade entre as tensões e deformações; os carregamentos são geralmente crescentes; e é maior a facilidade de aplicação e a interpretação das soluções elásticas.

A deformabilidade dos resíduos é, portanto, caracterizada pelo módulo de elasticidade e pelo coeficiente de Poisson, ou por outros parâmetros derivados desses.

A variação do módulo de deformabilidade depende de vários fatores, tais como a composição do RSU, estado de compactação, presença de cobertura de solo, diâmetro da placa (quando obtido de provas de carga), tipo de ensaio e idade dos resíduos (Manassero et al. 1996; Van Impe, 1998).

$\mathrm{Na}$ Figura 2.17 são apresentados resultados de módulo de deformabilidade para RSU obtidos por vários autores utilizando diferentes métodos de ensaios, bem como as envoltórias superior e inferior propostas por Manassero et al. (1996) e as relações 
obtidas por König e Jessberger (1997) a partir de 21 ensaios de compressão confiada de grandes dimensões. As relações apresentadas por König e Jessberger (1997) dão informações de recalque para RSU que não tenha sido submetido a cargas maiores do que aquelas aplicadas no ensaio.

De acordo com Knochenmus et al. (1998) (apud Carvalho, 1999), o módulo de deformabilidade para o resíduo urbano varia entre 0,5 a $3 \mathrm{MPa}$ e, em virtude da duração limitada dos ensaios de campo e laboratório, os resultados não levam em conta as variações do módulo com o tempo e com as mudanças físico-químicas e biológicas do resíduo.
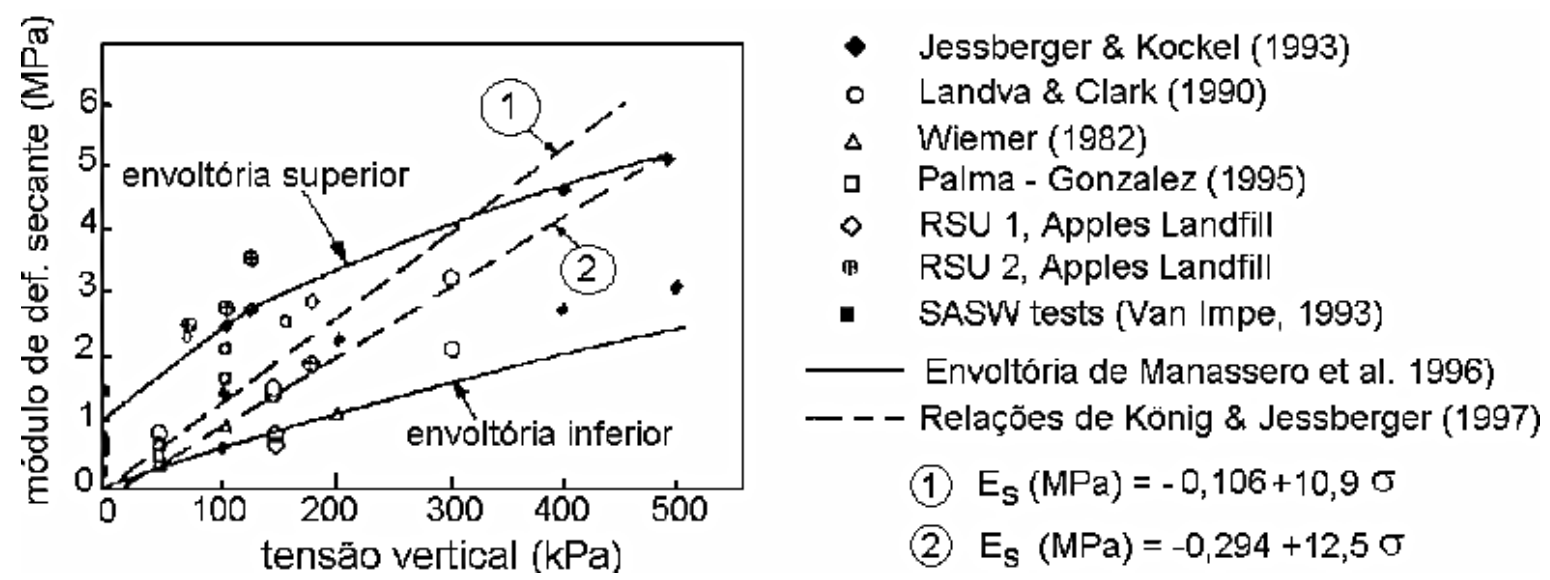

Figura 2.17 - Variação de módulo de deformação com a tensão vertical obtidos para diferentes resíduos sólidos urbanos (modificado de Knochenmus et al., 1998 apud Carvalho, 1999)

Carvalho (1999) realizou ensaios triaxiais, a 20\% de deformação axial, e de compressão confinada em resíduos com cerca de 15 anos, dos quais obteve valores de módulo de elasticidade apresentados na Figura 2.18. Os resultados mostram uma maior variação para menores níveis de deformação com tendência de estabilização com o aumento da deformação axial.

\footnotetext{
${ }^{9}$ Knochenmus, G.; Wojnarowicz, M.; Van Impe (1998). Stability of Municipal Soli Wastes. In: Proc. of Third International Congress on Environmental Geotechnics, Lisboa, Portugal, Sêco e Pinto (ed.), Balkema, Rotterdam, ISBN 905809 006x, p. 977-1000.
} 


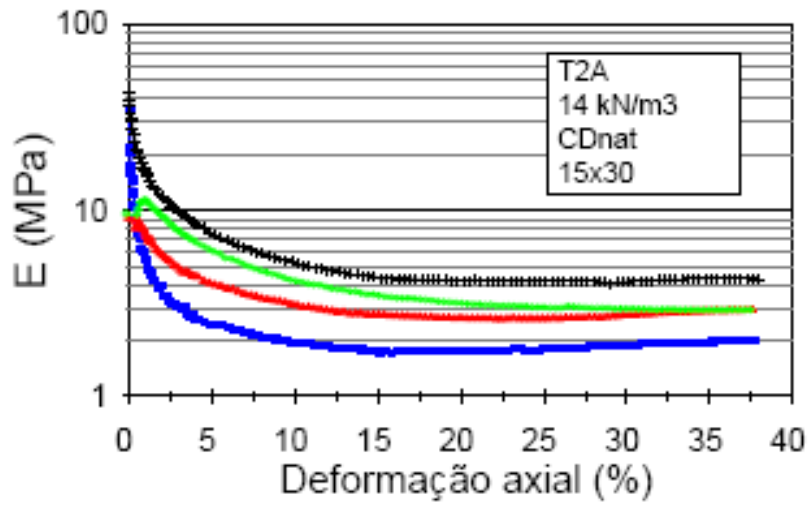

$\rightarrow 100 \mathrm{kPa} \rightarrow 200 \mathrm{kPa}+400 \mathrm{kPa} \rightarrow 400 \mathrm{kPa}$

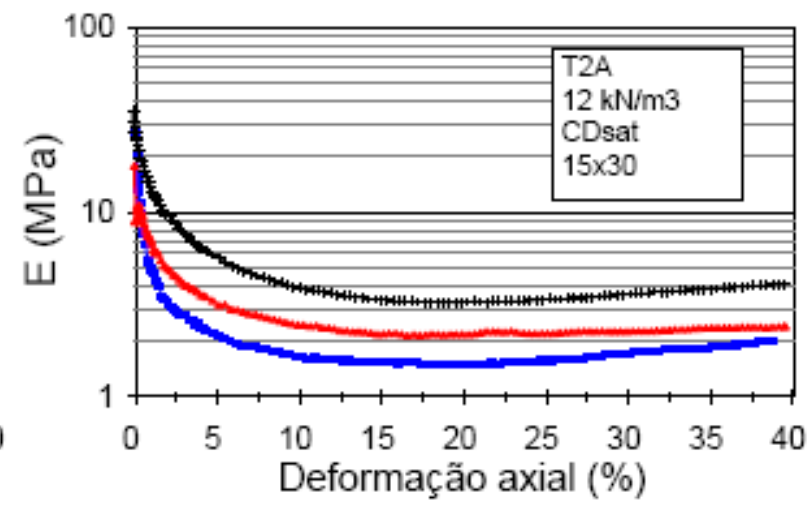

$\rightarrow 100 \mathrm{kPa} \rightarrow 200 \mathrm{kPa}+400 \mathrm{kPa}$

Figura 2.18 - Módulo de elasticidade x deformação axial para amostras com peso específico de $14 \mathrm{kN} / \mathrm{m}^{3}$ e $12 \mathrm{kN} / \mathrm{m}^{3}$, respectivamente (Carvalho, 1999)

Na Figura 2.19 é apresentada uma comparação entre os módulos de elasticidade obtidos em ensaios de compressão confinada e de ensaios triaxiais a $20 \%$ de deformação axial para uma das amostras estudadas. É possível notar que os módulos de elasticidade aumentam aproximadamente linearmente com o aumento da tensão octaédrica.

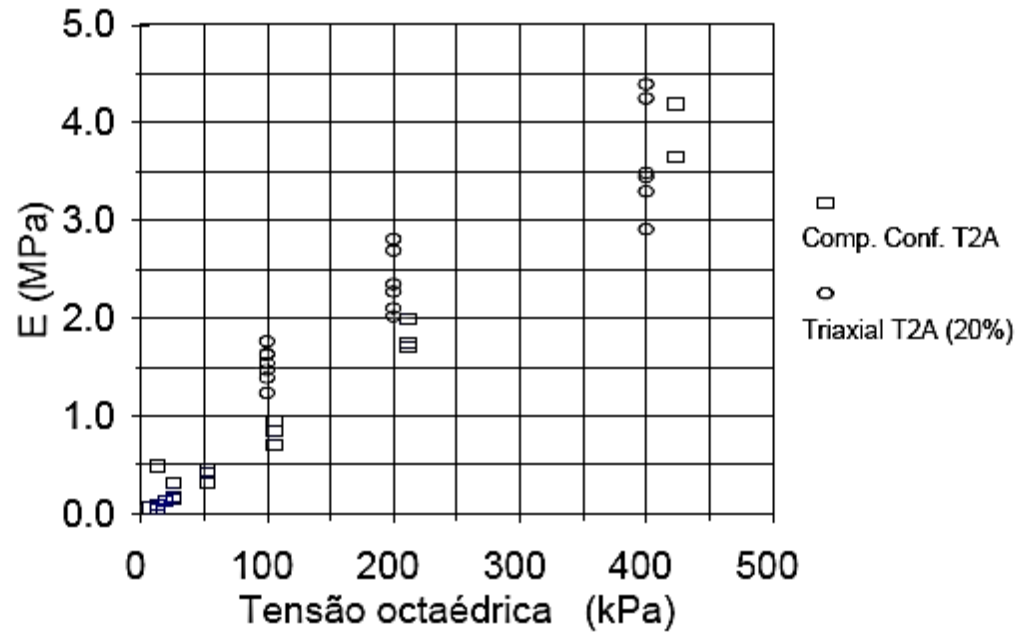

Figura 2.19 - Comparação entre os módulos de elasticidade obtidos de ensaios em compressão confinada e de ensaios triaxiais a $20 \%$ de deformação axial (Carvalho, 1999)

Gomes (2008) obteve em seu trabalho valores de módulos de deformabilidade dos resíduos a partir de diferentes conjuntos de dados, como ensaios edométricos, ensaios de compressão triaxial, instrumentação de aterros e ensaios in situ (SPT, CPT e prova de carga em placa em profundidade). 
Os resultados dos ensaios laboratoriais são apresentados na Figura 2.20. Nos ensaios edométricos, os valores dos módulos de compressão confinada foram convertidos em módulos de compressão não confinada equivalente e os de tensão vertical em tensão octaédrica por meio, respectivamente, das equações 2.2. e 2.3, adotando-se coeficiente de Poisson igual a 0,2 e $\mathrm{K}_{0}=0,33$. Os valores obtidos dos ensaios triaxiais correspondem a uma deformação axial de $15 \%$.

$$
E=\frac{\mathrm{D} \cdot(1+v) \cdot(1-2 v)}{(1-v) \cdot}
$$

Onde: $\mathrm{D}=$ módulo de compressão confinada, $\mathrm{E}=$ módulo de deformabilidade do ensaio, $v$ = coeficiente de Poisson.

$$
\sigma_{o c t}=\frac{\sigma_{v}\left(1+2 K_{0}\right)}{3}
$$

Onde: $\sigma_{\text {oct }}=$ tensão octaédrica, $\sigma_{v}=$ tensão vertical, $K_{0}=$ coeficiente de empuxo no repouso.

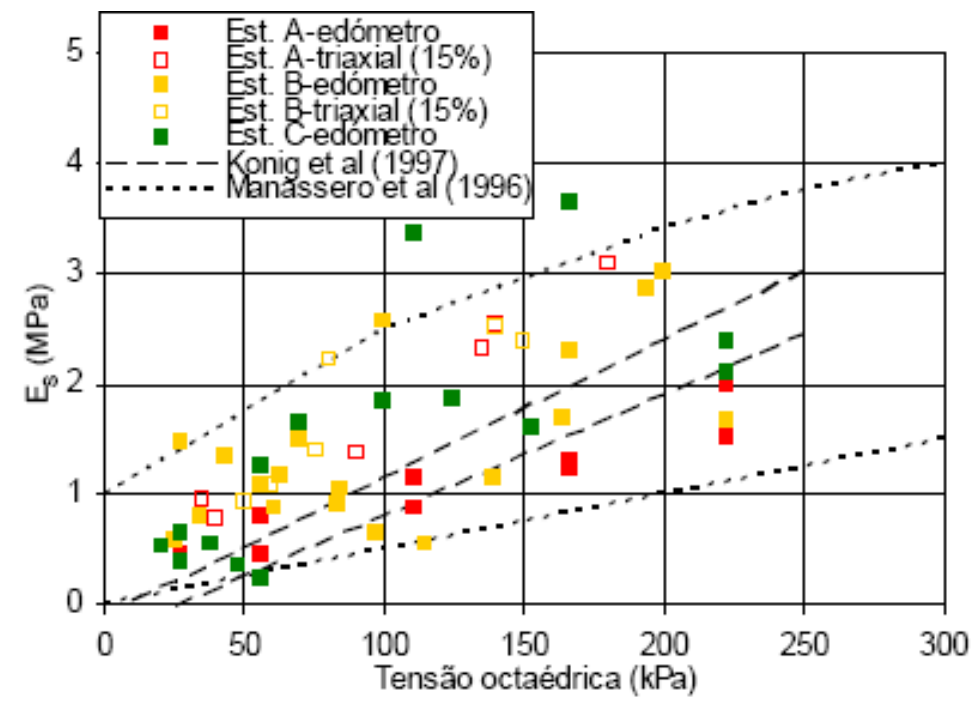

Figura 2.20 - Módulos de deformabilidade secante em função da tensão octaédrica (Gomes, 2008) A instrumentação consistiu de células de pressão, placas de recalque e aranhas magnéticas instaladas junto às células. Para a estimativa do módulo de deformabilidade a partir dos resultados dos ensaios SPT e CPT foram utilizadas correlações semi-empíricas com os ensaios de laboratório (edométrico e triaxial). $\mathrm{Na}$ Figura 2.21 constam os resultados obtidos por Gomes (2008), exceto pelos 
resultados das provas de carga em profundidade, que apresentaram elevada dispersão e módulos de deformabilidade superiores aos dos demais ensaios.

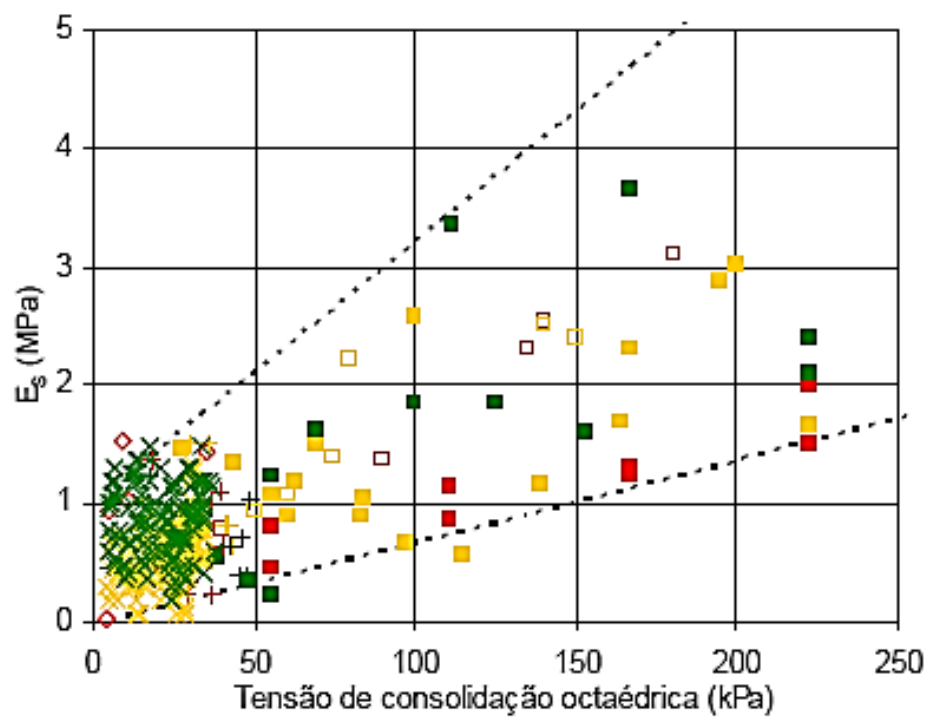

\begin{tabular}{|l|}
\hline$\square$ Est. A-edómetro \\
$\square$ Est. B-edómetro \\
$\square$ Est. C-edómetro \\
$\square$ Est. A-triaxial (def.=15\%) \\
$\square$ Est. B-triaxial (def.=15\%) \\
$\diamond$ Est. A-instrumentação \\
+ Est. A-SPT \\
+ Est. B-SPT \\
+ Est. C-SPT \\
$\times$ Est. B-CPT \\
$\times$ Est. C-CPT
\end{tabular}

Figura 2.21 - Módulos de deformabilidade não confinados do aterro de Sto Tirso (Gomes, 2008)

Gomes (2008) sugere os limites superior e inferior para o módulo de deformabilidade apresentados nas equações 2.4 e 2.5 .

$$
\begin{aligned}
& \text { Limite Superior: } E_{S}(M P a)=1,01+21,89 . \sigma(M P a) \\
& \text { Limite inferior: } E_{S}(M P a)=0,034+6,96 . \sigma(M P a)
\end{aligned}
$$

Azevedo et al. (2006), por outro lado, não obtiveram evidência de enrijecimento dos RSU em função do aumento da tensão vertical em ensaio de placa realizado em um lisímetro de grandes dimensões. Esses dados são corroborados por Campi (2011), que não observou tendência de alteração do módulo de elasticidade em função do aumento de tensão vertical em 15 ensaios de placa realizados nas camadas mais superficiais de um aterro sanitário de grande porte. 


\subsubsection{Coeficiente de Poisson e empuxo no repouso}

A Teoria da Elasticidade relaciona os coeficientes de Poisson, $v$, e coeficiente de empuxo no repouso, $K_{0}$ através das equações:

$$
\begin{aligned}
& K_{0}=\frac{v}{1-v} \\
& v=\frac{K_{0}}{1+K_{0}}
\end{aligned}
$$

Neste trabalho será apresentado um breve resumo dos valores de coeficiente de Poisson e coeficiente de empuxo no repouso encontrados na bibliografia.

Towhata et al. (2004) realizaram ensaios triaxiais em amostra de material orgânico e em amostra de lixo inflamável, basicamente compostas por restos de comida e recipientes de comida, do porto de Tókio. As amostras, compactadas com grau de compactação de $80 \%$ e umidade de $40 \%$, foram submetidas a ensaios triaxiais drenados, com incrementos de tensão vertical a velocidade constante, variando-se a tensão radial. Partindo de um estado inicial isotrópico, os autores verificaram uma redução nos valores de $\mathrm{K}$ com o aumento das tensões, até estabilizarem em valores entre 0,25 e 0,4 para tensões verticais superiores a $100 \mathrm{kPa}$. Os resultados obtidos pelos autores são apresentados na Figura 2.22.

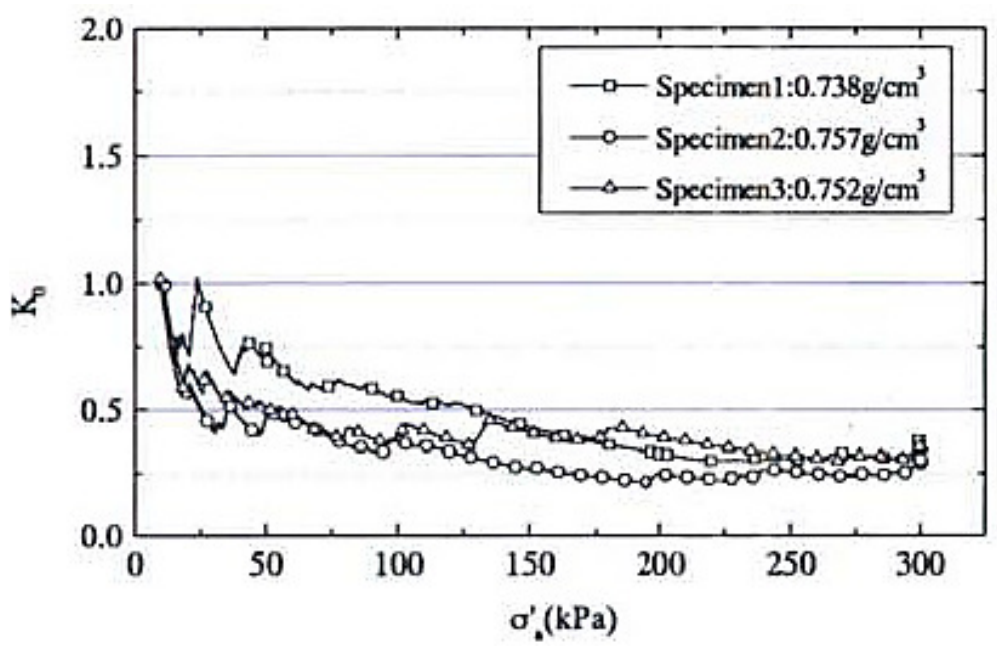

Figura 2.22 - Variação dos valores de $\mathrm{K}_{0}$ com o aumento do nível de tensa 
Aplicando-se os resultados obtidos por Towhata et al. (2004) nas equações da Teoria da Elasticidade, os valores de coeficiente de Poisson equivalentes variaram entre 0,20 a 0,29.

O valor médio obtido por Carvalho (1999) para o coeficiente de Poisson ( $v$ ) em ensaios cross-hole situava-se em torno de 0,33, em resíduos com 15 anos de um aterro de São Paulo.

Houston et al. (1995) ${ }^{10}$ (apud Gomes, 2008) realizaram ensaios geofísicos do tipo down-hole e obtiveram valores para o coeficiente de Poisson linearmente decrescentes com a profundidade, desde 0,3 até 0,11 , respectivamente para profundidades entre 1 e $10 \mathrm{~m}$. Sharma et al. (1990) ${ }^{11}$ (apud Gomes, 2008) também obtiveram um valor médio de $v$ de 0,46 para um aterro na Califórnia.

Matasovic \& Kavazanjian (1998) através de ensaios geofísicos obtiveram valores de coeficiente de Poisson de 0,25 para rochas brandas e 0,33 para os RSU, conforme pode-se observar na Figura 2.23.

${ }^{10}$ Houston W.N., Houston S.L., Elsayed J.W., e Sanders C.O., 1995. In situ testing methods for dynamicproperties of MSW landfills. Earthquake Design and Performance of Solid Waste Landfills, ASCE,Geotechnical Special Publication №54, p. $73-82$.

11 Sharma H.D., Michael T.D., e Olsen D.M., 1990. Field measurements of dynamic moduli and Poisson's ratios of refuse and underlying soils at a landfill site. Geotechnics of Waste Fills - Theory and Pratice, Landva/Knowles editors, ASTM - STP 1070, Philadelphia, p. 57 - 70. 


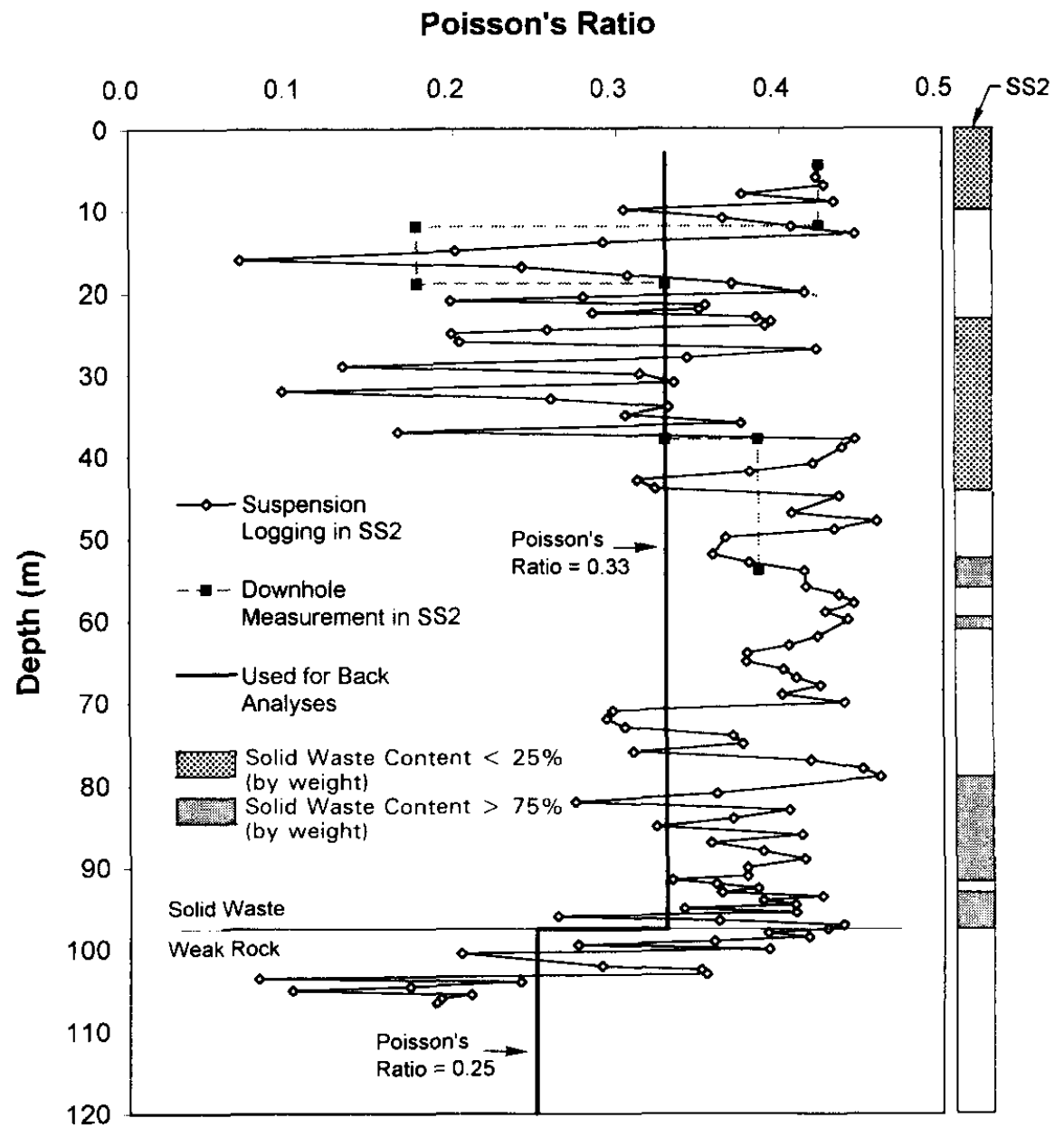

Figura 2.23 - Coeficientes de Poisson obtidos por Matasovic \& Kavazanjian (1998)

Valores de $\mathrm{K}_{0}$, obtidos através de instrumentação por células de tensão total instaladas nas direções vertical e horizontal, foram publicados por Dixon et al. (2004). Os valores de $\mathrm{K}_{0}$ variam entre 0,4 e 0,8, estabilizando na ordem de 0,8 para maiores profundidades, conforme se pode observar na Figura 2.24. 


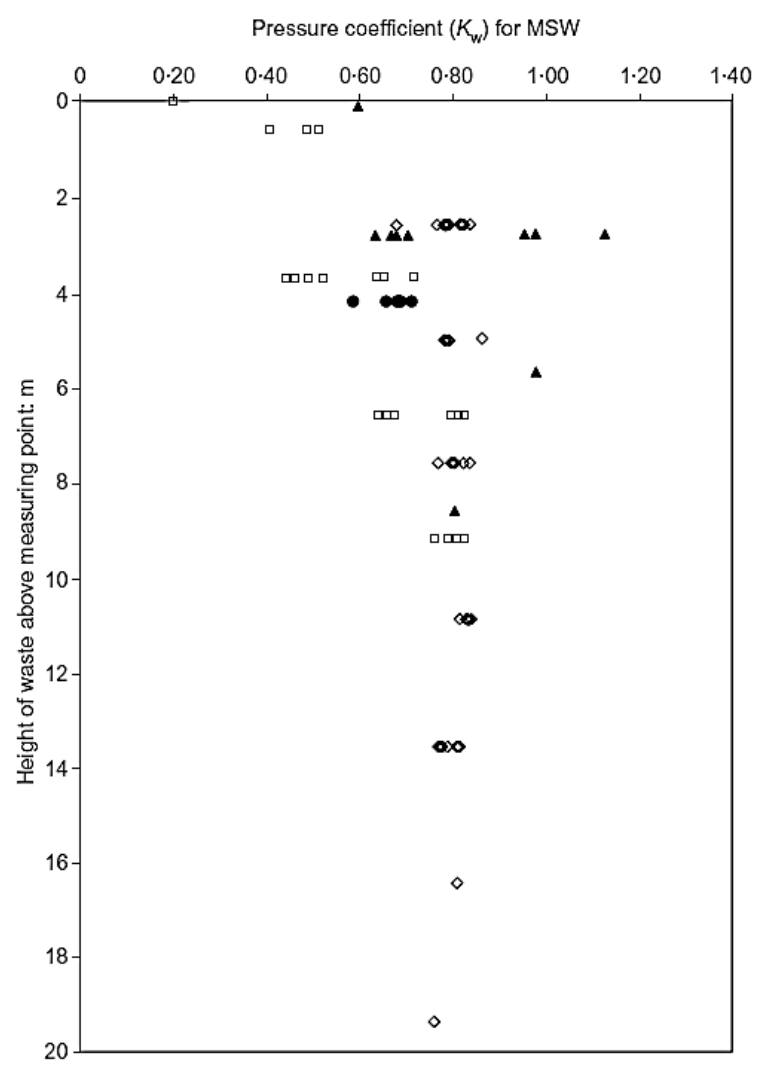

Figura 2.24 - Medidas de $\mathrm{K}_{0}$ em RSU (Dixon et al. (2004)).

Segundo os autores, as medidas podem representar um fenômeno real ou até uma limitação da instrumentação, ou ainda a dispersão de resultados pode ser atribuída a rotações sofridas pelas células dispostas na vertical ou à proximidade de um talude do aterro. Os valores de $v$ respectivos oscilam entre 0,28 e 0,44 , com os valores mais elevados atingidos a maiores profundidades.

Olivier (2003) ${ }^{12}$ (apud Gomes, 2008), em seu trabalho, instrumentou uma célula experimental de grandes dimensões equipada com células de tensões totais nas paredes laterais. $\mathrm{O}$ autor obteve valores de $\mathrm{K}_{0}$ entre 0,18 e 0,37 para cargas verticais de $130 \mathrm{kPa}$.

Gomes (2008) obteve valores de $\mathrm{K}_{0}$ e $v$ a partir de dados da instrumentação de aterro e de ensaios triaxiais. Os resultados dos ensaios triaxiais mostraram que, para níveis de deformação elevados, os valores de coeficiente de Poisson tendem a se estabilizar entre 0,2 e 0,33 . A ordem de grandeza é similar à dos resultados de

\footnotetext{
${ }^{12}$ Olivier F., 2003. Tassement dês Déchets en CSD de classe II: du site au modèle, Thèse de Doctorat, Université Joseph Fourier, Grenoble, 333 p.
} 
Carvalho (1999); segundo o autor, algumas diferenças entre os dois trabalhos podem estar associadas a variações na densidade e composição dos resíduos ensaiados. Alguns resultados de Gomes (2008) encontram-se na Figura 2.25.

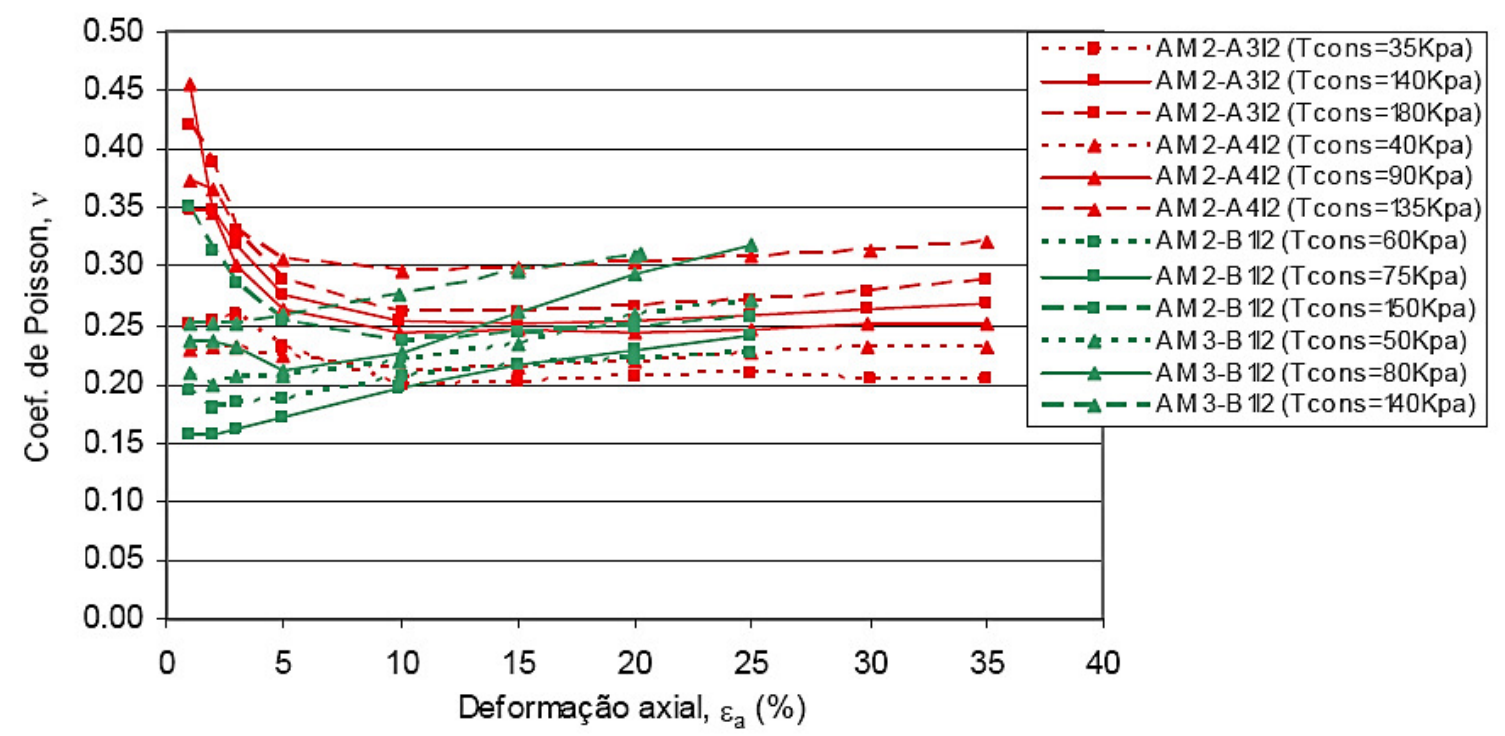

Figura 2.25 - Coeficientes de Poisson determinados a partir dos ensaios triaxiais em função da deformação axial

Já os dados obtidos do monitoramento do aterro de Sto Tirso forneceram valores crescentes de $\mathrm{K}_{0}$ e $v$ até níveis de deformação vertical da ordem de $20 \%$, entre 0,3 e 0,7 para $\mathrm{K}_{0}$ e entre 0,2 e 0,4 para $v$, com respectivos valores médios de 0,42 e 0,29. Para níveis de deformação superiores, obtiveram-se valores decrescentes ou com tendência a estabilizar, com $\mathrm{K}_{0}$ variando entre 0,48 a 0,23 e $v$ variando de 0,32 a 0,19 , com valores médios de 0,33 e 0,25 , respectivamente.

$\mathrm{Na}$ Figura 2.19 é apresentado um resumo de valores de $\mathrm{K}_{0} \mathrm{e} v$ em função da profundidade, elaborada por Zeccos (2005). 

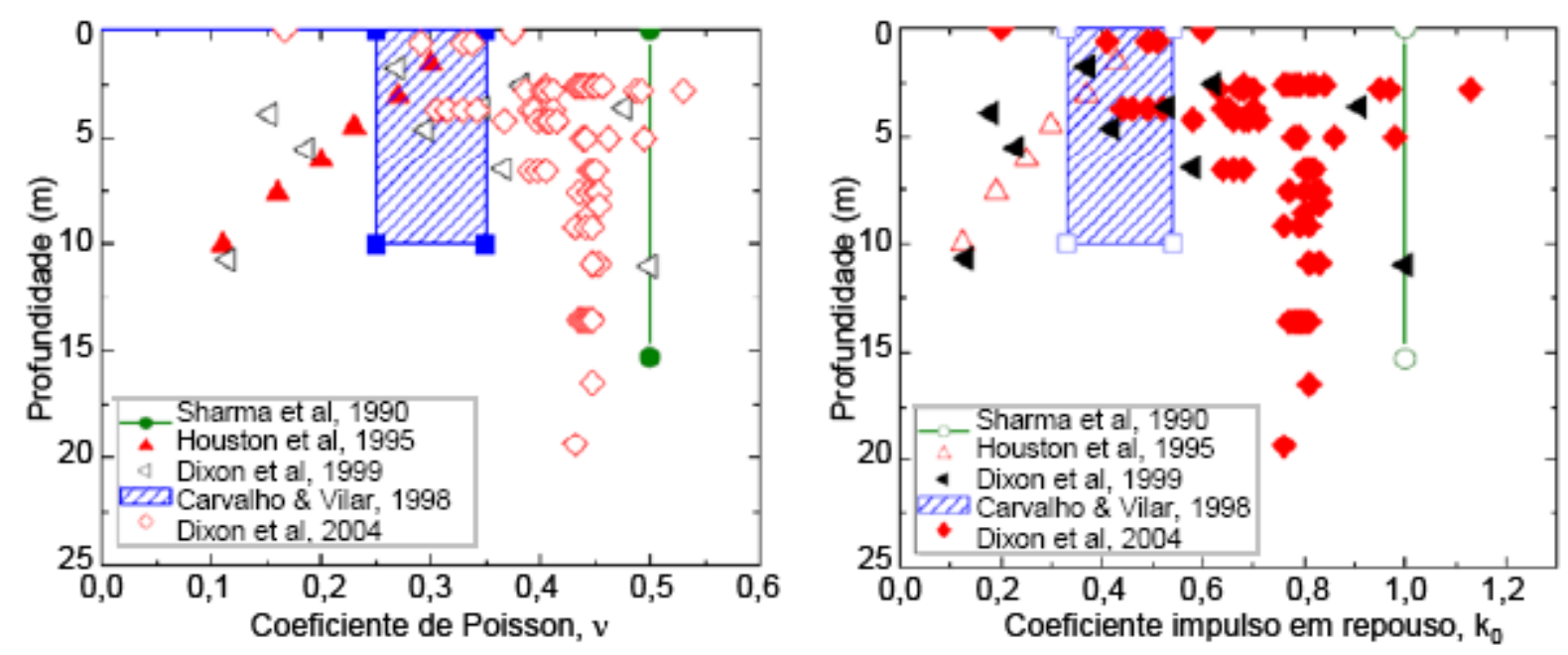

Figura 2.26 - Resumo de valores de v e $\mathrm{K}_{0}$ determinados in situ em função da profundidade (Zeccos, 2005)

Na Tabela 2.6 é apresentado um resumo dos valores de coeficiente de empuxo no repouso e coeficiente de Poisson obtidos na bibliografia.

Tabela 2.6 - Coeficiente de empuxo no repouso e coeficiente de Poisson

\begin{tabular}{|c|c|c|c|c|}
\hline Fonte & Método & $\mathrm{K}_{0}$ & $v$ & Observações \\
\hline Sharma et al. (1990) & Down-hole & - & 0,46 & $\begin{array}{l}\text { Valores médios; } 0 \text { a } 15 \mathrm{~m} \text { de } \\
\text { prof.; } \gamma=7,37 \mathrm{kN} / \mathrm{m}^{3}\end{array}$ \\
\hline $\begin{array}{l}\text { Jessberger \& Kockel } \\
\text { (1993) }\end{array}$ & Triaxiais & - & 0,05 a 0,35 & $\begin{array}{l}\text { Respectivamente para } \varepsilon_{\mathrm{a}} \\
\approx 1 \text { a } 20 \%\end{array}$ \\
\hline Houston et al. (1995) & Down-hole & - & 0,3 a 0,11 & 3 a $15 \mathrm{~m}$ prof.; $\gamma=6 \mathrm{kN} / \mathrm{m}^{3}$ \\
\hline Cuéllar et al. (1998) & SASW & - & 0,2 & $\begin{array}{l}\text { Valores médios; } 0 \text { a } 15 \mathrm{~m} \text { de } \\
\text { prof.; } g=7,37 \mathrm{kN} / \mathrm{m}^{3}\end{array}$ \\
\hline $\begin{array}{l}\text { Matasovic \& } \\
\text { Kavazanjian (1998) }\end{array}$ & $V_{s}$ e $V_{L}$ & - & 0,25 a 0,4 & $\begin{array}{l}\text { Valores médios; } 5 \text { a } 97 \mathrm{~m} \text { de } \\
\text { prof.; } \gamma_{\text {med }}=15,7 \mathrm{kN} / \mathrm{m}^{3}\end{array}$ \\
\hline Dixon et al. (1999) & Pressiômetro & $\begin{array}{c}0,06 \text { a } 0,9 \\
1,0\end{array}$ & - & $\begin{array}{l}\text { RSU com } 1 \text { a } 3 \text { anos } \\
\text { RSU com } 11 \text { anos }\end{array}$ \\
\hline Carvalho (1999) & Cross-hole & - & 0,27 a 0,38 & $\begin{array}{l}0 \text { a } 30 \mathrm{~m} \text { prof.; } \gamma=8 \mathrm{kN} / \mathrm{m}^{3} \text {; } \\
\text { RSU com } 15 \text { anos }\end{array}$ \\
\hline Landva et al. (2000) & $\begin{array}{l}\text { Comp. confinada } \\
\text { com leitura de } \\
\sigma_{\mathrm{h}} \\
\end{array}$ & 0,26 a 0,4 & 0,21 a 0,29 & $\begin{array}{l}\text { Respectivamente para } \\
\text { amostras com teor em } \\
\text { fibras entre } \approx 65 \text { e } 30 \%\end{array}$ \\
\hline Ngambi et al. (2001) a) & $\begin{array}{l}\text { Instrumentação } \\
\text { de aterro }\end{array}$ & 0,74 a 0,86 & - & $\begin{array}{l}\text { Profundidade entre } 4,5 \text { e } \\
16,5 \mathrm{~m}\end{array}$ \\
\hline
\end{tabular}


Tabela 2.6 - Coeficiente de empuxo no repouso e coeficiente de Poisson (conclusão)

\begin{tabular}{|c|c|c|c|c|}
\hline Fonte & Método & $\mathrm{K}_{0}$ & $v$ & Observações \\
\hline Olivier (2003) & $\begin{array}{l}\text { Células } \\
\text { experimentais }\end{array}$ & 0,18 a 0,37 & - & - \\
\hline Towhata et al. (2004) & Triaxiais & 0,25 a 0,4 & - & $\begin{array}{l}\text { Tensão vertical > } 100 \mathrm{kPa} \text { e } \\
\text { pequenas deformações } \\
\text { radiais }\end{array}$ \\
\hline Dixon et al. (2004) ${ }^{\text {a) }}$ & $\begin{array}{l}\text { Instrumentação } \\
\text { de aterro }\end{array}$ & 0,4 a 0,8 & - & $\begin{array}{l}\text { Profundidade entre } 0 \text { e } \\
20 \mathrm{~m}\end{array}$ \\
\hline Zeccos (2005) & Triaxiais cíclicos & - & $\begin{array}{l}0,28 \text { a } 0,4 \\
0,05 \text { a } 0,3\end{array}$ & $\begin{array}{l}\text { Amostras com } 100 \% \text { de } \\
\text { material }<20 \mathrm{~mm} \\
\text { Amostras com } 62 \text { a } 76 \% \text { de } \\
\text { material }<20 \mathrm{~mm}\end{array}$ \\
\hline \multirow[b]{2}{*}{ Gomes (2008) } & Triaxiais & - & 0,2 a 0,33 & Deformações elevadas \\
\hline & $\begin{array}{l}\text { Instrumentação } \\
\text { de aterro }\end{array}$ & $\begin{array}{c}0,7 \text { a } 0,3 \\
\left(0,42^{*}\right) \\
0,48 \text { a } 0,23 \\
\left(0,33^{*}\right)\end{array}$ & $\begin{array}{l}0,42 \text { a } 0,29(0,29 *) \\
0,32 \text { a } 0,19(0,25 *)\end{array}$ & $\begin{array}{l}\text { Deformações } \leq 20 \% \\
\text { Deformações > 20\% }\end{array}$ \\
\hline
\end{tabular}

(*) Valores médios

Fonte: ${ }^{\text {a) }}$ Zeccos (2005)

\subsubsection{Propriedades biológicas do RSU}

A biodegradação anaeróbia, o processo mais importante relacionado à fração orgânica dos resíduos sólidos urbanos, consiste na transformação dos componentes orgânicos, com o tempo e em condições de anaerobiose, em biogás, em líquidos, em matéria orgânica mineralizada e em compostos orgânicos mais simples (Tchobanoglous et al. 1993).

A decomposição biológica dos RSU aterrados ocorre inicialmente por processos aeróbios e em longo prazo predominantemente por processos anaeróbios.

Uma série de fatores influência os processos de biodegradação, dentre os quais o teor de umidade, composição do resíduo, temperatura, tamanho de partículas e grau de compactação dos RSU, disponibilidade de nutrientes, detalhes de projeto e de operação do aterro (compactação, existência de cobertura diária, drenagem) e condições climáticas favoráveis (Van Meerten et al. 1995). 
No processo de degradação, além do metano e dióxido de carbono, são gerados em menor quantidade outros gases, como: amônia, monóxido de carbono, hidrogênio, ácido sulfídrico, nitrogênio e hidrogênio. Ademais, o processo da decomposição predominantemente anaeróbio em aterros sanitários gera como subproduto da atividade bacteriana o chorume ou lixiviado. Esse líquido negro e com odor forte possui alto potencial poluente, composição química extremamente complexa e variável.

\subsubsection{Biogás}

As características de produção de produção de biogás e sua reutilização energética têm sido estudadas por inúmeros autores,, já que se trata de um fator chave na gestão de um aterro, quer por razões ambientais, quer econômicas (Gomes, 2008). Dentre os fatores que influenciam a produção de biogás, apresentados na Figura 2.27, pode-se destacar a quantidade de água disponível e a quantidade de nutrientes, visto que estes interferem diretamente no crescimento da população microbiana, responsável pela produção de gases.

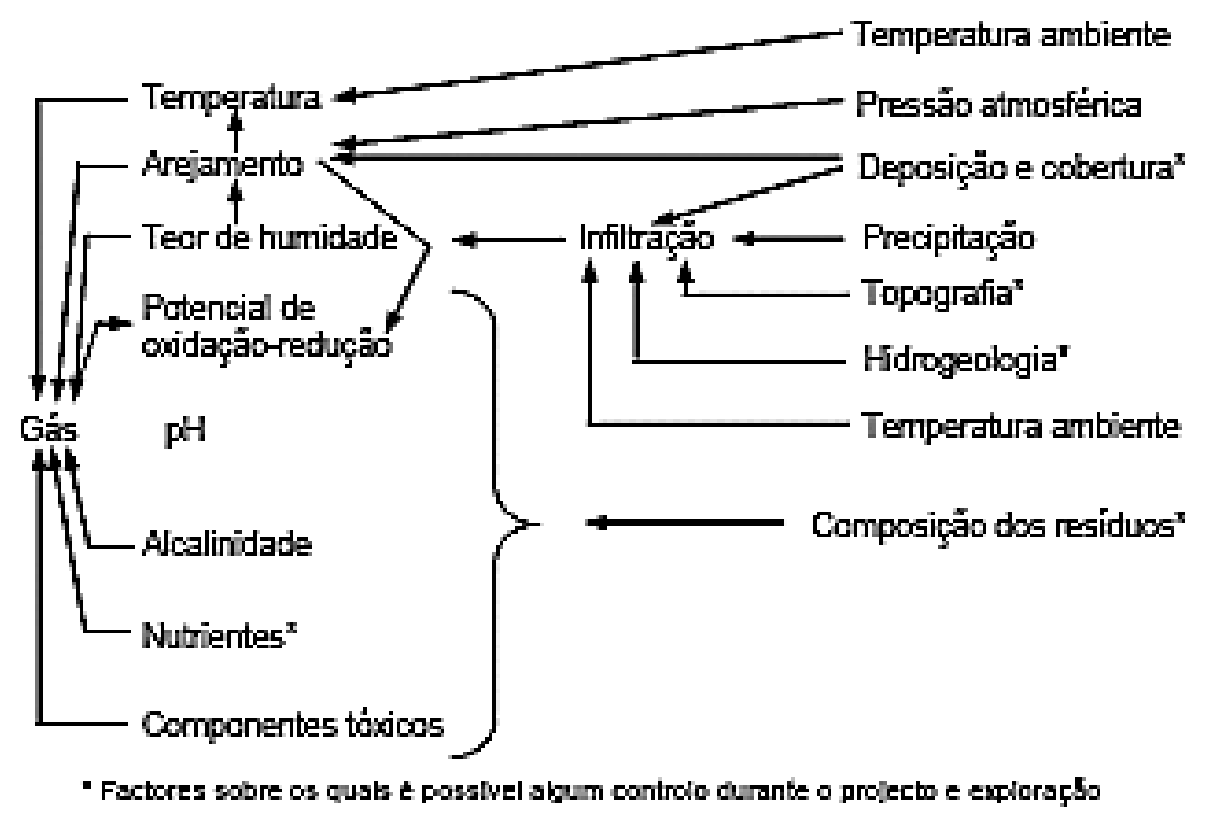

Figura 2.27 - Fatores que influenciam a produção de biogás 
A quantidade produzida de gás pode servir ainda como um bom indicador da fase de decomposição dos resíduos. Durante a fase aeróbia verifica-se a presença de oxigênio, o qual vai diminuindo até se esgotar totalmente na fase de transição; a fase ácida é marcada por um pico de produção de $\mathrm{CO}_{2}$ e de $\mathrm{H}_{2}$ (este último em menor quantidade), como resultado da fermentação ácida; a fase metanogênica caracteriza-se pela produção de metano, diminuição do dióxido de carbono e desaparecimento do hidrogênio, sendo os dois últimos consumidos nas reações de produção de metano; e a fase final de maturação é caracterizada por uma diminuição na produção geral de gases, verificando-se uma diminuição na produção de dióxido de carbono, e o aparecimento de algum oxigênio e nitrogênio (Gomes, 2008).

\subsubsection{Chorume ou Lixiviado}

Segundo Moravia (2007), lixiviado de aterro sanitário pode ser definido como o efluente líquido originado da umidade natural e da água presente nos resíduos, do resultado da degradação biológica dos materiais orgânicos e da água que infiltra na camada de cobertura e no interior das células existentes no aterro.

Pela norma brasileira NBR-8849, "Processos combinados" (ABNT, 1985), o lixiviado é definido como sendo o líquido produzido pela decomposição de substâncias contidas nos resíduos sólidos, de cor escura e mau cheiro. Pela NBR-15849, "Aterros Sanitários de Pequeno Porte - Diretrizes para localização, projeto, implantação, operação e encerramento" (ABNT, 2010), é definido como o líquido resultante da infiltração de águas pluviais no maciço de resíduos, da umidade dos resíduos e da água de constituição de resíduos orgânicos liberada durante sua decomposição no corpo do aterro sanitário.

O chorume ou lixiviado é resultado da percolação da água através dos resíduos em decomposição, que lixivia constituintes orgânicos e inorgânicos, além de carrear os produtos resultantes das reações de biodecomposição.

A composição química do lixiviado é geralmente estudada a partir de amostras provenientes de aterros ou de ensaios de laboratório em lisímetros (ou bioreactores) 
e correlacionada com as fases de decomposição dos resíduos (Tchobanoglous et al., 1993). Na Tabela 2.7 são apresentados os principais parâmetros utilizados para caracterização dos lixiviados. Esta lista está sendo revista pelo PROSAB (2011).

Tabela 2.7- Parâmetros para caracterização do lixiviado (Tchobanoglous et al., 1993)

\begin{tabular}{|c|c|c|c|}
\hline Físicos & Orgânicos & Inorgânicos & Biológicos \\
\hline $\begin{array}{l}\text { - Aspecto } \\
\text { - Potencial de oxidação- } \\
\text { redução (O/R) } \\
\text { - pH } \\
\text { - Condutividade } \\
\text { - Cor } \\
\text { - Turbidez } \\
\text { - Temperatura } \\
\text { - Cheiro }\end{array}$ & $\begin{array}{c}\text { - Carbono orgânico total } \\
\text { (COT) } \\
\text { - Carência química de } \\
\text { oxigénio (CQO) } \\
\text { - Fenóis } \\
\text { - Químicos orgânicos } \\
\text { - Ácidos voláteis } \\
\text { - Lignina, tanino } \\
\text { - Azoto orgânico (N-org) } \\
\text { - Óleos e gorduras } \\
\text { - Substâncias activas ao } \\
\text { azul-de-metileno } \\
\text { - Grupos orgânicos } \\
\text { funcionais } \\
\text { - Hidratos de carbono } \\
\text { - Compostos } \\
\text { organoclorados/clorados }\end{array}$ & $\begin{array}{c}\text { - Sólidos suspensos (SS) e } \\
\text { sólidos totais dissolvidos (STD) } \\
\text { - Sólidos voláteis suspensos } \\
\text { (SVS) e dissolvidos (SVD) } \\
\text { - Sulfato } \\
\text { - Cloreto } \\
\text { - Fosfato } \\
\text { - Alcalinidade e acidez } \\
\text { - Nitrato }\left(\mathrm{NO}_{3}{ }^{-}\right) \\
\text {- Nitrito }\left(\mathrm{NO}_{2}{ }^{-}\right) \\
\text {- Azoto amoniacal }\left(\mathrm{NH}_{3}-\mathrm{N}\right) \\
\text { - Metais pesados }(\mathrm{Pb}, \mathrm{Cu}, \mathrm{Ni}, \mathrm{Cr} \text {, } \\
\text { Zn, Cd, Fe, Mn, } \mathrm{Hg}, \mathrm{Ba}, \mathrm{Ag}) \\
\text { - Potássio } \\
\text { - Cálcio } \\
\text { - Magnésio } \\
\text { - Dureza } \\
\text { - Sódio } \\
\text { - Arsénio } \\
\text { - Cianeto } \\
\text { - Fluoreto } \\
\text { - Selénio }\end{array}$ & $\begin{array}{c}\text { - Carência bioquímica de } \\
\text { oxigénio (CBOs) } \\
\text { - Bactérias coliforme }\end{array}$ \\
\hline
\end{tabular}

As diferenças nas características presentes no lixiviado permitem classificá-lo em dois tipos: "lixiviado novo" e "lixiviado velho" (Moravia, 2007). De acordo com Moravia (2007), o "lixiviado novo" apresenta compostos orgânicos biodegradáveis, baixa concentração de nitrogênio amoniacal e elevada concentração de ácidos graxos voláteis de baixa massa molecular. "Lixiviado velho" apresenta baixa concentração de material orgânico biodegradável, elevada concentração de nitrogênio amoniacal e de compostos orgânicos refratários. Todavia, nos aterros sanitários brasileiros o lixiviado coletado em todas as células é drenado conjuntamente na tubulação de descarga, misturando-se "lixiviado novo" com "lixiviado velho".

Segundo Gomes (2008), os valores dos parâmetros indicados variam com a idade dos resíduos e, apesar da grande dispersão de valores publicados, é possível associar intervalos de valores típicos a cada parâmetro, em função da idade ou fase de decomposição dos resíduos. A Tabela 2.8 apresenta alguns destes intervalos para resíduos com diferentes idades. É possível observar que para resíduos novos o $\mathrm{pH}$ é basicamente ácido e para os resíduos mais velhos $\mathrm{o} \mathrm{pH}$ passa a ser essencialmente básico. 
Tabela 2.8 - Variação dos parâmetros dos lixiviados em função da idade do aterro (Gomes, 2008)

\begin{tabular}{|c|c|c|c|c|c|c|c|c|c|}
\hline \multirow{2}{*}{$\begin{array}{l}\text { Parâmetro } \\
(\mathrm{mg} /)^{*}\end{array}$} & \multicolumn{2}{|c|}{$\begin{array}{c}\text { Tchobanoglous et al } \\
\text { (1993) }\end{array}$} & \multicolumn{5}{|c|}{ Sarsby $(2000)^{\star *}$} & \multicolumn{2}{|c|}{ McBean et al (1995) } \\
\hline & $<2$ anos & $>10$ anos & 5 anos & 10 anos & 20 anos & 30 anos & 40 anos & $<3$ anos & $>4-5$ anos \\
\hline $\mathrm{CBO}_{5}$ & $2000-30000$ & $100-200$ & 2000 & 1200 & 350 & 100 & 70 & $10000-20000$ & $50-100$ \\
\hline $\mathrm{CQO}$ & $3000-60000$ & $100-500$ & 8000 & 4000 & 2000 & 500 & NS & $20000-40000$ & $500-3000$ \\
\hline COT & $1500-20000$ & $80-160$ & - & - & - & - & - & 9000-15000 & $100-1000$ \\
\hline STS & $200-2000$ & $100-400$ & - & - & - & - & - & - & - \\
\hline N-org & $10-800$ & $80-120$ & - & - & - & - & - & $500-1000$ & - \\
\hline $\mathrm{N}-\mathrm{NH}_{3}$ & $10-800$ & $20-40$ & 800 & 700 & 590 & 580 & 570 & $1000-2000$ & - \\
\hline Nitrato & $5-40$ & $5-10$ & - & - & - & - & - & - & - \\
\hline Fósforo total & $5-100$ & $5-10$ & - & - & - & - & - & - & - \\
\hline Ortofosfato & $4-80$ & $4-8$ & - & - & - & - & - & - & - \\
\hline $\begin{array}{c}\text { Alcalinidade } \\
\left(\mathrm{CaCO}_{3}\right)\end{array}$ & $1000-10000$ & $200-1000$ & - & - & - & - & - & - & - \\
\hline $\mathrm{pH}$ & $4,5-7,5$ & $6,6-7,5$ & - & - & - & - & - & $6-7$ & $7-8$ \\
\hline Dureza $\left(\mathrm{CaCO}_{3}\right)$ & $300-10000$ & $200-500$ & - & - & - & - & - & - & - \\
\hline Cálcio & $200-3000$ & $100-400$ & NS & 500 & 300 & 200 & NS & - & - \\
\hline Magnésio & $50-1500$ & $50-200$ & 100 & 200 & 150 & 100 & NS & - & - \\
\hline Potássio & $200-1000$ & $50-400$ & 580 & 570 & 440 & 380 & 350 & - & - \\
\hline Sódio & $200-2500$ & $100-200$ & 2000 & 2000 & 1200 & 500 & NS & - & - \\
\hline Cloreto & $200-3000$ & $100-400$ & 2400 & 2600 & 2700 & 2800 & 2800 & - & - \\
\hline Sulfato & $50-1000$ & $20-50$ & - & - & - & - & - & - & - \\
\hline Ferro total & $50-1200$ & $20-200$ & 540 & 380 & 100 & 40 & 20 & - & - \\
\hline
\end{tabular}

Souto \& Povinelli (2007) reuniram dados disponíveis na literatura referentes ao lixiviado de 25 aterros brasileiros, localizados em nove estados, e a partir destas informações construíram distribuições de frequência que permitiram determinar as faixas mais prováveis de concentração para 30 variáveis físico-químicas (Tabela 2.9). 
Tabela 2.9 - Variação da composição do lixiviado gerado em aterros brasileiros (Souto \& Povinelli, 2007)

\begin{tabular}{|c|c|c|c|}
\hline Variável & Faixa máxima & Faixa mais provável & FVMP \\
\hline pH & $5,7-8,6$ & $7,2-8,6$ & $78 \%$ \\
\hline Alcalinidade total $\left(\mathrm{mg} \mathrm{L}^{-1}\right)$ & $750-11400$ & $750-7100$ & $69 \%$ \\
\hline Dureza $\left(\mathrm{mg} \mathrm{L}^{-1}\right)$ & $95-3100$ & $95-2100$ & $81 \%$ \\
\hline Condutividade $(\mu \mathrm{S} / \mathrm{cm})$ & $2950-25000$ & $2950-17660$ & $77 \%$ \\
\hline $\mathrm{DBO}_{5}\left(\mathrm{mg} \mathrm{L}^{-1}\right)$ & $<20-30000$ & $<20-8600$ & $75 \%$ \\
\hline DQO $\left(\mathrm{mg} \mathrm{L}^{-1}\right)$ & $190-80000$ & $190-22300$ & $83 \%$ \\
\hline Óleos e graxas (mg L $\left.{ }^{-1}\right)$ & $10-480$ & $10-170$ & $65 \%$ \\
\hline Fenóis $\left(\mathrm{mg} \mathrm{L}^{-1}\right)$ & $0,9-9,9$ & $0,9-4,0$ & $58 \%$ \\
\hline $\operatorname{NTK}\left(\mathrm{mg} \mathrm{L}^{-1}\right)$ & $80-3100$ & Não há & - \\
\hline $\mathrm{N}$-amoniacal (mg L$\left.{ }^{-1}\right)$ & $0,4-3000$ & $0,4-1800$ & $72 \%$ \\
\hline $\mathrm{N}$-orgânico $\left(\mathrm{mg} \mathrm{L}^{-1}\right)$ & $5-1200$ & $400-1200$ & $80 \%$ \\
\hline N-nitrito $\left(\mathrm{mg} \mathrm{L}^{-1}\right)$ & $0-50$ & $0-15$ & $69 \%$ \\
\hline N-nitrato $\left(\mathrm{mg} \mathrm{L}^{-1}\right)$ & $0-11$ & $0-3,5$ & $69 \%$ \\
\hline P-total $\left(\mathrm{mg} \mathrm{L}^{-1}\right)$ & $0,1-40$ & $0,1-15$ & $63 \%$ \\
\hline Sulfeto $\left(\mathrm{mg} \mathrm{L}^{-1}\right)$ & $0-35$ & $0-10$ & $78 \%$ \\
\hline Sulfato $\left(\mathrm{mg} \mathrm{L}^{-1}\right)$ & $0-5400$ & $0-1800$ & $77 \%$ \\
\hline Cloreto $\left(\mathrm{mg} \mathrm{L}^{-1}\right)$ & $500-5200$ & $500-3000$ & $72 \%$ \\
\hline ST $\left(\mathrm{mg} \mathrm{L}^{-1}\right)$ & $3200-21900$ & $3200-14400$ & $79 \%$ \\
\hline $\mathbf{S V T}\left(\mathrm{mg} \mathrm{L}^{-1}\right)$ & $630-20000$ & $630-5000$ & $60 \%$ \\
\hline SFT $\left(\mathrm{mg} \mathrm{L}^{-1}\right)$ & $2100-14500$ & $2100-8300$ & $74 \%$ \\
\hline $\operatorname{SST}\left(\mathrm{mg} \mathrm{L}^{-1}\right)$ & $5-2800$ & $5-700$ & $68 \%$ \\
\hline SSV $\left(\mathrm{mg} \mathrm{L}^{-1}\right)$ & $5-530$ & $5-200$ & $62 \%$ \\
\hline Ferro $\left(\mathrm{mg} \mathrm{L}^{-1}\right)$ & $0,01-260$ & $0,01-65$ & $67 \%$ \\
\hline Manganês $\left(\mathrm{mg} \mathrm{L}^{-1}\right)$ & $0,04-2,6$ & $0,04-2,0$ & $79 \%$ \\
\hline Cobre $\left(\mathrm{mg} \mathrm{L}^{-1}\right)$ & $0,005-0,6$ & $0,005-0,15$ & $61 \%$ \\
\hline Níquel (mg L $\left.{ }^{-1}\right)$ & $0,03-1,1$ & $0,03-0,5$ & $71 \%$ \\
\hline Cromo (mg L $\left.{ }^{-1}\right)$ & $0,003-0,8$ & $0,003-0,5$ & $89 \%$ \\
\hline Cádmo (mg L $\left.{ }^{-1}\right)$ & $0-0,26$ & $0-0,065$ & $67 \%$ \\
\hline Chumbo (mg L $\left.{ }^{-1}\right)$ & $0,01-2,8$ & $0,01-0,5$ & $64 \%$ \\
\hline $\operatorname{Zinco}\left(\mathrm{mg} \mathrm{L}^{-1}\right)$ & $0,01-8,0$ & $0,01-1,5$ & $70 \%$ \\
\hline
\end{tabular}

\subsection{SOLOS REFORÇADOS}

Segundo Silva \& Montez (2009), para ser considerado um reforço, um elemento deve ser capaz de restringir os deslocamentos da estrutura de solo, melhorando seu comportamento em condições de serviço; em outras palavras, reforçar deve ser entendido como restringir deformações.

A associação do solo com os reforços leva o material composto a apresentar melhores características mecânicas. De acordo com a quantidade e a resistência 
dos reforços empregados, grandes desníveis podem ser atingidos, sendo que a quantidade e o comprimento dos reforços são estabelecidos por meio de análises de estabilidade externa e interna (Ehrlich \& Becker, 2009).

O comportamento de aterros de solo reforçado baseia-se na hipótese de que os elementos de reforço presentes no maciço de solo suportam forças de tração, as quais dependem do vínculo desses elementos com o solo, sendo, portanto, função da tensão normal atuante.

A resistência ao cisalhamento é composta de duas parcelas distintas: atrito e tração das fibras. Para pequenas deformações, há apenas a mobilização das forças de atrito no plano de cisalhamento. Com o aumento das deformações, os elementos de reforço são tracionados. A parcela das forças de tração aumenta até um valor máximo correspondente à resistência à tração ou ao vínculo dos elementos com o solo. A partir desse valor ocorre uma redução das forças de tração, e finalmente, acima de um determinado nível de deformação, a resistência ao cisalhamento se limita novamente ao atrito. A parcela devida ao atrito varia linearmente com a tensão normal, enquanto a parcela devida às forças de tração varia de forma descontínua em função da tensão normal (Koerner, 1997).

Uma massa de solo atinge a ruptura quando, em um determinado plano, a tensão cisalhante atuante e a resistência ao cisalhamento mobilizada se igualam. Em uma massa de solo reforçada, é verificado um incremento na resistência ao cisalhamento do conjunto devido à introdução do reforço, o que pode ser considerado como uma coesão aparente atribuída ao conjunto solo-reforço. Ainda, pode-se considerar que a inclusão de elementos no solo tem efeito semelhante ao de um aumento no confinamento (Abramento, 1998 e Sieira et al., 2005). O efeito do reforço na resistência ao cisalhamento pode ser visto na Figura 2.28 . 


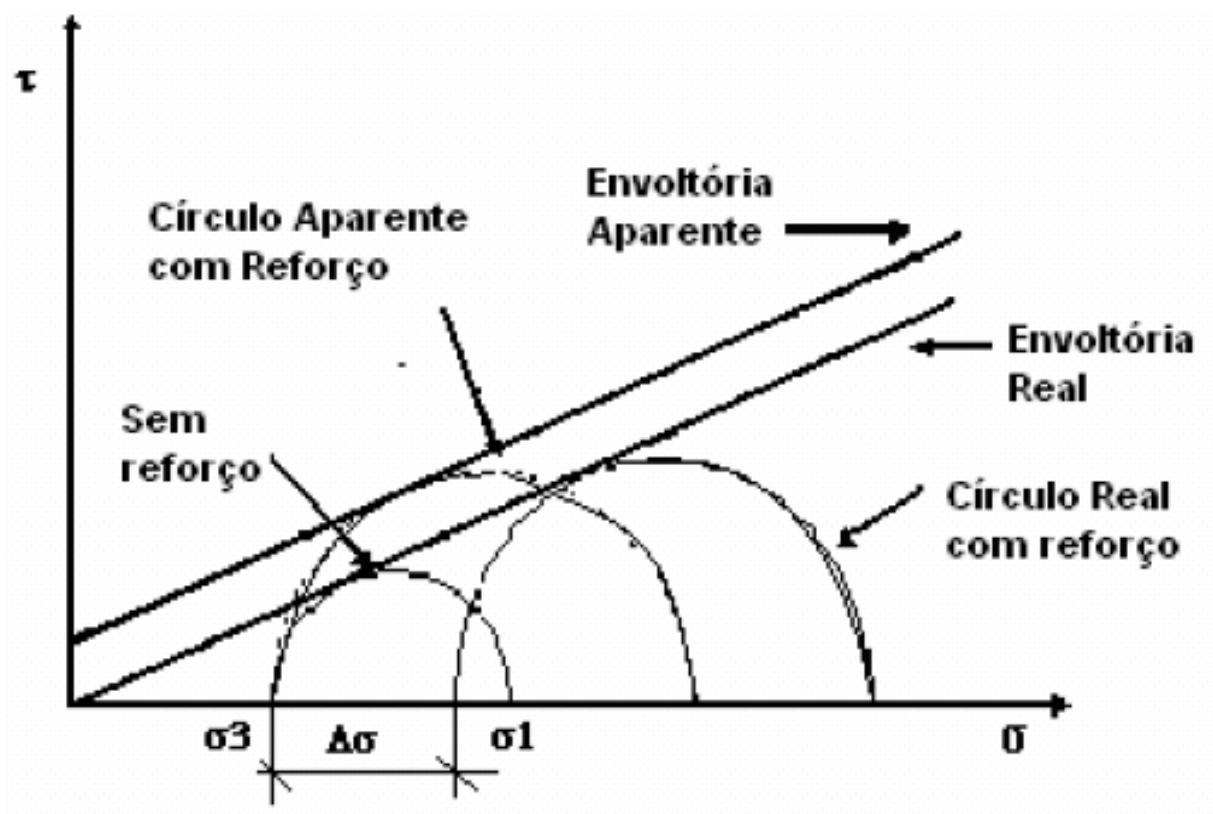

Figura 2.28 - Efeito do reforço na resistência ao cisalhamento (Abramento, 1998)

A utilização de geossintéticos como reforço de solos já é muito difundida na Geotecnia. Inicialmente foram utilizados os geotêxteis; a partir do desenvolvimento de novos produtos, contudo, as geogrelhas vêm se impondo como uma alternativa interessante de reforço.

Deformações elevadas de geotêxteis utilizados como reforços de muros de arrimo foram observadas ao longo do tempo em ensaios laboratoriais por Costa (2004). A autora observou também que a velocidade de carregamento influi na rigidez e na resistência do reforço, que tendem a aumentar com o acréscimo da velocidade de carregamento. Sugere também que seja revista a ideia de que, se o solo apresenta menor tendência à deformação ao longo do tempo do que o geossintético, ele irá restringir a fluência do reforço. Para o nível de deformações máximas medidas em estruturas instrumentadas, de 1 a $3 \%$, o nível de carregamento no geossintético é reduzido, enquanto o nível de tensões no solo é possivelmente bastante elevado. Para geogrelhas, a deformação de 1 a $2 \%$ corresponde a cerca de 10 a $20 \%$ da ruptura à tração, enquanto para esse mesmo nível de deformação o solo pode mobilizar um valor de ângulo de atrito próximo do valor de pico.

Segundo Becker (2006), durante muitos anos, estruturas de concreto armado ou ciclópico, atirantadas ou não, eram utilizadas em estruturas de contenção. Entretanto, com o aumento da altura do solo a conter e eventual má qualidade do solo de fundação, o custo destas estruturas eleva-se consideravelmente. A Figura 
2.29 apresenta uma comparação de custos de alguns tipos de estruturas de contenção.

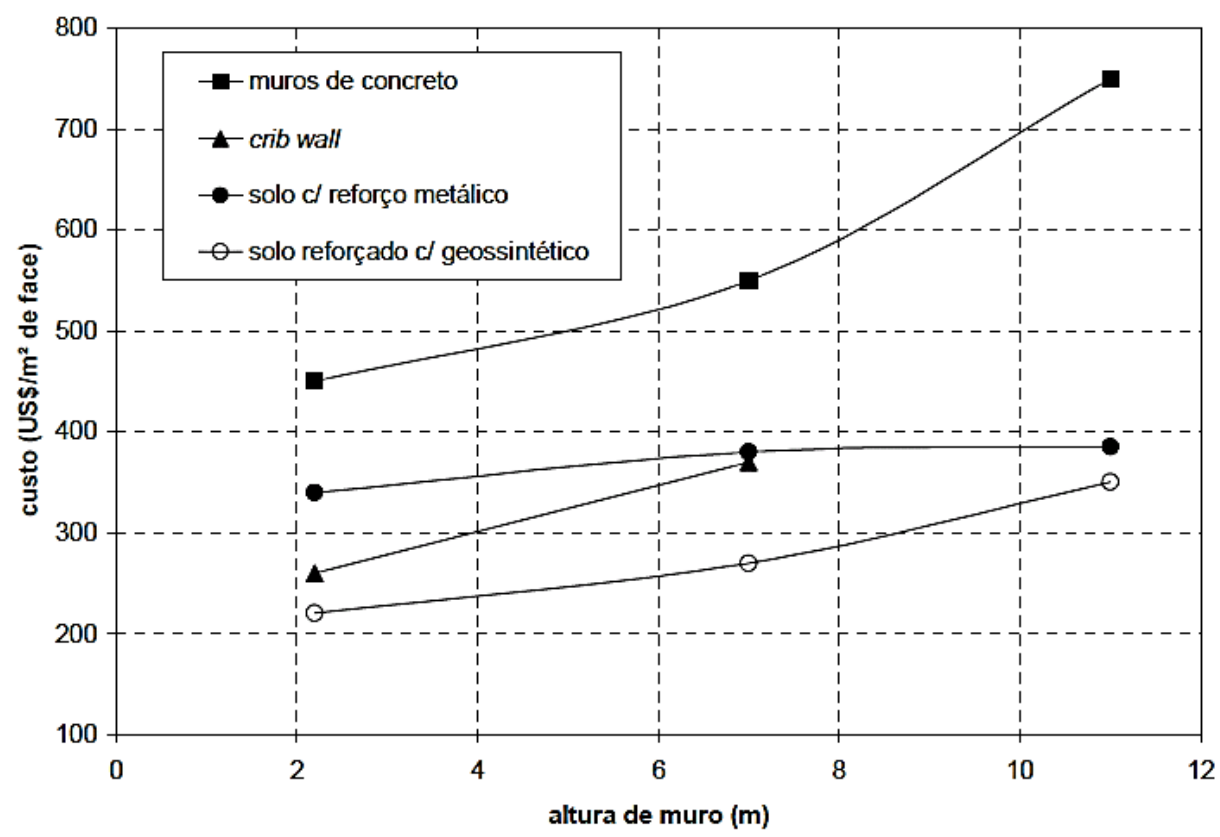

Figura 2.29 - Custos de construção, por área de face, em função da altura de muro, para várias soluções de contenção, conforme Elias et al. (2001)

Segundo Elias et al.(2001), manifestam-se claramente as vantagens das estruturas de contenção em solo reforçado, por apresentarem grande tolerância a recalques de fundação, facilidade construtiva e prazo de execução reduzido.

Os aterros reforçados apresentam características semelhantes às estruturas de contenção, já que o talude de um aterro reforçado também é uma estrutura que contém todo o maciço de terra atrás do mesmo, conforme exemplifica a Figura 2.30. 


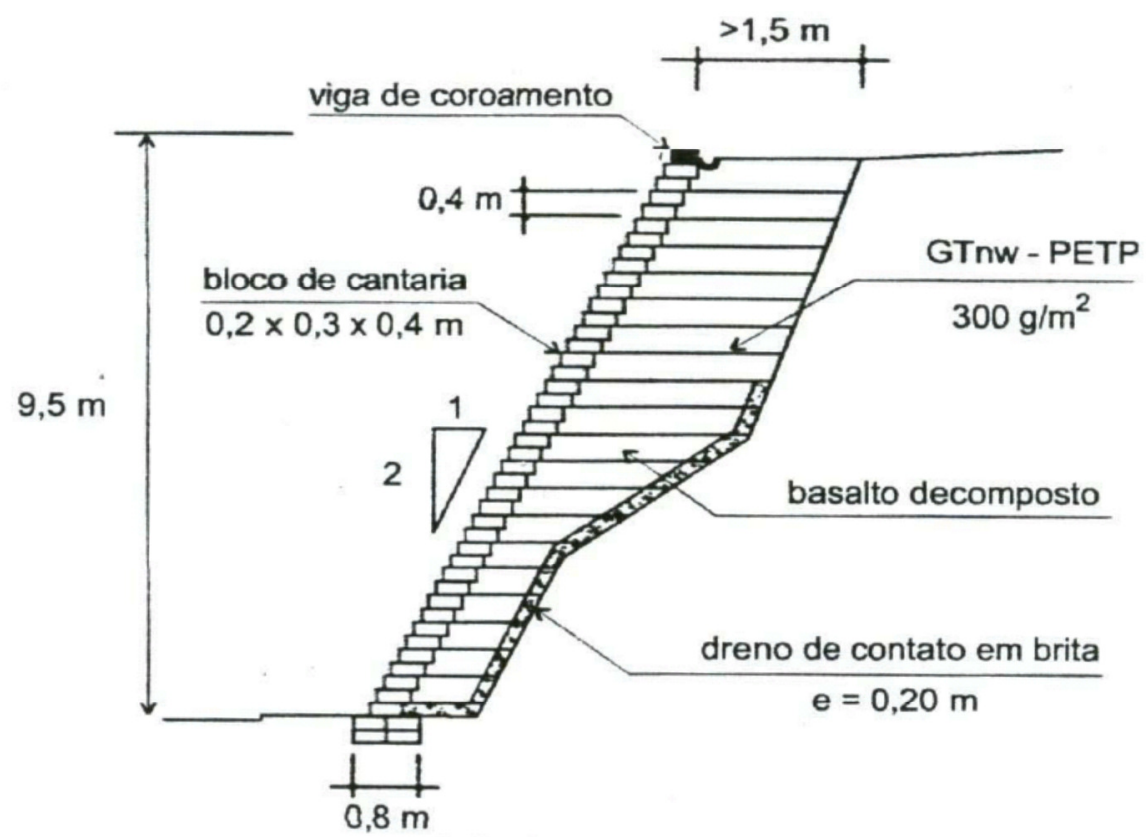

Figura 2.30 - Talude reforçado por geossintéticos com comprimento variável (Azambuja e Strauss, 1999)

Quando se aplicam geossintéticos em taludes inclinados, por exemplo, no revestimento de canais para impermeabilização ou taludes de corte como proteção contra erosão, por efeito de gravidade pode ocorrer instabilização dependendo do nível de tensões provocado pela inclinação do talude e dos parâmetros de interface entre solo-geossintético e geossintético-geossintético. Surge, então, a necessidade da obtenção dos parâmetros de interface para dimensionamento através de ensaios, tais como os de plano inclinado, cisalhamento direto e arrancamento. Esses parâmetros são utilizados para o estudo da estabilidade (Viana, 2003).

De acordo com Palmeira (1987) ${ }^{13}$ (apud Viana, 2003), três fatores muito importantes para um bom desempenho de uma estrutura de solo reforçado são: a natureza e características mecânicas do solo, a natureza e características mecânicas dos reforços, e a interação entre solo e reforço e como isso afeta a resposta de cada material.

13 Palmeira, E.M. (1987), The Study of Soil-Reinforcement Intaraction by Means Large Scale Laboratory Tests. D.Phil Thesis, University of Oxford, UK. 


\subsubsection{Geogrelhas}

De acordo com a norma NBR-12553, "Geossintéticos - Terminologia” (ABNT, 2003), geogrelhas são estruturas em forma de grelha com função predominante de reforço e são constituídas por elementos resistentes à tração. Elas podem apresentar resistência em uma direção predominante (unidirecional) ou em duas direções ortogonais (bidirecional).

Os principais tipos de geogrelhas em função do processo de fabricação segundo a NBR12553, "Geossintéticos - Terminologia (ABNT, 2003) são:

- Geogrelha extrudada (GGE): obtida através de processo de extrusão e sucessivo estiramento, que pode ser em único sentido formando geogrelhas unidirecionais, ou nos dois sentidos, formando geogrelhas bidirecionais, sendo geralmente fabricadas em polietileno ou polipropileno;

- Geogrelha soldada (GGB): composta por elementos de tração longitudinais e transversais, produzidos geralmente a partir de feixes de filamentos têxteis sintéticos, recobertos por um revestimento protetor, e soldados nas juntas. Temse também, atualmente, geogrelhas soldadas com raios laser, com elementos extrudados;

- Geogrelha tecida (GGW): composta por elementos de tração longitudinais e transversais produzidos geralmente a partir de feixes de filamentos têxteis sintéticos, tricotados ou intertecidos nas juntas e recobertos por um revestimento.

Na Figura 2.31 são apresentados os principais tipos de geogrelha. 


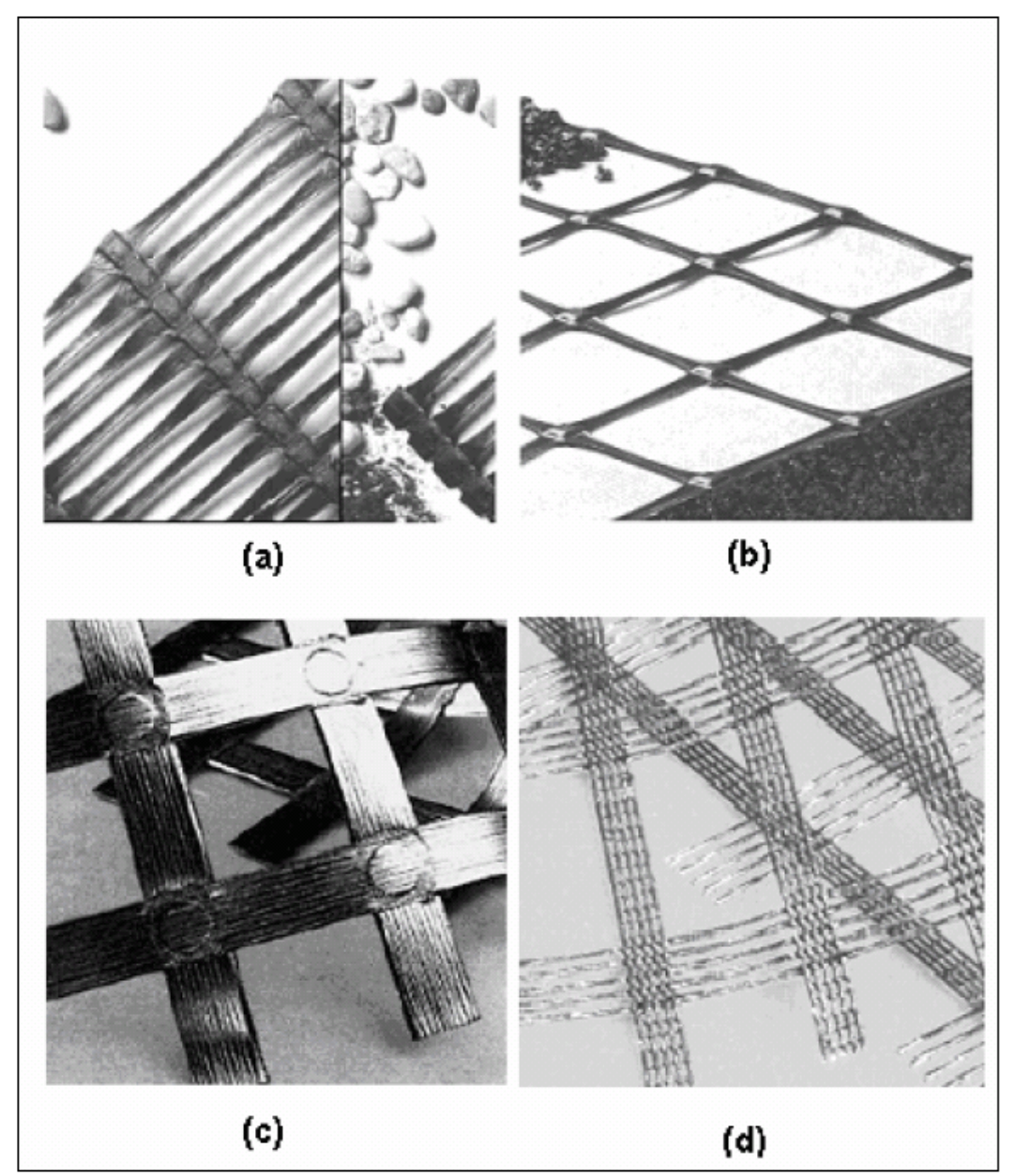

Figura 2.31 - Tipos de geogrelhas: (a) extrudada unidirecional; (b) extrudada bidirecional; (c) soldada; (d) tecida

As geogrelhas podem também ser produzidas através da perfuração de mantas poliméricas que são posteriormente tensionadas em um ou duas direções com o objetivo de melhorar suas propriedades físicas. Em geral, as geogrelhas resultantes deste processo de fabricação apresentam aberturas variando de 10 a $100 \mathrm{~mm}$, na forma de elipses alongadas, quadrados ou retângulos com cantos arredondados.

Dentre os requisitos das geogrelhas pode-se citar a elevada resistência à tração, elevado módulo de deformabilidade, baixa suscetibilidade à fluência, durabilidade compatível com a vida útil da obra e elevado grau de interação com o solo envolvente.

As principais aplicações da geogrelha são as seguintes:

- Reforço em taludes e muros de contenção;

- Separação / reforço em rodovias não pavimentadas e ferrovias; 
- Em conjunto com gabiões para construção de muros reforçados com controle de erosão e encontros de ponte;

- Reforço para execução de aterros sobre solos moles;

- Reforço de pavimento asfáltico;

- Em conjunto com geotêxteis ou geomembranas (formando geocompostos).

É importante a escolha do tipo de geogrelha a ser utilizada em cada obra: segundo Teixeira (2007), as características da geogrelha, como processo de fabricação, função da geogrelha, configuração geométrica da malha, polímero etc., tem papel fundamental no comportamento mecânico da geogrelha, ou seja, cada geogrelha possui um comportamento específico (Figura 2.32).

Os polímeros geralmente empregados na produção de geogrelhas são o polietileno de alta densidade (PEAD), o poliéster (PET), o polipropileno (PP), aramida ( $A$ ) e o álcool de polivilina (PVA). O tipo do polímero afeta as diversas características de comportamento dos geossintéticos, principalmente aquelas de longo prazo. Dentre as propriedades influenciadas pelo tipo de polímero destacam-se a resistência à degradação química por ação dos raios ultravioleta, resistência à temperatura e resistência à hidrólise, bem como o comportamento mecânico. Segundo Silva \& Montez (1999) nas temperaturas típicas tanto de climas tropicais quanto temperados, PET, AR e PVA, em geral, apresentam menor suscetibilidade à fluência que PP e PEAD. 


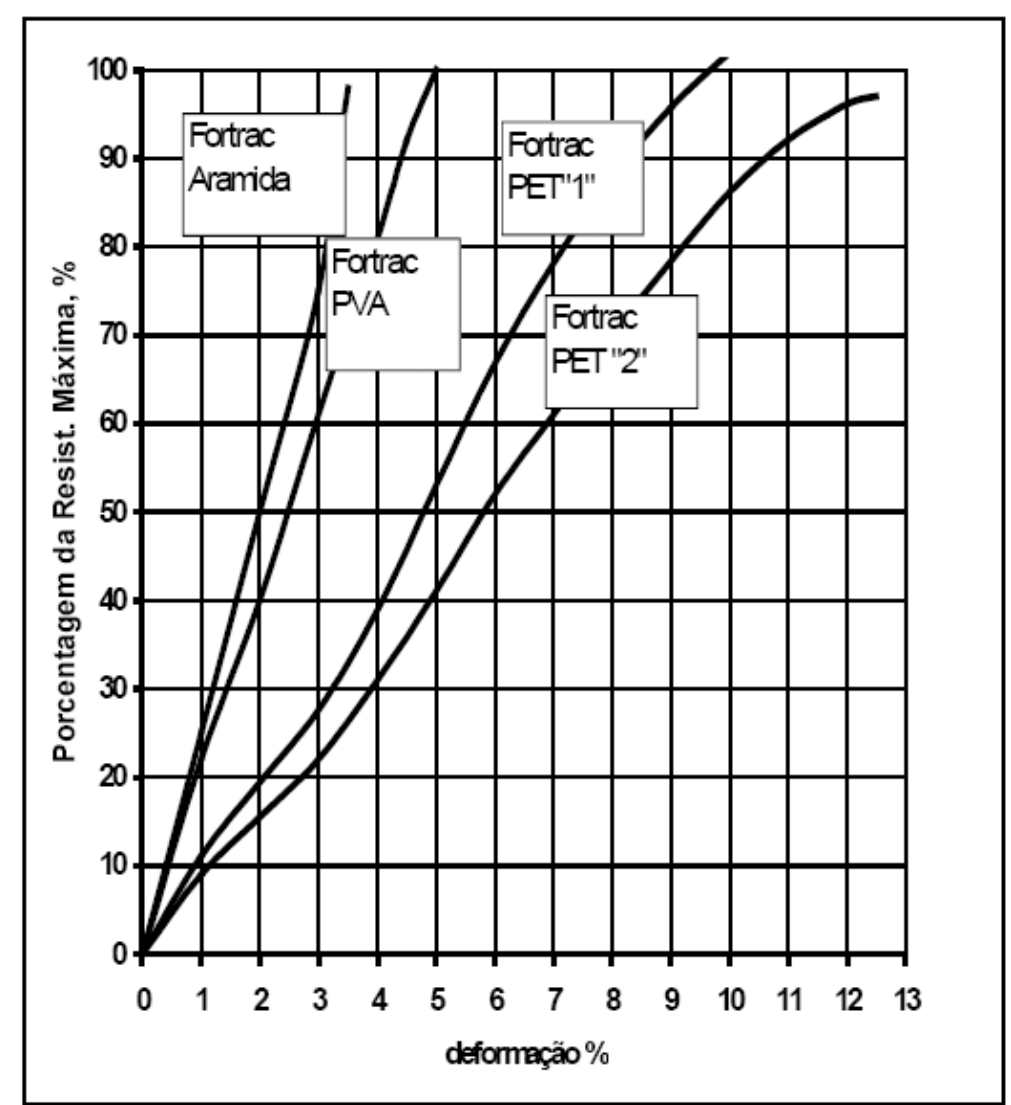

Figura 2.32 - Resistência mobilizada em função da deformação para diferentes tipos de geogrelha (Huesker, 2010)

\subsubsection{Mecanismos de interação solo-reforço}

Os mecanismos típicos de interação em estruturas de solo reforçado estão esquematizados na Figura 2.33. 


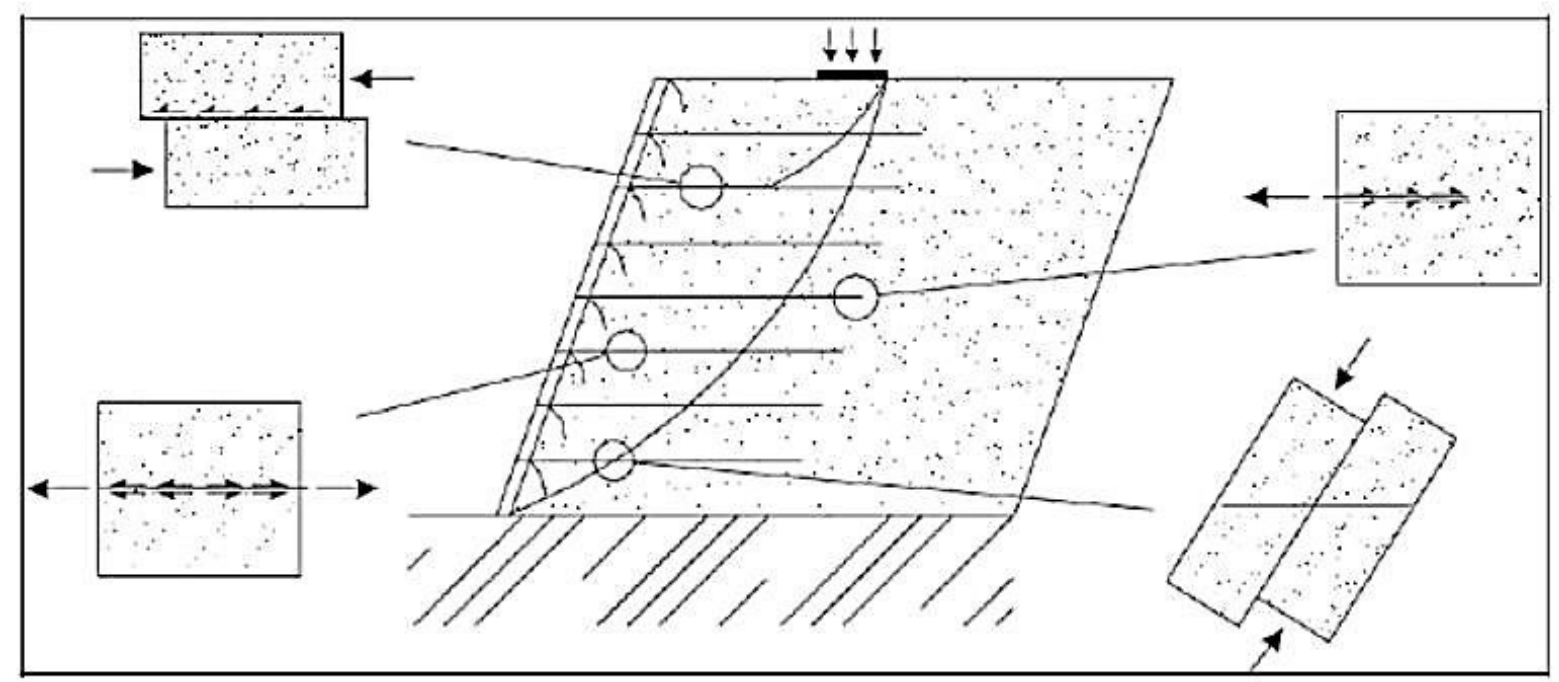

Figura 2.33 - Mecanismos de interação típicos em estruturas de solo reforçado (Palmeira, 1999)

Como as geogrelhas (reforço utilizado neste trabalho) são elementos vazados, o solo penetra nos vazios, e a interação entre geogrelha e solo ocorre por cisalhamento nas interfaces e por resistência passiva contra elementos transversais. Segundo Juran e Chen (1988) ${ }^{14}$ (apud Becker, 2006), os mecanismos de interação resumem-se ao atrito lateral nos elementos longitudinais, embricamento do solo preso entre os vazios e resistência passiva contra os elementos transversais. A Figura 2.34 apresenta os esforços em uma geogrelha em estrutura de solo-reforçado (Palmeira, 1999), enquanto os mecanismos de interação entre solo e geogrelha estão representados na Figura 2.35.

${ }^{14}$ Juran, I.; Chen, C.L. (1988). Soil-geotextile Pullout Interaction Properties: Testing and Interpretation. Transportation Research Record 1188. 37-47. 


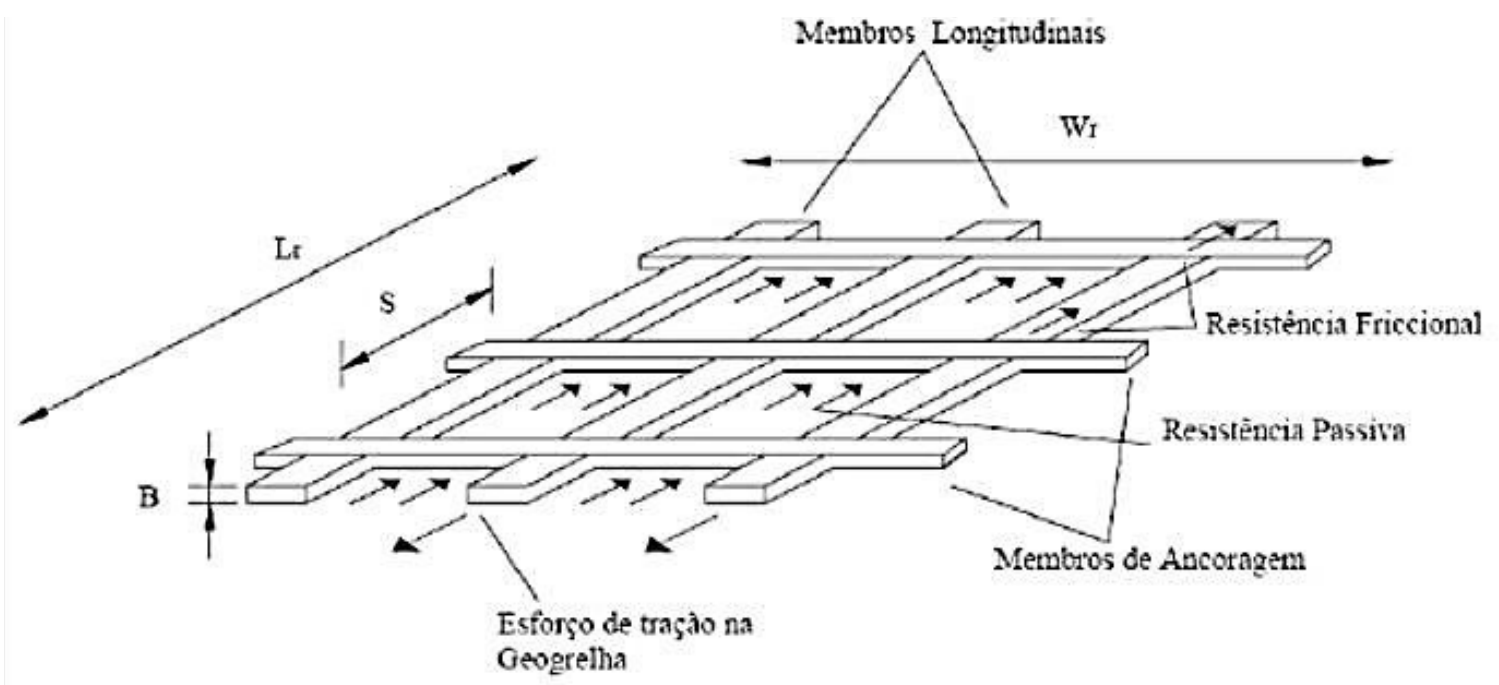

Figura 2.34 - Esquema de geometria de uma geogrelha com os esforços envolvidos (Palmeira, 1999)

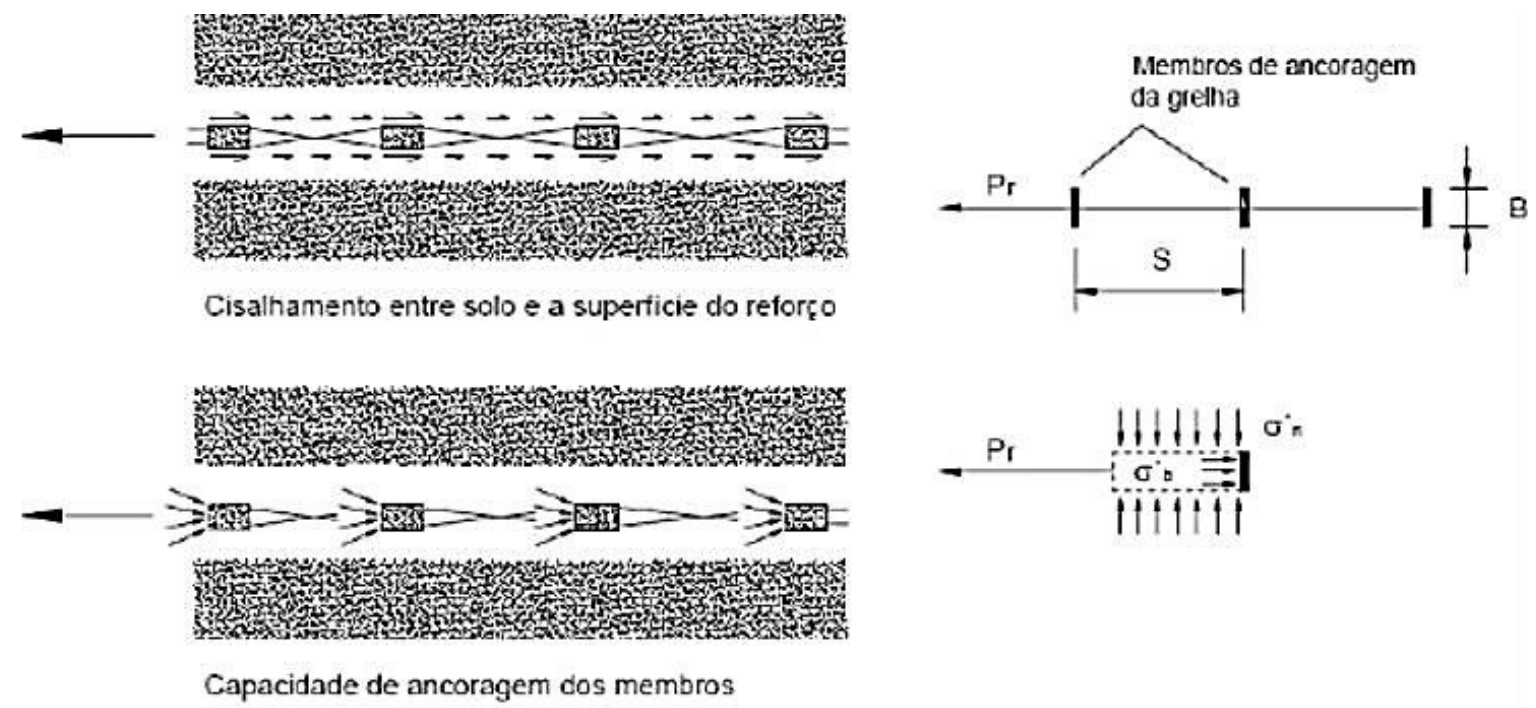

(a)

(b)

Figura 2.35 - Aderência entre grelha e solo: (a) mecanismos de interação e (b) definição da análise (Jewell, 1996)

O grau de interação solo-reforço é característico de cada material, e dependente tanto de aspectos da estrutura física do geossintético como das características do solo confinante. 
Para Milligan e Palmeira (1987) ${ }^{15}$ (apud Becker, 2006), a ruptura interna em um solo reforçado pode ocorrer de três formas:

- A superfície de ruptura 1 atravessa e, eventualmente, rompe o reforço no ponto A;

- Não havendo ruptura no ponto $A$, pode haver o arrancamento no trecho $A B$;

- Cisalhamento na interface solo-reforço, ao longo do trecho CD, segundo a superfície 2.

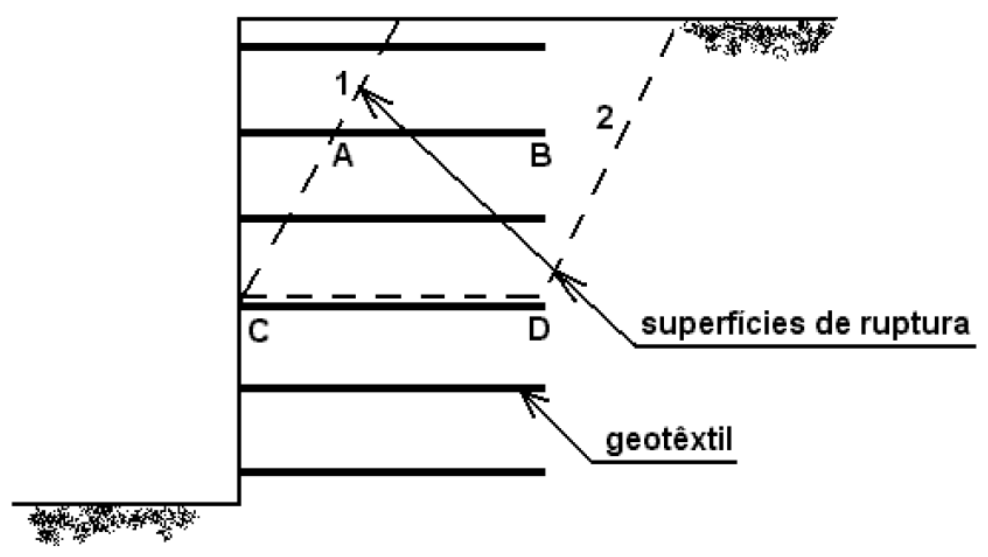

Figura 2.36 - Mecanismos de ruptura interna em uma estrutura de solo reforçado (Milligan \& Palmeira, 1987 apud Becker, 2006)

\subsubsection{Parâmetro de interface}

Para estimativa dos parâmetros de interação solo-geossintético, vários tipos de ensaios laboratoriais podem ser utilizados, bem como ensaios de campo e retroanálises de rupturas. O tipo mais comum de ensaio é o de cisalhamento direto, porém ensaios de arrancamento, tração confinada, cisalhamento direto com reforço inclinado, ensaio em plano inclinado etc. também são realizados.

${ }^{15}$ Milligan, G.W.E.; Palmeira, E.M. (1987). Prediction of bond between soil and reinforcement. In: Int. Symp. On Prediction and Performance on Geotextile Engineering, Calgary, p.147 - 153, 1987. Proceddings... 
Viana (2003) afirma que os ensaios com equipamento em plano inclinado são os mais indicados para estimar os ângulos de atrito de interface, pois a mobilização da resistência de interface ocorre a baixas tensões normais, sob condições mais próximas às de campo. Porém, segundo Ramirez et al.(2002), este equipamento apresenta o inconveniente de que a tensão normal diminui durante o ensaio em função da inclinação da rampa, por isso outros autores (Giroud et al., 1990 e Girard et al., 1994) recomendam que este ensaio seja complementado com ensaios de cisalhamento direto para uma melhor estimativa dos parâmetros de projeto.

$\mathrm{Na}$ literatura são encontrados diversos estudos sobre a interação solo-geossintético (Koerner et al., 1997; Tupa, 1994; Gourc et al.,1996; Koutsourais et al.,1998; Jones \& Dixon, 1998; Viana, 2003; Becker, 2006; Palmeira, 2011). Dentre os principais fatores de influência relatados em bibliografia estão:

- Confinamento do reforço;

- Rigidez à tração do reforço.

A tensão ou deformação de equilíbrio entre os geossintéticos e o solo depende da relação entre a rigidez de ambos, podendo ser representada pelo índice de rigidez relativa, definida por Ehrlich e Mitchell (1994):

$$
S i=\frac{J r}{K \cdot P a \cdot S v}
$$

Onde:

$S i$ - Índice de rigidez relativa

$J r$ - Módulo de rigidez à tração;

K - Módulo inicial tangente do solo do modelo hiperbólico (Duncan et al., 1980);

$P a$ - Pressão atmosférica;

$S v$ - Espaçamento vertical entre reforços.

O produto $J r$ pode ser obtido conhecendo-se a resistência à tração por unidade de largura do geossintérico (Tr) e o alongamento máximo na ruptura ( $\varepsilon r)$.

$$
J r=\frac{T r}{\varepsilon r}
$$


Conforme se pode observar nas equações apresentadas, quanto maior o valor de $\mathrm{J} r$, maior é a rigidez relativa do reforço, maiores são as tensões no reforço e menores são as deformações da estrutura de solo reforçado.

Tabela 2.10 - Valores típicos para o índice de rigidez relativa (Ehrlich \& Becker, 2009)

\begin{tabular}{lc}
\hline \multicolumn{1}{c}{ Tipo de geossintético } & Si \\
\hline Geogrelhas de PVA (1) & 0,020 a 0,200 \\
Geogrelhas de PET (1) & 0,010 a 0,100 \\
Geogrelhas de PP (1) & 0,015 a 0,150 \\
Geotêxteis tecidos (1) & 0,010 a 0,100 \\
Geotêxteis não tecidos em geral (2) & 0,001 a 0,003 \\
\hline
\end{tabular}

(1): resistência à tração entre 20 e $200 \mathrm{kN} / \mathrm{m}$; (2): resistência à tração entre 20 e 50kN/m

\subsubsection{Compatibilidade de deformações}

A compatibilidade das deformações entre o solo e o elemento de reforço é de suma importância no comportamento de maciços reforçados, gerando inúmeros estudos sobre o comportamento mecânico de reforços (Gray et al.,1982; Jewell e Wroth, 1987; Palmeira, 2011). É também um aspecto importante quando se deseja utilizar reforços geossintéticos como elemento de reforço de maciços constituídos por resíduos sólidos urbanos, cuja deformabilidade é maior e resistência, menor, comparadas aos solos de uma forma geral. Em condições de trabalho é razoável admitir a hipótese de aderência perfeita entre o solo e o reforço, de modo que não ocorra o deslizamento entre eles, desta forma as deformações do solo e do reforço são as mesmas na interface. Sob deformação horizontal nula, $\varepsilon_{x}=0$, o solo está na condição de repouso $\left(K_{0}\right)$ e o reforço, não tracionado. À medida que ocorrem deformações laterais, as tensões horizontais no solo diminuem, tendendo à condição ativa $\left(K_{a}\right)$, e crescem as trações nos reforços até que o equilíbrio seja satisfeito (Figura 2.37). 


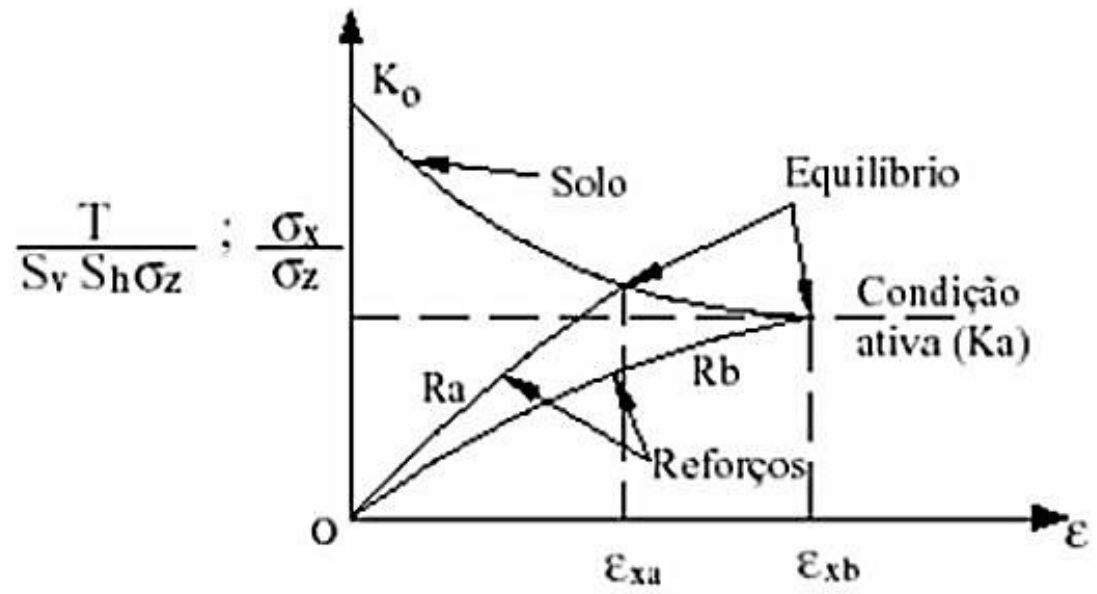

Figura 2.37 - Tensões ( $\sigma$ e T) e deformações $(\varepsilon)$ no solo e no reforço (Ehrlich, 1994).

( $S_{v}$ e $S_{h}$ : espaçamento vertical e horizontal dos reforços; $R_{a}>R_{b}$ : Rigidez dos reforços)

Jewell $\left(1985^{16}, 1990^{17}\right)$ (apud Oliveira, 2006) propõe o conceito de curva de compatibilidade para definir o equilíbrio de maciços reforçados. Constroem-se as curvas do esforço requerido para a manutenção do equilíbrio na massa do solo em função da deformação específica na direção do reforço e da força em função da deformação específica no reforço. Admitindo-se aderência perfeita na interface soloreforço, a interseção das curvas representa o ponto onde força e deformação específica no solo e no reforço são idênticas, condição em que o equilíbrio é atingido.

Pode-se utilizar a Figura 2.38 para visualizar o efeito da rigidez do reforço sobre o estado de tensão e deformação da estrutura. Quanto mais extensível for este elemento, maior a tendência ao estado ativo, menores as cargas e maiores deformações do maciço. Entretanto, observa-se na Figura 2.39 que, quando a resistência do solo apresenta um pico seguido de um queda para um valor residual, são verificadas cargas maiores nas inclusões mais extensíveis.

${ }^{16}$ JEWELL, R. A., (1985), "Limit equilibrium analysis of reinforced soil walls". Proc. of 11th Int. Conf. on Soil Mech. and Foundations, San Francisco, pp. 1705-1708.

17 JEWELL, R. A., 1990, "Strength and deformation in reinforced soil design". In: Proc. $4{ }^{\text {th }}$ International Conference on Geotextiles, Geomembranes and Related Products, v. 3, pp. 913-946, The Hague. 


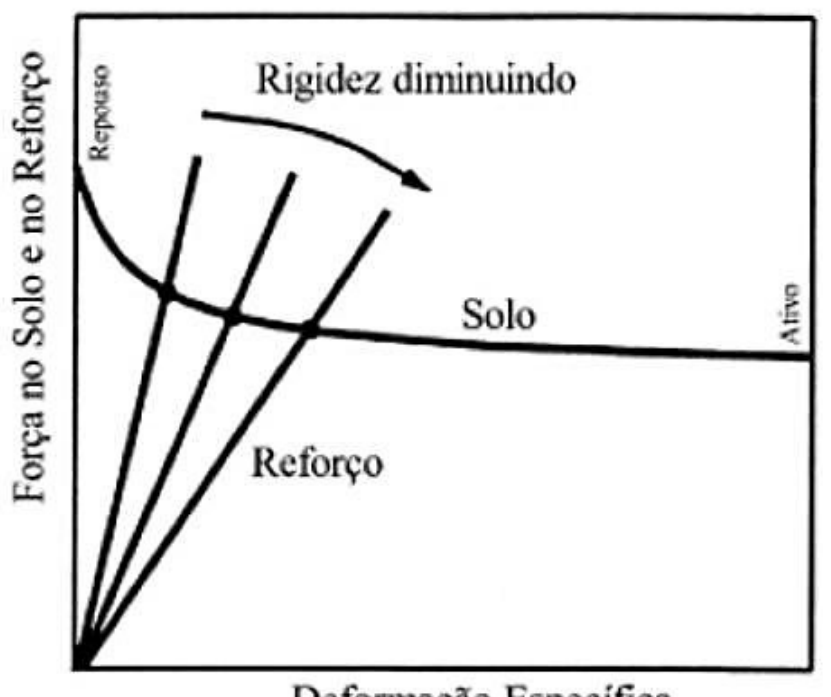

Deformação Especifica

Figura 2.38 - Curva de compatibilidade solo-reforço (modificada de Jewell, 1990)

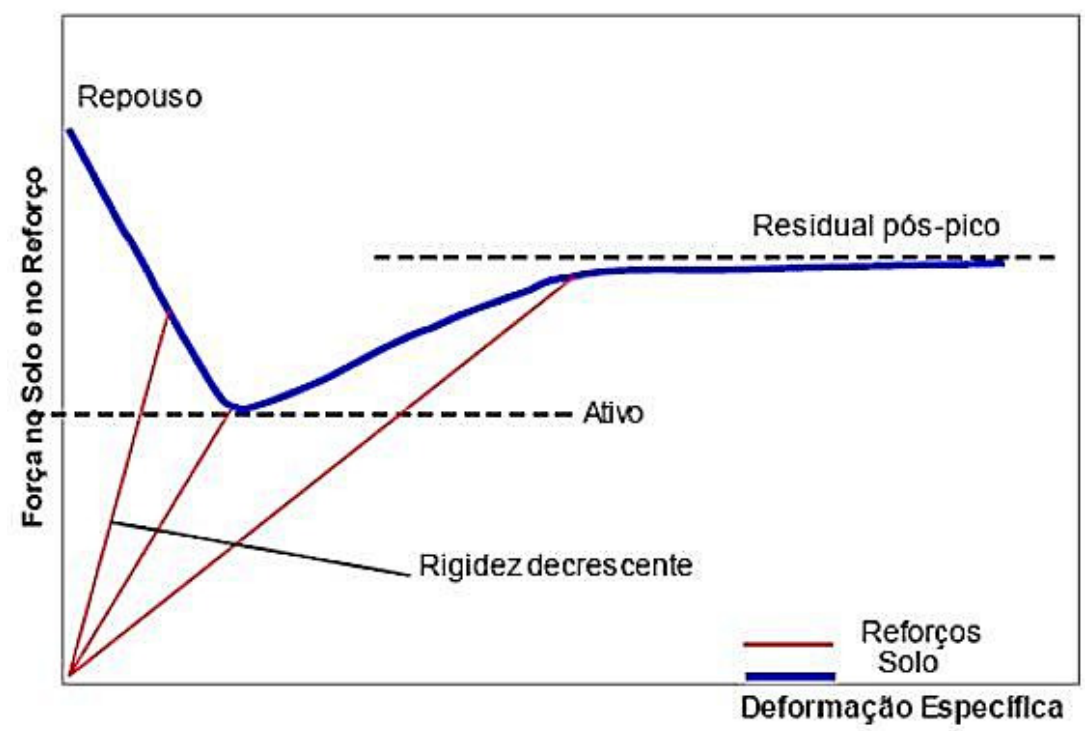

Figura 2.39 - Curva de compatibilidade solo-reforço (Ehrlich, 2004).

A compatibilidade de deslocamentos entre o solo e o reforço é uma das possíveis razões para explicar o motivo de reforços mais rígidos provocarem menores deslocamentos. Os reforços mais rígidos precisam sofrer menores deslocamentos para mobilizar maiores forças de tração e os solos mais rígidos mobilizam menores forças de tração nos reforços do que os solos menos rígidos (Pedroso, 2000).

Segundo Pedroso (2000), o aumento da rigidez dos reforços geossintéticos, em estruturas de contenção executadas com solos pouco resistentes, resulta numa redução significativa dos deslocamentos horizontais. O autor concluiu em sua pesquisa que os arranjos mais eficientes podem ser conseguidos utilizando-se um 
espaçamento vertical menor na parte inferior da estrutura de contenção e um espaçamento maior na parte superior.

\subsubsection{Durabilidade e degradação físico-química dos geossintéticos}

Os geossintéticos são elementos constituídos de materiais poliméricos e utilizados para diversas finalidades. Durante o processo de fabricação dos geossintéticos são utilizados aditivos ou polímeros extremamente resistentes à maioria dos processos químicos e biológicos que ocorrem na natureza, sobretudo, no solo (Palmeira, 1999). Realmente, os geossintéticos tradicionais, com raras exceções, não têm apresentado problemas consideráveis nas obras onde são enterrados no solo (Bueno, 2007). Entretanto, a utilização de geossintéticos em obras ambientais expõe esses materiais a efeitos agressivos, como temperatura, agentes químicos, radioatividade, agentes biológicos, oxidação, hidrólise, entre outros (Palmeira, 1999; Bueno, 2007).

Matheus (2002) realizou um estudo sobre o envelhecimento acelerado e dano induzido no desempenho e durabilidade de alguns geossintéticos, observando que nos ensaios de envelhecimento por aplicação de radiação ultravioleta, numa exposição de até 3800 horas, alguns geossintéticos não perderam resistência a tração, enquanto nos ensaios de envelhecimento térmico apresentaram uma redução de resistência de cerca de $11 \%$.

Bueno (2007), com base em estudos de outros autores, afirma que a perda de resistência de materiais sintéticos cresce com a intensidade da radiação solar, temperatura e tempo de exposição, condições que dependem da latitude e da estação do ano.

Nas ações físico-químicas que afetam a durabilidade dos geossintéticos estão incluídas:

a) Degradações fotoquímicas (radiações solares UV), que provocam a quebra das ligações químicas nas macromoléculas dos polímeros, reduzindo a resistência do geossintético; 
Quando a degradação está associada ao elemento oxigênio, podem ocorrer as degradações do tipo foto-oxidativas, decorrentes da ação de determinados espectros da radiação solar que ativam reações de remoção de hidrogênio.

b) Degradações térmicas (fundamentalmente aumentos de temperatura) que aceleram a velocidade das reações químicas e consequentemente a degradação dos polímeros.

Quando associadas ao elemento oxigênio, podem provocar as degradações termo-oxidativas, que ocorrem em ambientes ligeiramente ácidos ou neutros sob temperaturas elevadas. Não chega a ser significativa do ponto de vista de perda de resistência, mas é maior nas poliolefinas, em especial nos polipropilenos. O maior efeito da oxidação não é a perda de resistência, mas a perda de ductilidade.

c) Hidrólise: É a reação inversa de esterificação e pode afetar sensivelmente as resistências das fibras de poliéster. Ambientes fortemente alcalinos ou de concentração salina podem provocar perdas superiores a 35\% da resistência de fibras de PET, mas em ambientes neutros ou ligeiramente ácidos essa reação dificilmente é ativada.

d) Trincamento por tensão ("Stress cracking"): É um mecanismo que costuma ocorrer exclusivamente nas poliolefinas, em especial no polietileno. Consiste no crescimento de lesões e trincamento que só ocorrem em níveis expressivos de tensões associadas a ambientes agressivos.

Santos et al. (2002), citado por Pinto (2005), estudaram laboratorialmente as degradações termo-oxidativas em geossintéticos constituídos por polipropileno e poliéster, tendo constatado que existe sensibilidade dos polímeros a esta degradação, mas que não é muito significativa, tendo-se verificado uma perda de resistência à tração de cerca de $2 \%$ para o poliéster e cerca de $9 \%$ para o polipropileno (Figura 2.40). 


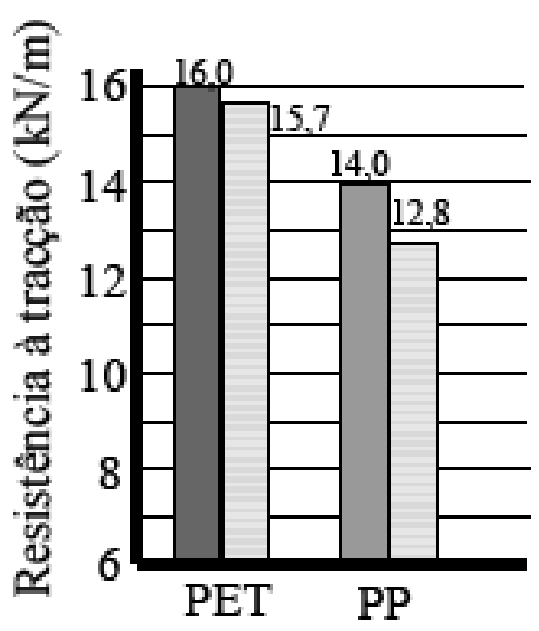

\section{Referência}

Danificada

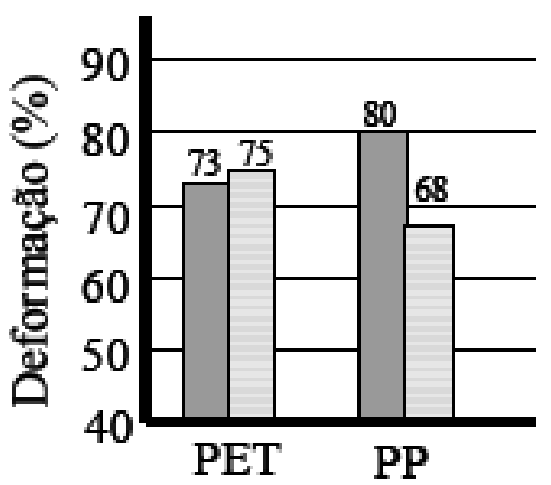

Figura 2.40 - Degradação termo-oxidativa em geotêxteis não tecidos em polipropileno e em poliéster (Santos et al., 2002 modificado por Pinto, 2005)

Os estudos realizados em laboratório por Santos et al. (2002) sobre geotêxteis não tecidos em poliéster e polipropileno em soluções ácidas e básicas mostraram pouca sensibilidade dos materiais a soluções ácidas e uma maior sensibilidade a soluções básicas.

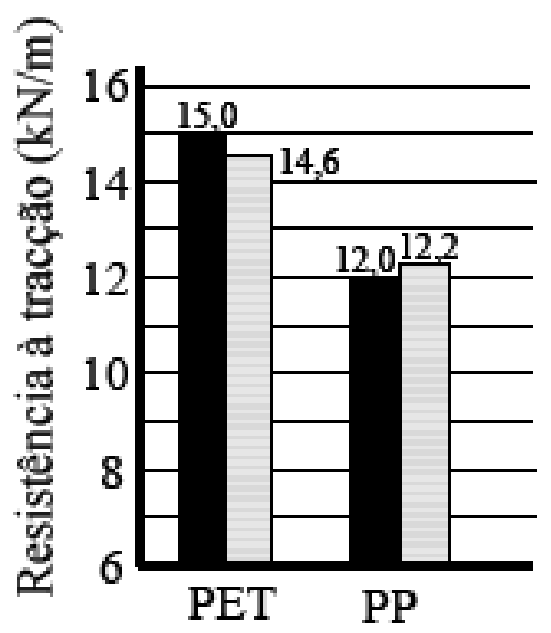

$\square$ Referência

$\square$ Danificada

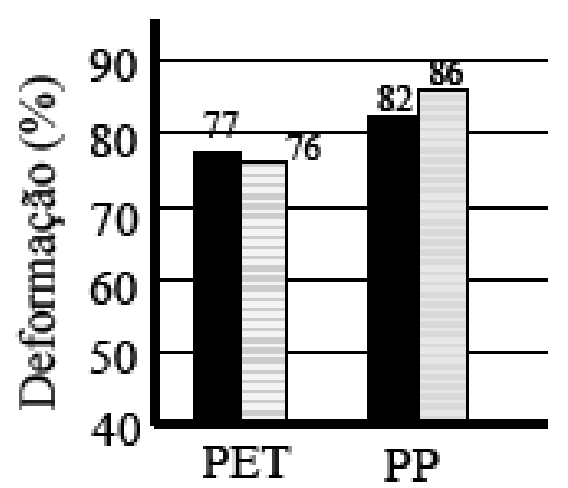

Figura 2.41 - Efeito de soluções ácidas em geotêxteis não tecidos em PP e PET (Santos et al., 2002 modificado por Pinto, 2005). 

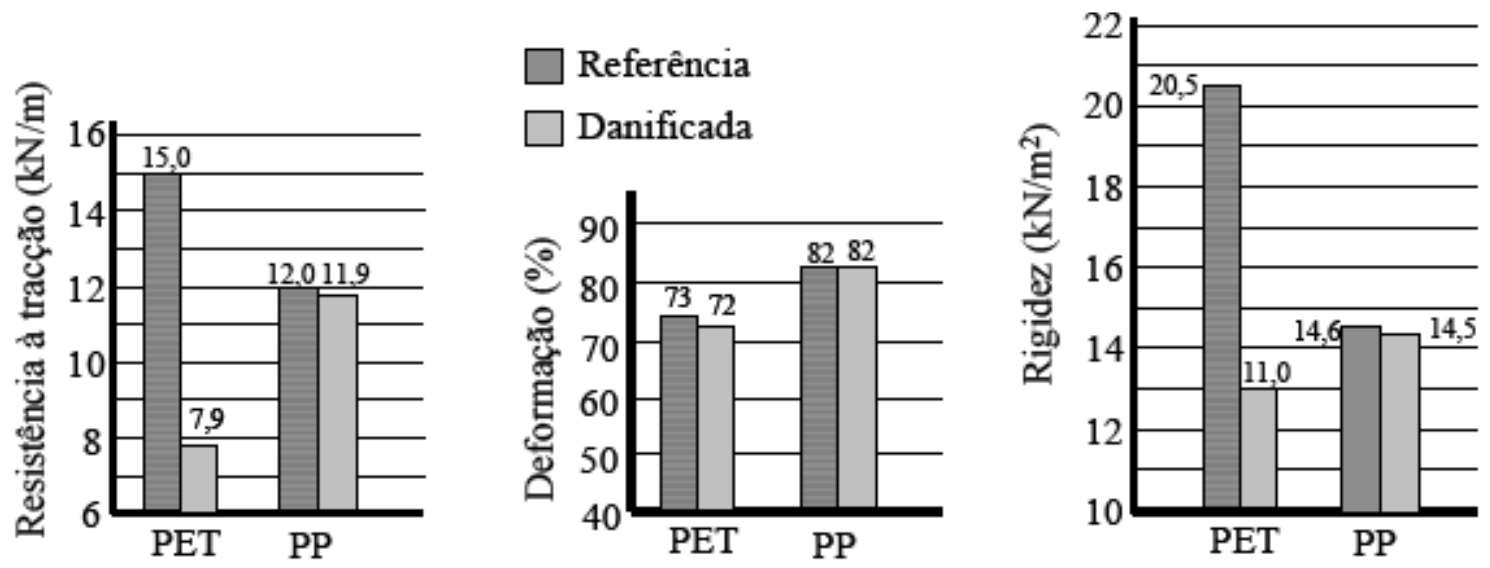

Figura 2.42 - Efeito de soluções alcalinas em geotêxteis não tecidos em PP e PET (Santos et al., 2002 modificado por Pinto, 2005)

A temperatura, além de acelerar o mecanismo de fluência, pode alterar as propriedades físicas, caso o material seja exposto ao calor por um longo período (Abramento, 1995).

De acordo com Pilarczyk (2000), citado por Pinto (2005), os polímeros mais sensíveis às degradações térmicas são o polietileno e o polipropileno, sendo o poliéster e a poliamida menos sensíveis, conforme se pode observar na Figura 2.43.

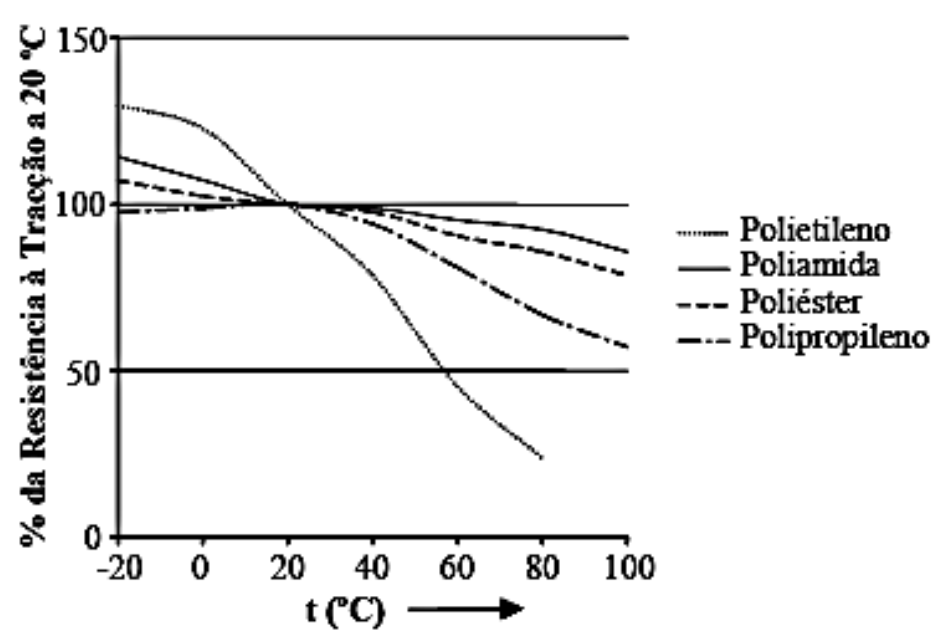

Figura 2.43 - Efeito da temperatura na resistência à tração (adaptado de Pilarczyk, 2000 apud Pinto 2005)

Segundo Bueno (2007), os testes acelerados de fluência em plásticos, através da elevação da temperatura, são a única opção dos projetistas para obter dados sobre o comportamento tempo-dependente dos geossintéticos. No entanto, caso as características do produto sejam alteradas, tal prática pode induzir a erros de 
avaliação sobre a estabilidade desses materiais quando submetidos a tensões constantes.

Para obtenção da resistência em longo prazo por extrapolação analítica ou por aceleração térmica, a resistência obtida em ensaio laboratorial deve ser corrigida por meio de um fator de redução (fe), conforme a equação a seguir (Ingold, 1993):

$$
f e=\ln \left(\frac{t_{d}}{t_{e}}\right)
$$

Onde:

$t_{d}-$ Tempo de projeto = vida útil da estrutura;

$t_{e}-$ Tempo de duração do ensaio.

Como a temperatura do ensaio $\left(C_{e}\right)$ pode ser diferente da temperatura dentro do solo ou do resíduo $\left(C_{d}\right)$, os pesquisadores têm empregado correções de tempo e temperatura com base na formulação de Arrehenius:

$$
t_{d c o r r}=t_{d} \times e^{\left(\frac{C_{d}-C_{e}}{\alpha}\right)}
$$

Onde:

$t_{d c o r r}$ - Vida útil corrigida;

$\alpha$ - Coeficiente de correção de temperatura.

O coeficiente de correção de temperatura pode ser estimado com base no polímero predominante na estrutura do geossintéticos. Valores típicos para alguns polímeros estão apresentados a seguir:

- Poliéster: $\alpha=5,6$

- Polipropileno: $\alpha=7,2$

- Polietileno: $\alpha=4,2$

O efeito da temperatura é fator importante a ser analisado, visto que em aterros sanitários a variação térmica tanto do chorume como da massa de resíduos é muito maior do que no solo. Artieres et al. (1997) afirmam que tal variação na temperatura 
do chorume pode chegar a $50^{\circ} \mathrm{C}$ próximo à geomembrana, sendo encontrados em literatura medições de até $70^{\circ} \mathrm{C}$ (Haxo \& Haxo, 1988; Landreth, 1988).

\subsubsection{Degradação biológica}

As ações biológicas são consequência da presença de micro-organismos no meio onde está colocado o geossintético. Estes micro-organismos podem atacar os polímeros ou até mesmo os aditivos, deixando os geossintéticos vulneráveis à degradação. Podem ainda dar origem ao desenvolvimento de produtos nocivos aos constituintes poliméricos. No entanto, estudos realizados até ao momento apontam para uma boa resistência biológica dos polímeros mais comuns na fabricação de geossintéticos; os micro-organismos consomem somente as frações poliméricas de muito baixo peso molecular, o que faz com que as propriedades dos plásticos não sejam praticamente afetadas (Pinto, 2005).

Allen (1991) ${ }^{18}$ (apud Azambuja, 1994) recomenda para estruturas não críticas, mesmo permanentes, um fator de degradação biológica igual a 1,0 desde que os polímeros empregados possuam alto peso molecular. Voskamp e Risseuw (1997) ${ }^{19}$ (apud Azambuja,1994) sugerem um valor mínimo igual a 1,02, enquanto Koerner $(1990)^{20}$ (apud Nascimento, 2002) apresenta um intervalo de 1,0 a 1,3 para os sistemas de contenção.

\footnotetext{
${ }^{18}$ Allen, T.M. (199!). Determination of Long-term Tensile Strenght of Geosynthetics: a State-of-the-art rewiew. In: Geosynthetics'91 Conf. Atlanta, p. $350-380$.

${ }_{19}$ Voskamp, W., Risseuw, P (1897). Method to Stablish the maximum allowable load under working conditions of polyester reinforcing fabrics. Geotextiles and Geomembranes, v.6, no 1-3, p 173 - 184.

${ }^{20}$ Koerner, R. M., Koerner, G. R. (1990). A Quantification and Assessment of Installation Damage to Geotextile. Fouth International Conference on Geotextiles, Geomembranes and Related Products, The Hague, , v.2, pp 597-602.
} 


\subsubsection{Fadiga e fluência}

A fluência é o processo pelo qual as dimensões do material modificam-se com o tempo quando submetidos à carga constante. A magnitude das deformações por fluência depende da composição do polímero, do seu estado físico e da estrutura das fibras.

A fluência é usualmente apresentada através de relações tensão-deformação para diferentes tempos de aplicação de carregamentos, ou seja, diferentes famílias de curvas tensão-deformação.

Den Hoedt (1986) ${ }^{21}$ (apud Becker, 2001) através de ensaios de fluência realizados para níveis de tensão de cerca de 20 a $60 \%$ da resistência à tração, verificou a sensibilidade dos 4 tipos de polímeros mais utilizados a fenômenos de fluência. $O$ autor constatou maior sensibilidade do polietileno, seguida do polipropileno, poliamida e do poliéster.

O polipropileno e o polietileno apresentam alta susceptibilidade à fluência, relacionada à sua baixa temperatura de transição vítrea. A temperatura de transição vítrea do polipropileno é da ordem de $-10^{\circ} \mathrm{C}$, enquanto a do polietileno é inferior à $100^{\circ} \mathrm{C}$ (Den Hoedt, 1986). Além disso, estes polímeros apresentam elevada cristalinidade, conduzindo a uma maior fluência. Portanto, a utilização de reforços geossintéticos constituídos desses polímeros em ambientes sujeitos a elevada temperatura deve ser restrita, sendo aconselhável a utilização de reforços constituídos por poliésteres, álcool de polivinila ou poliamidas. Os poliésteres e as poliamidas apresentam baixa cristalinidade e, consequentemente, menor fluência.

Müller-Rochholz e Reinhard (1990) ${ }^{22}$ (apud Becker, 2001) destacam que o aumento da temperatura acelera significativamente a fluência do polipropileno. No entanto, no poliéster, essa influência é desprezível.

21 Den Hoedt, G. (1986). Creep and Relaxation of Geotextile Fabrics. Geotextiles and Geomembranes, Amsterdam, v.4, n.2, p.83-92.

${ }^{22}$ Müller-Rochholz, J.; Reinhard, K. (1990). Creep of Geotextiles at Different Temperatures. In: 4th International Conference on Geotextiles, Geomembranes and Related Products, 1990, The Hague Netherlands, Proceedings... The Hague - Netherlands, p.657 - 659 . 
Os ensaios de fluência geralmente são realizados em laboratório, com temperatura controlada e sem confinamento. Há evidências experimentais de que o confinamento altera as propriedades de fluência dos geotêxteis não tecidos (Kabir, 1984 ${ }^{23}$ apud Msouti et al. (1997); Becker, 2001). Costa (1999) realizou ensaios de fluência confinada e não-confinada em geotêxteis não-tecidos agulhados, fabricados a partir de filamentos de poliéster e fibras cortadas de polipropileno, concluindo que a fluência do geotêxtil de poliéster foi bem menor em relação aos geotêxteis de polipropileno (cerca de 10 vezes inferior para um carregamento correspondente a $40 \%$ da resistência à tração) e que o confinamento proporciona reduzir as deformações ao longo do tempo. Já para geotêxteis tecidos e, em particular, para geogrelhas, o efeito do confinamento na fluência é desprezível (Becker e Ehrlich, 2009).

Nos ensaios de fluência sob tração não confinada, normalizados pela NBR-15226, "Geossintéticos - Determinação do Comportamento em Deformação e na Ruptura, por Fluência sob Tração Não-Confinada." (ABNT, 2005), corpos-de-prova com $200 \mathrm{~mm}$ de largura e $100 \mathrm{~mm}$ de comprimento são submetidos a carregamentos constantes, obviamente inferiores à resistência a tração do material, e registram-se as deformações em tempos pré-estabelecidos. A temperatura e a umidade do recinto também devem ser controladas.

Becker e Ehrlich (2009) sugerem que o projetista deve evitar que o reforço atinja o estado último de ruptura ou que sofra deformações excessivas que prejudiquem a aparência ou o uso da estrutura, propondo duas alternativas:

- Minorar a resistência à tração de curto prazo, dividindo-a por um fator de redução que leve em conta o tipo de polímero e que considere o tempo de vida útil da obra e as deformações aceitáveis de forma implícita e empírica. Segundo os autores, esse método é utilizado quando não se dispõe de resultados de ensaios de fluência.

\footnotetext{
${ }^{23}$ Kabir, N. (1984). In-isolation and in-soil behaviour of geotextiles. Tese (Doutorado), Université de Strathclyde. 220p.
} 
- Estabelecer um valor de deformação máximo permitido para o reforço e determinar a carga distribuída correspondente à vida útil da obra no gráfico de isócronas.

Fadiga estática é o fenômeno pelo qual um material, decorrido um determinado intervalo de tempo, alcança a ruína com cargas menores do que a sua resistência de curto prazo. A fadiga estática é por vezes representada pelo tempo que uma fibra leva para romper com um determinado nível de tensão.

Segundo Azambuja (1992), a fadiga estática depende unicamente das propriedades dos polímeros e, por isso, independe do processo de manufatura dos geossintéticos. Já a fluência depende não só do polímero como da estrutura dos geossintéticos. Isto ocorre porque existem deformações dos geossintéticos por reordenação de fibras e reacomodação de filamentos sob carga constante.

\subsubsection{Danos mecânicos na instalação}

Dano mecânico é toda transformação da estrutura do geossintético resultante de esforços ocorridos durante seu manuseio, instalação e compactação do solo sobrejacente. Alguns autores distinguem ainda duas fases do dano mecânico: aqueles ocorridos até a compactação e os decorrentes das solicitações iniciais de serviço (Bonaparte et al., 1988; Paulson, 1990).

Durante o processo de instalação os geossintéticos estão sujeitos a danos mecânicos, ocasionados pela compactação, tráfego de máquinas, equipamentos e operários, e lançamento de materiais pontiagudos e/ou granulares.

Segundo Bueno (2007), os principais fatores que afetam a intensidade do dano são o tipo de geossintético e o espaçamento entre as camadas de geossintético e o material de aterro.

De acordo com os resultados de ensaios com amostras danificadas e virgens apresentados por Koerner (1992), sempre ocorre redução na resistência do geossintético devido a danos na instalação, sendo tal redução variável. $O$ autor 
sugere a utilização de um fator de redução em geral entre 1,0 e 2,0, chegando a 3,0 em casos mais extremos.

A ocorrência de danos mecânicos reduz localmente a seção transversal do material, provocando o aumento das tensões nos locais danificados e, consequentemente, reduz o intervalo de tempo em que o geossintético sofrerá ruptura, além da possibilidade de iniciar a ruptura por rasgamento no geossintético (Jewell, 1996).

Miguel et al. (2009) estudaram o efeito dos danos durante a instalação de uma geogrelha tecida em poliéster (PET) no seu comportamento mecânico de tração a curto e a longo prazo, através de ensaios de campo para dois tipos de solos e duas energias de compactação. Os resultados indicam que o solo com partículas maiores e a maior energia de compactação levam a maiores reduções nas propriedades mecânicas.

Brown e Greenwood (2002) relatam a ocorrência de rupturas prematuras em plásticos durante sua utilização porque o mecanismo de degradação crítico não foi devidamente considerado.

\subsubsection{Sinergia dos efeitos de degradação}

Segundo Lopes e Lopes(2009), os diversos agentes de degradação que afetam a durabilidade dos geossintéticos podem interagir entre si, com o polímero e com os aditivos, com efeitos significativos, dependendo do agente degradante.

O efeito total da ação simultânea de vários agentes e mecanismos de degradação sobre um material pode ser muito diferente, normalmente mais danoso, do que o efeito de cada um deles atuando de forma isolada (efeito sinérgico).

Assim, é fundamental a realização de ensaios acelerados que simulem de forma plausível o conjunto de condições que afetam a durabilidade dos geossintéticos. Para a realização desses ensaios é necessário saber a natureza e a concentração dos agentes degradantes mais críticos na aplicação a qual se destina o geossintético. No entanto, a definição desses agentes não é fácil, uma vez que é necessário saber a situação de exposição em serviço e as características do material a ser utilizado. 


\subsubsection{Fatores de redução}

Em um projeto de solo/estrutura reforçada, no qual se busca a estabilidade da estrutura por meio de reforços geossintéticos, a resistência requerida do reforço, denominada resistência de projeto, é geralmente obtida através de métodos de equilíbrio-limite. O valor da tração requerida é então comparada ou composta com as resistências das geogrelhas disponíveis no mercado.

No entanto, a resistência disponível do reforço é obtida considerando-se diversos fatores de redução, que visam compensar a perda da capacidade resistiva devido aos efeitos da fluência, danos mecânicos de instalação, danos químicos e demais incertezas, conforme descrito a seguir:

- Fluência: deformação lenta função da carga permanente à qual fica sujeito o geossintético;

- Danos mecânicos de instalação: função das condições de manuseio no campo, execução da instalação do geossintético, compactação do solo do aterro etc.

- Danos químicos e ambientais: função da composição química do solo e das condições de exposição do geossintético a substâncias químicas e raios UV.

- Outros, de acordo com situações especificas.

A resistência a tração disponível do reforço (admissível) é obtida por meio da seguinte equação:

$$
T a=\frac{T \max }{f c r . f m r . f a \cdot f m}
$$

Onde:

Tmax - Resitência a tração do reforço

$f c r$ - fator de redução parcial para fluência à tração;

fmr - fator de redução parcial para danos mecânicos de instalação;

$f a$ - fator de redução parcial para danos químicos e ambientais; 
fm - fator de redução parcial para incertezas estatísticas na determinação da resistência do geossintético.

Azambuja (1999) sugeriu em seu trabalho os seguintes fatores de redução:

- Fluência

Tabela 2.11 - Fator de fluência para diferentes tipos de polímero

\begin{tabular}{cc}
\hline Polímero & Fator de fluência \\
\hline Poliéster (PET) e PVA & $2,0-2,5$ \\
Polipropileno (PP) & $3,5-4,0$ \\
Polietileno de alta densidade (PEAD)* & $4,5-5,0$ \\
\hline
\end{tabular}

${ }^{*}$ *) válido para polímeros orientados por encruamento

- Dano mecânico

Tabela 2.12 - Fatores de redução para dano mecânico

\begin{tabular}{cc}
\hline Geossintético & Fator de redução por dano mecânico \\
\hline Geogrelha flexível, revest. Acrílico & $1,10-1,50$ \\
Geogrelha flexível, revest. PVC & $1,05-2,00$ \\
Geogelha rígida PP & $1,05-1,45$ \\
Geogrelha PEAD & $1,05-1,60$ \\
\hline
\end{tabular}

- Degradação química e ambiental

Tabela 2.13 - Fatores de redução por degradação ambiental, para geossintéticos não certificados.

\begin{tabular}{|c|c|c|}
\hline Geossintético & Polímero & Fator de redução por dano mecânico \\
\hline \multirow{3}{*}{ Temporário } & Polipropileno & $1,00-1,25$ \\
\hline & Polietileno e PVA & $1,00-1,25$ \\
\hline & Poliéster & $1,00-1,25$ \\
\hline \multirow{3}{*}{ Geogrelha rígida PEAD } & Polipropileno & $1,25-2,00$ \\
\hline & Polietileno e PVA & $1,10-1,15$ \\
\hline & Poliéster & $1,25-2,00$ \\
\hline
\end{tabular}

Obs.: Os valores mais altos referem-se a ambientes severamente desfavoráveis - fortemente ácidos para poliolefinas e fortemente alcalinos para o poliéster. 


\subsubsection{Métodos de dimensionamento}

O dimensionamento de estruturas em solo reforçado compreende a verificação da estabilidade interna e externa. A estabilidade externa é verificada considerando-se a estrutura de solo reforçado como um muro de gravidade, no qual são verificadas as condições de estabilidade ao deslizamento, tombamento, capacidade de carga da fundação e instabilidade global.

Nesta seção, será abordada com maior ênfase a estabilidade interna da estrutura em solo reforçado, por se tratar de um aspecto particular para o dimensionamento desse tipo de estrutura.

Conforme previamente discutido no item 2.3.2 e exemplificado na Figura 2.33, a ruptura interna de uma estrutura em solo reforçado pode se dar por ruptura à tração dos reforços, arrancamento dos reforços ou instabilidade localizada na face. A seguir são apresentados os aspectos que devem ser verificados no dimensionamento desta estruturas.

\subsubsection{Máxima tensão de tração no reforço}

A máxima tensão de tração no reforço ( $\left.T_{\text {máx }}\right)$ é um dos aspectos mais importantes no projeto de estruturas de solo reforçado. Os procedimentos usuais para obtenção do valor de $\mathrm{T}_{\text {máx }}$ baseiam-se em métodos de equilíbrio-limite, porém há controvérsias em relação ao dimensionamento por esses métodos, uma vez que alguns autores afirmam levar a um dimensionamento conservador e outros alertam para a possibilidade de dimensionamento contra a segurança.

\section{a) Métodos de dimensionamento por equilíbrio-limite}

São os mais difundidos e empregados, pela sua facilidade de utilização.

Esses métodos adotam as seguintes hipóteses: 
- Estrutura em situação de colapso iminente;

- Superfície de ruptura conhecida;

- Comportamento rígido perfeitamente plástico do solo;

- Inclinação e distribuição dos reforços ao longo da superfície de ruptura conhecidas;

- Total mobilização da resistência ao cisalhamento do solo, ao longo de toda a superfície de ruptura.

b) Método do U.S. Forest Service (Steward, Willianson e Mohney (1977))

Neste método a face pode ser vertical ou inclinada, e a superfície de ruptura atravessa a massa de solo reforçado, com uma inclinação de $45+\varnothing^{\prime} / 2$ em relação à horizontal, conforme a Figura 2.44.
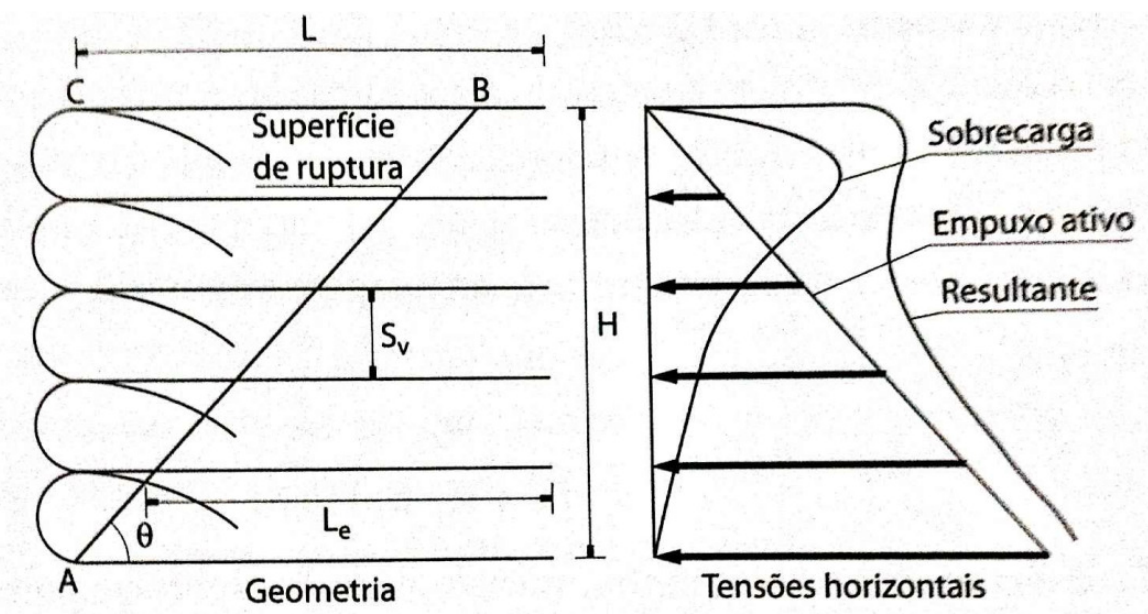

Tensões horizontais

Figura 2.44 - Configuração de um muro de solo reforçado, segundo Steward, Willianson e Mohney (1977) apud Ehrlich \& Becker (2009)

O método assume que, caso não haja sobrecarga, a distribuição das tensões horizontais é linear, dada por:

$$
\sigma^{\prime} x=k \cdot \gamma \cdot z
$$

Onde:

$\sigma^{\prime} x$ - Tensão horizontal efetiva; 
$k$ - coeficiente de empuxo;

$\gamma$ - Peso específico do solo;

z - Profundidade considerada.

O espaçamento vertical dos reforços é dado por:

$$
S v=\frac{T d}{\sigma^{\prime} x \cdot F S g}
$$

Onde:

$S v$ - Espaçamento vertical entre reforços;

$T d$ - Resistência à tração de projeto do geossintético (considerando os fatores de redução);

FSg - Fator de segurança global da estrutura (geralmente entre 1,3 e 1,5).

Obs.: É usual dimensionar o espaçamento vertical para a camada inferior, dada a maior tensão horizontal atuante.

O comprimento de ancoragem é obtido pela equação:

$$
L e=S v \cdot \sigma^{\prime} x \cdot \frac{F S a}{2 .(a+\gamma \cdot z . t g \delta)}
$$

Onde:

Le - Comprimento de ancoragem;

FSa - Fator de segurança ao arrancamento (geralmente de 1,3 a 1,5);

$a$ - Adesão da interface solo-geossintético;

$\delta$ - Ângulo de atrito da interface solo-geossintético.

\section{c) Métodos de dimensionamento empíricos}

O método de dimensionamento empírico apresentado elaborado por Elias, Christopher e Berg (2001) é baseado em uma relação entre o tipo de reforço e as tensões horizontais que se desenvolvem em uma massa de solo reforçado. 
A força de tração no reforço, em certa profundidade do muro é determinada com base na tensão vertical à mesma profundidade e no coeficiente de empuxo lateral, segundo a equação:

$$
T(z)=\sigma^{\prime} x(z) \cdot S v=\sigma^{\prime} z(z) \cdot K \cdot S v
$$

Onde:

$T(z)$ - Força de tração na profundidade z, medida a partir da crista;

$\sigma^{\prime} z(z)-$ Tensão vertical na profundidade $z$.

Para a determinação do coeficiente de empuxo lateral, multiplica-se o coeficiente de empuxo ativo pelo valor da razão $K / K a$ obtida na Figura 2.45 para a profundidade desejada.

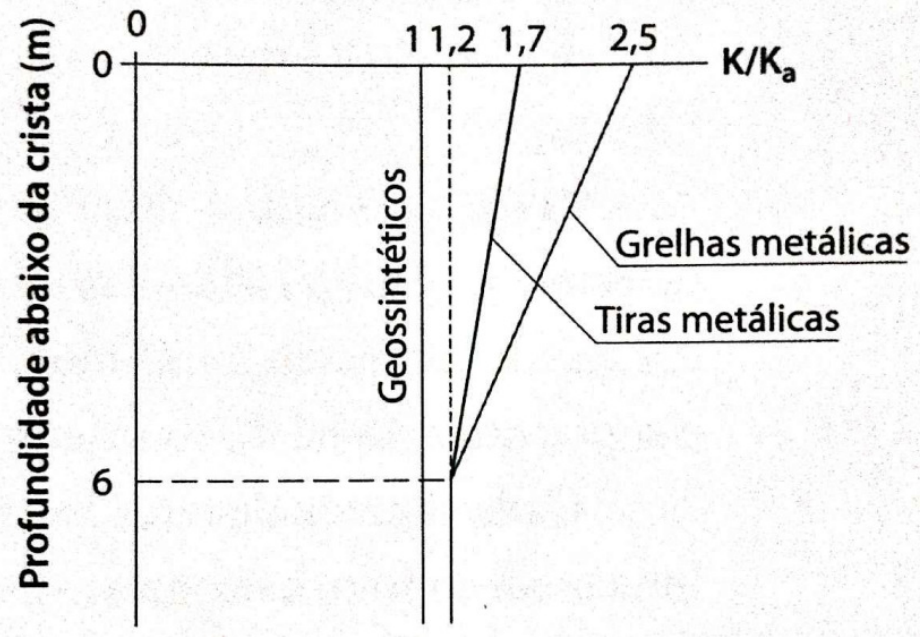

Figura 2.45 - Variação da razão $K / K a$ em função da profundidade, para muros de solo reforçado (Elias, Christopher e Berg (2001) apud Ehrlich \& Becker (2009).

\section{d) Métodos de dimensionamento com compatibilidade de deformações}

O método, desenvolvido por Ehrlich e Mitchell (1994), baseia-se na compatibilidade de deformações no solo e no reforço, considerando a influência da rigidez relativa solo-reforço e da energia de compactação. O modelo constitutivo do reforço é linear elástico e supõe que não há deslizamento relativo entre solo e reforço. 


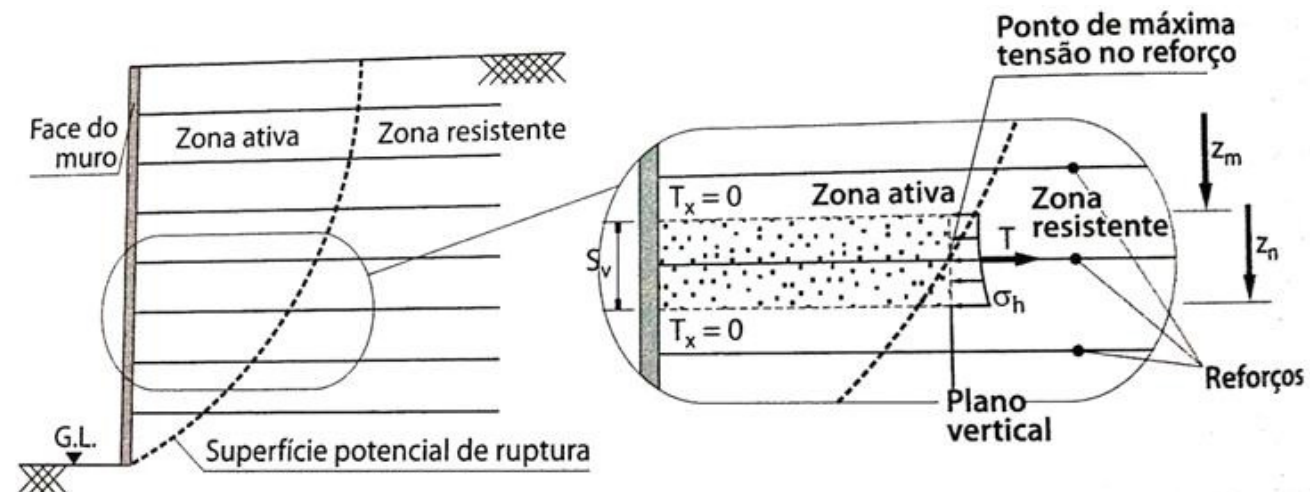

Figura 2.46 - Equilíbrio interno da massa de solo reforçado, segundo Ehrlich e Mitchell (1994) apud Ehrlich \& Becker (2009)

Para o cálculo de $T_{\text {máx }}$ são utilizados ábacos em função da inclinação do paramento e do ângulo de atrito efetivo do material de enchimento.

Neste trabalho este método é apresentado de forma simplificada, uma vez que o intuito é apresentar os métodos disponíveis e os conceitos envolvidos, e não uma revisão completa sobre este assunto. Para um estudo mais detalhado há diversas referências, como por exemplo a de Ehrlich \& Becker (2009).

\subsection{GEOSSINTÉTICOS EM ATERROS DE RSU}

Os geossintéticos são largamente utilizados em projetos de aterros sanitários, principalmente para compor barreiras contra fluxos na base e na cobertura. Alguns geossintéticos que podem ser utilizados em obras de aterros sanitários são:

- geogrelhas, como reforço do revestimento de fundo nos taludes, assim dos solos de cobertura sobre as geomembranas;

- georredes, como colchão drenante;

- geomembranas, que são mantas impermeáveis feitas de materiais poliméricos, como barreiras para líquidos, gases e/ou vapores;

- geocompostos, que consistem na combinação de dois ou mais geossintéticos, para separação, filtração ou drenagem; 
- geocompostos argilosos, que são combinações de bentonita e geossintéticos, como barreiras hidráulicas;

- geotubos, para coletar e drenar rapidamente o chorume, conduzindo-o para um sistema de tratamento;

- geotêxteis, para filtração ou como colchão para proteger a geomembrana contra danos.

A Figura 2.47 ilustra as múltiplas aplicações de geossintéticos, tanto na cobertura quanto no revestimento de fundo de um aterro de resíduos.

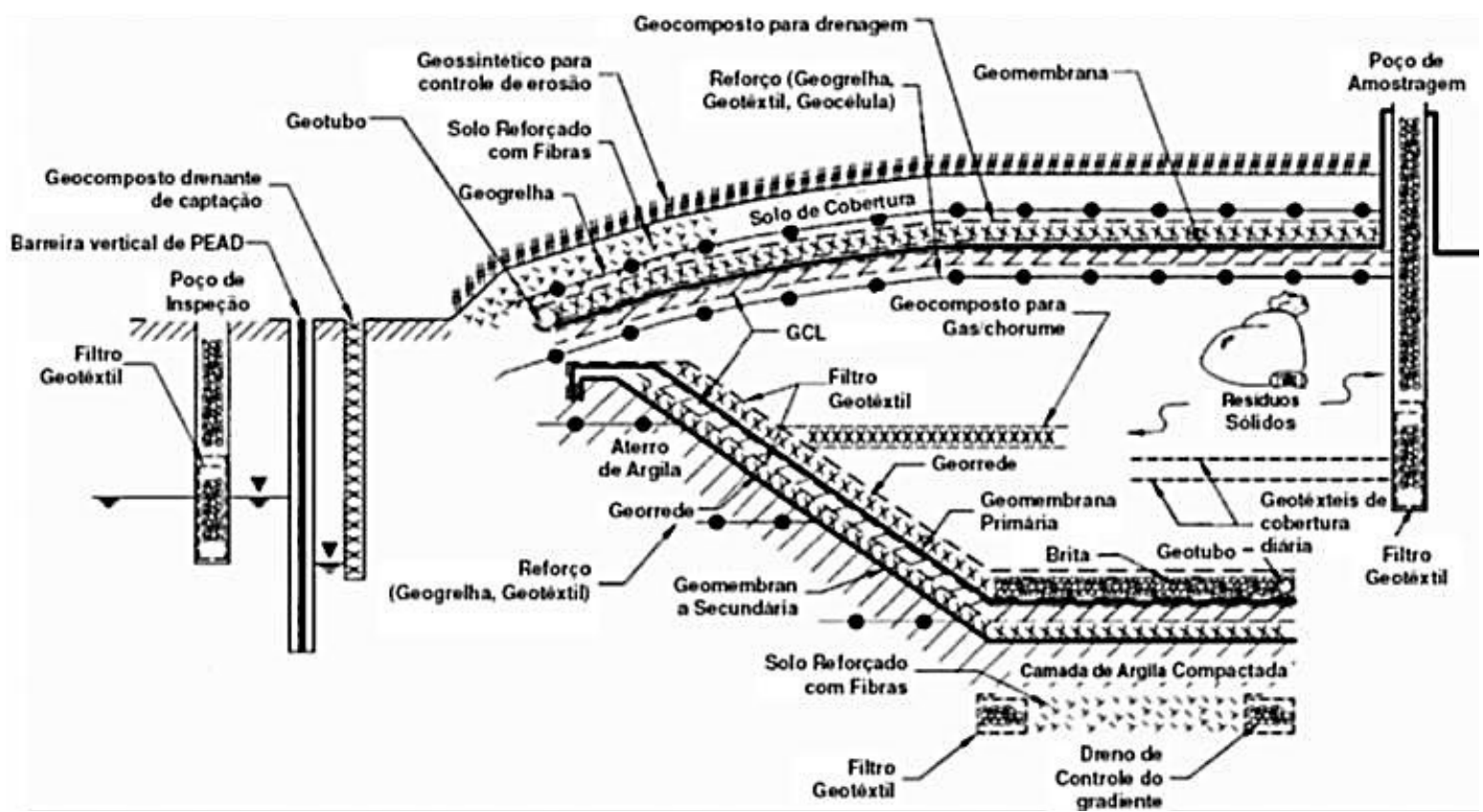

Figura 2.47 - Aplicações típicas de geossintéticos em aterros de resíduo (Koerner, 1994)

O revestimento de fundo da Figura 2.47 é constituído de um sistema duplo de impermeabilização, que inclui uma combinação geomembrana/GCL como barreira primária e uma combinação geomembrana/solo compactado como barreira secundária. O sistema de detecção de vazamentos, localizado entre a primeira e segunda barreira, é uma combinação geotêxtil/georrede. O sistema de coleta do chorume, sobreposto à barreira primária, consiste em um colchão de brita e uma rede de geotubos perfurados. Uma camada de geotêxtil sob a brita atua como proteção da geomembrana primária contra puncionamento pelo material sobrejacente. O sistema de coleta do chorume sobre a barreira primária nos taludes laterais é um geocomposto drenante (geotêxtil/georrede) ligado à camada de brita 
na base. Um filtro geotêxtil evita a colmatação do sistema de captação e remoção do chorume.

O nível de água subterrânea na base do aterro pode ser controlado por meio de drenos construídos com filtros geotêxteis. Além disso, pode ser necessária a estabilização do solo de fundação abaixo da base do aterro, utilizando-se mistura de solo com fibras para reforço distribuídas aleatoriamente, enquanto os taludes íngremes laterais de solo compactado do revestimento de fundo podem ser reforçados com geogrelhas.

O sistema de cobertura do aterro contém uma barreira composta geomembrana/GCL. A camada de drenagem sobreposta à geomembrana é um geocomposto drenante (geotêxtil/georrede). O sistema de cobertura de solo inclui reforços de geogrelha, geotêxtil ou geocélula sob a barreira contra infiltração, empregados para minimizar as possíveis deformações induzidas devido a recalques diferenciais dos resíduos ou pela futura expansão vertical do aterro. A cobertura pode incluir um reforço de geogrelha ou geotêxtil acima da barreira para aumentar a estabilidade da cobertura vegetal (camada de solo de cobertura para plantio). Fibras para reforço também podem ser usadas para a estabilização do trecho inclinado do solo vegetal. Um geocomposto para controle de erosão sobre o solo vegetal promove a proteção contra erosões laminar e em ravinas.

O uso de geotêxteis como filtros nos poços de inspeção e amostragem de água subterrânea e chorume é também ilustrado. Finalmente, uma barreira vertical de PEAD e um geocomposto drenante de captação são utilizados ao longo do perímetro do aterro.

Embora nem todos os componentes mostrados na Figura 2.47 sejam necessários em todos os aterros sanitários, estão ilustradas as várias aplicações de geossintéticos que podem ser consideradas em projetos desse tipo de obra.

São raros os casos encontrados na bibliografia relatando a utilização de geossintéticos no interior de maciços de RSU, enquanto é comum o uso de camadas de geossintéticos com diversas funções associadas à cobertura e ao revestimento de fundo.

A utilização de geossintéticos como reforço, na maioria dos casos, se restringe ao solo de cobertura, em taludes laterais do revestimento de fundo e em diques 
periféricos e/ou de partida. Utiliza-se reforço na camada de solo compactado da cobertura a fim de diminuir a ocorrência de deformações excessivas que causem a abertura de trincas de tração e melhorar as condições de estabilidade do maciço. Em aterros onde há taludes laterais escavados de grande declividade, pode ser necessário reforço no revestimento de fundo para melhorar a interface entre a geomembrana/GCL e o sistema de drenagem. Diques de partida ou periféricos podem ser construídos com taludes de maior declividade, portanto com menor volume de solo, se reforçados com geossintéticos.

A inclinação usual dos taludes do aterro sanitário torna desnecessária a utilização de reforços no maciço, ou seja, os aterros sanitários são usualmente projetados de forma que os fatores de segurança sejam atendidos sem que haja necessidade de utilização de reforço no interior da massa de resíduos. A inclinação dos taludes depende muito do local a ser utilizado para construção do aterro, sendo comum a utilização de taludes médios com inclinação de $1 \mathrm{~V}: 2,5 \mathrm{H}$ a $1 \mathrm{~V}: 3,0 \mathrm{H}$. 


\section{MATERIAIS E MÉTODOS}

A ideia para verticalização dos aterros sanitários teve como base o método de montante de barragens de rejeitos de mineração, com alteamentos sucessivos por meio de diques reforçados. Neste método, constrói-se um dique de partida e os resíduos são dispostos a montante até atingirem a altura do dique; a partir daí vão sendo construídos sucessivamente diques periféricos alteados a montante, apoiados sobre o material depositado (Figura 3.1).

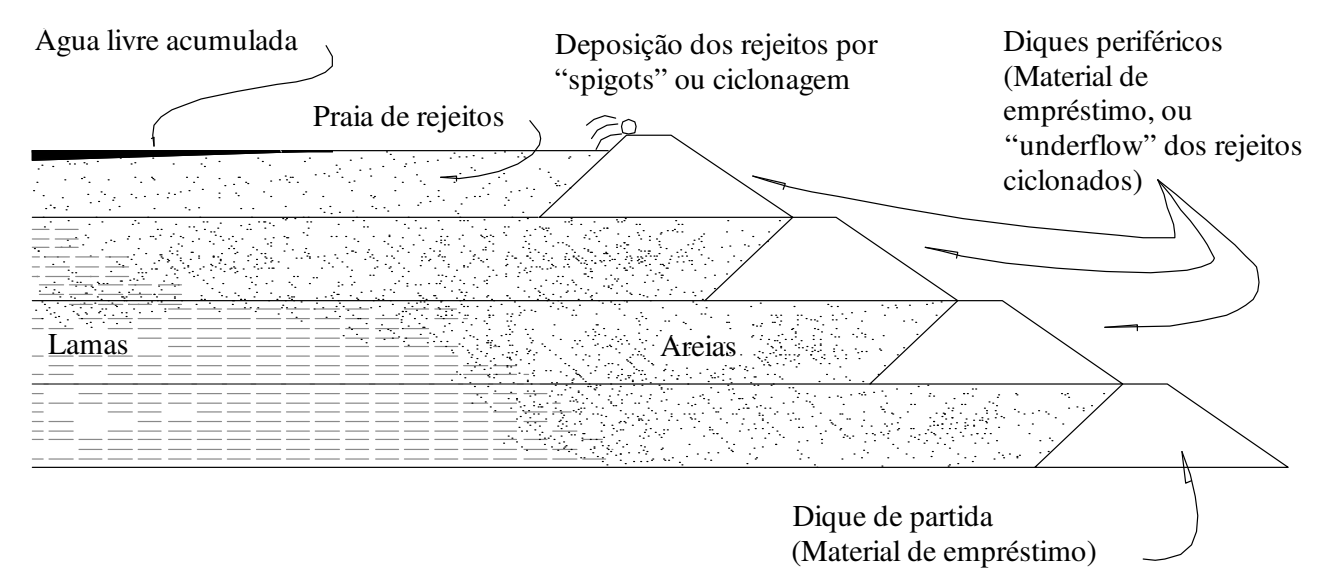

Figura 3.1 - Método de montante de construção de barragens de rejeitos (Boscov, 2008)

Inicialmente foi definida uma seção padrão de um aterro sanitário de grande porte para o estudo, considerando-se valores típicos de declividades de talude, altura e largura de bermas obtidos por meio de revisão bibliográfica e da experiência profissional do pesquisador.

A seguir estudaram-se algumas alternativas de reforço por geogrelhas nos diques periféricos e na massa de resíduos.

A Figura 3.2 representa esquematicamente a colocação dos reforços nas estruturas. 


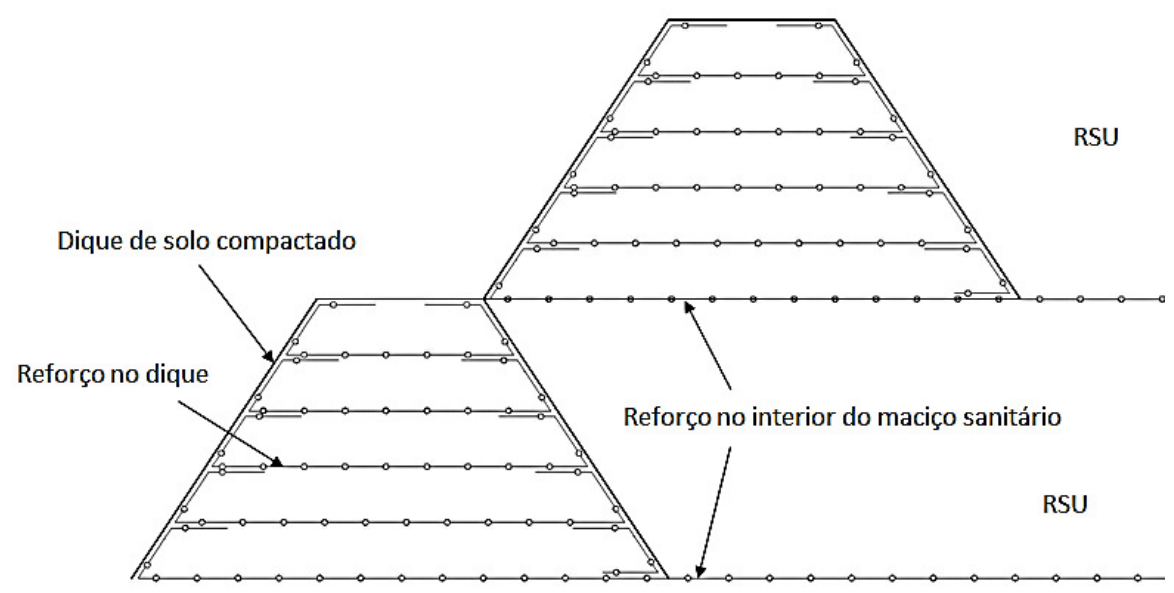

Figura 3.2 - llustração das disposição dos reforços nas estruturas

Adotaram-se parâmetros de resistência e deformabilidade para os materiais utilizados no aterro com base na revisão bibliográfica. Com esta seção foram realizadas análises de equilíbrio limite e tensão-deformação em diversas etapas construtivas.

\subsection{ANÁLISE EQUILÍBRIO-LIMITE}

\subsubsection{Materiais}

Os materiais considerados nas análises de estabilidade por meio de métodos equilíbrio-limite foram os resíduos sólidos urbanos que compõem o maciço, o solo de fundação, o solo utilizado para execução do dique, e a geogrelha utilizada como elemento de reforço do maciço de RSU e do dique.

\subsubsection{RSU e solos}

Para realização das análises foram adotados parâmetros totais para os solos, cujo critério de resistência considerado foi o de Mohr-Coulomb, conforme 
apresentado na Tabela 3.1.

Tabela 3.1 - Parâmetros adotados

\begin{tabular}{|c|c|c|c|}
\hline Material & $\begin{array}{l}\text { Peso específico } \\
m\left(\mathrm{kN} / \mathrm{m}^{3}\right)\end{array}$ & $\begin{array}{l}\text { Coesão } \\
\text { c (kPa) }\end{array}$ & $\begin{array}{c}\text { Ângulo de Atrito } \\
\phi\left(1^{\circ}\right)\end{array}$ \\
\hline $\begin{array}{l}\left({ }^{*}\right) \text { Dique } \\
\text { (argila compactada) }\end{array}$ & 18 & 10 & 30 \\
\hline$\left({ }^{* *}\right)$ Resíduo compactado & 11 & 13,5 & 22 \\
\hline Solo de fundação & \multicolumn{3}{|c|}{ Material rígido (resistência infinita) } \\
\hline
\end{tabular}

$\left(^{*}\right)$ Parâmetros fornecidos pela Moretti Engenharia;

$\left.{ }^{* *}\right)$ Parâmetros de resistência obtidos da retroanálise da ruptura do Aterro Bandeirantes (Benvenuto e Cunha, 1991) e peso específico obtido do CTR-.Itapevi (Andrade, 2010) ${ }^{24}$

\subsubsection{Geogrelha}

Os parâmetros das geogrelhas consideradas neste estudo foram obtidos de um catálogo comercial da Huesker e são referentes a geogrelhas de PVA de alta tenacidade, baixa fluência e alta resistência química, com resistência à tração de $100 \mathrm{KN} / \mathrm{m}$, posicionadas a cada $1 \mathrm{~m}$ de aterro e ancoradas em ambas as extremidades. Para as geogrelhas no interior do maciço sanitário foi adotada resistência à tração de $400 \mathrm{kN} / \mathrm{m}$, posicionadas a cada $6 \mathrm{~m}$ de aterro (a cada novo dique alteado) e ancoradas em ambas as extremidades. Os valores de resistência à tração apresentados são de projeto e representam a resistência residual após a aplicação do fator de redução total.

Vale lembrar que, utilizando o fator de redução total $(\mathrm{FR})$ proposto por Vertematti (2004), a resistência nominal da geogrelha pode variar de 3 a 28 vezes em relação à resistência de projeto da geogrelha, dependendo da utilização do geossintético (capítulo 2.3.10).

Em projetos, a especificação da resistência à tração pode ser feita através do fornecimento da resistência de projeto ou através da resistência nominal da

\footnotetext{
${ }^{24}$ Andrade, A.C.P. (2010). Comunicação pessoal.
} 
geogrelha, com a apresentação do fator de redução total. Neste trabalho, optou-se pela primeira opção.

\subsubsection{Geometrias estudadas}

As análises de estabilidade foram realizadas para as seguintes seções transversais (Figura 3.3):

- Aterro de resíduos com seção trapezoidal (altura 6m, 15m e 30m, inclinação da berma de $1 \mathrm{H}: 2 \mathrm{~V}, 1 \mathrm{H}: 1 \mathrm{~V}, 1,5 \mathrm{H}: 1 \mathrm{~V}$ e $\mathrm{Ru}=0$ a 0,3$)$;

- Dique de solo (altura 5,6m e 7m, inclinação do talude de 1,5H:1V, $1 \mathrm{H}: 1 \mathrm{~V}$, $1 \mathrm{H}: 1,5 \mathrm{~V}$ e $1 \mathrm{H}: 2 \mathrm{~V}$ e $\mathrm{Ru}=0$ a 0,3$)$;

- Aterro de resíduos com bermas de 5m de largura a cada $6 \mathrm{~m}$ de altura;

- Aterro de resíduos com dique de partida e alteamento com bermas;

- Aterro de resíduos com dique de partida reforçado e alteamento com bermas;

- Aterro de resíduos com diques sucessivos em diversas etapas construtivas (6, $12,18,24,30,36,42$ e $48 m)$;

- Aterro de resíduos com diques sucessivos reforçados em diversas etapas construtivas $(6,12,18,24,30,36,42$ e 48m);

- Aterro de resíduos com diques sucessivos em diversas etapas construtivas (6, $12,18,24,30,36,42$ e 48m) e reforço entre camadas de resíduos (a cada 6m);

- Aterro de resíduos com diques sucessivos reforçados em diversas etapas construtivas $(6,12,18,24,30,36,42$ e 48m) e reforço entre camadas de resíduos (a cada $6 \mathrm{~m})$; 


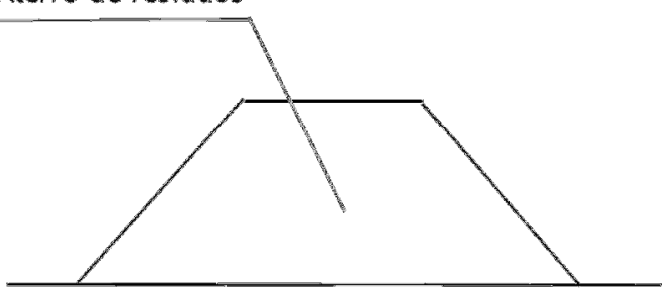

(a)

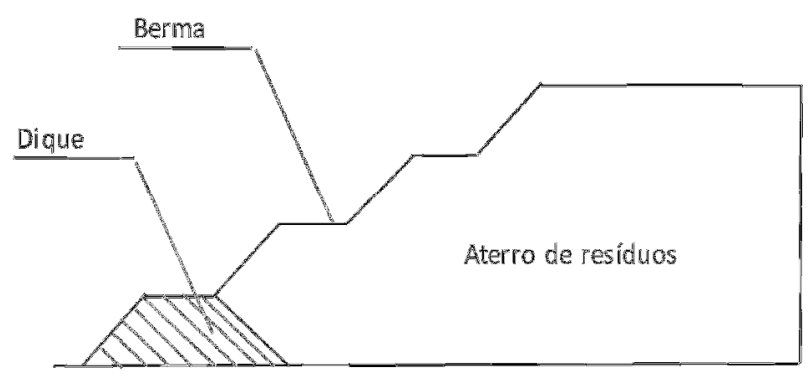

(c)

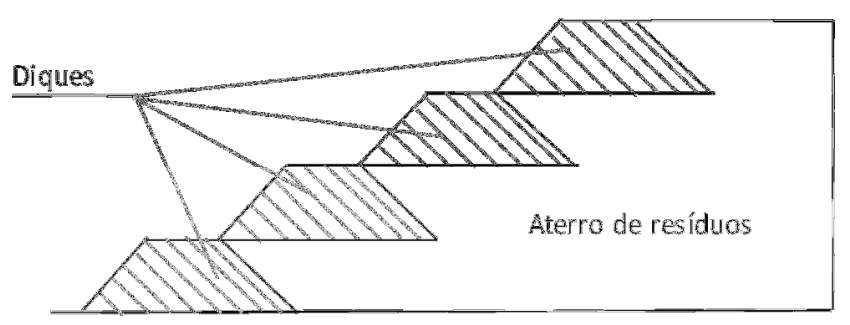

(e)

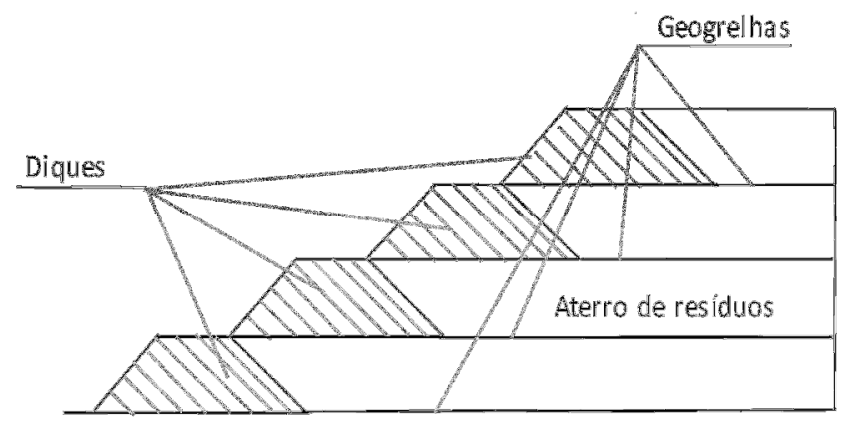

(g)

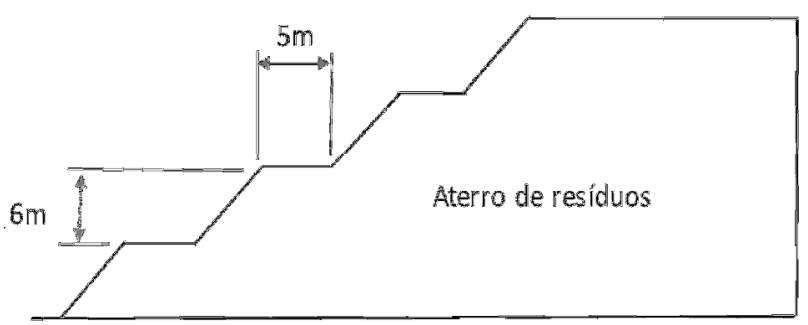

(b)

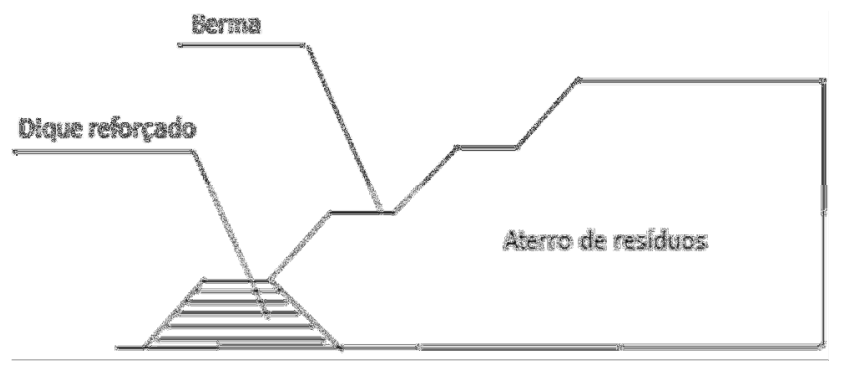

(d)

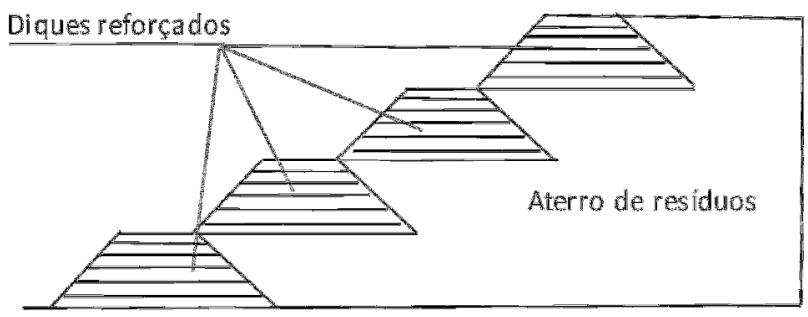

(f)

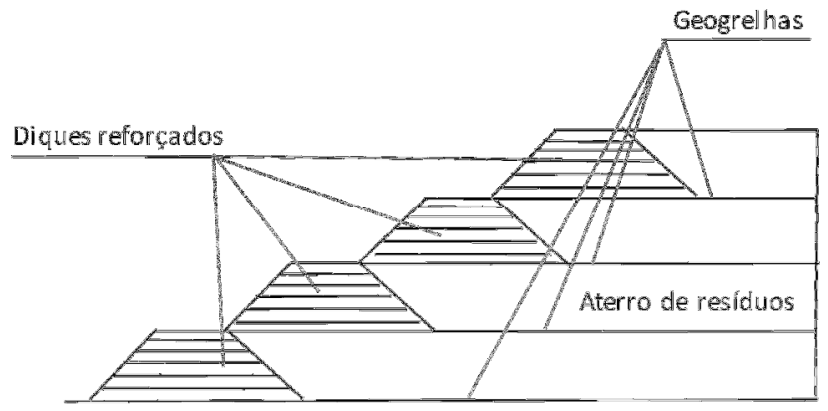

(h)

Figura 3.3 - Configurações estudadas: (a) Dique de solo ou aterro de resíduos de seção trapezoidal; (b) Aterro de resíduos com bermas de equilíbrio; (c) Dique de partida e aterro com bermas; (d) Dique de partida reforçado e aterro com bermas; (e) Diques sucessivos; (f) Diques sucessivos reforçados;

(g) Aterro com diques sucessivos e reforço entre camadas de resíduos; (h) Aterro com diques sucessivos reforçado e reforço entre camadas de resíduos

Dentre os estudos de estabilidade de taludes de lixo, Oliveira (2002) sugere taludes de inclinações máximas de $1 \mathrm{~V}: 1 \mathrm{H}$ com bermas de $6 \mathrm{~m}$ de largura a cada $10 \mathrm{~m}$, para 
alturas máximas de $20 \mathrm{~m}$, para se obter um fator de segurança igual a 1,3. Para aterros com 30m de altura, o autor sugere a adoção de inclinações $1 \mathrm{~V}: 1,5 \mathrm{H}$. Nessas análises utilizaram-se valores de ângulo de atrito entre 20 e $35^{\circ}$, coesão entre 5 e $33 \mathrm{kPa}$ e parâmetro de pressão neutra $r_{u}$ de 0 e 0,2. Os parâmetros de resistência foram determinados por retroanálises de taludes carregados até a ruptura.

\subsection{3 "Software"}

As análises de estabilidade foram realizadas com o "software" SLIDE, da Rocscience. Trata-se um programa específico para análises de estabilidade 2D através de métodos de equilíbrio-limite, dentre os quais Bishop simplificado, Janbu simplificado, Janbu corrigido, Morgenstein-Price, entre outros. O programa permite selecionar, para cada material, o peso específico, o parâmetro de pressão neutra, o critério de resistência e os parâmetros de resistência correspondentes.

O programa também desenha redes de fluxo, cujos resultados (pressões neutras, gradientes hidráulicos e vazões) podem ser utilizados nas análises de estabilidade.

As análises de estabilidade foram realizadas utilizando-se os métodos de Bishop Simplificado (ruptura circular).

As hipóteses adotadas nas análises de estabilidade foram:

- Solo do dique e massa de resíduos homogêneos e isotrópicos;

- Reforço geossintético homogêneo;

- Materiais não saturados;

- Solo de fundação com resistência infinita;

- Pressões neutras de compactação, sobrecarga das camadas sobrejacentes, infiltração de águas pluviais e geração de lixiviado e gases representadas conjuntamente pelo parâmetro de pressão neutra $r_{u}$;

- Reforços geossintéticos ancorados em ambas as extremidades (não ocorre deslizamento). 
- Orientação da contribuição do reforço: bissetriz entre a paralela e a tangente à superfície de ruptura.

O critério de resistência adotado para os solos e RSU foi o de Mohr-Coulomb.

\subsubsection{Metodologia}

Inicialmente, foram estudadas diferentes geometrias de aterros de resíduos em talude único, variando-se a inclinação do talude de $0,5 \mathrm{H}: 1 \mathrm{~V}$ a $3 \mathrm{H}: 1 \mathrm{~V}$ e as alturas de aterro $(\mathrm{H}=6 \mathrm{~m}, \mathrm{H}=15 \mathrm{~m}$ e $\mathrm{H}=30 \mathrm{~m})$, conforme Figura 3.3a.

Para analisar a estabilidade local dos diques sem reforço, foram investigadas diferentes geometrias, avaliando-se inclinações do talude de $1 \mathrm{H}: 0,75 \mathrm{~V}$ a $1 \mathrm{H}: 2 \mathrm{~V}$ e três alturas de dique $(\mathrm{H}=5 \mathrm{~m}, \mathrm{H}=6 \mathrm{~m}$ e $\mathrm{H}=7 \mathrm{~m})$, para rupturas do tipo circular, conforme Figura 3.3a. Visando um fator de segurança mínimo de 1,5 e com base nos resultados obtidos, adotou-se como configuração final um dique de $6 \mathrm{~m}$ de altura e taludes com inclinação de 1H:1V.

$\mathrm{Na}$ sequencia foram estudadas as situações de aterro de resíduos construído com bermas de RSU (Figura 3.3b) e a partir de um dique de partida de solo sem e com reforço (Figura 3.3c e Figura 3.3d), para as alturas de 6, 12, 18, 24, 30, 36, 42 e $48 \mathrm{~m}$. As inclinações dos taludes, de RSU ou de solo (reforçado ou não) foram sempre de $1 \mathrm{H}: 1 \mathrm{~V}$. O reforço geossintético utilizado nos diques apresenta resistência a tração de projeto de $100 \mathrm{kN} / \mathrm{m}$.

Em seguida foi analisada a situação de aterro construído em bermas a partir de diques sucessivos sem reforço (Figura 3.3e) e com reforço (Figura 3.3f). Por fim, foram analisadas as configurações de diques sucessivos e maciço reforçado com geogrelhas com resistência de projeto de $400 \mathrm{kN} / \mathrm{m}$, posicionadas no interior da massa de resíduo, a cada $6 \mathrm{~m}$ de altura (Figura $3.3 \mathrm{~g}$ ) e diques sucessivos reforçados e maciço reforçado com geogrelhas (Figura 3.3h), para alturas de 6, 12, 18, 24, 30, 26,42 e $48 m$.

As análises foram realizadas considerando-se o parâmetro $r_{u}$ variando de 0,0 a 0,3. 
Os fatores de segurança admitidos foram definidos com base na NBR-11682 "Estabilidade de Encostas" (ABNT, 2009), segundo a qual o fator de segurança (FS) mínimo recomendado para situação definitiva é de 1,5, para nível alto de segurança contra danos materiais e ambientais e nível médio de segurança contra perda de vidas humanas.

\subsection{ANÁLISE TENSÃO-DEFORMAÇÃO}

\subsubsection{Materiais}

Os materiais que compõem o dique, RSU e solo de fundação considerados nas análises de tensão-deformação foram os mesmos das análises de estabilidade por métodos de equilíbrio limite.

A inserção da geogrelha no interior do maciço de RSU foi simulada de duas formas: (1) considerando a compatibilidade de deformações entre o reforço e os materiais adjacentes e (2) considerando a existência de uma interface estrutural, com o reforço geossintético (geogrelha) inserido no meio de uma camada granular (areia), possibilitando o escorregamento e diferença entre as deformações do reforço e o material adjacente.

Os parâmetros dos materiais utilizados nas análises tensão-deformação estão apresentados nas

Tabela 3.2 e Tabela 3.3. 
Tabela 3.2 - Parâmetros adotados para solos e RSU.

\begin{tabular}{|c|c|c|c|c|c|c|}
\hline \multirow[b]{3}{*}{ Material } & \multirow{3}{*}{$\begin{array}{c}\text { Peso } \\
\text { específico } \\
\gamma\left(\mathrm{kN} / \mathrm{m}^{3}\right)\end{array}$} & \multicolumn{4}{|c|}{ Parâmetros } & \multirow{3}{*}{$\begin{array}{l}\text { Comportamento } \\
\text { reológio }\end{array}$} \\
\hline & & \multicolumn{2}{|c|}{ Elásticos } & \multicolumn{2}{|c|}{ Plásticos } & \\
\hline & & $\begin{array}{c}\text { Módulo de } \\
\text { elasticidade } \\
\text { E (MPa) }\end{array}$ & $\begin{array}{c}\text { Coef. de } \\
\text { Poisson } \\
\text { v }\end{array}$ & $\begin{array}{l}\text { Coesão } \\
\text { c (kPa) }\end{array}$ & $\begin{array}{c}\text { Ângulo } \\
\text { de atrito } \\
\phi\left(^{\circ}\right)\end{array}$ & \\
\hline $\begin{array}{l}\text { Argila compactada } \\
\text { (diques periféricos) }\end{array}$ & 18 & 20 & 0,30 & 10 & 30 & Material \\
\hline RSU compactados & 11 & 3 & 0,33 & 13,5 & 22 & $\begin{array}{c}\text { isotrópico / } \\
\text { Critério de } \\
\text { Mohr-Coulomb }\end{array}$ \\
\hline Solo de fundação & - & 50 & 0,30 & 25 & 30 & \\
\hline
\end{tabular}

Para a camada granular, utilizada como material da interface estrutural entre a geogelha e os RSU, foram adotados os parâmetros default do software PHASE2.

Tabela 3.3 - Parâmetros adotados para a camada granular (interface estrutural)

\begin{tabular}{|c|c|c|c|}
\hline Material & Areia & Rigidez normal (kPa/m) & 100000 \\
\hline Coesão(kPa) & 0 & $\begin{array}{l}\text { Rigidez ao cisalhamento } \\
(\mathrm{kPa} / \mathrm{m})\end{array}$ & 10000 \\
\hline Ângulo de atrito $\left({ }^{\circ}\right)$ & 35 & Critério de ruptura & Mohr-coulomb \\
\hline Resistência a tração (kPa) & 0 & & \\
\hline
\end{tabular}

As geogrelhas foram utilizadas no reforço dos diques (posicionadas a cada $1 \mathrm{~m}$ de altura) e no maciço sanitário (a cada $6 \mathrm{~m}$ ). $\mathrm{O}$ reforço nos diques tem o intuito de garantir o fator de segurança à estabilidade local do talude, enquanto o reforço no interior do maciço sanitário tem por objetivo garantir a estabilidade global do maciço. Utilizaram-se geogrelhas com diferentes resistências a tração para cada caso (Tabela 3.4). 
Tabela 3.4 - Parâmetros de resistência das geogrelhas

\begin{tabular}{lccc}
\hline $\begin{array}{c}\text { Geogrelha utilizada } \\
\text { para o reforço }\end{array}$ & Material & $\begin{array}{c}\text { Módulo de tração } \\
(\mathrm{kN} / \mathrm{m})\end{array}$ & $\begin{array}{c}\text { Resistência à tração } \\
\text { de pico } \\
(\mathrm{kN} / \mathrm{m})\end{array}$ \\
\hline & Elasto-plástico & 4000 & 100 \\
Dique & Elasto-plástico & 12000 & 400 \\
Maciço de RSU & & & \\
\hline
\end{tabular}

Obs.: Parâmetros obtidos do Guia de Características Técnicas de Geossintéticos de Reforço Geotécnico da Huesker (2009)

\subsubsection{Geometria estudada}

Para as análises tensão-deformação foram estudadas quatro configurações de alteamento:

- Diques sucessivos;

- Diques sucessivos reforçados;

- Diques sucessivos e maciço sanitário reforçado;

- Diques sucessivos reforçados e maciço sanitário reforçado.

Os diques sucessivos são reforçados com geogrelhas posicionadas a cada $1 \mathrm{~m}$ de altura e o maciço é reforçado com geogrelhas a cada $6 \mathrm{~m}$ no interior da massa de resíduos. Cada dique possui $6 \mathrm{~m}$ de altura, $17 \mathrm{~m}$ de largura na base e $5 \mathrm{~m}$ de largura na crista, configurando a geometria do aterro com uma inclinação média de 1,5H:1V. 


\subsection{3 "Software"}

As análises tensão-deformação foram realizadas com o "software" PHASE2 da Rocscience. Este programa permite realizar análises elasto-plásticas em 2D pelo método de elementos finitos para o cálculo de tensões e deslocamentos, podendoser utilizado em diversos problemas de engenharia geotécnica e civil.

O programa permite representar diferentes tipos de solo, adotando-se comportamento elástico ou elasto-plástico. As propriedades elásticas disponíveis permitem simular materiais isotrópicos, transversalmente isotrópicos, ortotrópicos e hiperbólicos. Os critérios de ruptura podem ser escolhidos entre Mohr-Coulomb, Hoek-Brown, Drucker-Prager, Drucker-Prager generalizado, Cam-Clay e Cam-Clay modificado.

As geogrelhas podem ser modeladas considerando-se os parâmetros de interface, no qual são inseridos parâmetros de elasticidade e resistência das geogrelhas e dos materiais adjacentes, assim como condições de engastamento da geogrelha; caso seja adotada a hipótese de compatibilidade de deformações, dá-se entrada somente aos parâmetros da geogrelha.

As saídas do programa permitem obter, para cada fase de carregamento, os valores das tensões principais e desviadoras, deslocamentos verticais e horizontais, deformações volumétricas, máxima deformação cisalhante, entre outros.

O "software" ainda permite a verificação da estabilidade do aterro, com a determinação do fator de segurança, através da função "Strength Reduction Factor", que reduz os parâmetros de resistência dos materiais até que seja atingida a ruptura.

\subsubsection{Metodologia}

Primeiramente, foram estabelecidas as mesmas inclinações de talude, largura dos diques periféricos e posicionamento dos reforços utilizados nas análises de estabilidade pelos métodos de equilíbrio limite. 
As hipóteses adotadas nas análises tensão-deformação foram:

- Solo do dique e massa de resíduos homogêneos e isotrópicos;

- Reforço geossintético homogêneo;

- Materiais não saturados;

- Pressões neutras de compactação, sobrecarga das camadas sobrejacentes, infiltração de águas pluviais e geração de lixiviado e gases consideradas indiretamente nos parâmetros dos RSU, obtidos de ensaios "in situ" realizados em aterros sanitários;

Estabeleceu-se a altura de $48 \mathrm{~m}$ para o maciço sanitário.

Nas análises tensão-deformação foram analisadas duas configurações:

- diques sucessivos

- diques sucessivos reforçados

- diques sucessivos e maciço reforçado

- diques sucessivos reforçados e maciço reforçado.

A malha utilizada no modelo é constituída por cerca de 2000 elementos triangulares com 6 nós, distribuídos de forma uniforme. As condições de contorno foram definidas com o solo de fundação fixo e o eixo de simetria permitindo somente deslocamentos verticais. A Figura 3.4 ilustra a malha de elementos utilizada e as condições de contorno consideradas. 


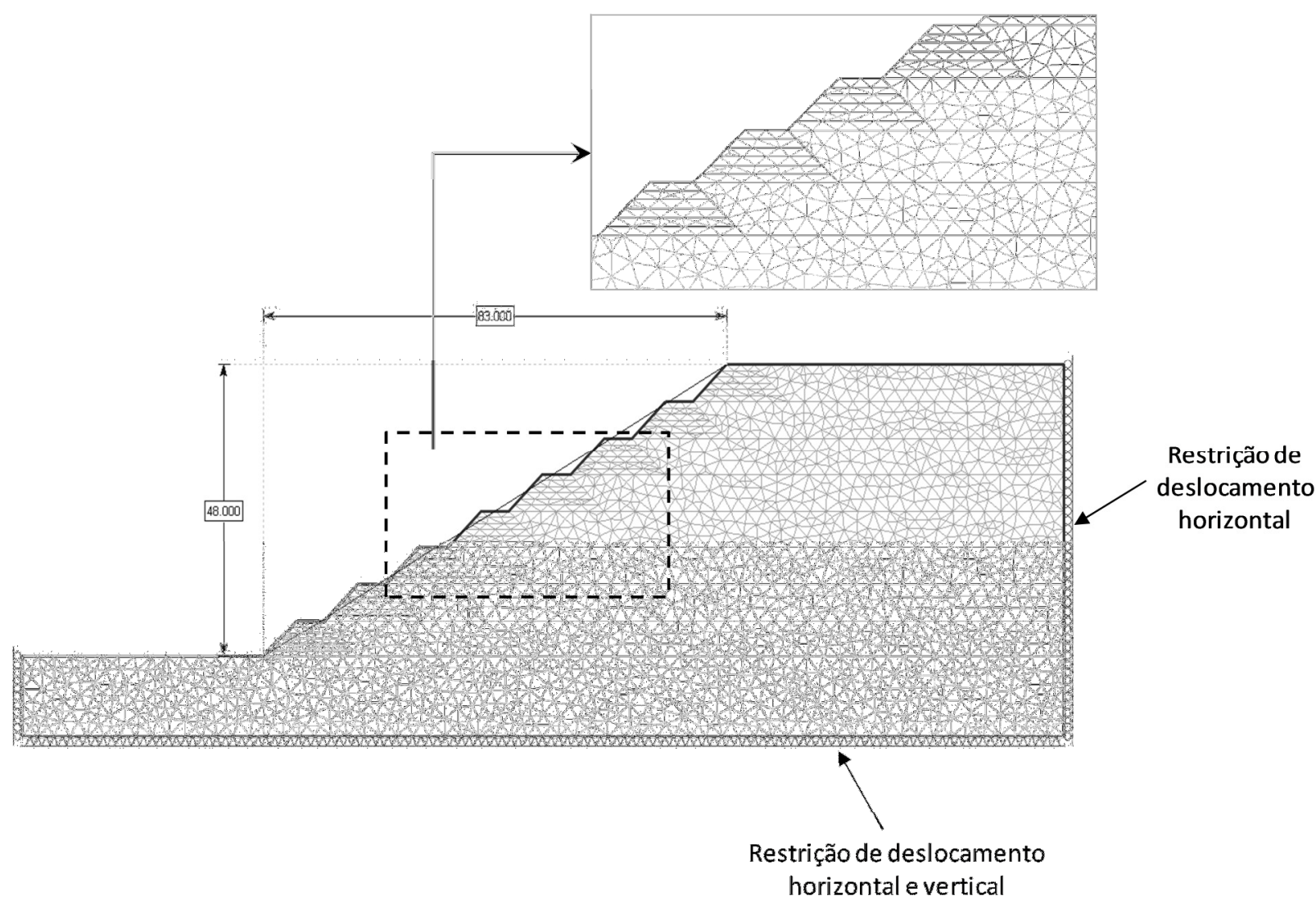

Figura 3.4 - Malha de elementos finitos

As etapas construtivas foram definidas em 16 estágios. O primeiro estágio consistiu na construção do primeiro dique, sobreposto à geogrelha disposta sobre a fundação (a mesma geogrelha utilizada no maciço sanitário). O segundo estágio correspondeu à execução da camada de RSU desde o nível da fundação até o nível da crista do primeiro dique. No terceiro estágio colocou-se a geogrelha sobre a camada de resíduos e executou-se o segundo dique. O quarto estágio correspondeu à execução da camada de RSU desde o nível da crista do primeiro dique até a crista do segundo dique, e assim sucessivamente. Em suma, os estágios compreenderam a colocação da geogrelha mais resistente sobre os resíduos, a construção de um dique e o preenchimento da região a montante do dique com RSU até o nível da crista, sucessivamente.

Ao final de cada estágio foram tabelados os valores máximos de deslocamento vertical, horizontal e total e os fatores de segurança, conforme exemplificado nas Figura 3.5 Figura 3.8. O fator de segurança foi determinado através da função 
"Strength Reduction Factor" a cada dois estágios ou a cada camada de 6m de resíduos.

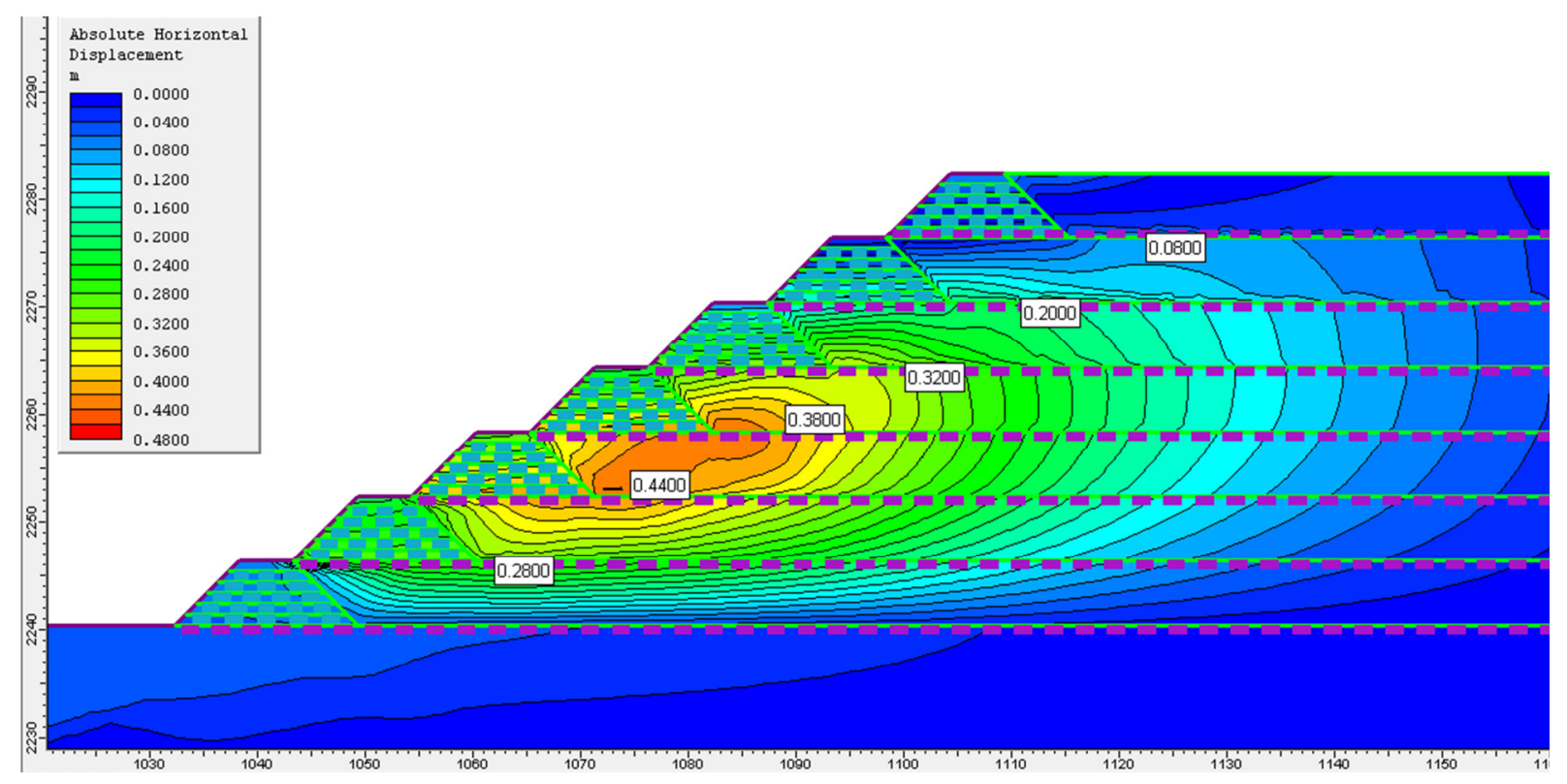

Figura 3.5 - Deslocamentos horizontais absolutos

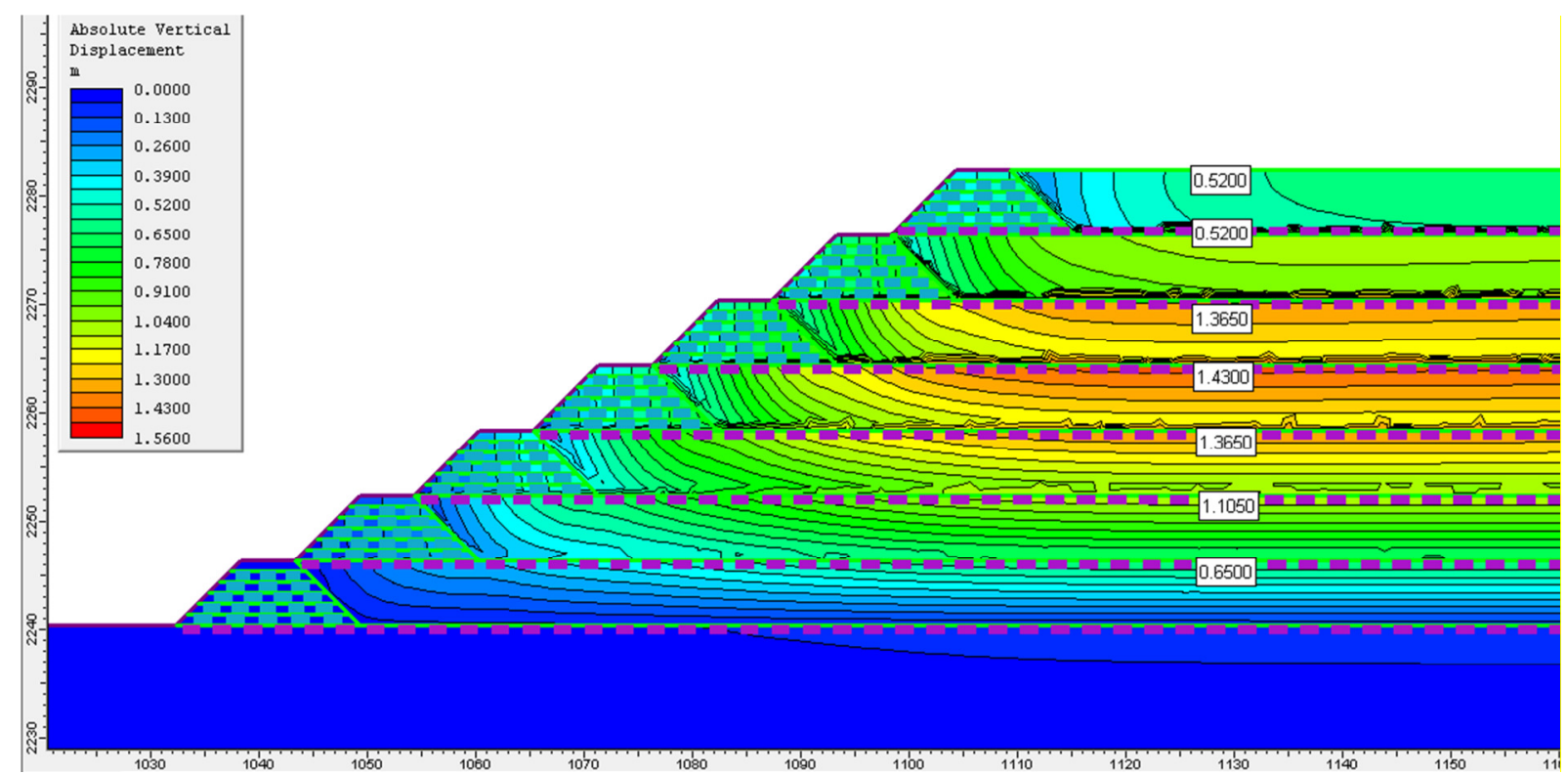

Figura 3.6 - Deslocamentos verticais absolutos 


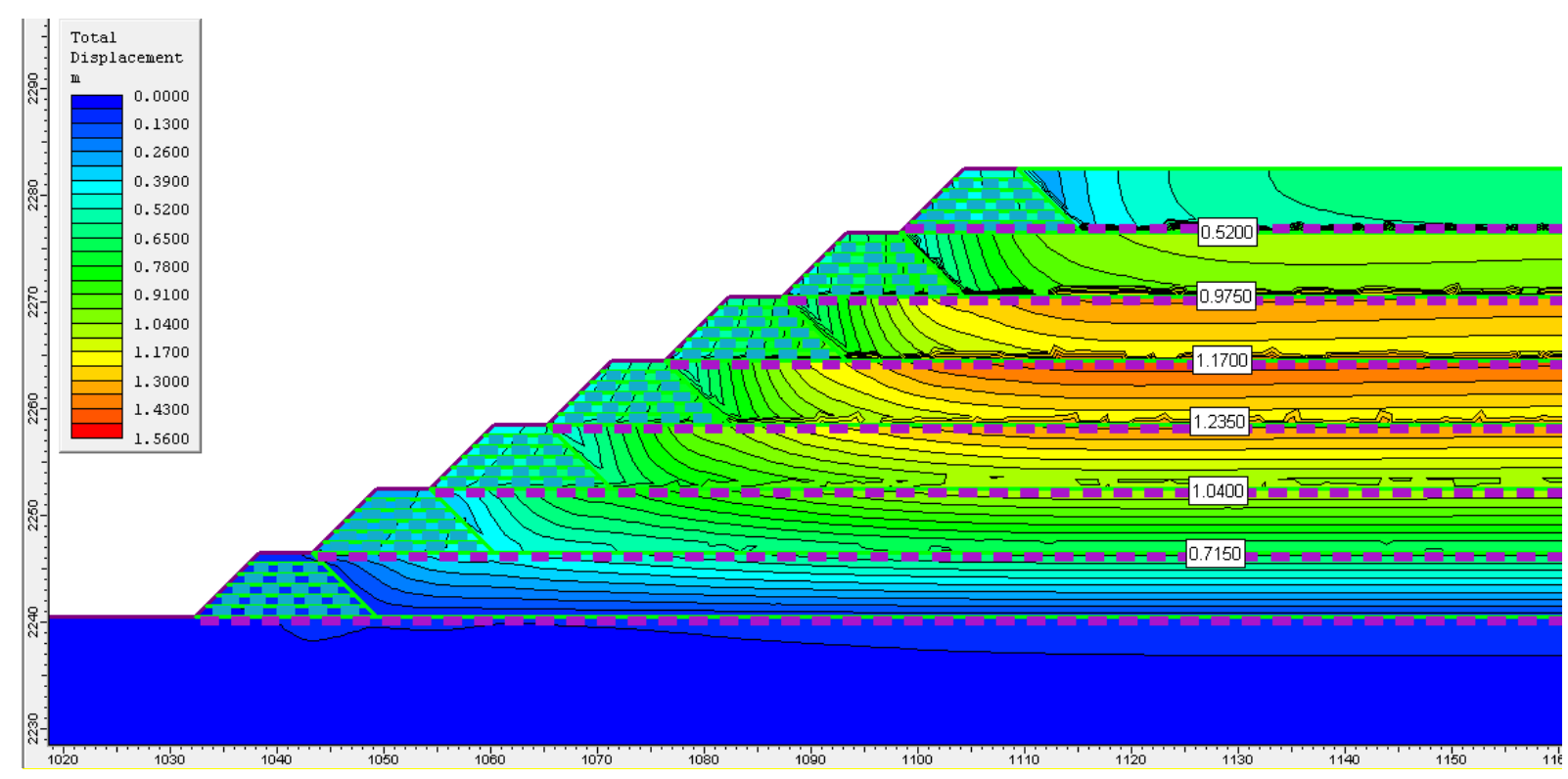

Figura 3.7 - Deslocamentos totais

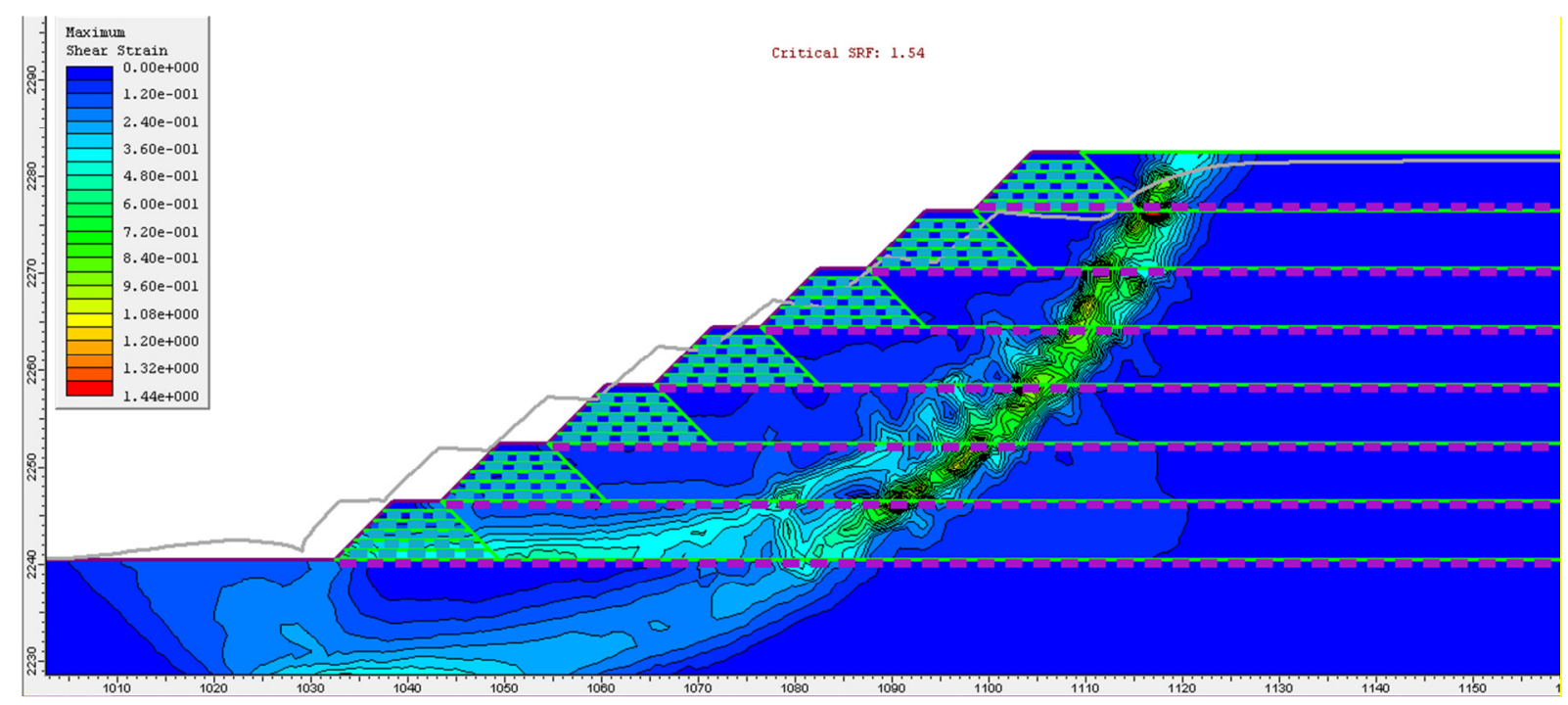

Figura 3.8 - Máxima tensão de cisalhamento (com contorno da superfície deformada)

As análises foram inicialmente realizadas com as geogrelhas inseridas no modelo através da função "liner" disponível no "software", que permite representar o reforço como elemento de barra ou geossintético (geotêxtil, geogrelha etc.). Neste caso, a geogrelha foi representada como um elemento geossintético com parâmetros elástico (módulo de tração) e plástico (resistência à tração de pico).

Depois de terem sido simuladas as quatro configurações propostas, aprofundou-se o estudo da interação das geogrelhas com o maciço de RSU repetindo-se algumas situações com as geogrelhas inseridas no modelo através da função "structural 
interface" (interface estrutural) disponível no "software", que permite o deslizamento entre a geogrelhas e as camadas adjacentes. São representados os materiais que envolvem o reforço por meio de parâmetros relativos ao critério de ruptura adotado, neste caso Mohr-Coulomb, parâmetros de rigidez normal e cisalhante, e valores de pressão neutra no contato. O objetivo foi representar a situação de construção em campo, que é a colocação da geogrelha entre duas camadas de areia. 


\section{APRESENTAÇÃO E ANÁLISE DOS RESULTADOS}

\subsection{ANÁLISE DE ESTABILIDADE POR MÉTODOS DE EQUILÍBRIO LIMITE}

Os fatores de segurança obtidos para diferentes alturas e inclinações de talude de aterro de resíduos, para valores de $r_{u}$ variando de 0,0 a 0,3, para a configuração em seção trapezoidal são apresentados nas Figuras 4.1 a 4.3.

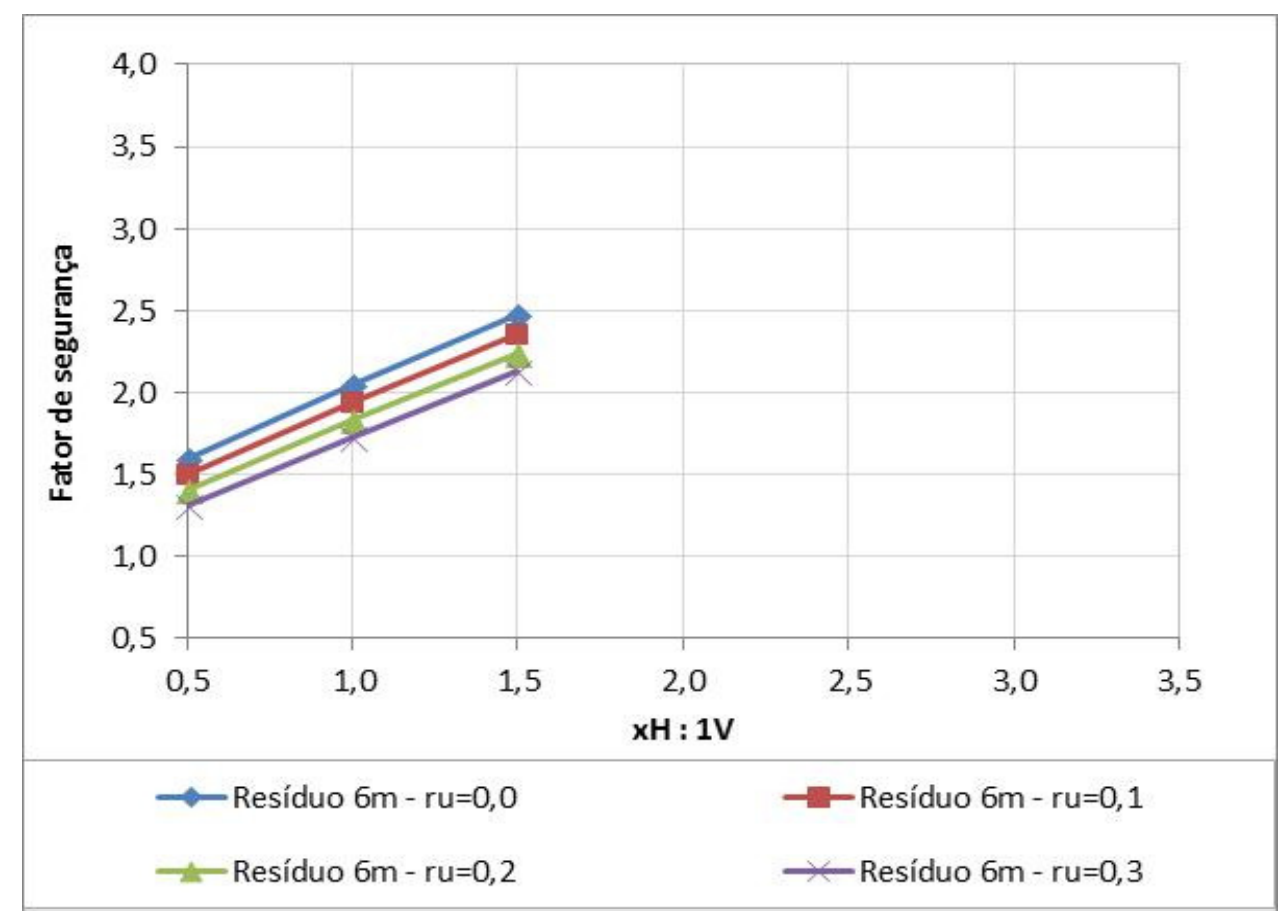

Figura 4.1- Fatores de segurança para aterro de resíduos com altura de $6 \mathrm{~m}$. 


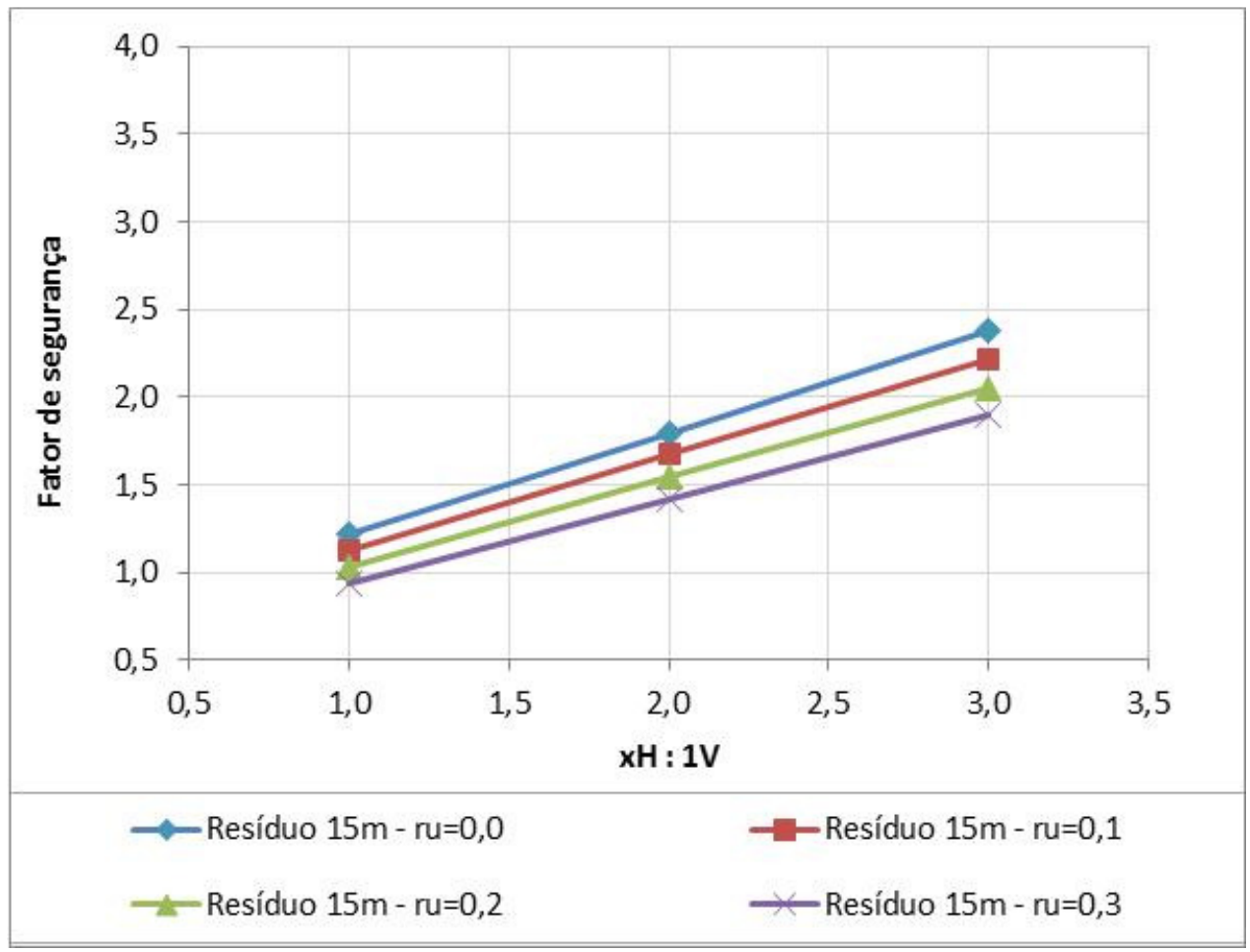

Figura 4.2 - Fatores de segurança para aterro de resíduos com altura de 15m.

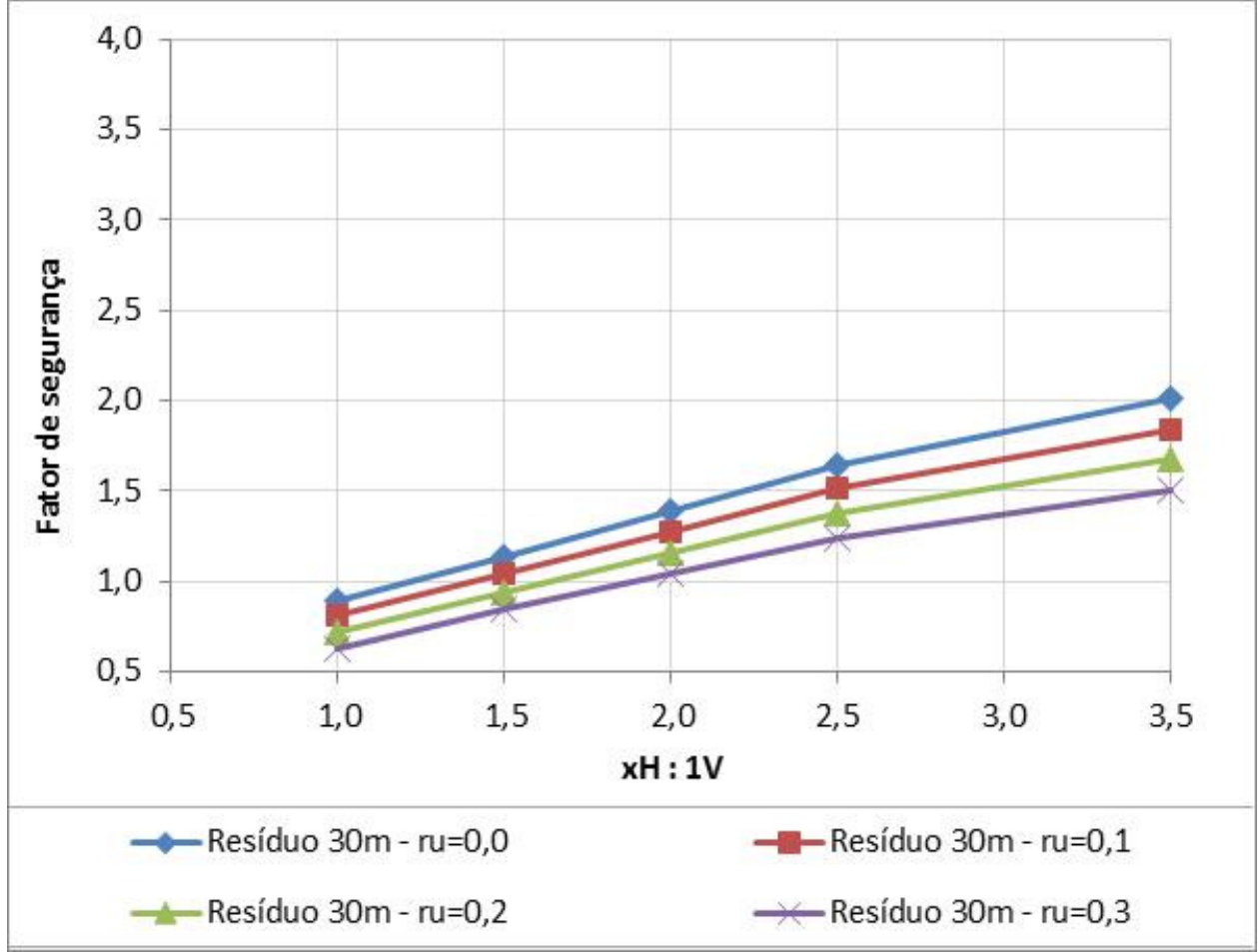

Figura 4.3 - Fatores de segurança para aterro de resíduos com altura de 30m

Os resultados apresentados na Figura 4.1 indicam que para o aterro de resíduos em talude único com $6 \mathrm{~m}$ de altura o FS de 1,5 seria atendido com taludes iguais ou mais abatidos do que $1 \mathrm{H}: 1 \mathrm{~V}$ para qualquer valor de $r_{u}$ entre 0 e 0,3. Para as alturas 
de $15 \mathrm{~m}$ e $30 \mathrm{~m}$, o FS de 1,5 seria atendido com taludes com inclinação mínima de 2,2H:1V (interpolado graficamente) e 3,5H:1V, respectivamente.

Na Figura 4.4 é apresentado um resumo dos resultados para diferentes alturas de aterro de resíduos e diferentes valores de $r_{u}$.

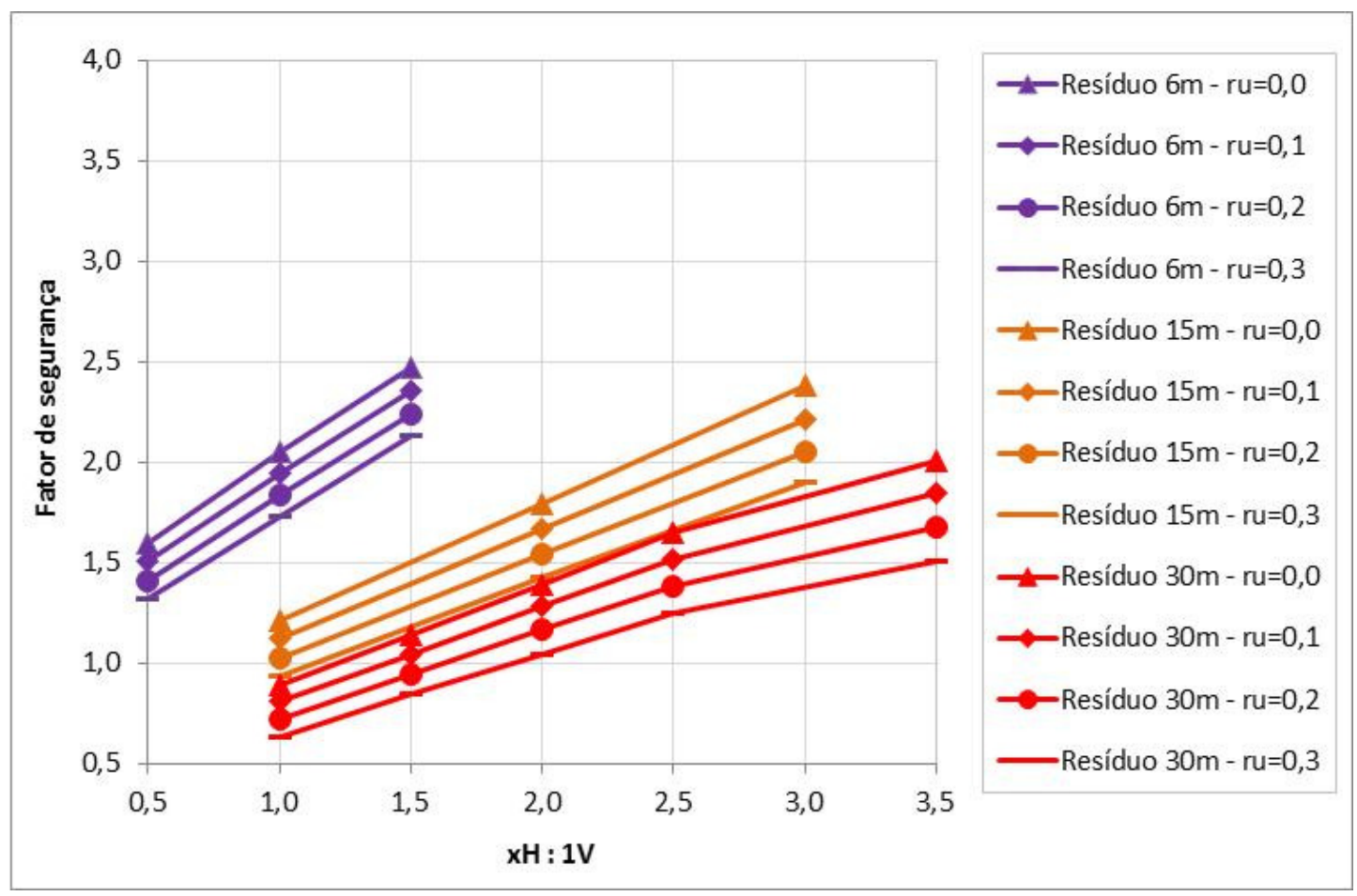

Figura 4.4 - Variação do fator de segurança com a altura e inclinação do aterro de resíduos

O fator de segurança para um aterro de $6 \mathrm{~m}$ na condição seca $\left(r_{u}=0\right)$ é maior do que 1,5 para as inclinações possíveis e praticáveis pelo método de compactação em rampa.

Na Figura 4.4 verifica-se a diminuição do fator de segurança com o aumento do valor de $r_{u}$. A diminuição no fator de segurança, variando-se o $r_{u}$ de 0,0 a 0,3 , chega a $17 \%$ no aterro de resíduo com altura de $6 \mathrm{~m}, 23 \%$ no aterro com $15 \mathrm{~m}$ e $29 \%$ no aterro com $30 \mathrm{~m}$, ou seja, o fator de segurança diminui quanto maior for o valor do $r_{u}$ e maior for a altura do aterro de resíduos.

Os fatores de segurança para diques de solo compactado com seção trapezoidal, parâmetro de pressão neutra variando de 0 a 0,3, e alturas de $5 \mathrm{~m}, 6 \mathrm{~m}$ e $7 \mathrm{~m}$ são apresentadas, respectivamente, nas Figuras 4.5 a 4.7. 


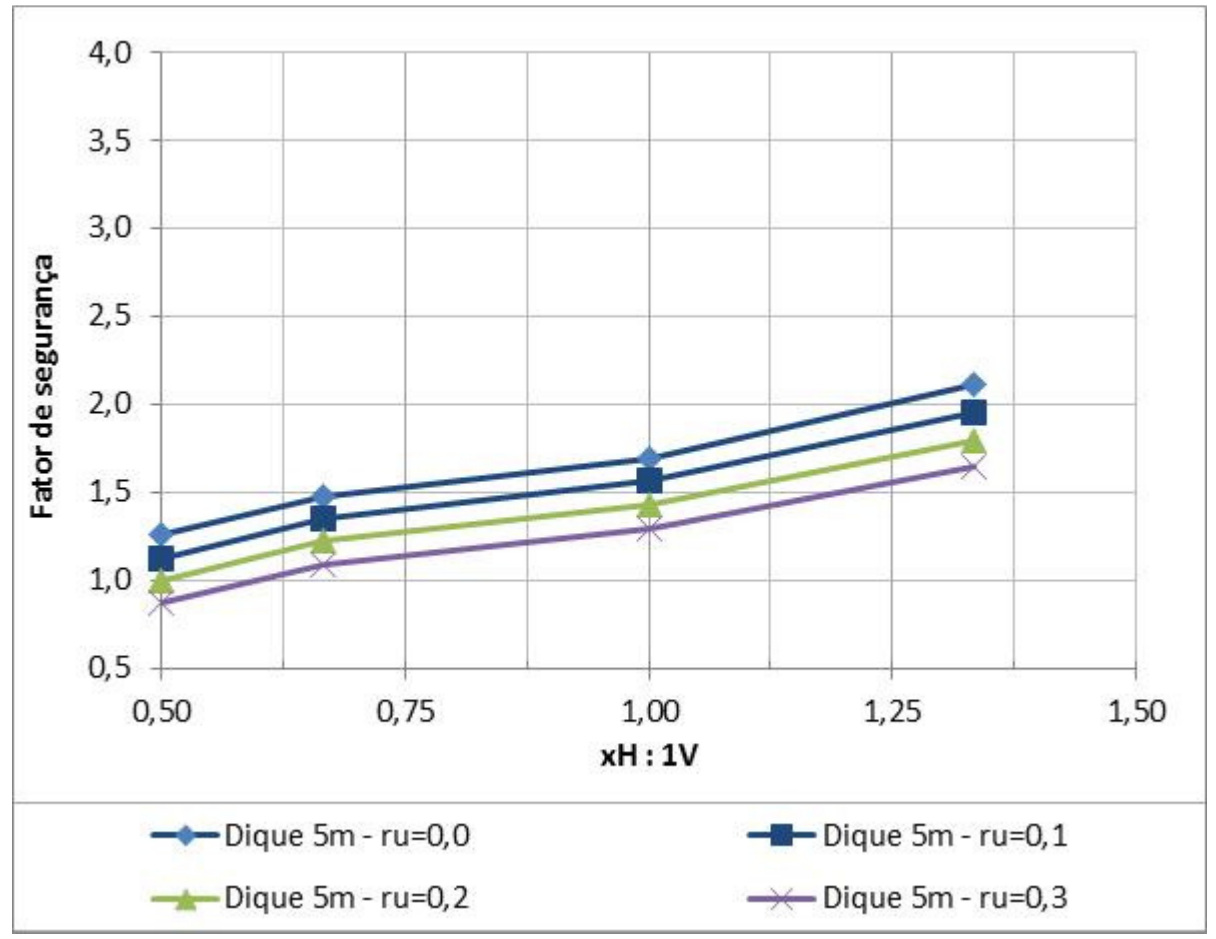

Figura 4.5 - Fatores de segurança para dique de solo com $5 \mathrm{~m}$

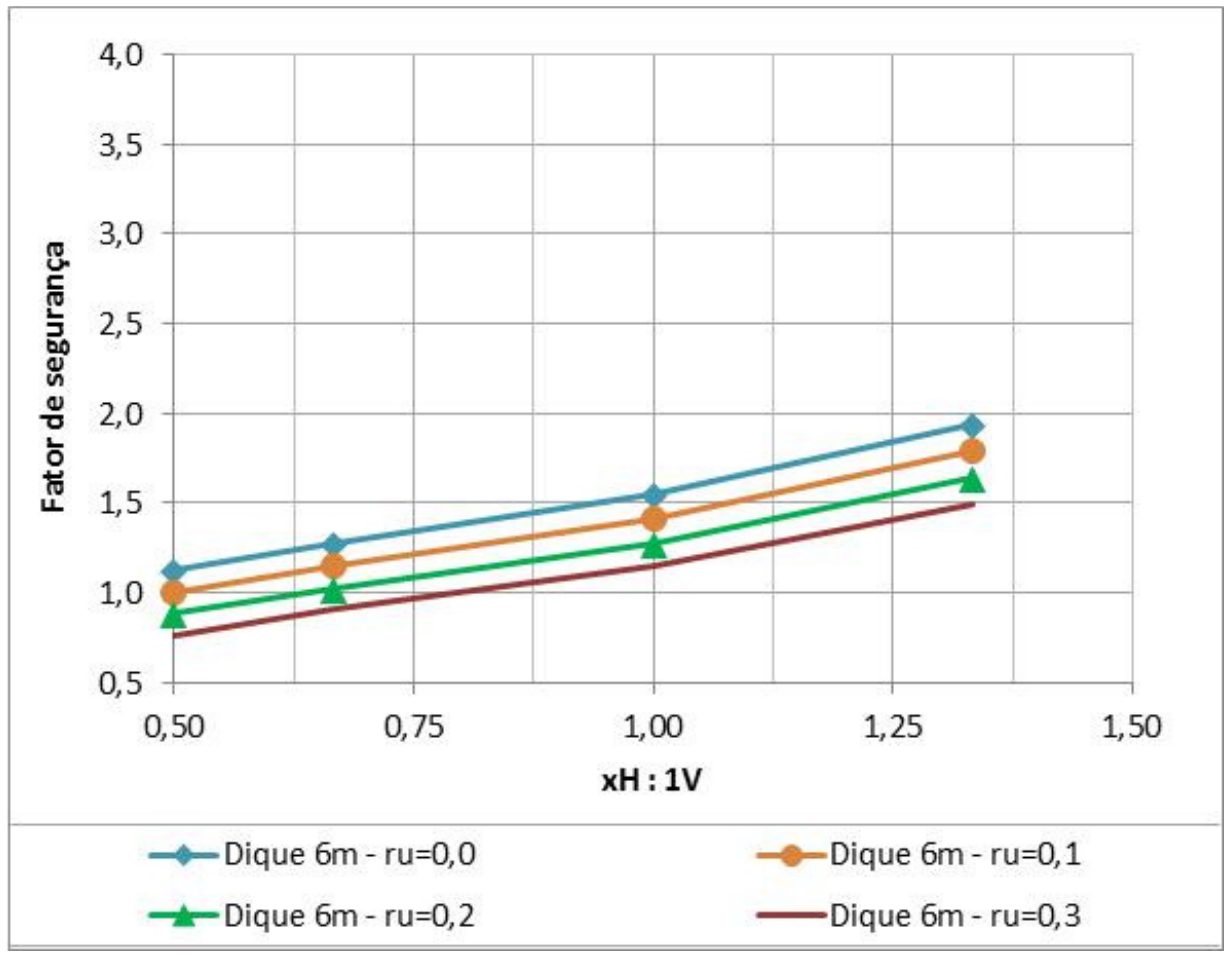

Figura 4.6 - Fatores de segurança para dique de solo com 6m 


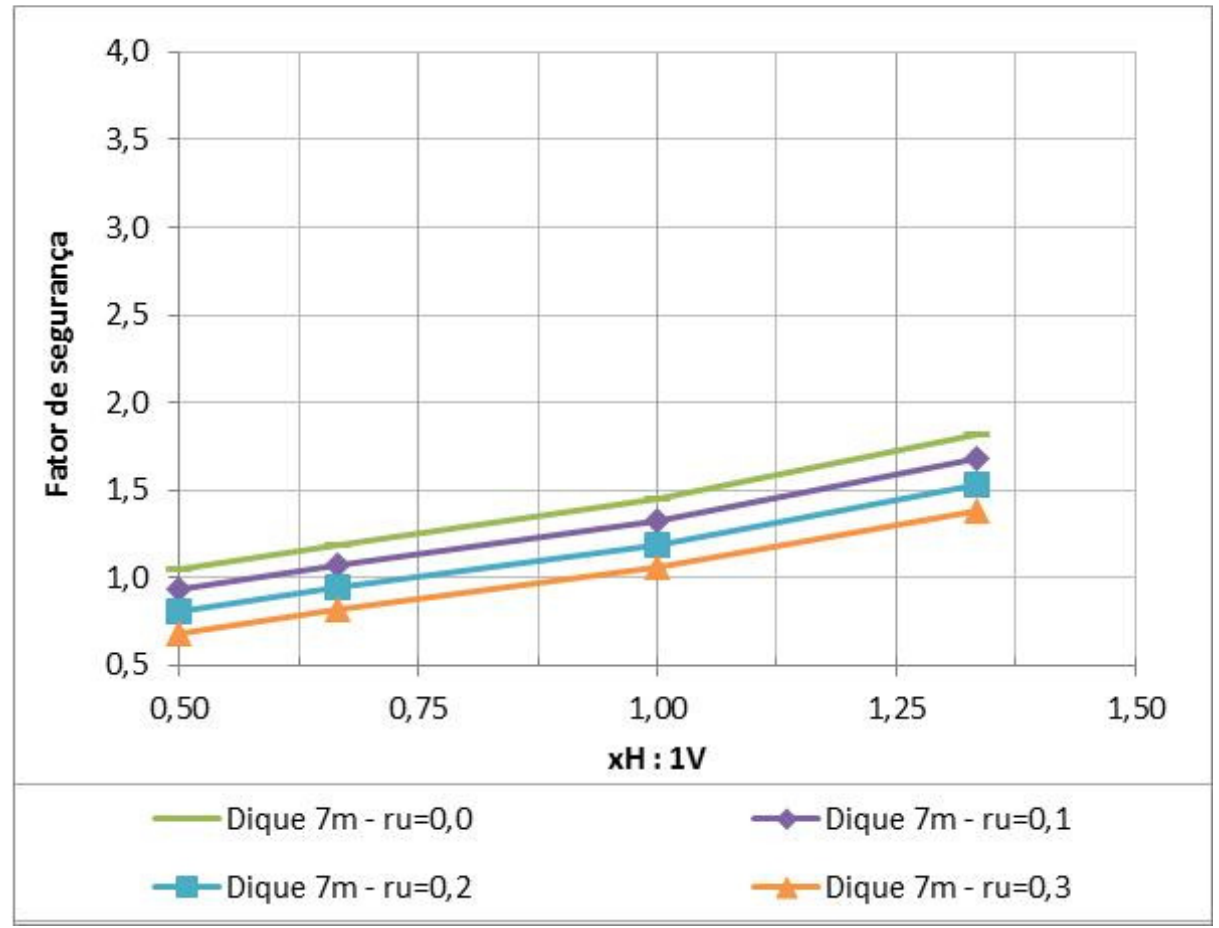

Figura 4.7 - Fatores de segurança para dique de solo com $7 \mathrm{~m}$.

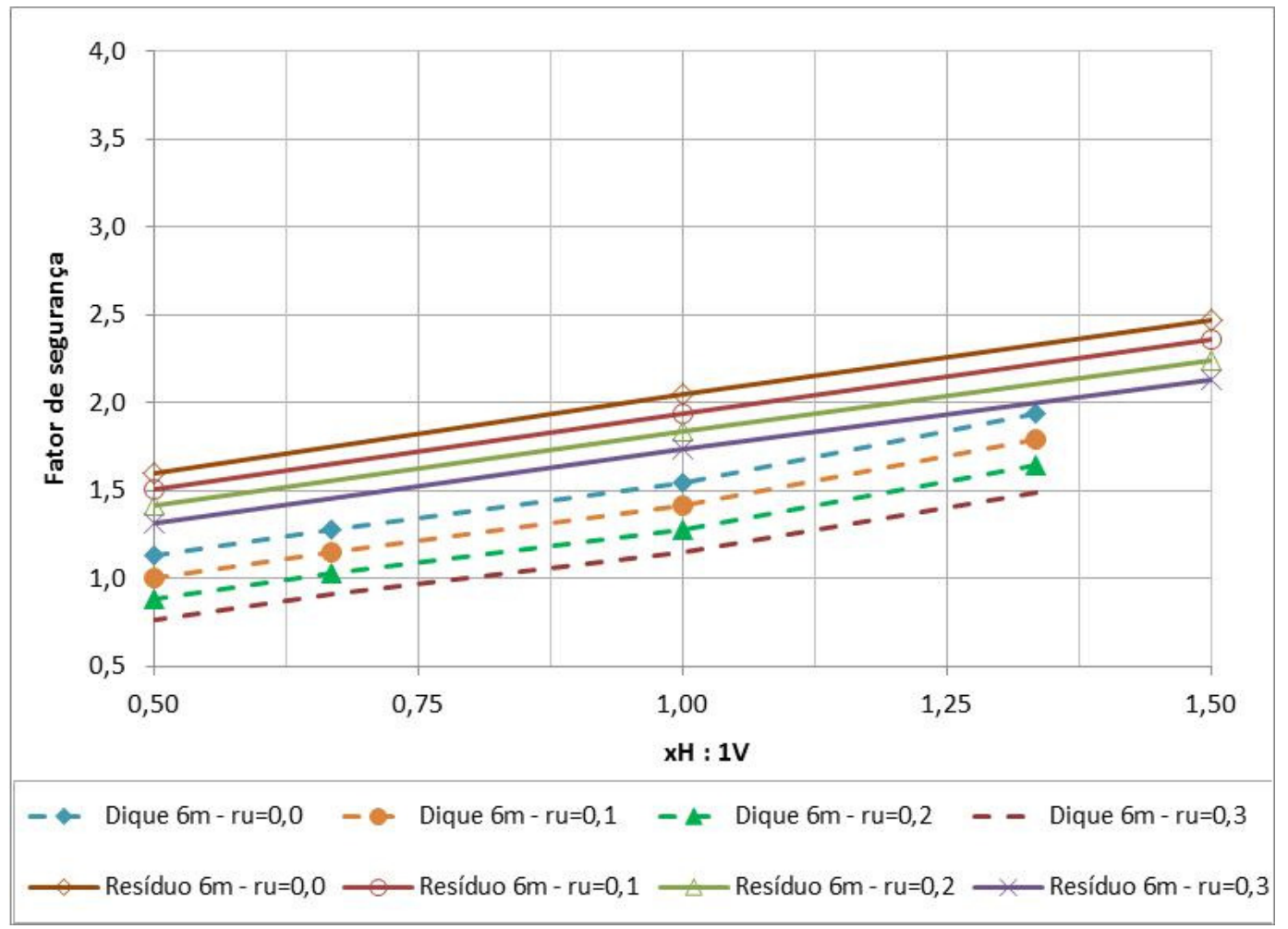

Figura 4.8 - Comparação entre fatores de segurança para dique de solo e aterro de resíduos com mesma altura

O fator de segurança de final de construção adotado para barragens de solo compactado é da ordem de 1,2 a 1,3. O ru é da ordem de 0,1 a 0,2 (Cruz, 1996). O 
fator de segurança igual a 1,2 é atingido para as alturas de $5 \mathrm{~m}$ e $6 \mathrm{~m}$ com inclinação de $1 \mathrm{H}: 1 \mathrm{~V}$ mesmo para $r_{u}=0,3$. Entretanto, para $7 \mathrm{~m}$ e $r_{u}=0,2$, o fator de segurança já é ligeiramente inferior a 1,2. Os diques de solo compactado com alturas de 5, 6 e 7 m necessitariam taludes com inclinação, 0,70H:1,0V, 0,95H:1,0V e 1,12H:1,0V, respectivamente, para $r_{u}=0$. Para $r_{u}=0,2$ as inclinações mínimas necessárias passam para $1,07 \mathrm{H}: 1,0 \mathrm{~V}, 1,2 \mathrm{H}: 1,0 \mathrm{~V}$ e $1,3 \mathrm{H}: 1,0 \mathrm{~V}$. Com base nesses resultados, adotou-se talude de $1 \mathrm{H}: 1 \mathrm{~V}$ para o dique de partida e para os demais diques. Os taludes das bermas também foram adotados como $1 \mathrm{H}: 1 \mathrm{~V}$, o que corresponde a um fator de segurança de 1,5 para a ruptura local.

Os resultados apresentados na Figura 4.8 mostram que o método de análise de equilíbrio limite para aterro sanitário deve ser aplicado com cautela, uma vez que podem levar a resultados nem sempre confiáveis, conforme observado. Neste caso, como a coesão aparente dos RSU é superior à considerada para a argila, devido ao teor de fibras, e o peso específico é muito menor, os resultados mostraram que aparentemente é mais seguro a execução de um aterro de resíduos com $6 \mathrm{~m}$ (parâmetros: $C=13,5 \mathrm{kPa}, \varphi=22^{\circ}$ e $\gamma=11 \mathrm{kN} / \mathrm{m}^{3}$ ) do que de um dique de argila compactada de mesma altura (parâmetros: $\mathrm{c}=10 \mathrm{kPa}, \varphi=30^{\circ}$ e $\gamma=18 \mathrm{kN} / \mathrm{m}^{3}$ ). Além disso, o $r_{u}$ de aterros de solo compactado em final de construção é conhecido $(<0,2)$, enquanto o do aterro sanitário não é tão conhecido (Benvenuto, 2010).

Os resultados das análises para o aterro de resíduos construído com taludes e bermas para diferentes valores de $r_{u}$ são apresentados na Figura 4.9. Nota-se que 0 FS de 1,5 é atendido com 10 e $18 \mathrm{~m}$, para $r_{u}=0,3$ e $r_{u}=0,0$, respectivamente. $A$ estabilidade $(F S \geq 1,0)$ é garantida para alturas inferiores a $25 \mathrm{~m}$ para $r_{u}=0,3,36 \mathrm{~m}$ para $r_{u}=0,2,42 \mathrm{~m}$ para $r_{u}=0,1$, assim como para $48 \mathrm{~m}$, altura máxima analisada, quando $r_{u}=0$. $O$ aumento do $r_{u}$ de 0 a 0,3 reduz em média cerca de $23,5 \%$ o fator de segurança para esta configuração de aterro sanitário.

A execução de aterros sanitários com esta configuração proposta de taludes e bermas resulta em um talude médio equivalente de $1,8 \mathrm{H}: 1,0 \mathrm{~V}$, cujo fator de

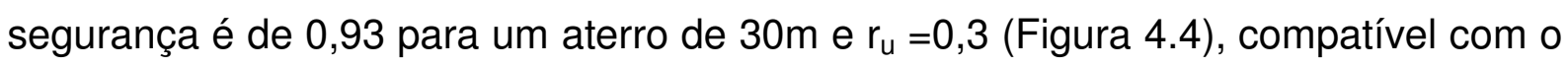
obtido na Figura 4.9. 


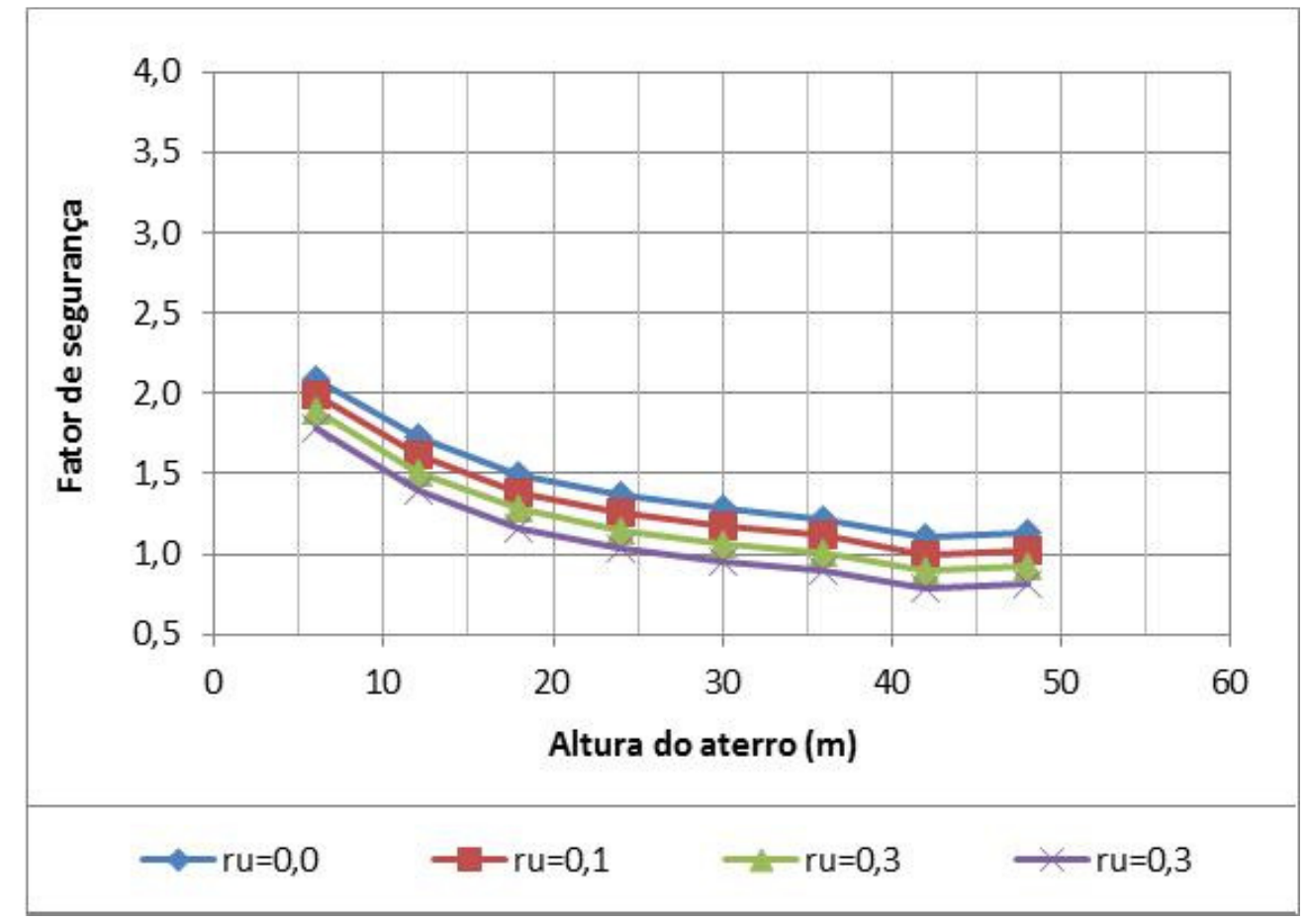

Figura 4.9 - Fatores de segurança para a configuração de aterro com bermas

A configuração composta de um dique de partida de solo compactado (reforçado ou não) e taludes e bermas nas demais etapas construtivas resulta em um aumento no valor do fator de segurança para alturas menores que $18 \mathrm{~m}$. Para alturas superiores, as superfícies de ruptura passam fora dos limites do dique de partida e a utilização do reforço geossintético não contribui para o aumento do fator de segurança. $O$ reforço geossintético no dique de partida proporciona um aumento considerável do FS para a segunda berma (aterro com 18m) e $r_{u}=0$, passando de 1,56 a 1,73; contudo, para as alturas subsequentes, os fatores de segurança são iguais ao caso de dique de partida não reforçado. Para $r_{u}=0,1$ o reforço mostra-se eficiente para alturas de até $18 \mathrm{~m}$ e para $r_{u}=0,2$ e 0,3 até $12 \mathrm{~m}$, conforme apresentado nas Figura 4.10 e 4.11. 


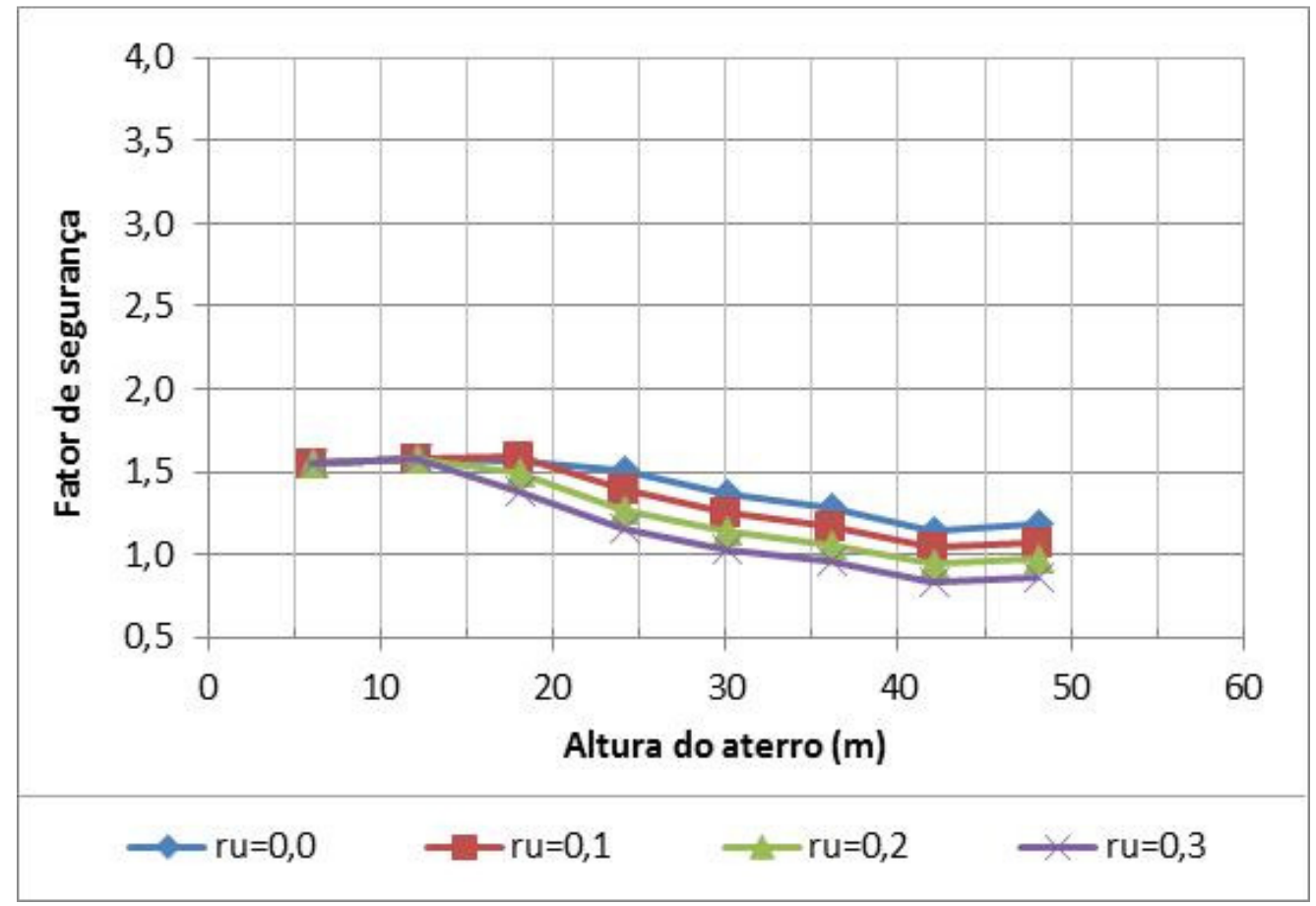

Figura 4.10 - Fatores de segurança para a configuração do aterro com dique de partida e bermas

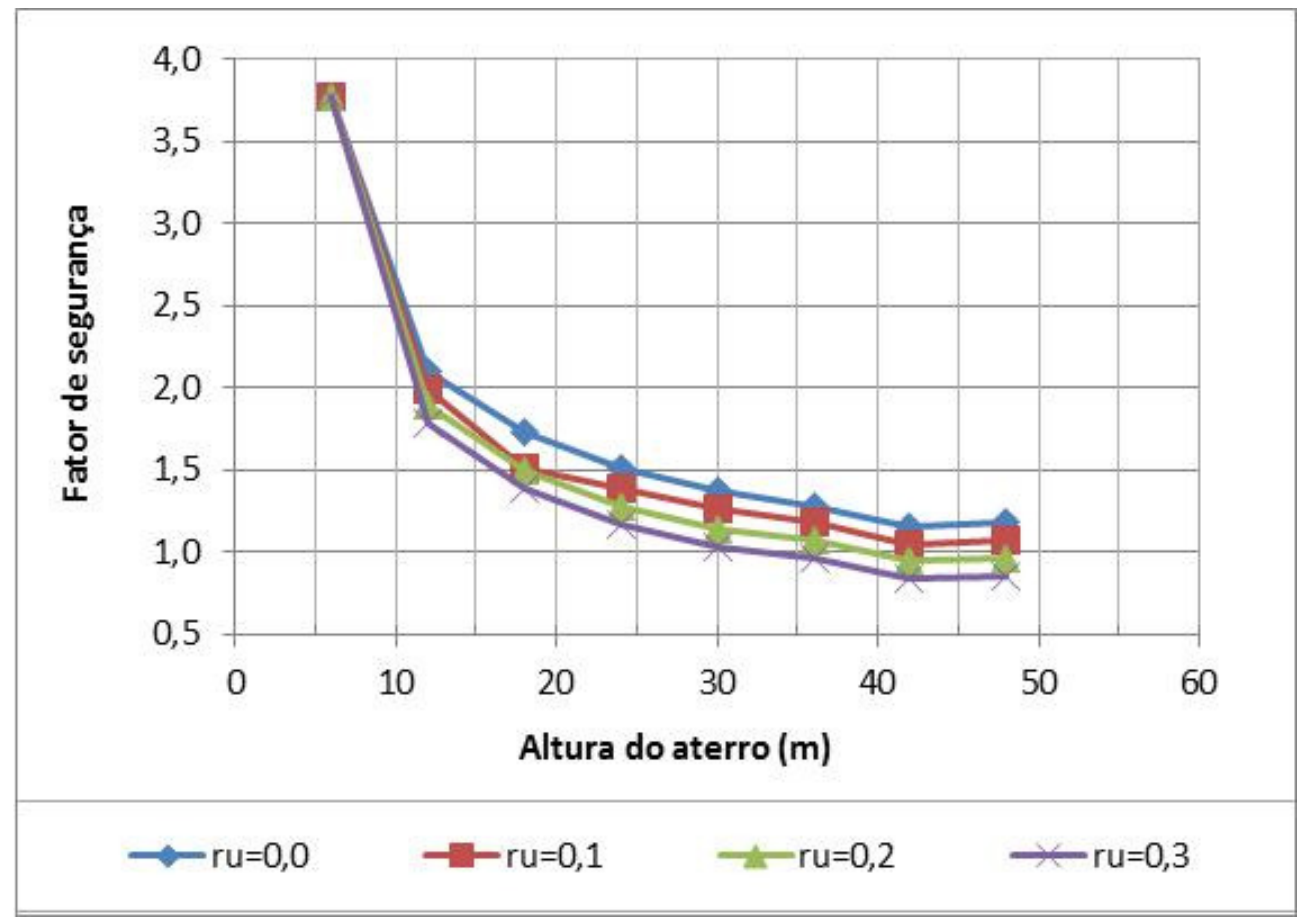

Figura 4.11 - Fatores de segurança para a configuração do aterro com dique de partida reforçado e bermas.

Os fatores de segurança para aterro de resíduos com diques perimetrais sucessivos são apresentados na Figura 4.12. 


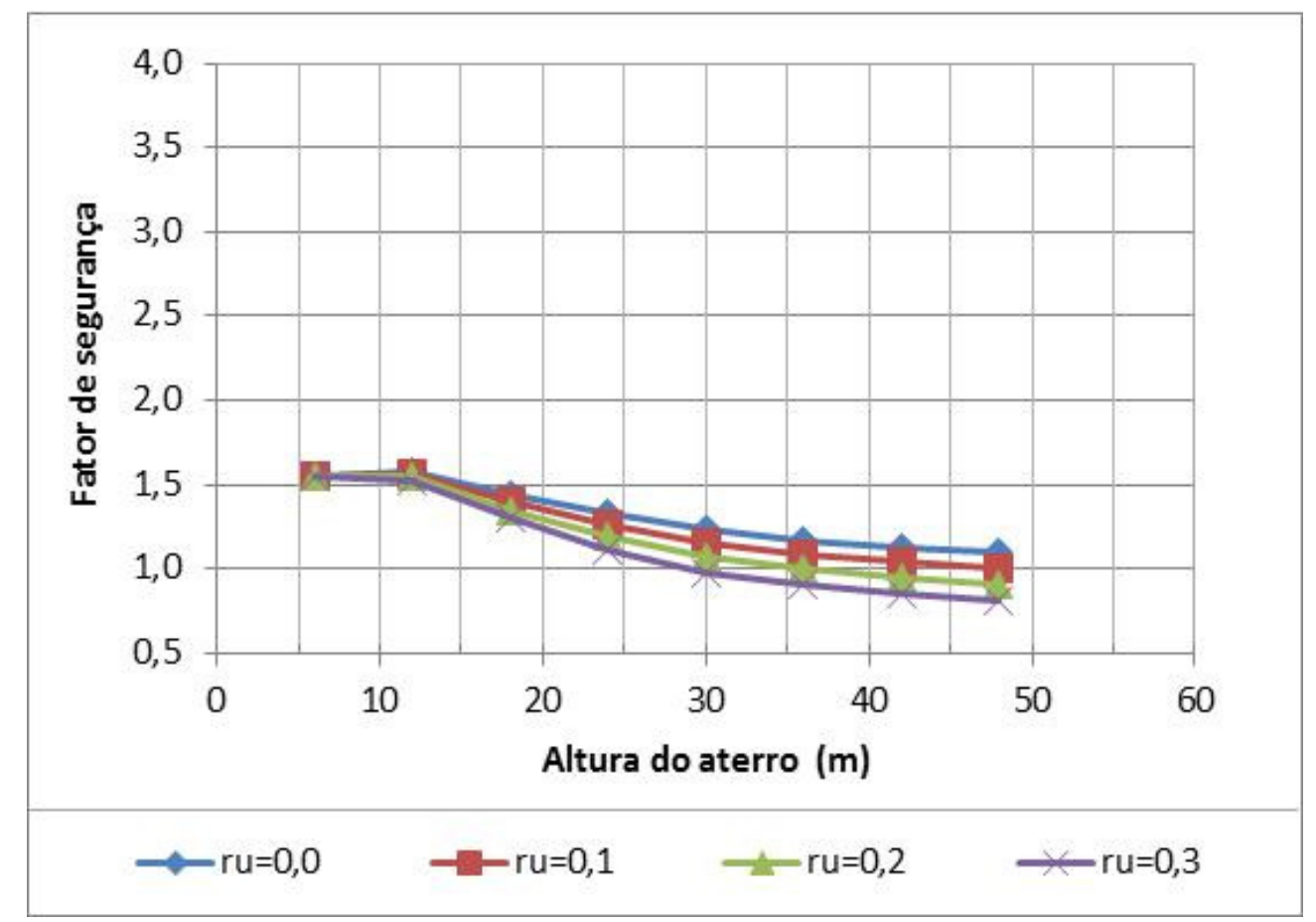

Figura 4.12 - Fatores de segurança para a configuração do aterro com diques sucessivos

A construção de diques sucessivos não reforçados apresenta menor fator de segurança do que a configuração com dique de partida e bermas, provavelmente devido ao aumento do peso próprio da seção mista (e, portanto, aumento das forças instabilizadoras) sem contrapartida de aumento de resistência no círculo crítico, o qual passa pela massa de resíduos.

A utilização de geogrelhas para reforço dos diques promove o aumento dos fatores de segurança para alturas até $30 \mathrm{~m}$, já que para alturas superiores a variação no fator de segurança é pouco significativa, conforme apresentado na Figura 4.13. 


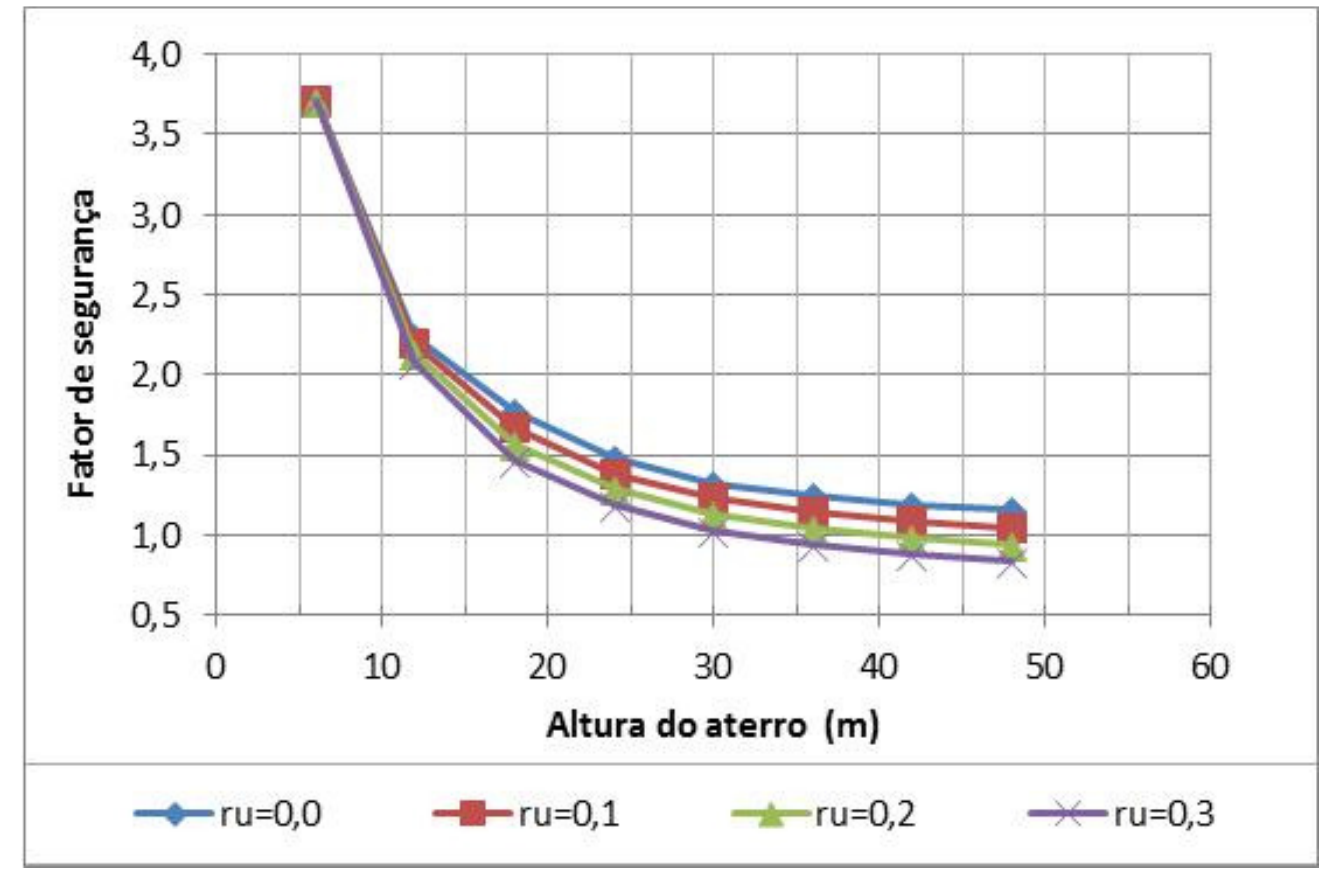

Figura 4.13 - Fatores de segurança para a configuração do aterro com diques sucessivos reforçados

Isso pode ser explicado pela mudança na posição das superfícies de ruptura: conforme a altura do aterro aumenta, as superfícies de ruptura tendem a passam cada vez mais por fora dos diques reforçados e mais por dentro da massa de resíduos, conforme se pode observar na Figura 4.14.

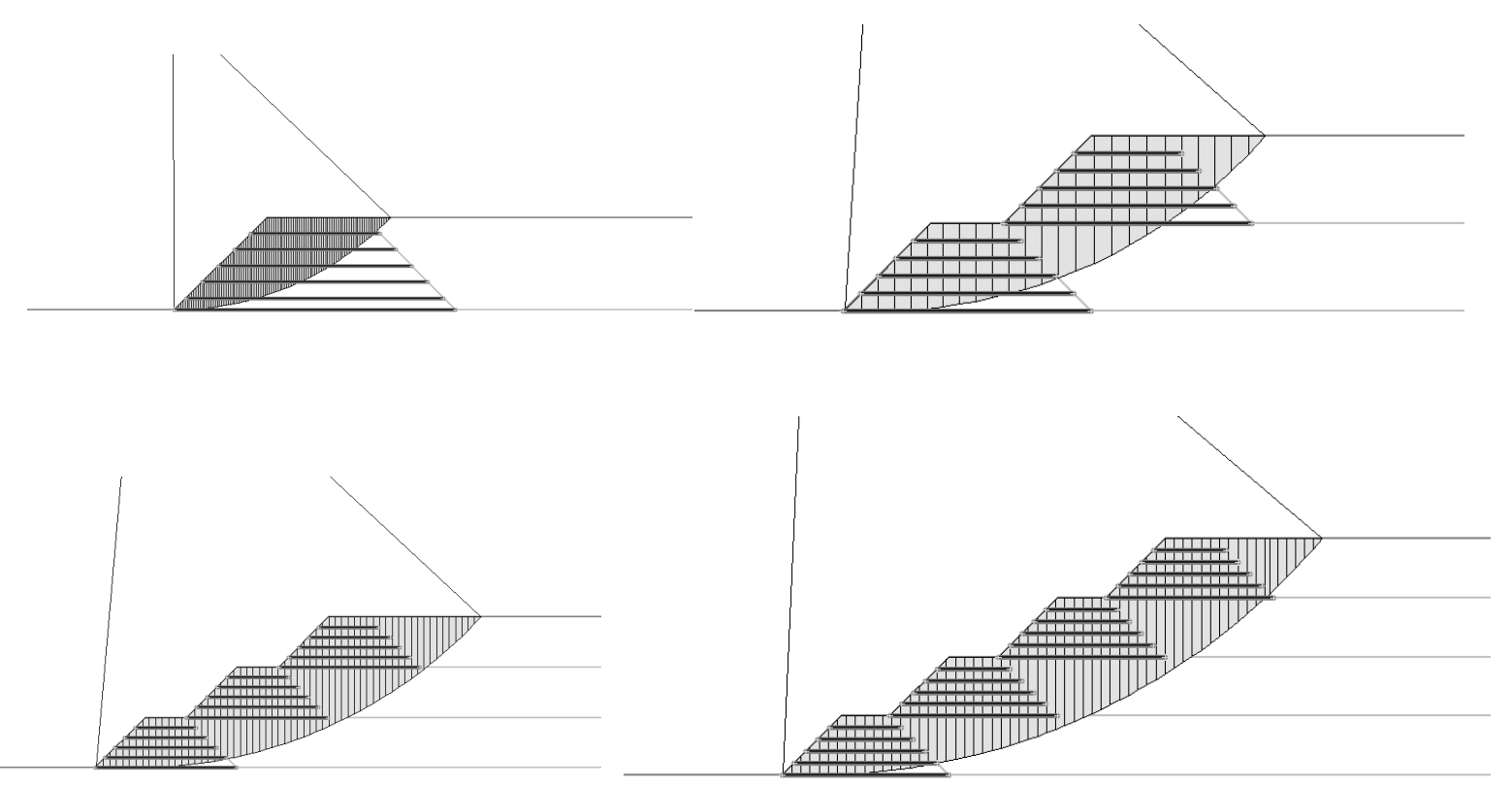

Figura 4.14 - Variação da superfície de ruptura com o alteamento do aterro 
Com a inclusão das geogrelhas no interior da massa de lixo a cada $6 \mathrm{~m}$ de altura, as superfícies de ruptura tendem a ser locais (taludes dos diques), com fator de segurança em torno de 1,55 para altura de até $24 \mathrm{~m}$. Entretanto, para alturas superiores a $24 \mathrm{~m}$, as superfícies de ruptura passam dentro da massa de lixo, justificando a diminuição dos fatores de segurança. Porém, a contribuição dos reforços pode ser notada, uma vez que para as mesmas alturas os fatores de segurança são maiores que os obtidos para a configuração de aterro sanitário não reforçado. Este comportamento é mostrado na

Figura 4.13. Os fatores de segurança obtidos apresentam um aumento nos valores para alturas até $24 \mathrm{~m}$, como esperado.

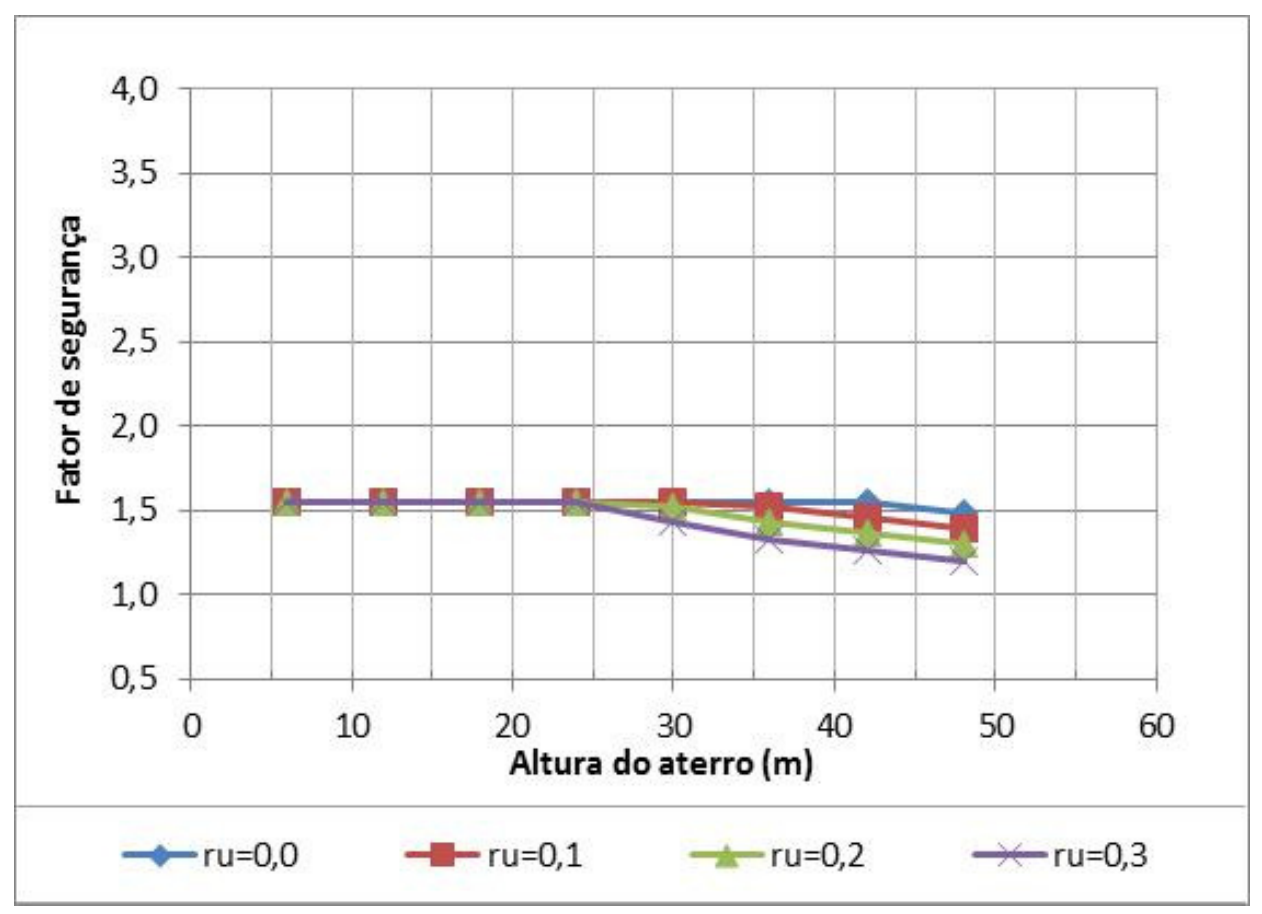

Figura 4.15 - Fatores de segurança para a configuração de diques sucessivos e maciço reforçado

A utilização do reforço proporciona considerável aumento nos fatores de segurança, em virtude dos reforços geossintéticos, inseridos tanto nos diques como no interior do maciço sanitário, contribuírem consideravelmente para a estabilidade do aterro.

A resistência à tração dos reforços atuam no mesmo sentido das forças estabilizantes ou resistentes da superfície de ruptura, contribuindo para o aumento do fator de segurança, conforme se pode observar na Figura 4.16 e Figura 4.17. 


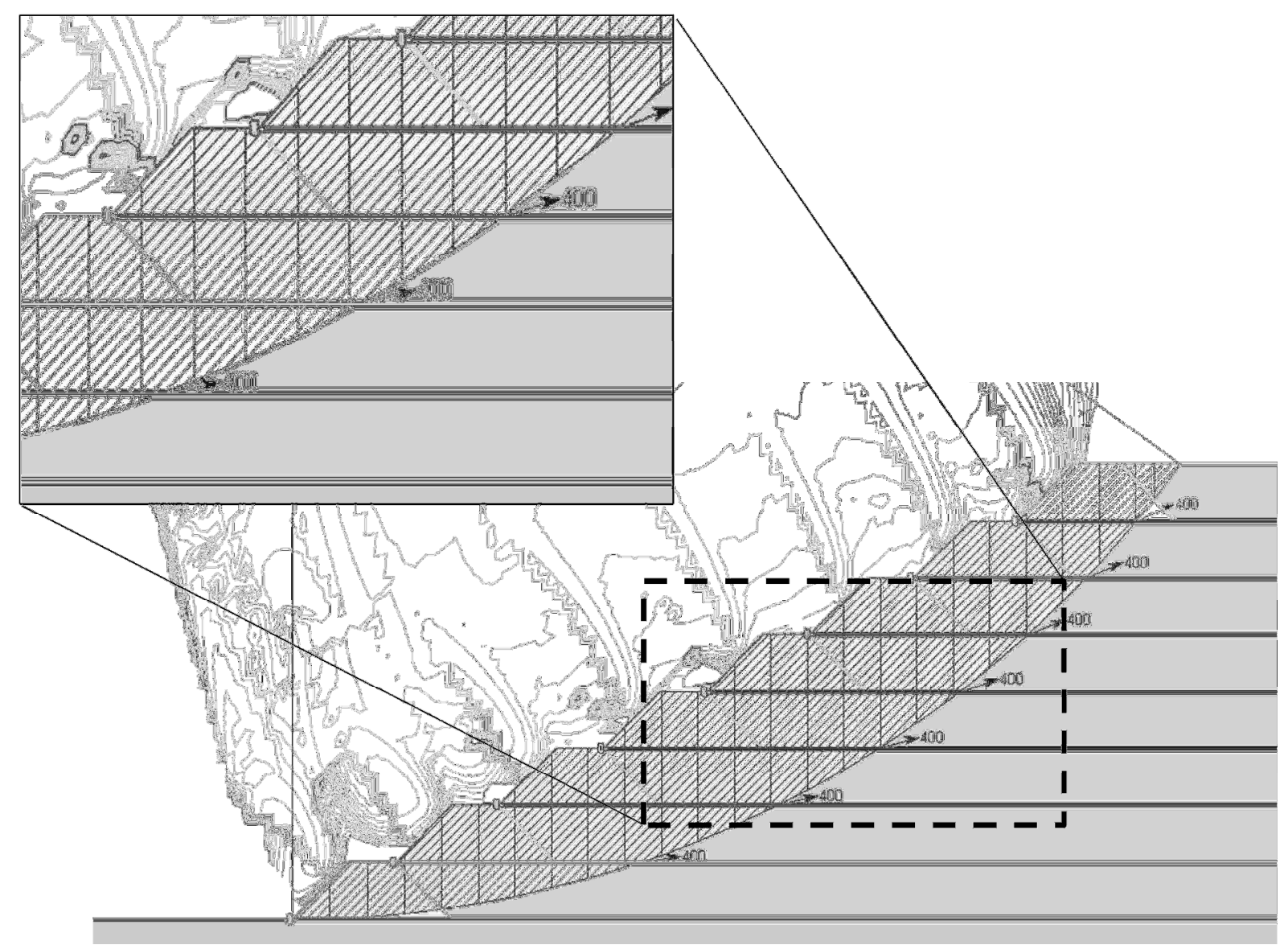

Figura 4.16 - Contribuição do reforço na estabilidade do aterro

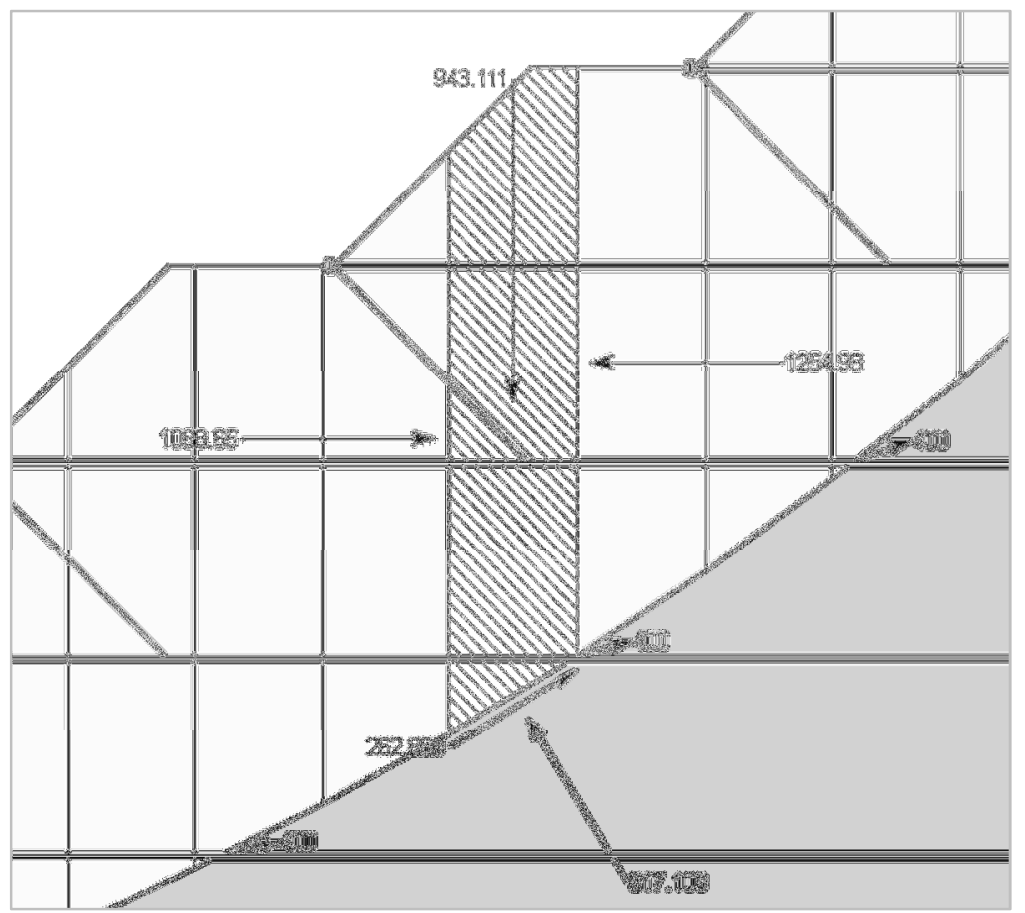

Figura 4.17 - Forças atuantes em uma das lamelas do circulo de ruptura 
Tal fato corrobora o princípio teórico de que adicionar elementos resistentes à tração a materiais pouco resistentes à tração (solos) melhora a resistência do conjunto.

Caso não houvesse os reforços no interior do maciço, os fatores de segurança seriam próximos aos obtidos para a configuração sem reforço a partir do ponto em que as superfícies críticas começassem a passar fora dos diques e dentro da massa de resíduos.

Na Figura 4.18 são apresentados os fatores de segurança para a configuração de diques sucessivos reforçados e maciço reforçado.

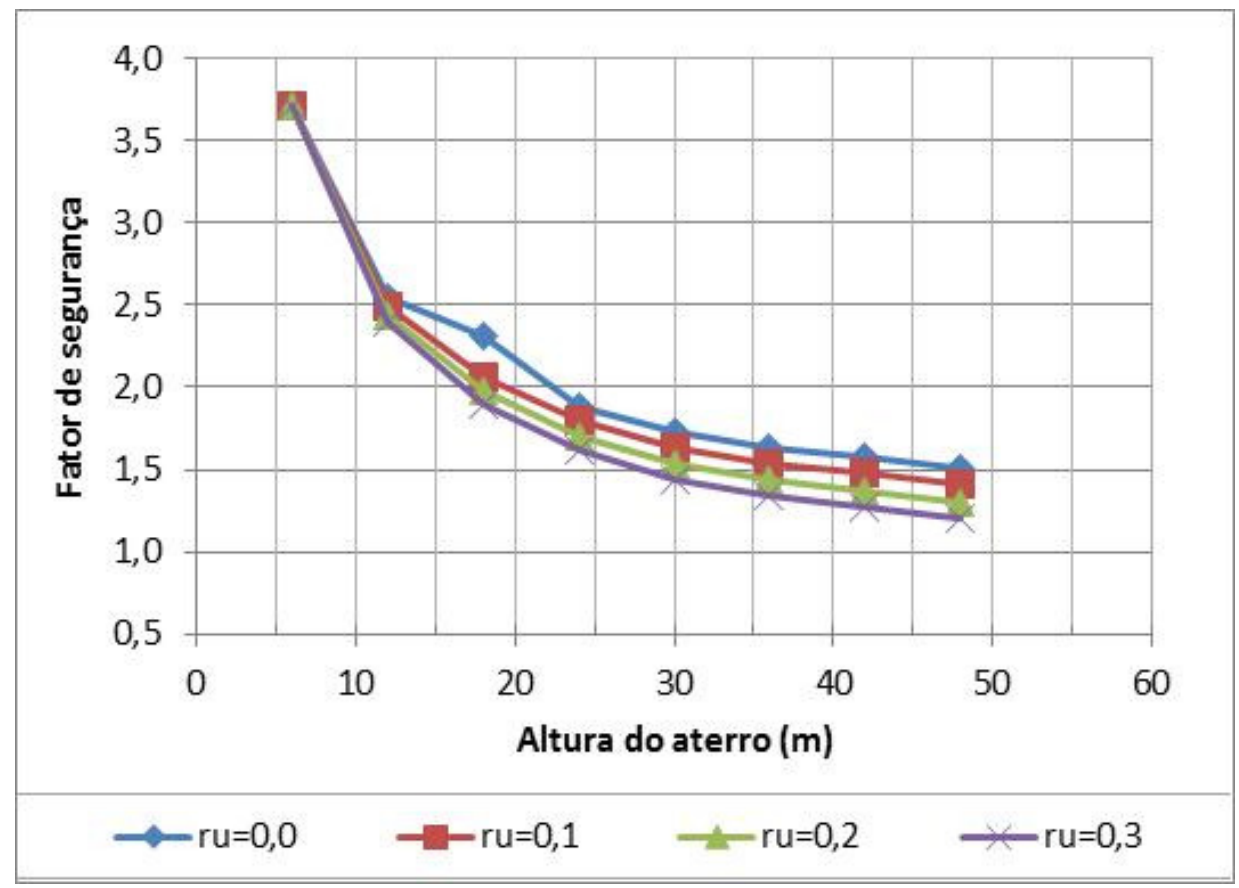

Figura 4.18 - Fatores de segurança para a configuração do aterro com diques sucessivos reforçados e com reforços no interior do maciço sanitário

A Figura 4.19 compara os fatores de segurança de todas as configurações estudadas para a condição de pressões neutras nulas na massa de resíduos $\left(r_{u}=0,0\right)$. A Figura 4.20, a Figura 4.21 e a Figura 4.22 apresentam, respectivamente, os fatores de segurança de todas as configurações estudadas para pressões neutras nulas na massa de resíduos equivalentes a $r_{u}=0,1,0,2$ e 0,3. 


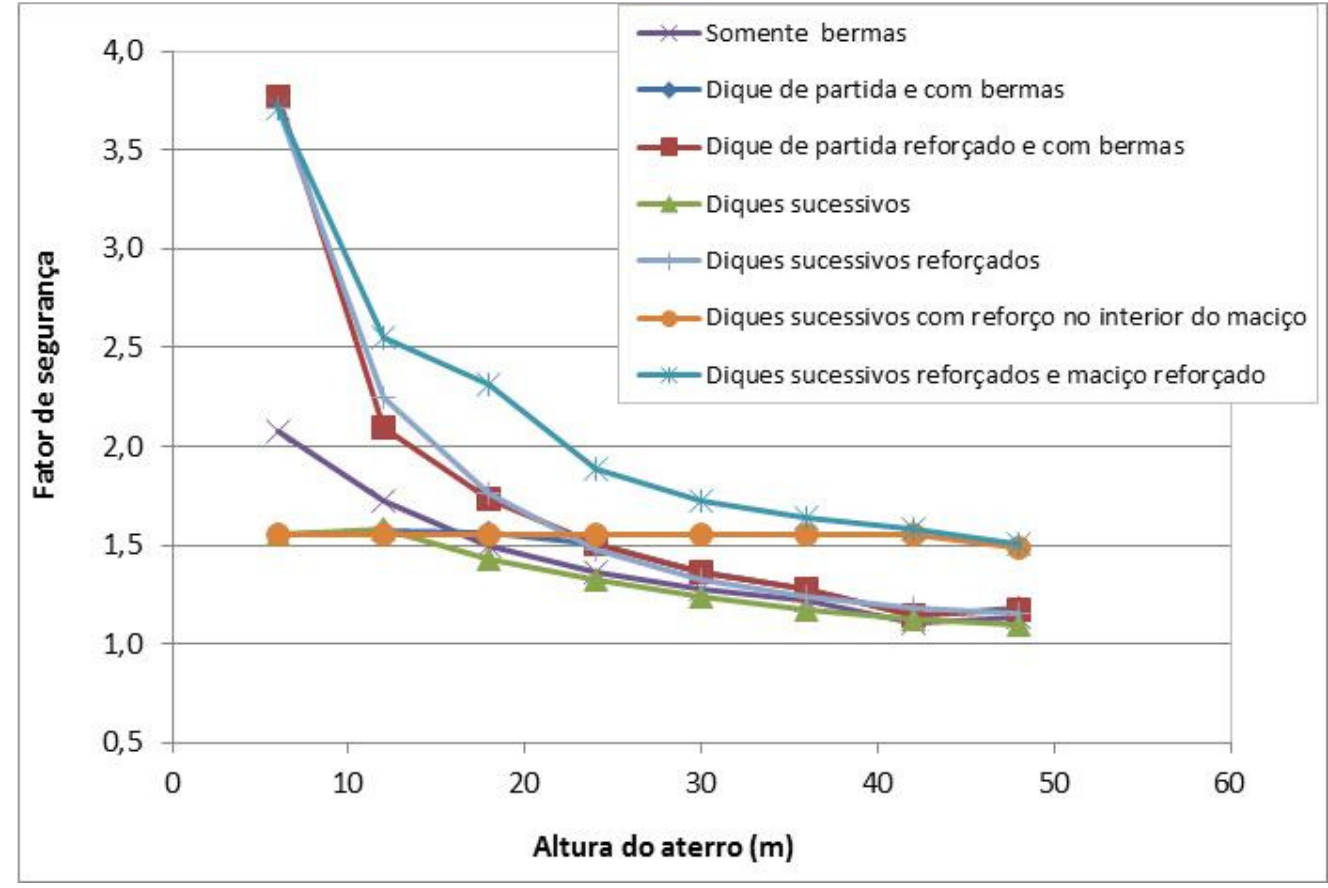

Figura 4.19 - Fatores de segurança das configurações analisadas para $r_{u}=0$

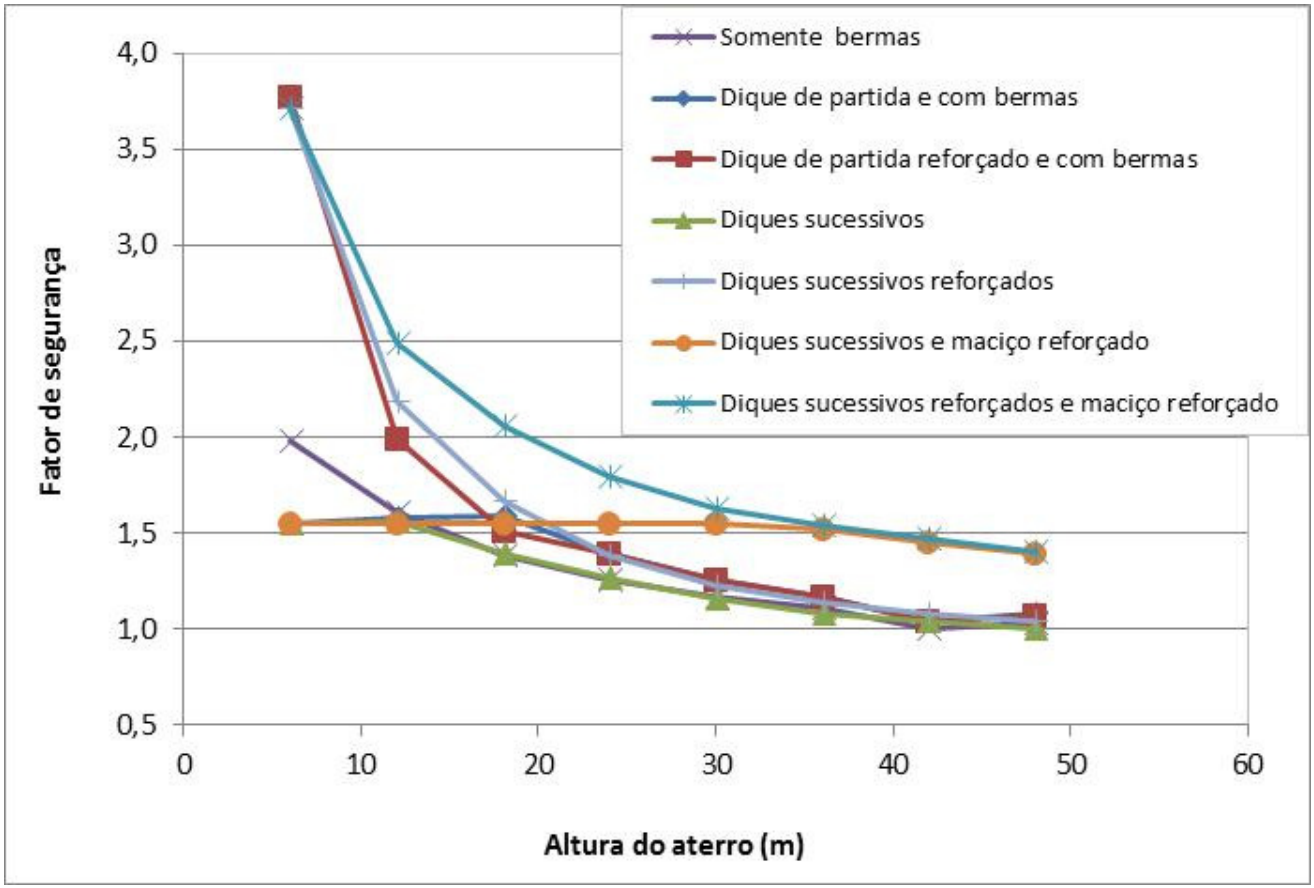

Figura 4.20 - Fatores de segurança das configurações analisadas para $r_{u}=0,1$ 


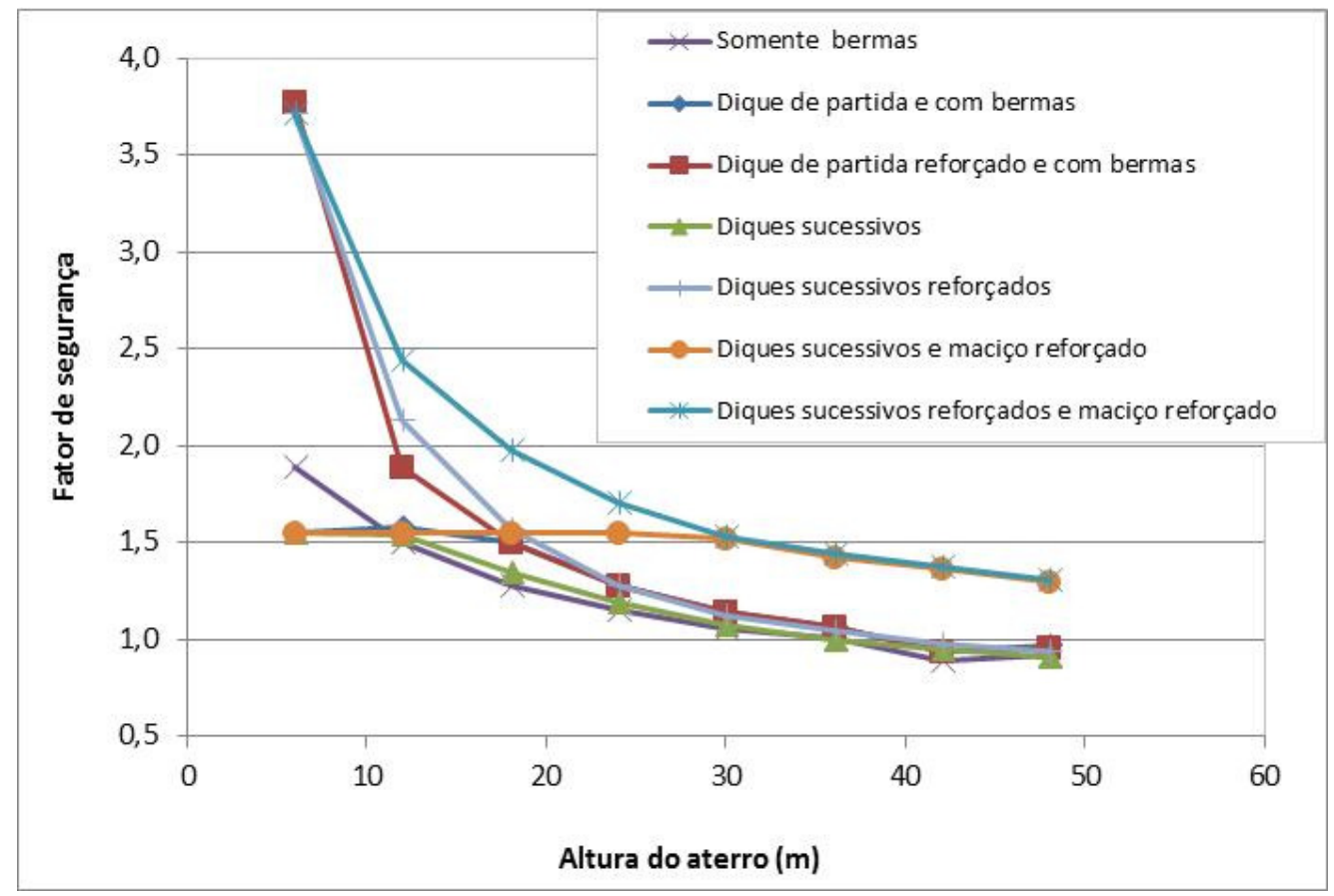

Figura 4.21 - Fatores de segurança das configurações analisadas para $r_{u}=0,2$

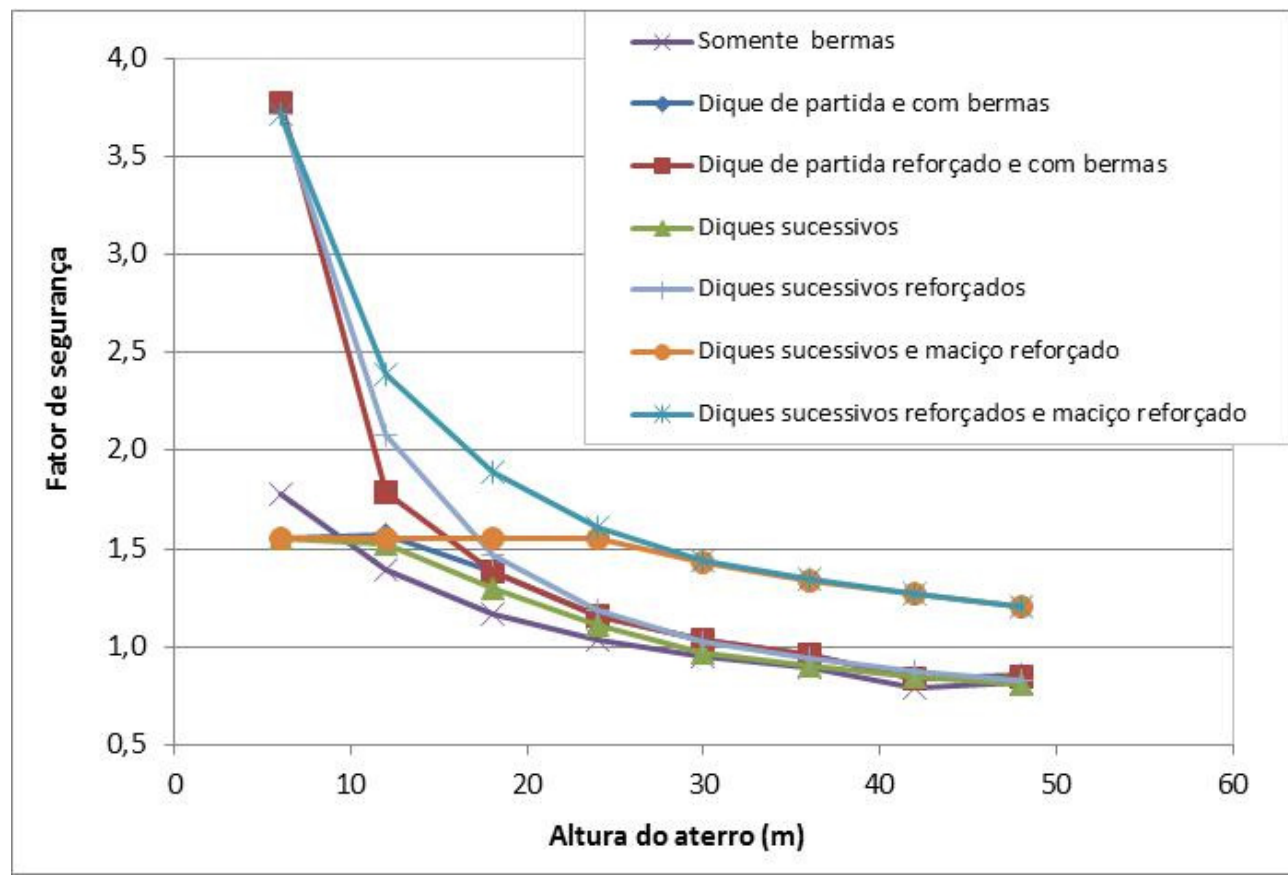

Figura 4.22 - Fatores de segurança das configurações analisadas para $r_{u}=0,3$

Conforme se pode observar, o aterro com bermas de $5 \mathrm{~m}$ de largura e taludes de $6 \mathrm{~m}$ de altura e declividade $1 \mathrm{H}: 1 \mathrm{~V}$ só atinge o fator de segurança adequado para a altura de $18 \mathrm{~m}$. Com o dique de partida, o fator de segurança aumenta, de modo que o valor de fator de segurança igual a 1,5 é garantido para $24 \mathrm{~m}$ de altura; neste caso, 
para $18 \mathrm{~m}$ o fator de segurança é 1,56 . Entretanto, esse aumento se torna menos significativo à medida que a altura do aterro cresce (maior número de bermas), tornando-se indiferente para a altura de $30 \mathrm{~m}$.

Os resultados para configuração de diques sucessivos e maciço reforçado mostram que a utilização adequada do reforço geossintético permite o alteamento do aterro sem que haja perda considerável no fator de segurança do aterro.

A situação com diques sucessivos reforçados e com reforço no interior do maciço sanitário permite a construção de um aterro de 48m de altura, atendendo ao fator de segurança de 1,5. O aumento do fator de segurança em relação às configurações anteriores, contudo, diminui com o aumento de altura do aterro.

A consideração das pressões neutras, representadas pelo parâmetro $r_{u}$, reduz significativamente o fator de segurança. Adotando-se um valor médio de 0,2 para $r_{u}$, como utilizado para solos, o fator de segurança decresce em média 15\% para a configuração de alteamento com bermas, $11 \%$ com alteamento com dique de partida e bermas, $13 \%$ com alteamento usando dique de partida reforçado e bermas, $10 \%$ para diques sucessivos, $4 \%$ para diques sucessivos e maciço sanitário reforçado e $7 \%$ para diques sucessivos reforçados e maciço sanitário reforçado.

A configuração com diques sucessivos e reforços geossintéticos dentro da massa de lixo prova ser a mais eficiente, uma vez que com $r_{u}=0$ o fator de segurança é garantido para a maior altura analisada, ou seja, $F S=1,5$ sem necessidade de reforçar os diques periféricos. Além do mais, para o pior caso de pressões neutras $\left(r_{u}=0,3\right)$, o fator de segurança obtido foi de 1,2 para $48 \mathrm{~m}$ de altura, conforme apresentado na Figura 4.22. A utilização de reforço ainda proporciona menor redução dos fatores de segurança com o aumento de $r_{u}$.

De modo geral, as modificações introduzidas em relação ao aterro com bermas fazem-se notar para alturas até $18 \mathrm{~m}$. Maiores alturas não são beneficiadas a ponto de atingirem o fator de segurança desejado para a configuração proposta. Isto se deve à posição da cunha de ruptura, que passa por zonas não reforçadas com geogrelha, o que justifica o uso de reforços no interior da massa de resíduos.

Na Tabela 4.1 são apresentados os resultados obtidos nas análises equilíbrio-limite. 
Tabela 4.1 - Resumo dos resultados obtidos nas análises equilíbrio-limite.

\begin{tabular}{|c|c|c|c|c|c|c|c|c|c|c|c|c|c|c|c|c|c|c|c|c|c|c|c|c|c|c|c|c|}
\hline \multirow{3}{*}{$\begin{array}{c}\text { Altura } \\
\text { do } \\
\text { aterro } \\
(\mathrm{m})\end{array}$} & \multicolumn{4}{|c|}{ Bermas } & \multicolumn{4}{|c|}{$\begin{array}{c}\text { Dique de partida e } \\
\text { bermas }\end{array}$} & \multicolumn{4}{|c|}{$\begin{array}{l}\text { Dique de partida } \\
\text { reforçado e bermas }\end{array}$} & \multicolumn{4}{|c|}{ Diques sucessivos } & \multicolumn{4}{|c|}{$\begin{array}{l}\text { Diques sucessivos } \\
\text { reforçados }\end{array}$} & \multicolumn{4}{|c|}{$\begin{array}{l}\text { Diques sucessivos e } \\
\text { maciço reforçado }\end{array}$} & \multicolumn{4}{|c|}{$\begin{array}{l}\text { Diques sucessivos } \\
\text { reforçados e maciço } \\
\text { reforçado }\end{array}$} \\
\hline & \multicolumn{4}{|c|}{$\mathbf{r}_{\mathbf{u}}$} & \multicolumn{4}{|c|}{$r_{u}$} & \multicolumn{4}{|c|}{$r_{u}$} & \multicolumn{4}{|c|}{$\mathbf{r}_{\mathrm{u}}$} & \multicolumn{4}{|c|}{$\mathbf{r}_{\mathbf{u}}$} & \multicolumn{4}{|c|}{$\mathbf{r}_{\mathbf{u}}$} & \multicolumn{4}{|c|}{$r_{u}$} \\
\hline & 0,0 & 0,1 & 0,2 & 0,3 & 0,0 & 0,1 & 0,2 & 0,3 & 0,0 & 0,1 & 0,2 & 0,3 & 0,0 & 0,1 & 0,2 & 0,3 & 0,0 & 0,1 & 0,2 & 0,3 & 0,0 & 0,1 & 0,2 & 0,3 & 0,0 & 0,1 & 0,2 & 0,3 \\
\hline 6 & 2,08 & 1,98 & 1,89 & 1,78 & 1,55 & 1,55 & 1,55 & 1,55 & 3,77 & 3,77 & 3,77 & 3,77 & 1,55 & 1,55 & 1,55 & 1,55 & 3,71 & 3,71 & 3,71 & 3,71 & 1,55 & 1,55 & 1,55 & 1,55 & 3,71 & 3,71 & 3,71 & 3,71 \\
\hline 12 & 1,72 & 1,61 & 1,50 & 1,39 & 1,58 & 1,58 & 1,58 & 1,58 & 2,09 & 1,99 & 1,89 & 1,78 & 1,58 & 1,56 & 1,54 & 1,53 & 2,24 & 2,19 & 2,14 & 2,08 & 1,55 & 1,55 & 1,55 & 1,55 & 2,55 & 2,49 & 2,44 & 2,39 \\
\hline 18 & 1,50 & 1,39 & 1,28 & 1,17 & 1,56 & 1,59 & 1,50 & 1,38 & 1,73 & 1,51 & 1,50 & 1,38 & 1,43 & 1,39 & 1,35 & 1,30 & 1,77 & 1,67 & 1,57 & 1,47 & 1,55 & 1,55 & 1,55 & 1,55 & 2,31 & 2,06 & 1,98 & 1,90 \\
\hline 24 & 1,37 & 1,26 & 1,15 & 1,04 & 1,51 & 1,39 & 1,28 & 1,16 & 1,50 & 1,39 & 1,28 & 1,16 & 1,33 & 1,27 & 1,19 & 1,11 & 1,48 & 1,38 & 1,28 & 1,19 & 1,55 & 1,55 & 1,55 & 1,55 & 1,89 & 1,80 & 1,71 & 1,61 \\
\hline 30 & 1,28 & 1,17 & 1,06 & 0,95 & 1,36 & 1,25 & 1,14 & 1,03 & 1,36 & 1,25 & 1,14 & 1,03 & 1,24 & 1,16 & 1,07 & 0,97 & 1,32 & 1,22 & 1,13 & 1,03 & 1,55 & 1,55 & 1,52 & 1,43 & 1,72 & 1,63 & 1,54 & 1,44 \\
\hline 36 & 1,22 & 1,11 & 1,00 & 0,90 & 1,28 & 1,17 & 1,07 & 0,96 & 1,28 & 1,17 & 1,07 & 0,96 & 1,17 & 1,09 & 1,00 & 0,90 & 1,24 & 1,14 & 1,05 & 0,94 & 1,55 & 1,52 & 1,43 & 1,33 & 1,64 & 1,54 & 1,44 & 1,35 \\
\hline 42 & 1,10 & 1,00 & 0,89 & 0,79 & 1,14 & 1,05 & 0,94 & 0,84 & 1,15 & 1,04 & 0,94 & 0,83 & 1,13 & 1,04 & 0,95 & 0,85 & 1,19 & 1,08 & 0,98 & 0,87 & 1,55 & 1,46 & 1,36 & 1,27 & 1,58 & 1,48 & 1,37 & 1,27 \\
\hline 48 & 1,13 & 1,03 & 0,92 & 0,82 & 1,18 & 1,08 & 0,97 & 0,86 & 1,18 & 1,07 & 0,96 & 0,85 & 1,10 & 1,01 & 0,91 & 0,81 & 1,15 & 1,05 & 0,94 & 0,83 & 1,49 & 1,39 & 1,30 & 1,20 & 1,50 & 1,40 & 1,30 & 1,20 \\
\hline
\end{tabular}




\subsection{ANÁLISE TENSÃO-DEFORMAÇÃO}

Inicialmente, analisou-se a configuração de alteamento em diques sucessivos. Os resultados mostram que a estabilidade é garantida para a maior altura analisada (48m), no entanto, o fator de segurança de 1,5 só é atingido para alturas menores do que $12 \mathrm{~m}$ (Figura 4.23).

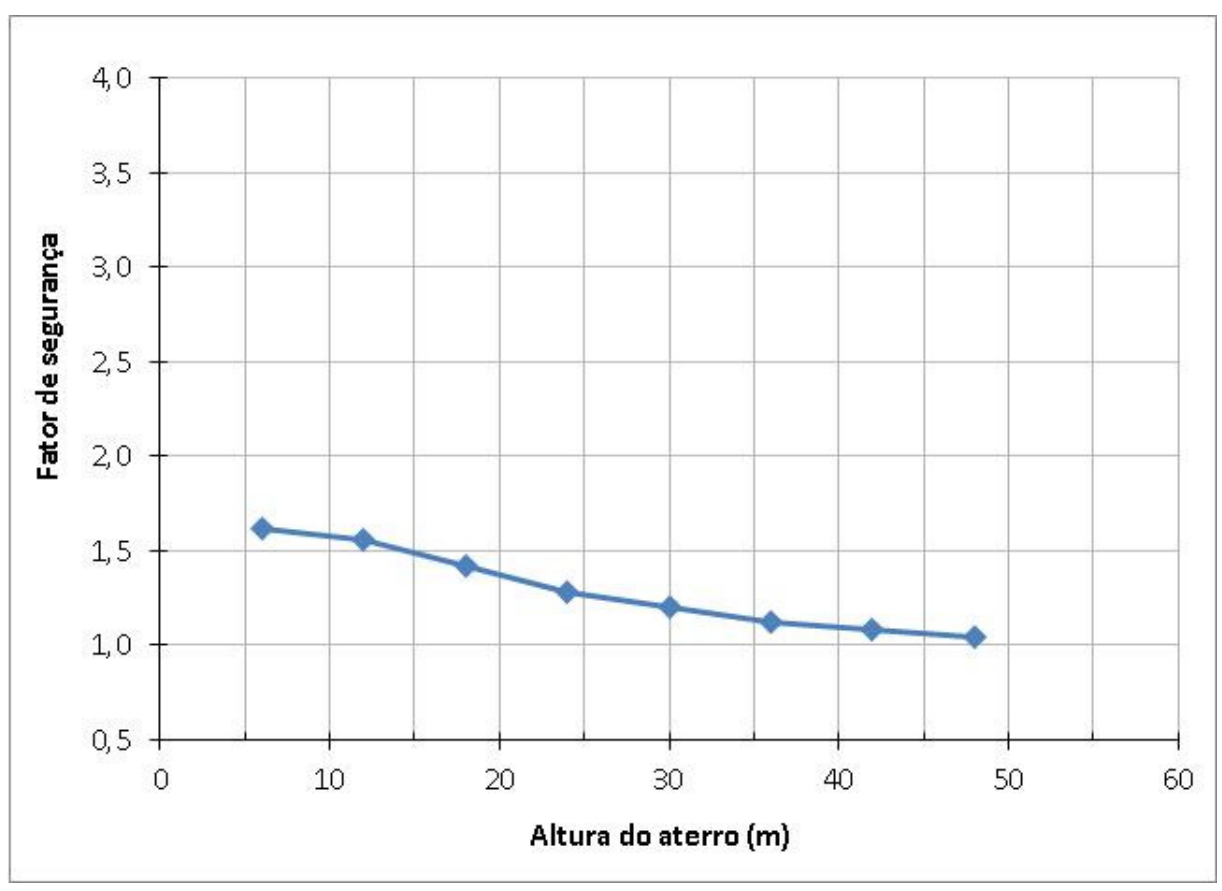

Figura 4.23 - Fatores de segurança para configuração em diques sucessivos

Comparando-se os resultados obtidos nas análises tensão-deformação com as das análises por métodos de equilíbrio limite para o alteamento realizado por meio de diques sucessivos, nota-se que as análises tensão-deformação para alturas até $18 \mathrm{~m}$ não apresentam variações significativas quando comparadas as análises equilíbriolimite para $r_{u}=0,0$. Para alturas superiores a $18 \mathrm{~m}$, os fatores de segurança situam-se entre os valores obtidos para $r_{u}=0,0$ e 0,1 . A Figura 4.24 ilustra os aspectos comentados. 


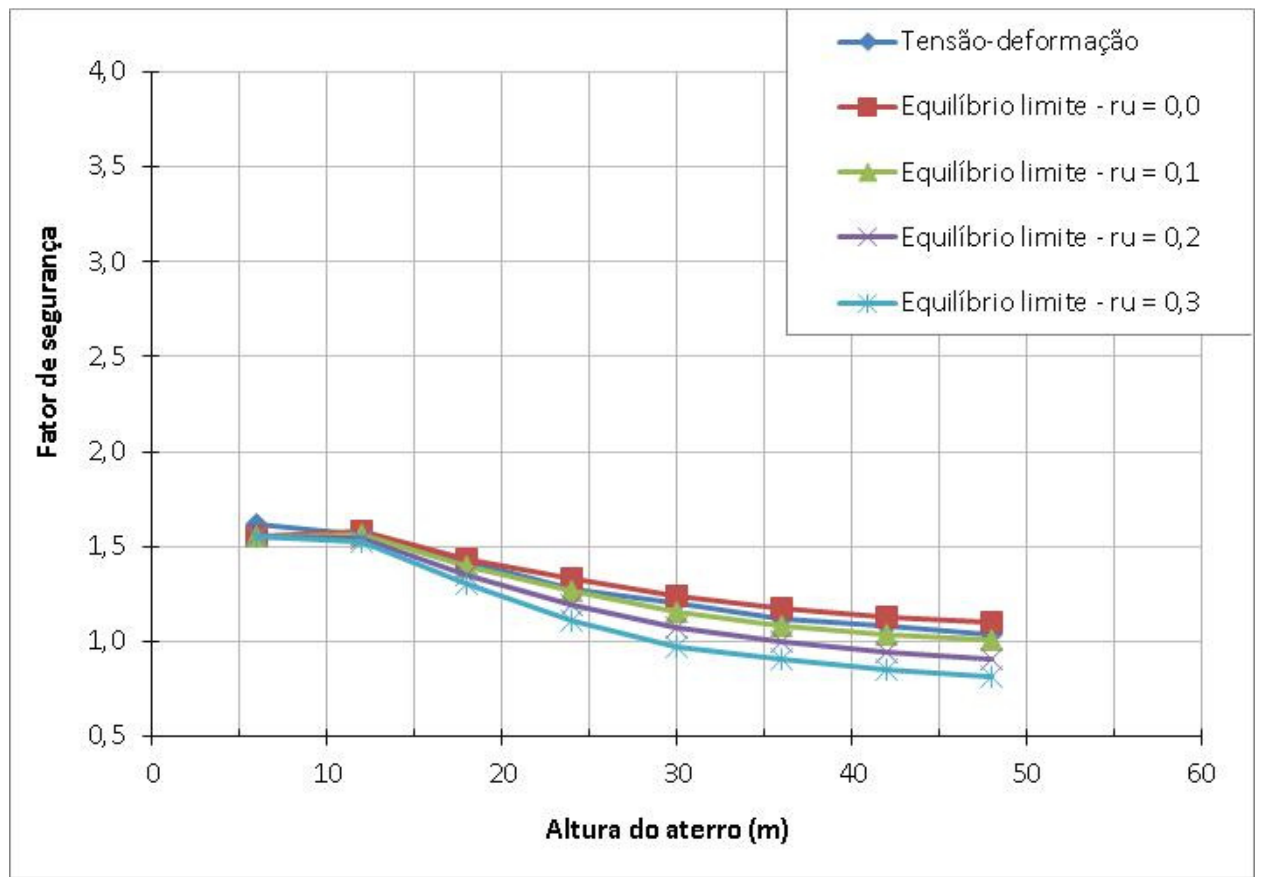

Figura 4.24 - Comparação entre os fatores de segurança obtidos nas análises tensão-deformação e equilíbrio limite

Nas Figura 4.25 e Figura 4.26 são apresentadas as deformações e deslocamentos verticais, horizontais e totais máximas obtidas em cada estágio de alteamento para configuração em diques sucessivos.

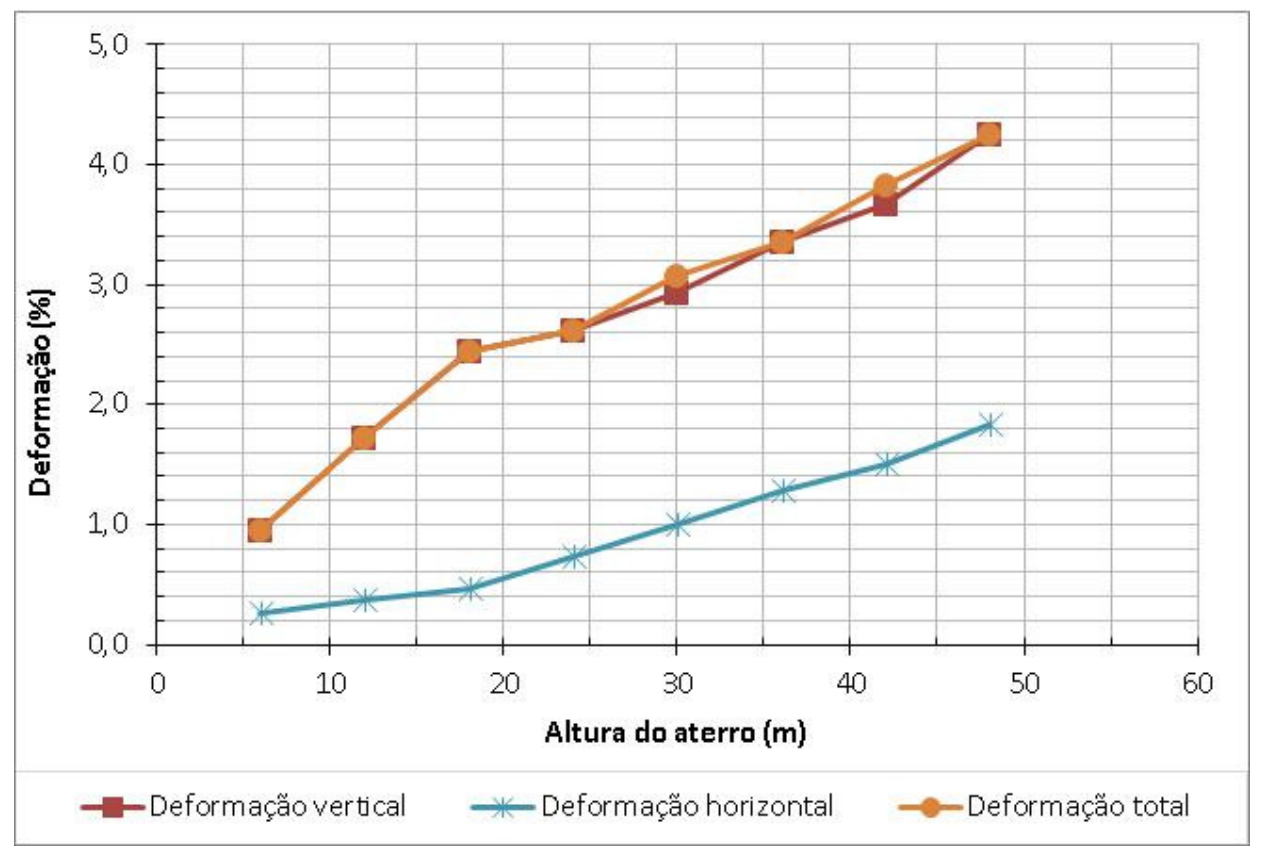

Figura 4.25 - Deformações máximas obtidas para configuração em diques sucessivos 


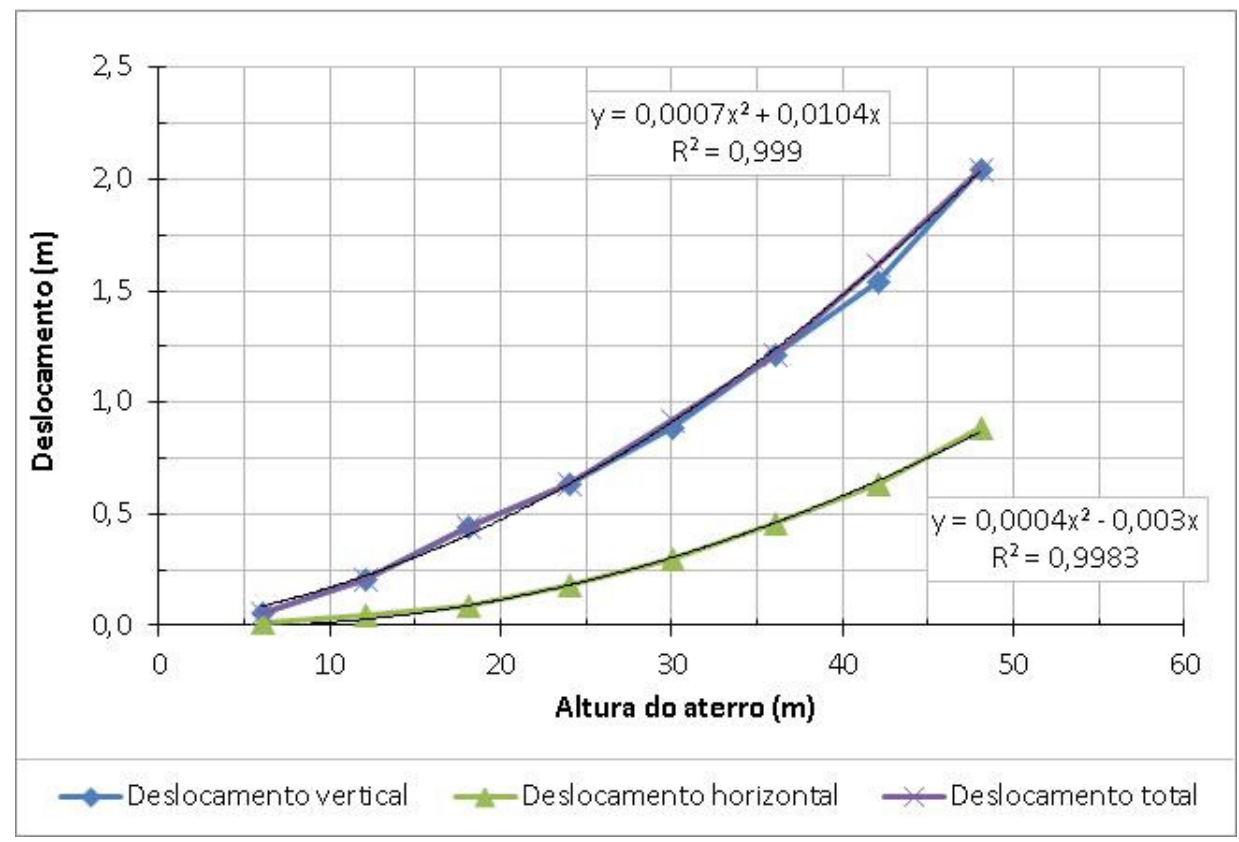

Figura 4.26 - Deslocamentos máximos obtidos para configuração em diques sucessivos

Verifica-se que as deformações são essencialmente verticais, conforme esperado, e chegam a cerca de $3 \%$ para altura de $30 \mathrm{~m}$. Este valor inferior aos reportados na bibliografia (compressão dos RSU entre 10 e 30\%em relação à espessura inicial), mas neste trabalho não foram considerados os recalques de longo prazo devidos à biodegradação e ao "creep". Tal dado reforça o fato de que grande parte das deformações e deslocamentos é decorrente da degradação da matéria orgânica ao longo do tempo e constitui uma parcela significativa do total.

Em seguida, estudou-se a influência da utilização de reforços geossintéticos nos diques de solo compactado em diversas etapas construtivas. Os resultados obtidos são apresentados na Figura 4.27. 


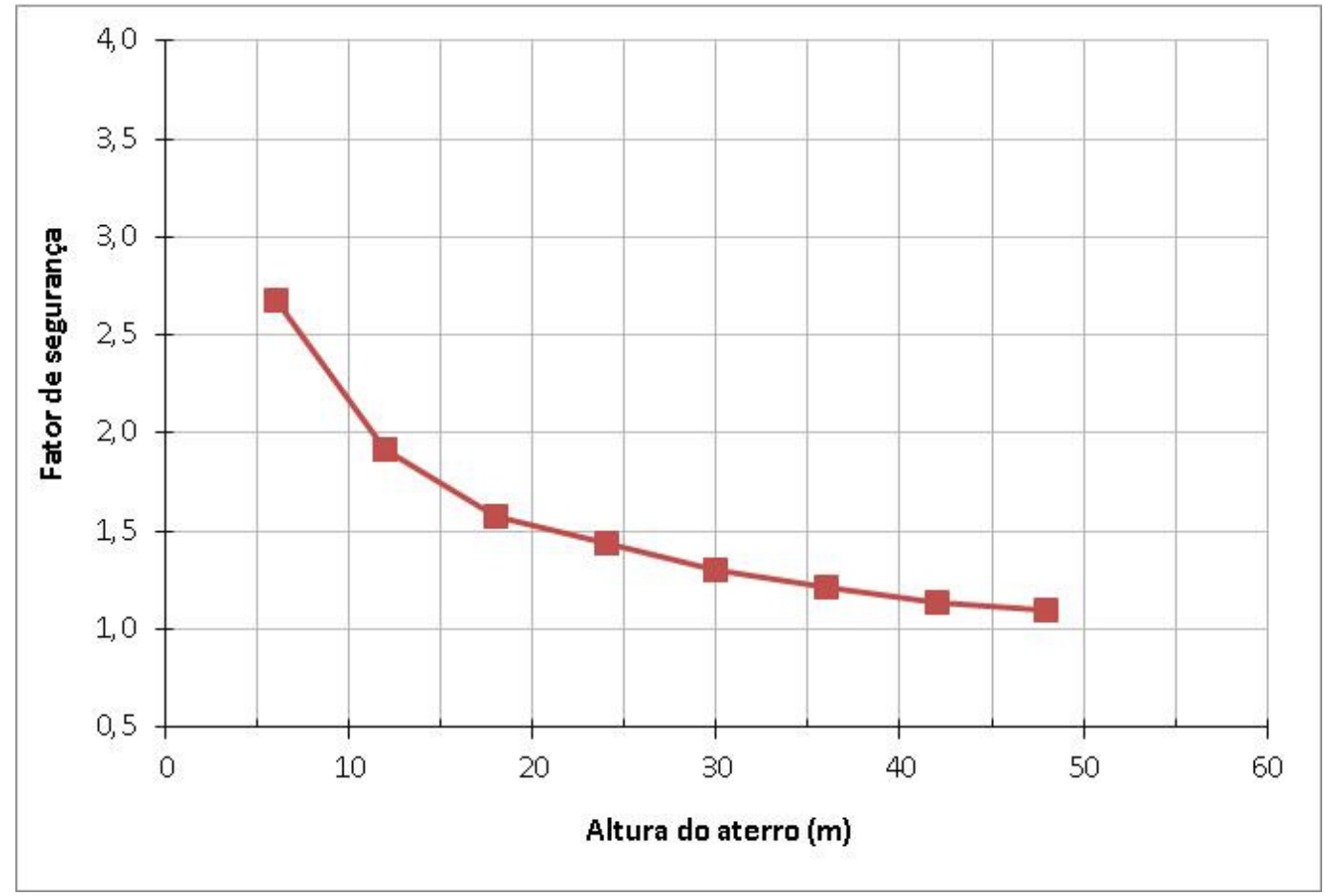

Figura 4.27 - Fatores de segurança para configuração em diques sucessivos reforçados

Os resultados obtidos mostram que a estabilidade também é garantida para a maior altura de aterro analisada e o fator de segurança superior a 1,5 só é garantido para alturas até $18 \mathrm{~m}$.

Comparando-se os resultados obtidos nas análises anteriores (sem reforço nos diques), nota-se que a influência do reforço é maior para as menores alturas de aterro e diminuem conforme o aterro é alteado. Assim como ocorreu nas análises de equilíbrio limite, à medida que o aterro aumenta, a zona plastificada, que indica a posição da superfície de ruptura, tende a passar por regiões menos resistentes, por fora dos diques reforçados e no interior da massa de resíduos, diminuindo a influência dos reforços, conforme pode-se observar na Figura 4.28. 

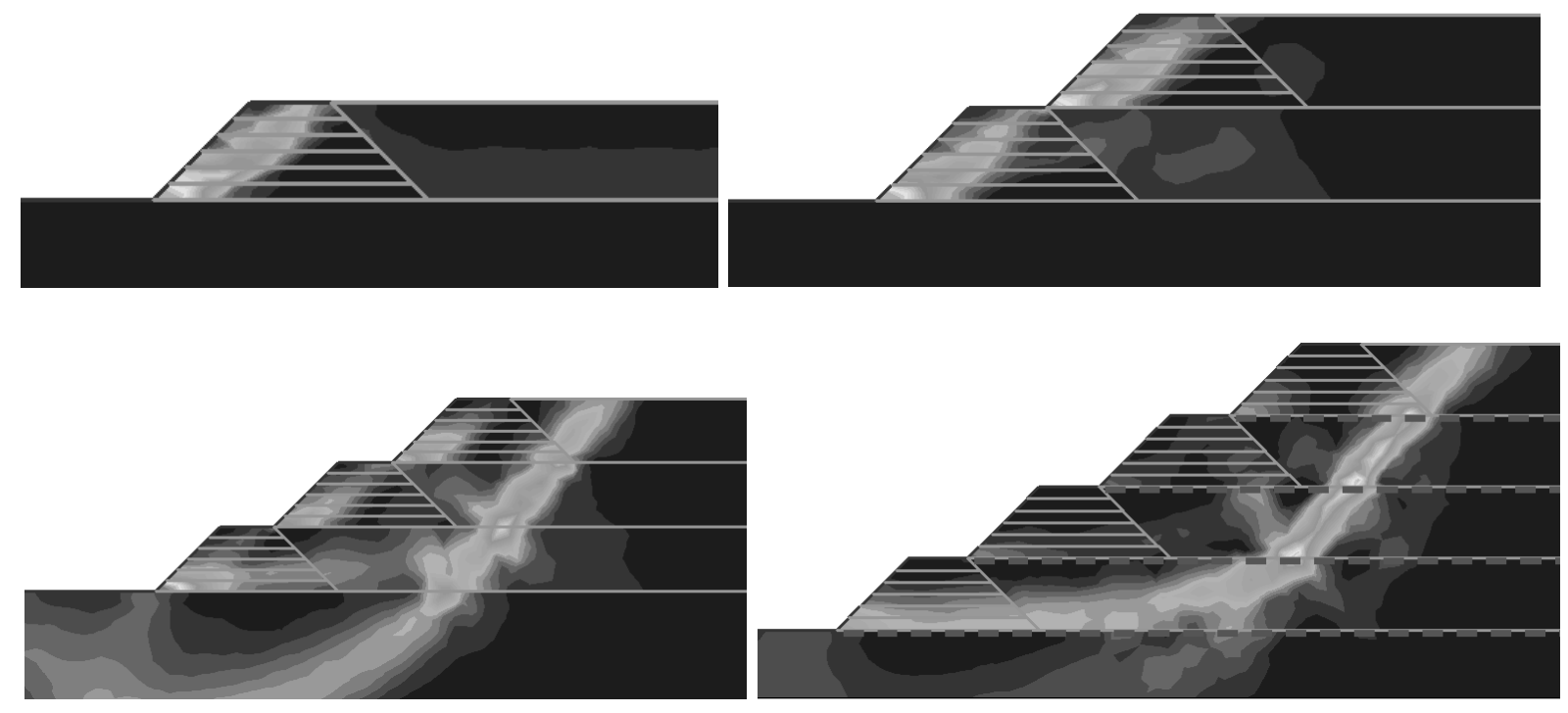

Figura 4.28 - Variação da zona plastificada com o alteamento do aterro

Em comparação com os resultados obtidos nas análises de equilíbrio limite, pode-se observar que as maiores discrepâncias nos fatores de segurança ocorrem para alturas até $12 \mathrm{~m}$; para alturas maiores ou iguais a $18 \mathrm{~m}$ os fatores de segurança aproximam-se dos obtidos nas análises equilíbrio limite, especialmente para a condição com $r_{u}=0,1$, conforme pode-se observar na Figura 4.29.

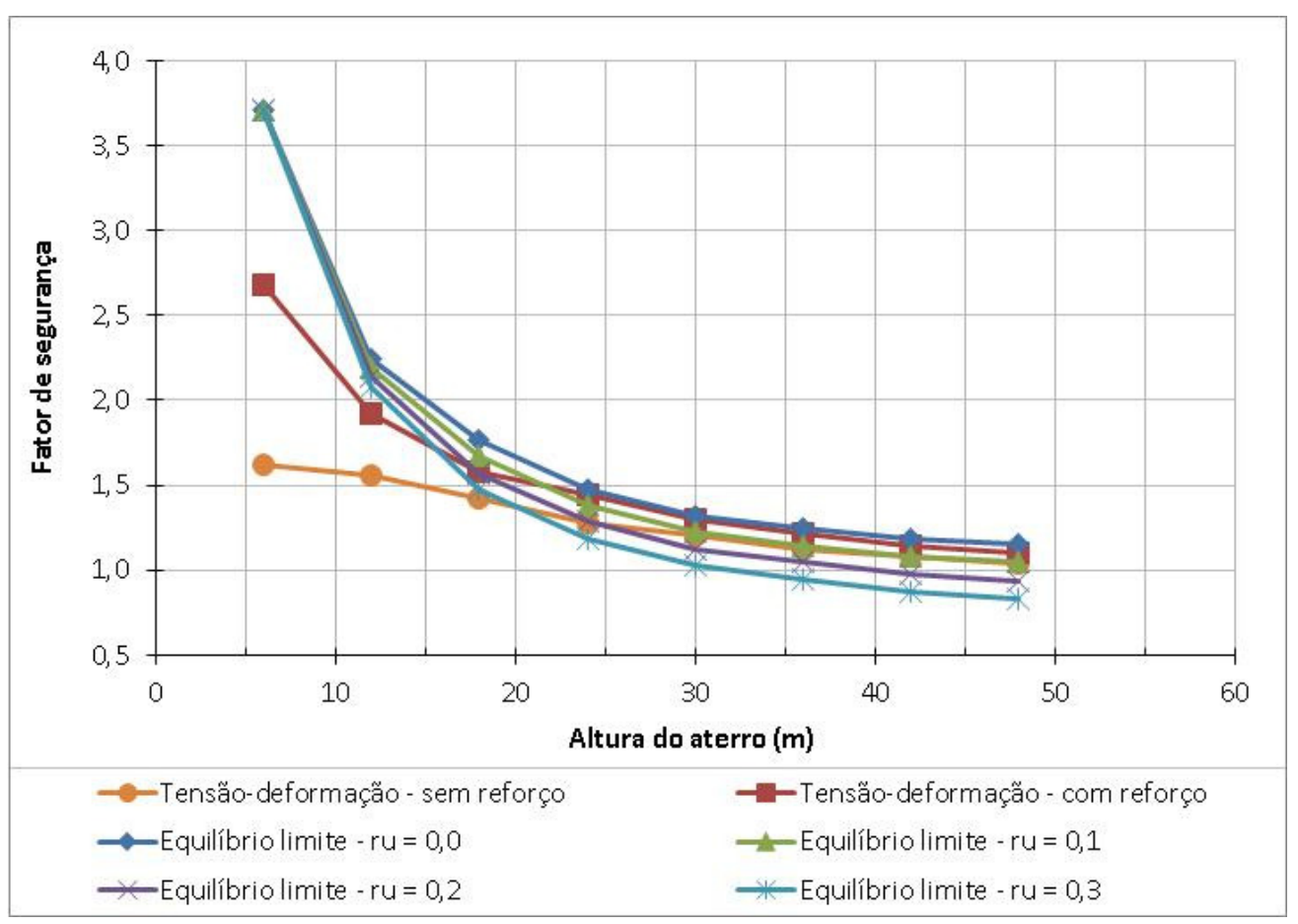

Figura 4.29 - Comparação entre as configurações sem reforço e com as análises equilíbrio limite 
$\mathrm{Na}$ Figura 4.30 são apresentadas as deformações verticais, horizontais e totais máximas obtidas em cada estágio de alteamento para configuração em diques sucessivos reforçados. Os deslocamentos obtidos para a configuração em diques sucessivos reforçados encontram-se na Figura 4.31.

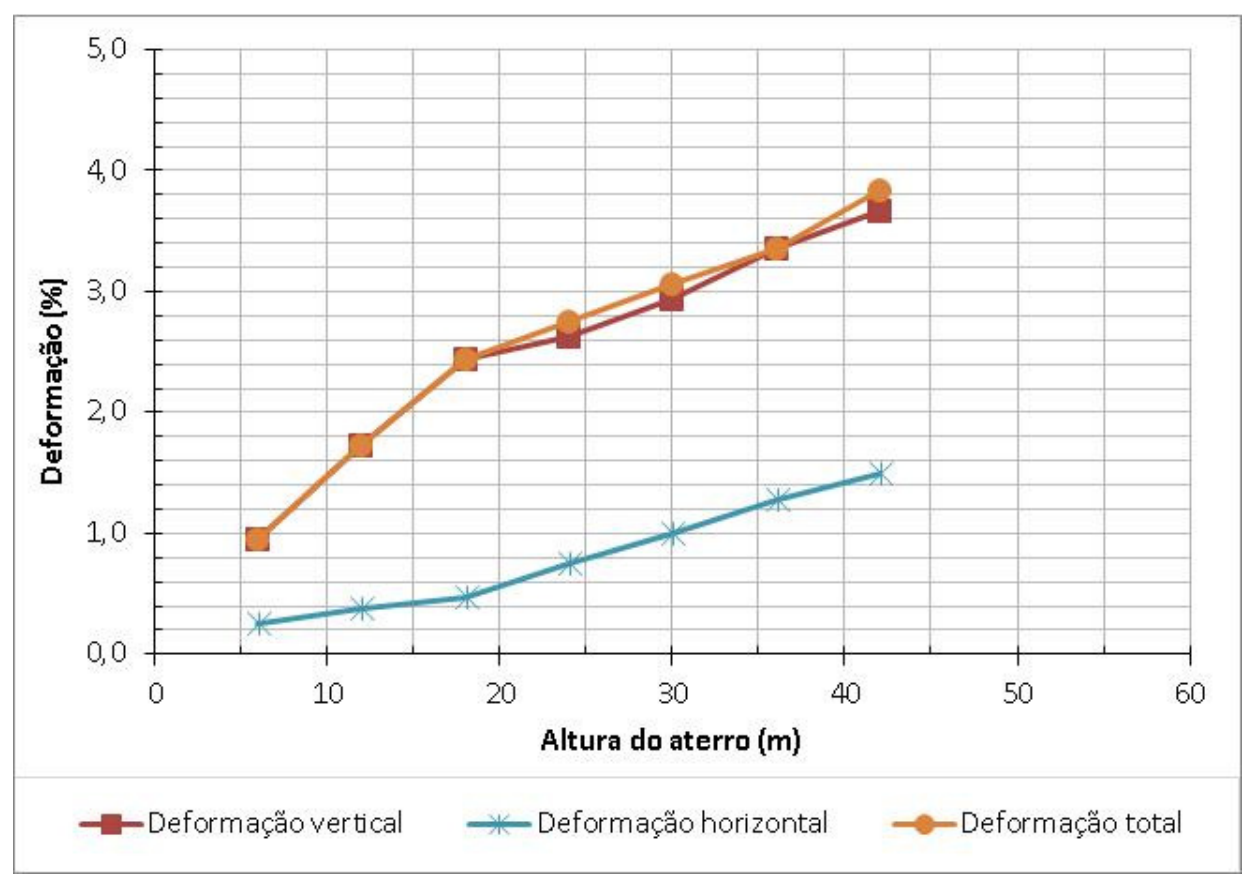

Figura 4.30 - Deformações máximas para configuração em diques sucessivos reforçados

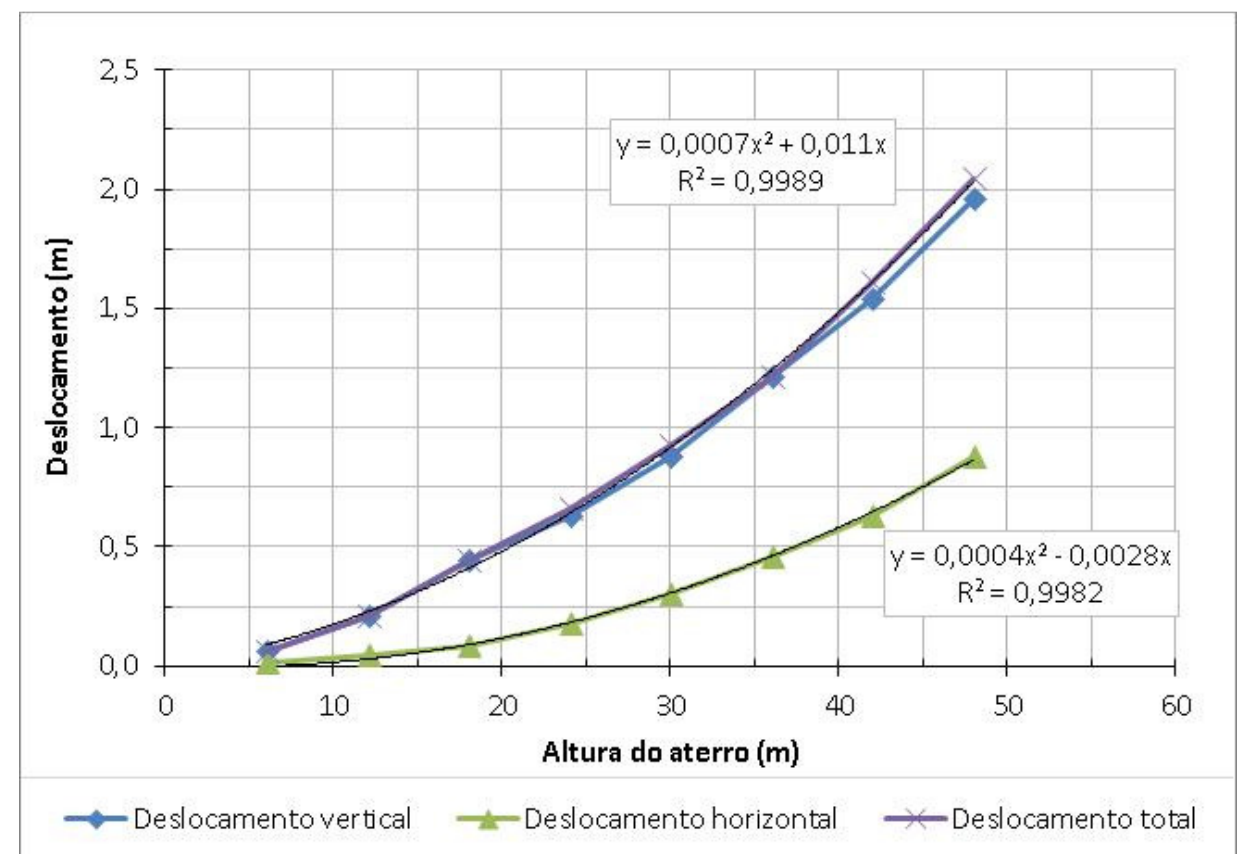

Figura 4.31 - Deslocamentos máximos para a configuração em diques sucessivos reforçados 
Em comparação com a configuração de diques sucessivos sem reforço, os níveis de deformação não apresentaram nenhuma redução para uma mesma altura de aterro, talvez porque as deformações e os deslocamentos ocorram principalmente na massa de resíduos, que não apresenta nenhum tipo de reforço para ambas as configurações.

A seguir, analisou-se a configuração de alteamento por diques sucessivos e maciço reforçado (reforço no interior do maciço sanitário).

Conforme apresentado na Figura 4.32, pode-se observar que para altura de $6 \mathrm{~m}$, ou seja, somente dique de partida, o fator de segurança é da ordem de 1,54 e, portanto, compatível com o obtido na análise equilíbrio-limite para mesma altura, cujo valor foi de 1,55. O fator de segurança aumenta em função da altura, atingindo um pico em $18 \mathrm{~m}$, e posteriormente diminui, até o valor de 1,4 para $48 \mathrm{~m}$ de altura.

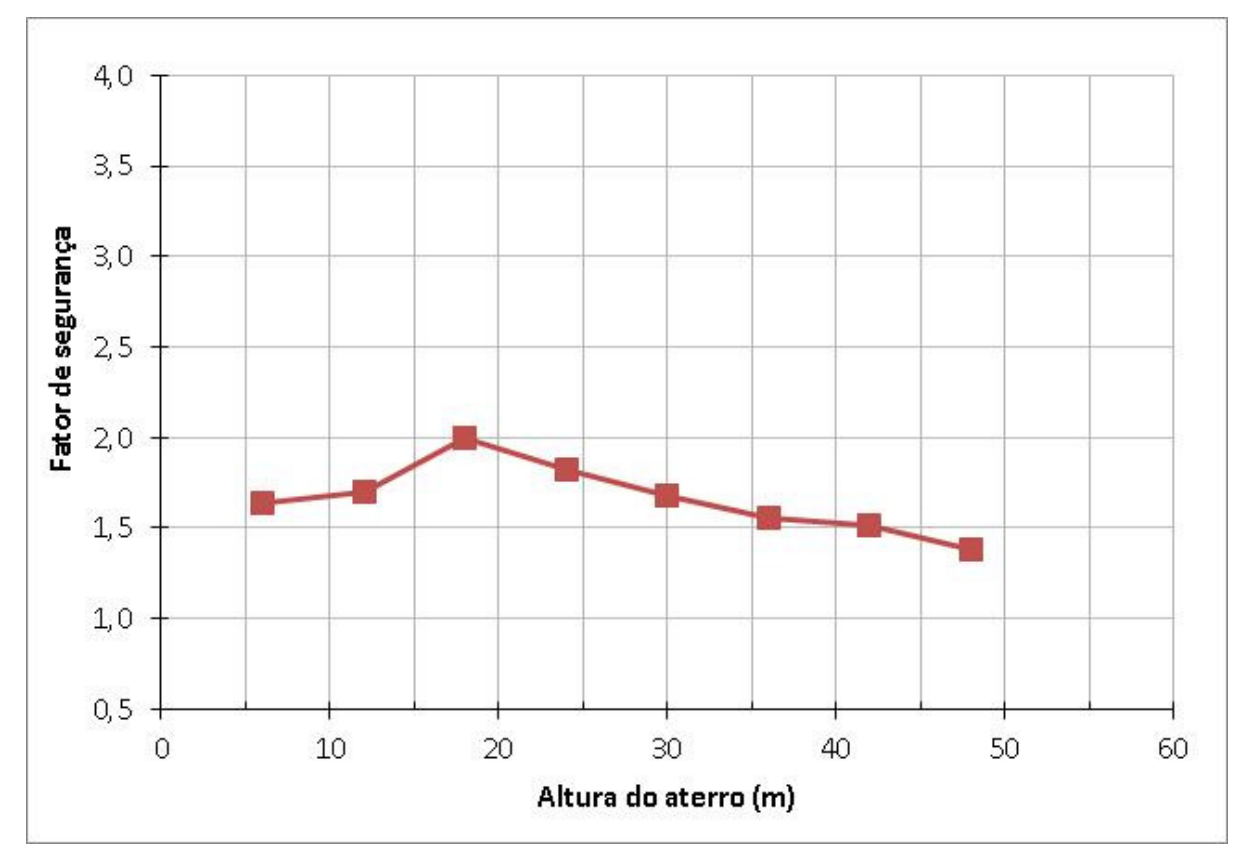

Figura 4.32 - Fatores de segurança obtidos em cada estágio de alteamento para configuração de diques sucessivos e maciço reforçado

Esses resultados têm certa lógica, uma vez que para a altura de aterro de $6 \mathrm{~m}$ a superfície de ruptura passa exclusivamente pelo dique de solo e não conta com a contribuição da resistência à tração do reforço. Para a altura de aterro de $12 \mathrm{~m}$, a superfície de ruptura também passa pelos diques de solo, porém já conta com a contribuição da resistência à tração do reforço posicionado entre as duas primeiras camadas de resíduos. Para a altura de aterro de $18 \mathrm{~m}$, a superfície de ruptura passa 
parcialmente pelos diques de solo e parcialmente pelos resíduos, contando com a contribuição de dois reforços, o que resulta ainda em aumento do fator de segurança. Para alturas superiores a $24 \mathrm{~m}$, a superfície de ruptura passa exclusivamente pelos resíduos, por trás dos diques, e também conta com a resistência à tração dos reforços, porém os resíduos apresentam menor resistência do que a argila compactada. Por outro lado, esses resultados mostram uma incongruência do "software", uma vez que a estabilidade do aterro para alturas até $30 \mathrm{~m}$ fica condicionada à estabilidade local dos diques, cujo fator de segurança é da ordem de 1,54, portanto o fator de segurança deve ficar limitado superiormente a este valor.

Os fatores de segurança considerando-se o limite superior de 1,54 (estabilidade do dique) são apresentados na Figura 4.33.

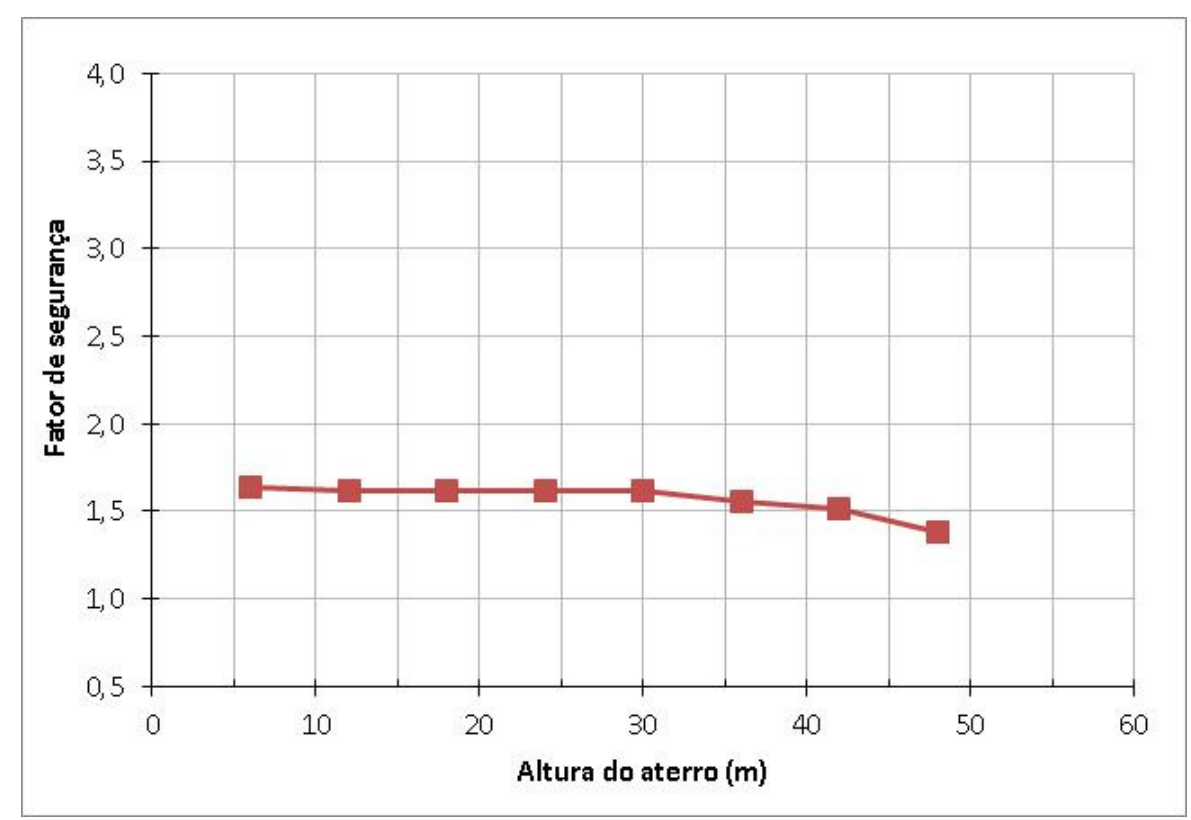

Figura 4.33 - Fatores de segurança corrigidos em cada estágio de alteamento para configuração de diques sucessivos e maciço reforçado

Analisando-se em conjunto os resultados das análises tensão-deformação e de equilíbrio limite para a mesma configuração nota-se que os fatores de segurança são compatíveis. Na configuração de diques sucessivos reforçados, os fatores de segurança obtidos pelas análises tensão-deformação aproximam-se bastante dos resultados obtidos nas análises de equilíbrio limite para $r_{u}=0,1$, conforme pode-se observar na Figura 4.34. 


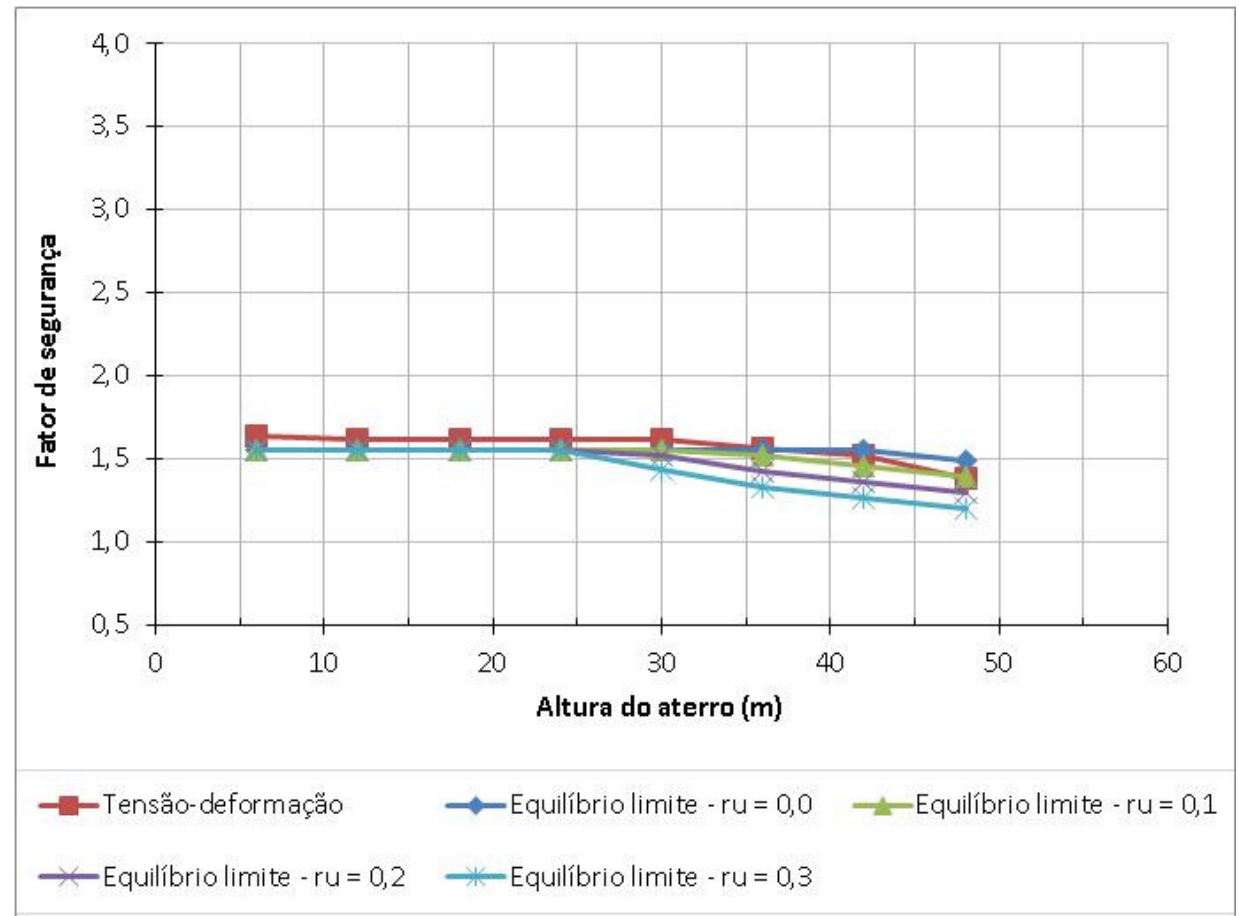

Figura 4.34 - Comparação entre os resultados das análises tensão-deformação e equilíbrio limite para configuração de diques sucessivos e maciço sanitário reforçado

As deformações e deslocamentos para esta configuração estão apresentados, respectivamente, na Figura 4.35 e na Figura 4.36. As deformações máximas verificadas para a configuração de diques sucessivos e maciço reforçado chegam a cerca de $4 \%$ para $48 \mathrm{~m}$, sendo essencialmente verticais; as deformações horizontais chegam a cerca de 1,8\% para a mesma altura. Em comparação com as alternativas sem reforço geossintético no interior do maciço sanitário, as deformações para a situação com maciço reforçado apresentam principalmente menores deformações horizontais, que chegam a ser cerca de $1 \%$ menores do que a configuração sem reforço para altura de $36 \mathrm{~m}$ (maior altura atingida para configuração sem reforço no maciço sanitário). 


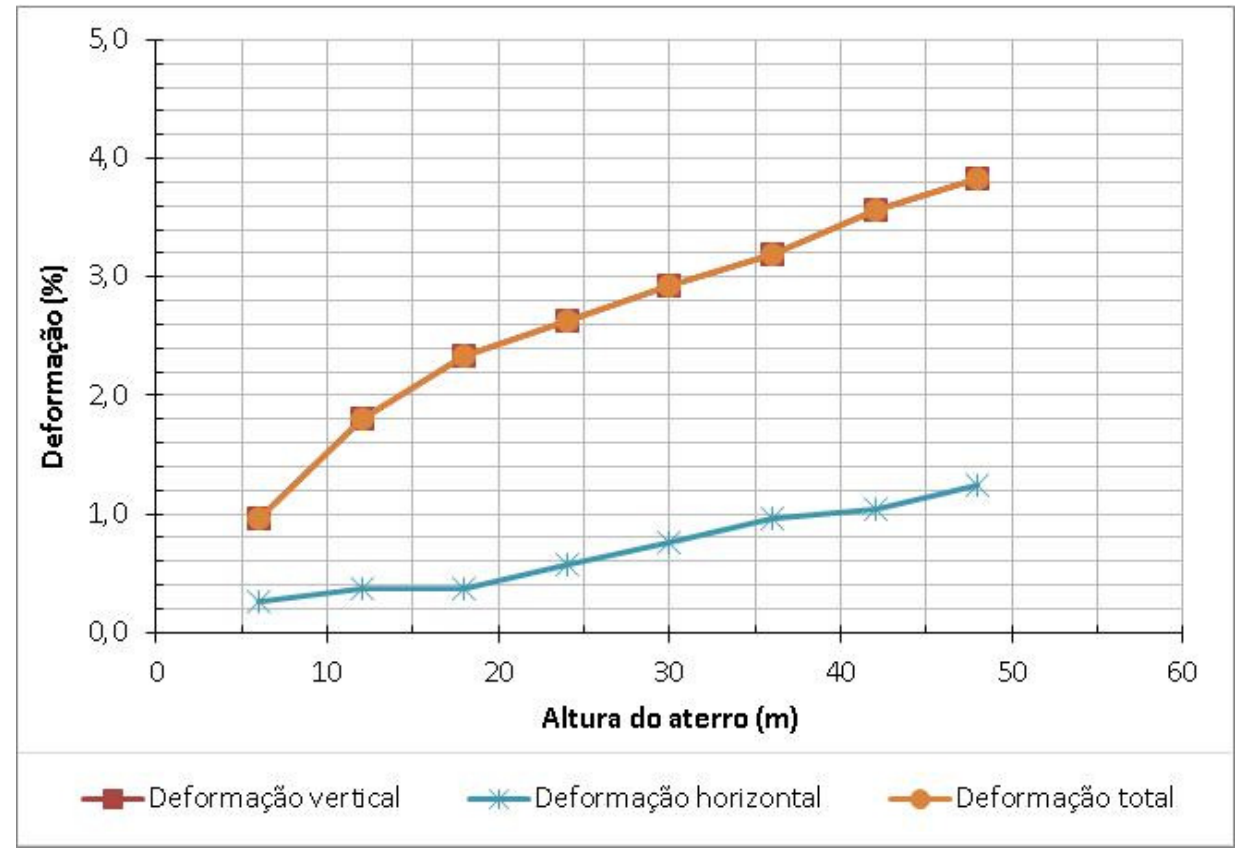

Figura 4.35 - Deformações para configuração em diques sucessivos e maciço reforçado

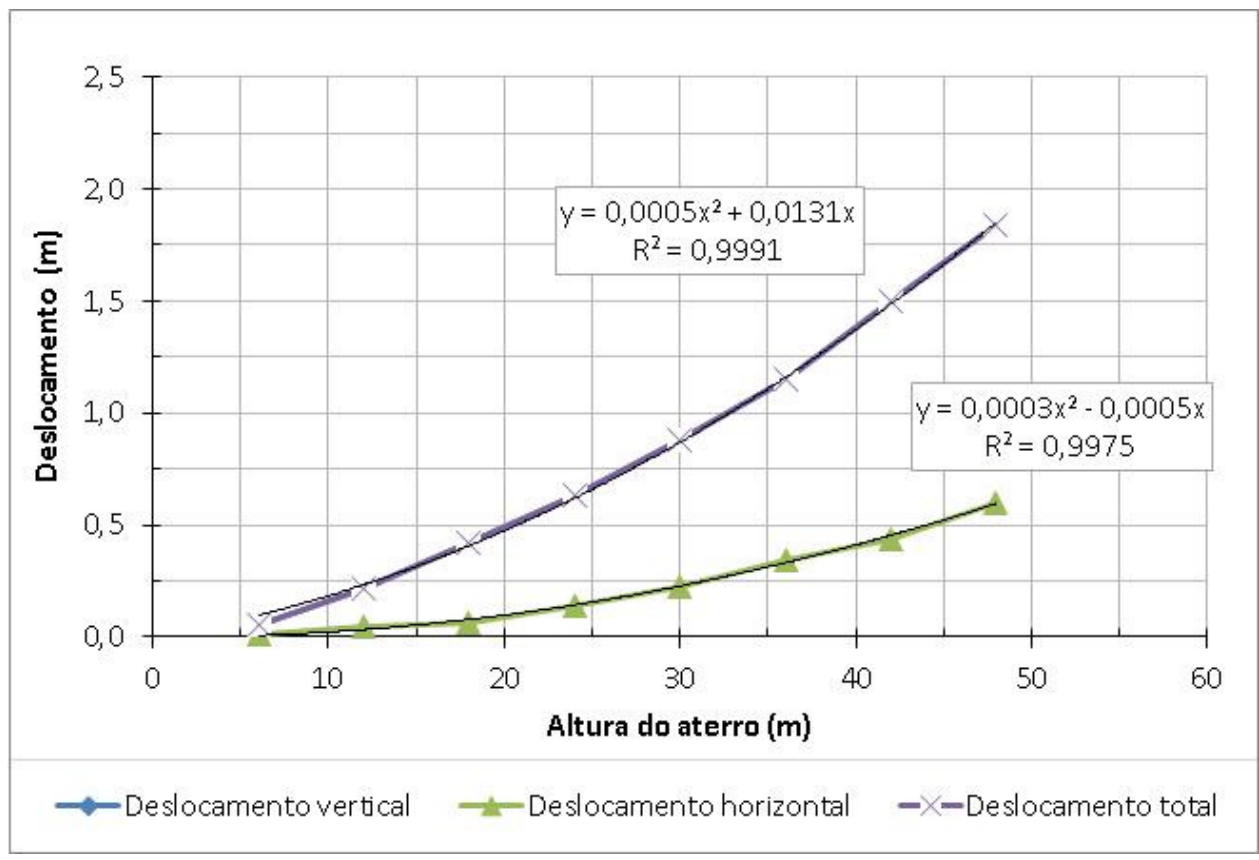

Figura 4.36 - Deslocamentos para configuração em diques sucessivos e maciço reforçado

Para a configuração de alteamentos realizados através de diques sucessivos reforçados e maciço reforçado, os resultados apresentados na Figura 4.37, indicam que a estabilidade do aterro é garantida para a altura máxima estudada $(48 \mathrm{~m}) \mathrm{com}$ fator de segurança de 1,28 , porém abaixo do valor mínimo estipulado para final de construção $(1,5)$. 


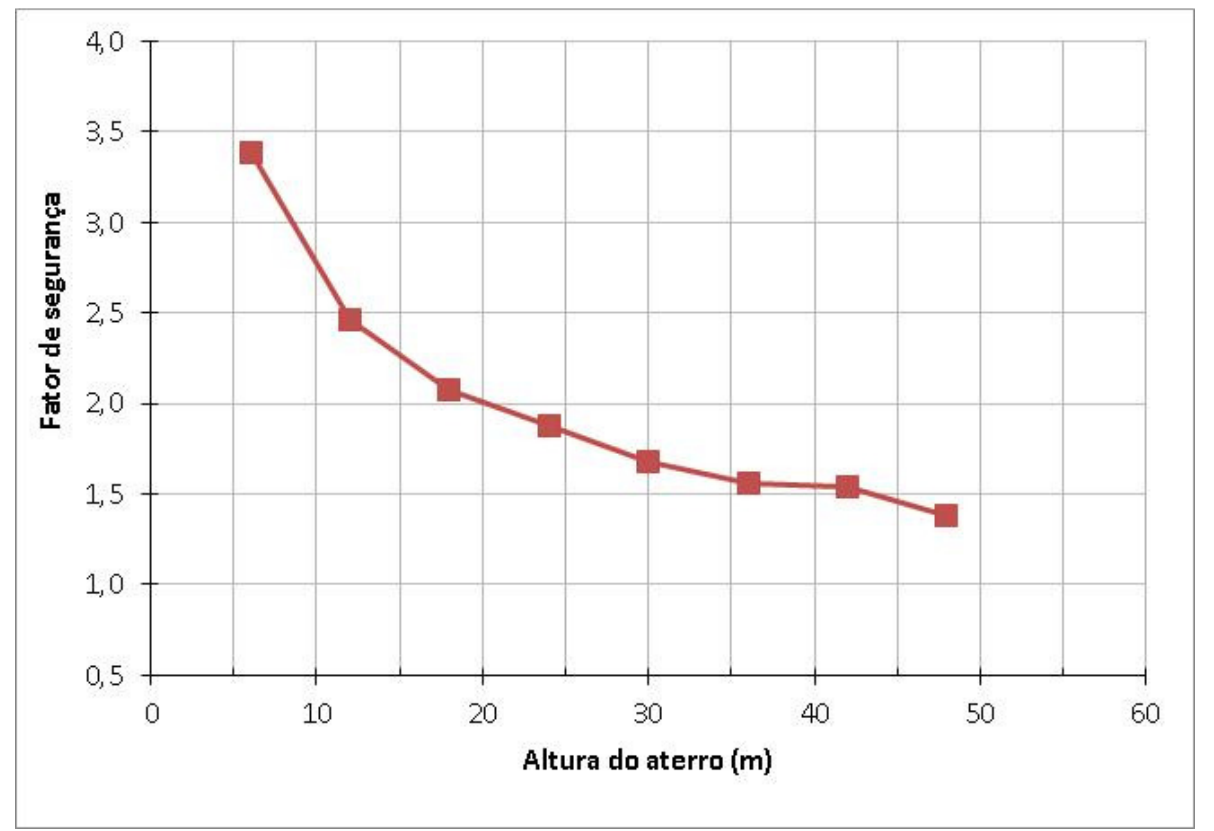

Figura 4.37 - Fatores de segurança obtidos para cada etapa de alteamento para configuração de diques sucessivos reforçados e maciço reforçado

A Figura 4.38 mostra que os resultados obtidos nas análises tensão-deformação na condição sem interface estrutural situam-se bem próximos aos resultantes das análises de equilíbrio limite com $r_{u}=0,1$.

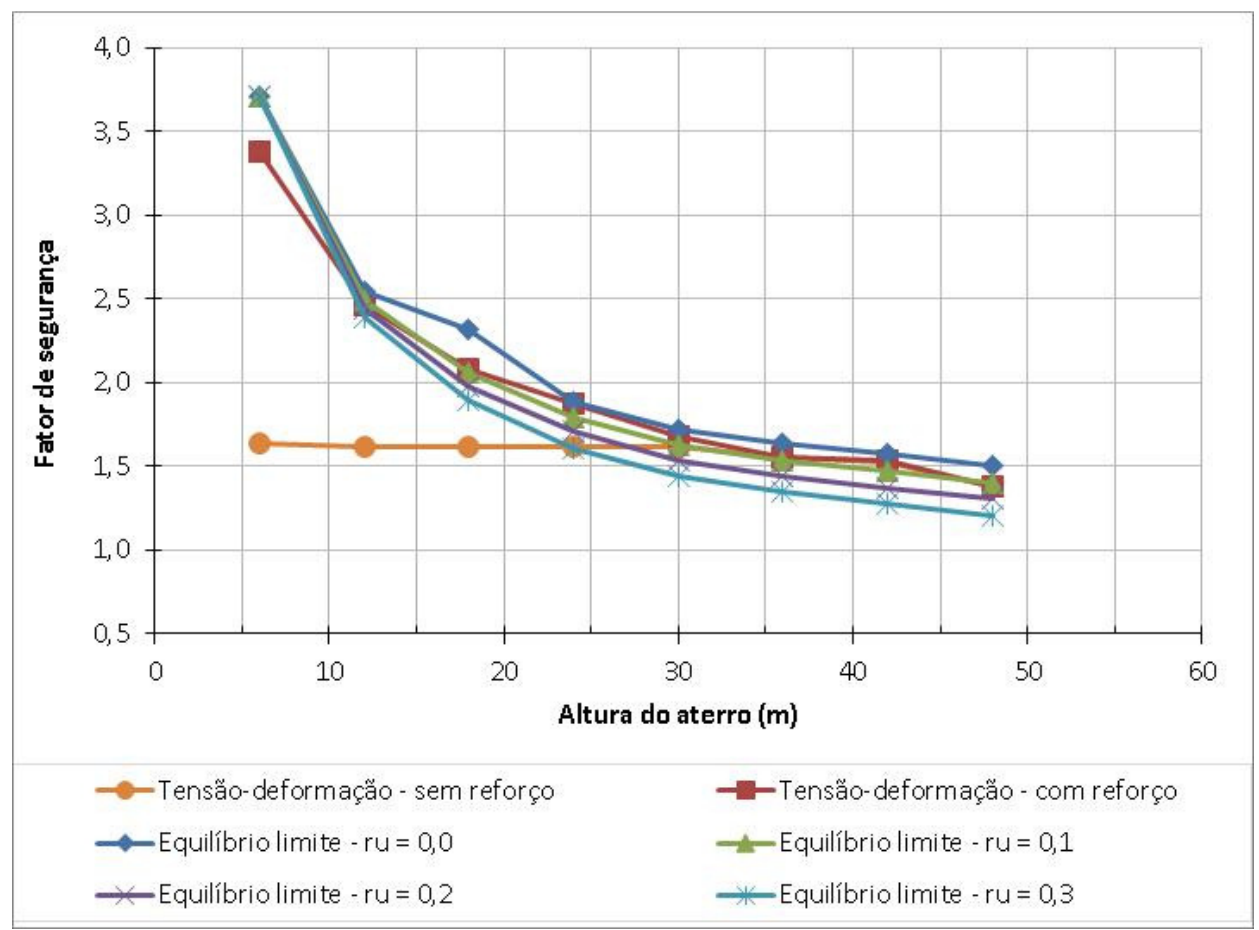

Figura 4.38 - Comparação entre os resultados das análises tensão-deformação e equilíbrio limite para configuração de diques sucessivos com e sem reforço e maciço sanitário reforçado 
Estando o maciço reforçado, o fator de segurança 1,5 seria atendido para uma altura de até $30 \mathrm{~m}$ e a estabilidade para altura de $48 \mathrm{~m}$ também estaria garantida ( $F S \geq 1$ ), com diques reforçados ou não. Para a altura final estudada, $48 \mathrm{~m}$, o fator de segurança seria igual a 1,28.

Na Figura 4.39 são apresentados os valores de deslocamento vertical, horizontal e total para as configurações sem e com reforço nos diques e maciço reforçado.

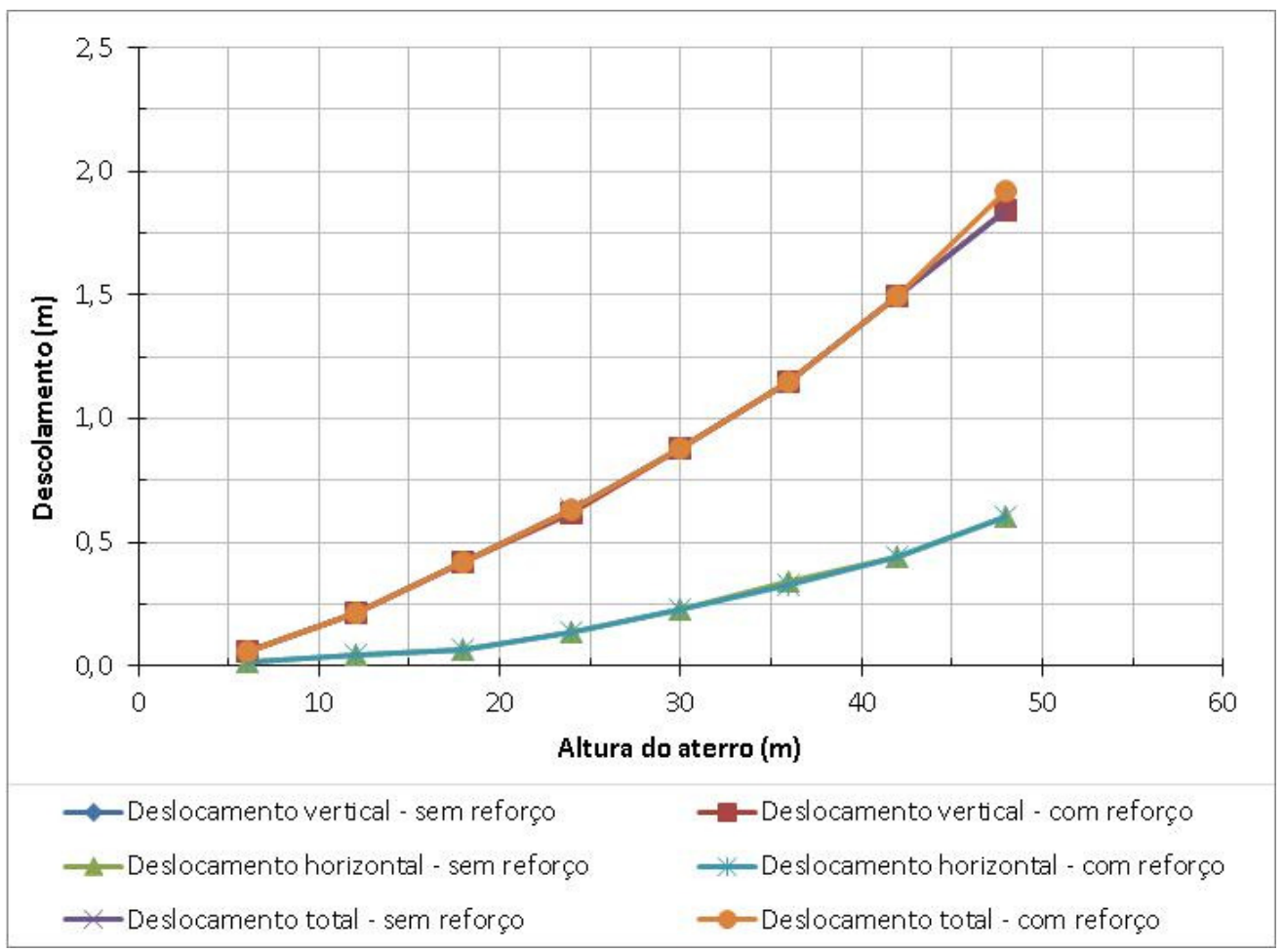

Figura 4.39 - Deslocamentos obtidos para as configurações sem e com reforço nos diques e maciço reforçado

Nota-se que os deslocamentos são praticamente iguais e essencialmente verticais nas duas configurações. Os deslocamentos horizontais representam em média cerca de $30 \%$ dos deslocamentos totais, conforme mostra a Figura 4.39. As maiores deformações verticais medidas (Figura 4.40) são da ordem de 4\% para o aterro com $48 \mathrm{~m}$ de altura, valor inferior aos encontrados na bibliografia (10 a $30 \%$ ) e que consideram a biodegradação dos materiais orgânicos que compõe o maciço. 


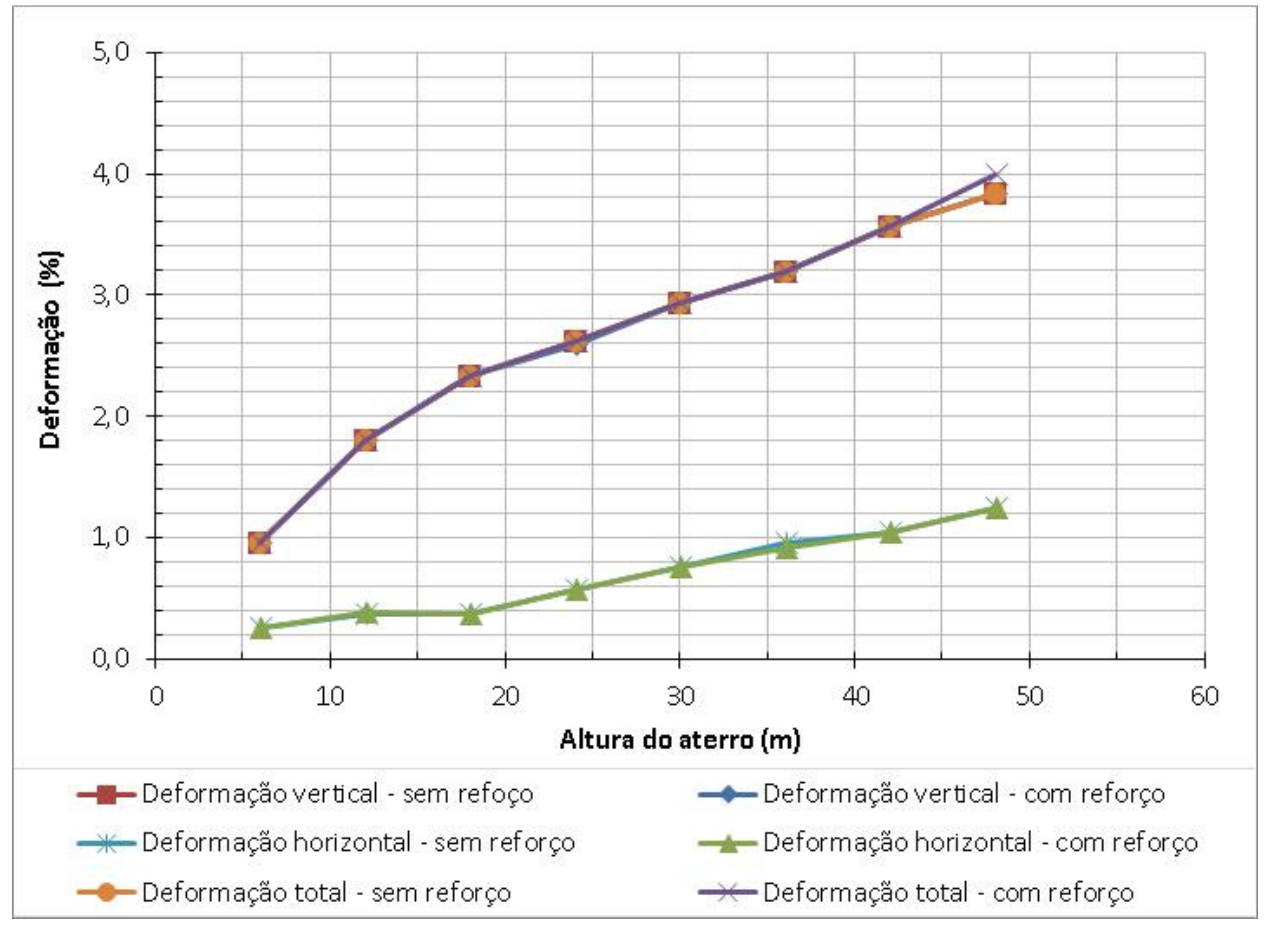

Figura 4.40 - Deformações obtidas para as configurações sem e com reforço nos diques e maciço reforçado

Na Figura 4.41 são apresentados os resultados obtidos de fator de segurança nas análises tensão-deformação para as configurações estudadas.

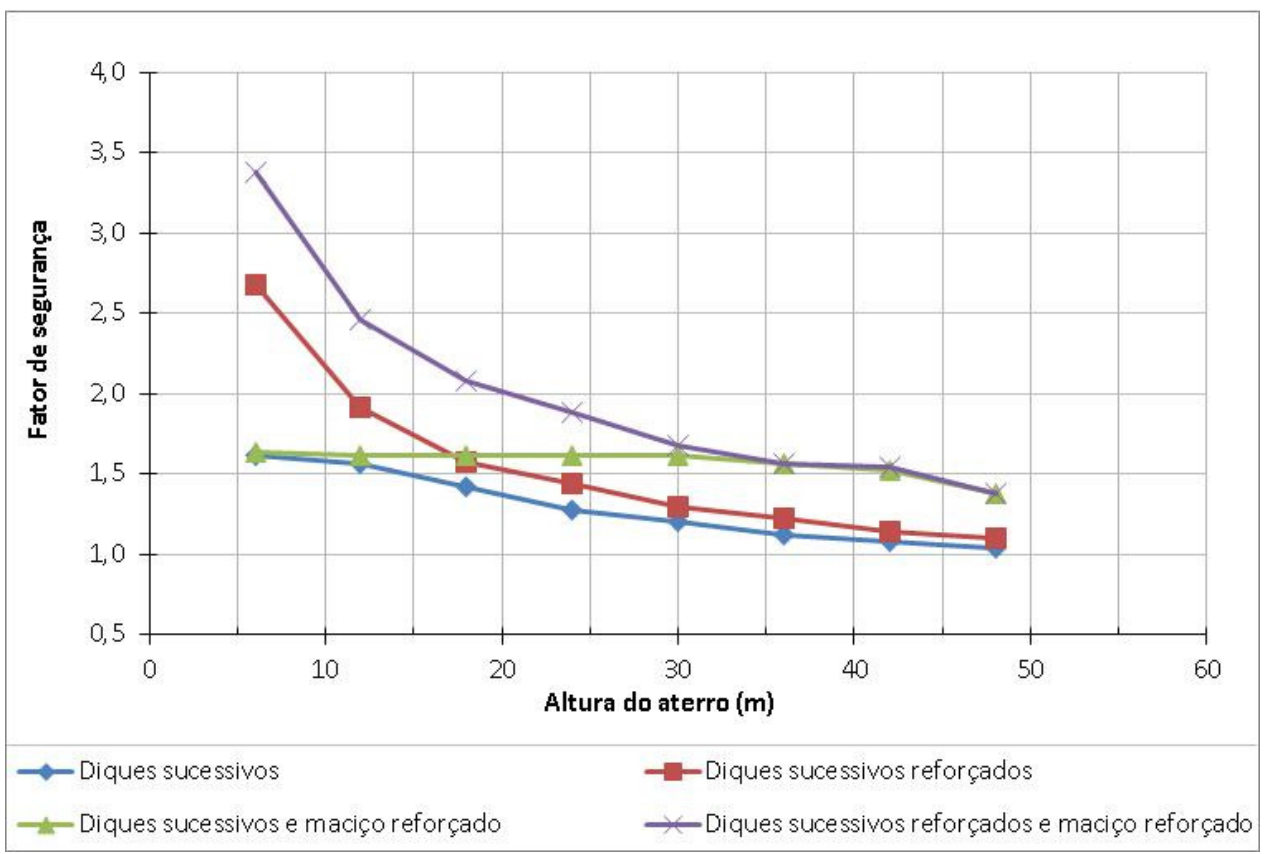

Figura 4.41 - Comparação dos resultados obtidos nas análises tensão-deformação para as configurações estudadas 
A configuração com diques e maciço reforçados apresentou os maiores valores de fator de segurança e permitiria a execução do aterro com $48 \mathrm{~m}$ de altura, embora com fator de segurança abaixo de 1,5, para a geogrelha considerada no estudo. É possível que com a utilização de reforços com maior resistência ou com a introdução de mais reforços no interior do maciço seja atingido o fator de segurança desejado. Os resultados confirmam a eficácia da utilização dos reforços para o alteamento dos aterros, uma vez que as configurações sem reforço no maciço sanitário não se mantiveram estáveis para todas as alturas analisadas.

Em continuação, analisou-se a mesma geometria do aterro considerando uma interface estrutural entre o reforço geossintético no interior do maciço sanitário e os RSU. Os resultados obtidos, utilizando os parâmetros "default" do "software" para a camada granular no qual o reforço encontra-se inserido, são apresentados na Figura 4.42.

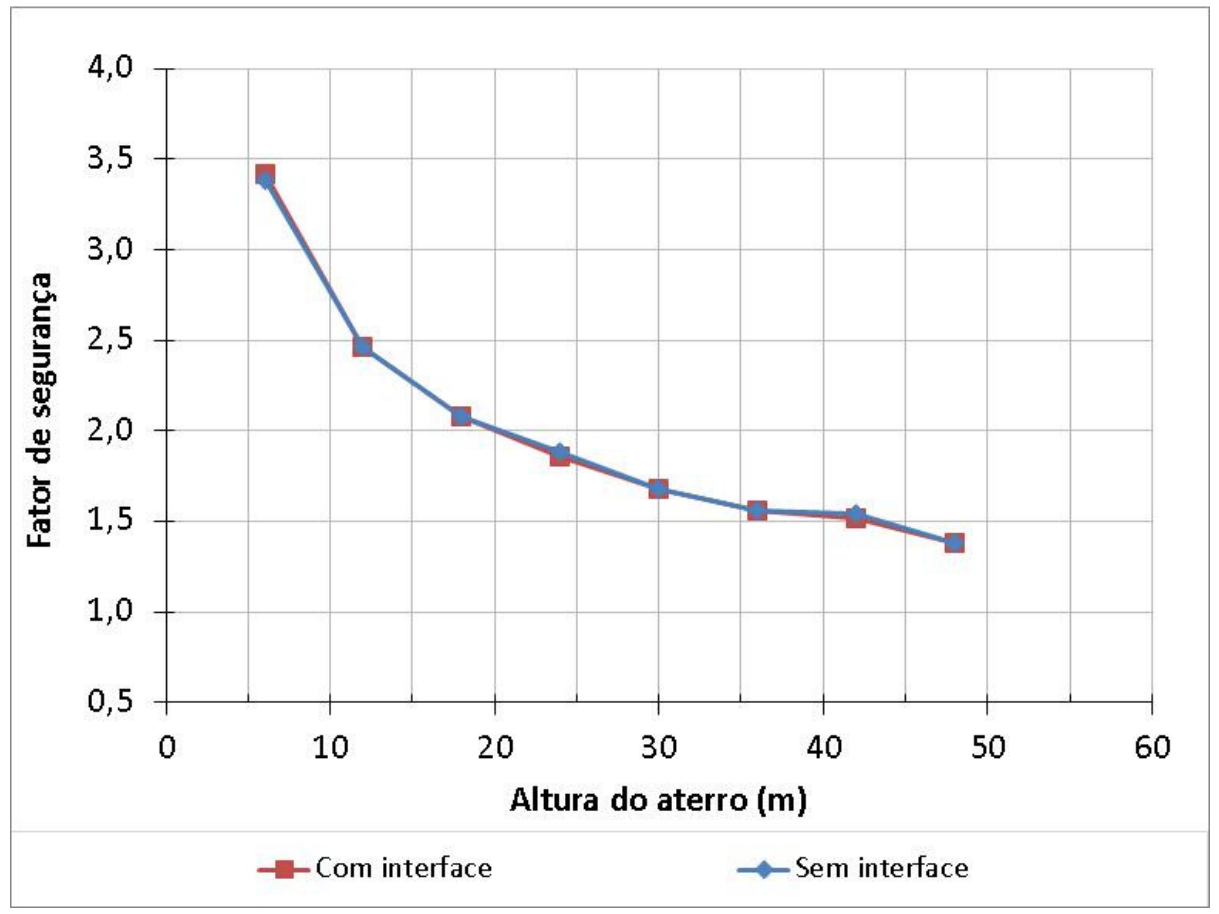

Figura 4.42 - Comparação entre fatores de segurança com e sem interface estrutural no reforço geossintético

A consideração da interface estrutural, utilizando os parâmetros do "software", não resultou em diferenças significativas nos fatores de segurança. Os deslocamentos e as deformações máximas (Figuras 4.41 e 4.42), por outro lado, mostraram-se 
ligeiramente superiores aos obtidos nas análises sem interface estrutural, conforme mostram as Figuras 4.41 e 4.42.

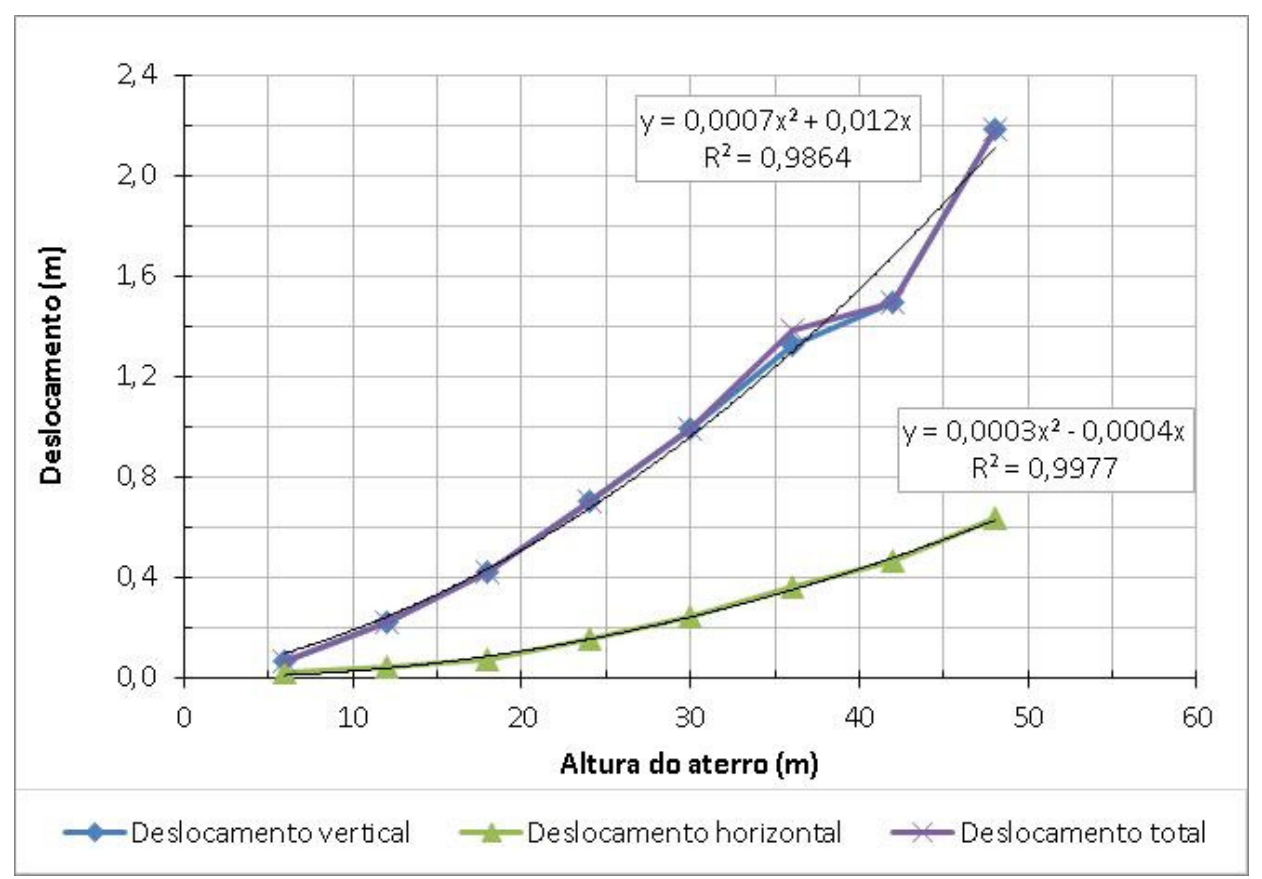

Figura 4.43 - Deslocamentos máximos obtidos nas análises com interface estrutural

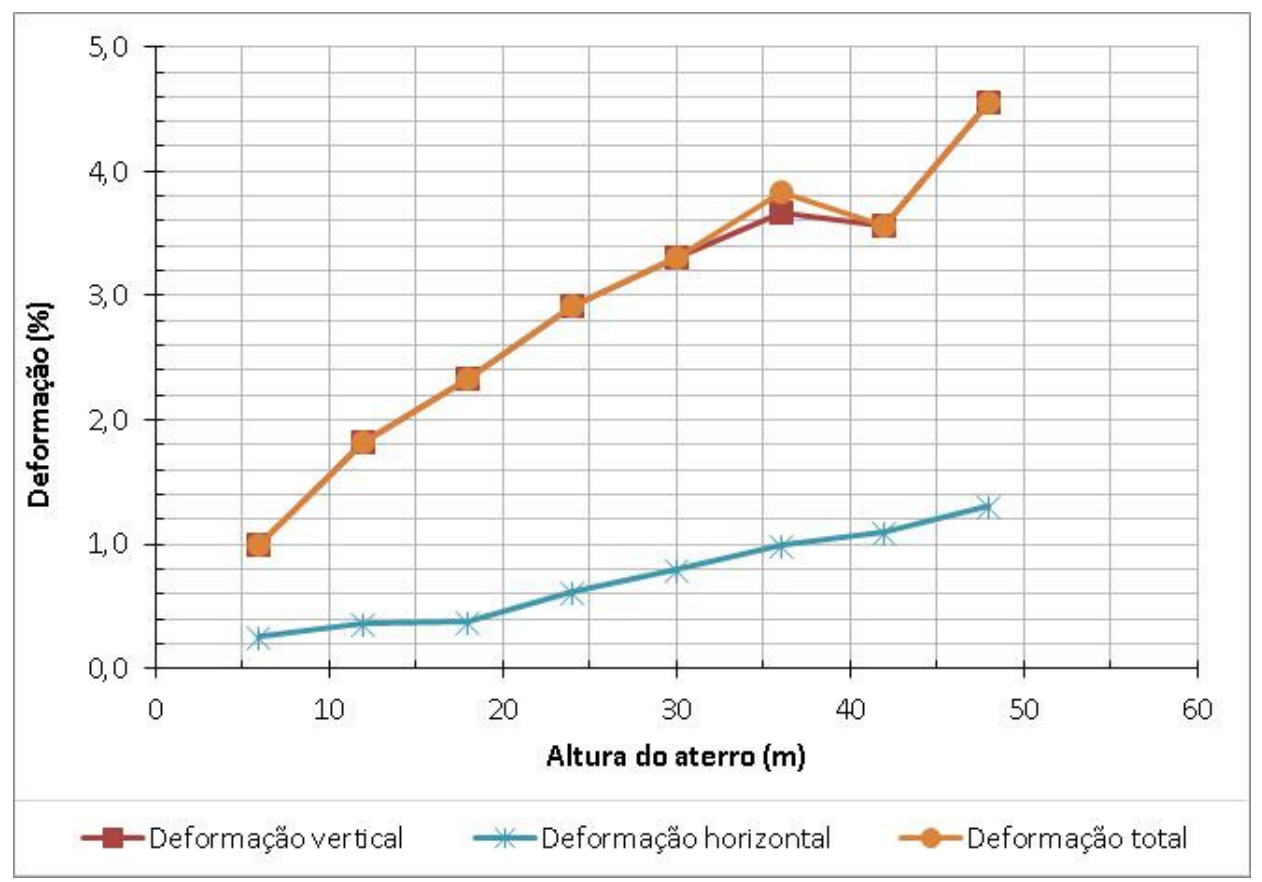

Figura 4.44 - Deformações máximas obtidas nas análises com interface estrutural 


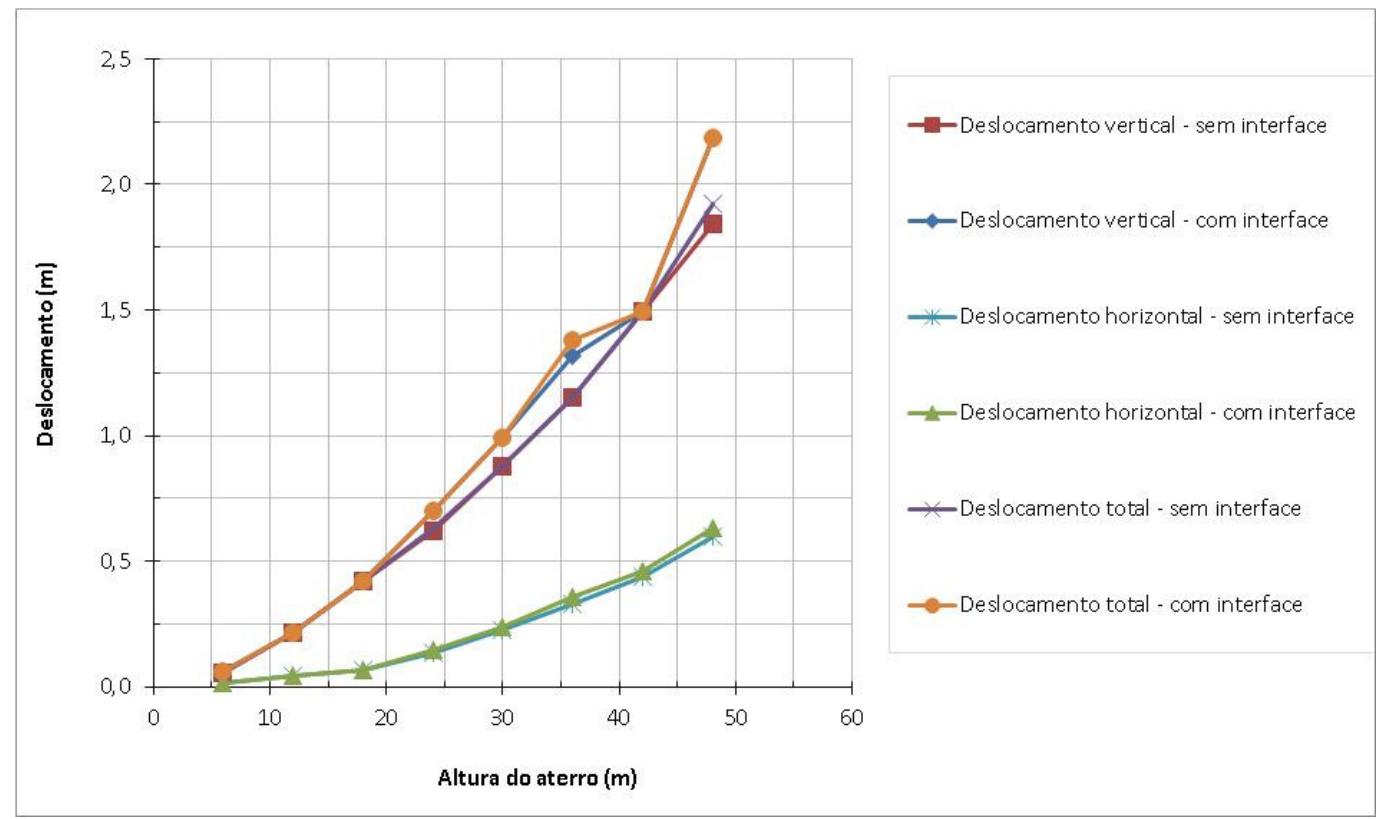

Figura 4.45 - Comparação entre os valores de deslocamento com e sem interface estrutural

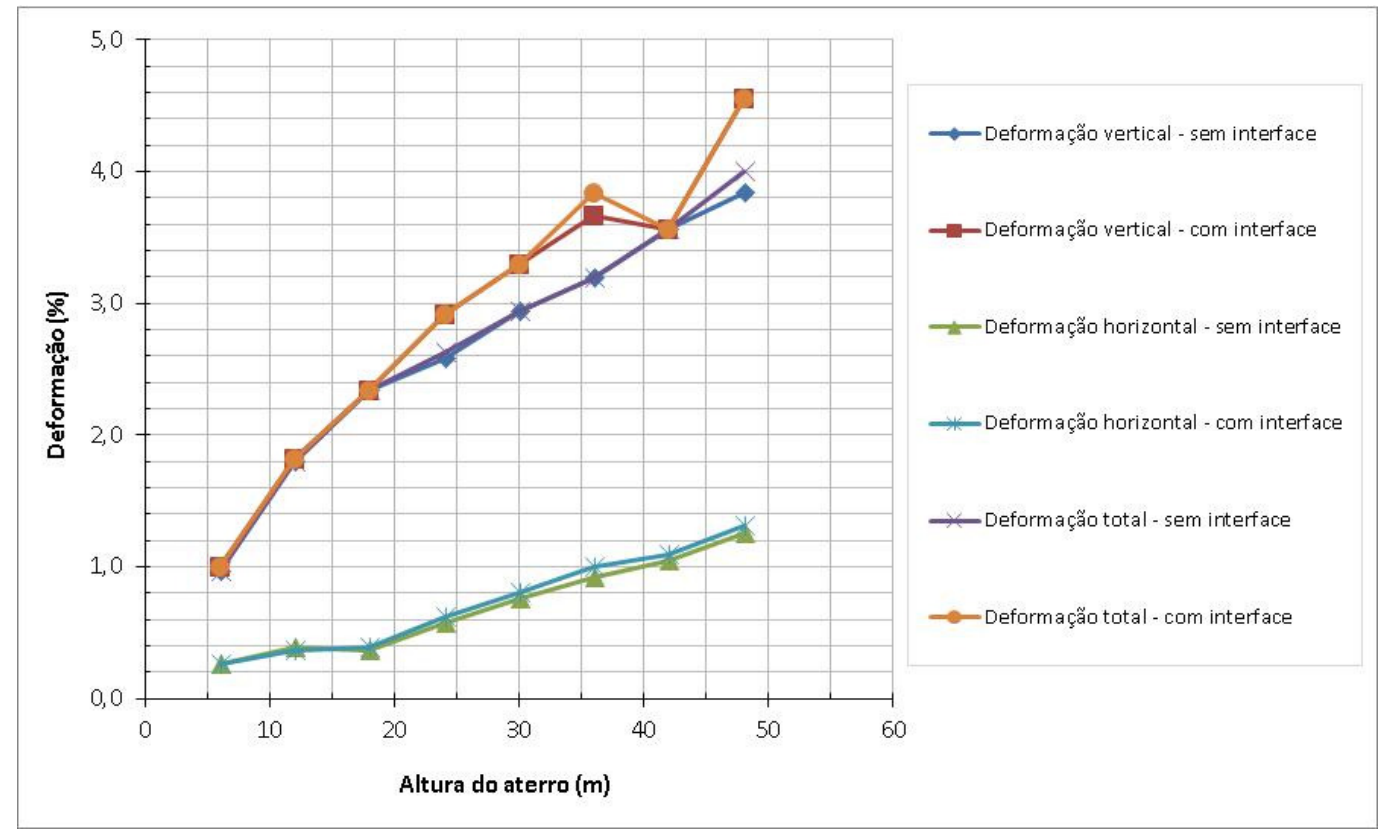

Figura 4.46 - Comparação entre os valores de deformação com e sem interface estrutural

Os valores de deslocamento e deformação mostram-se maiores para a situação com interface estrutural, embora a diferença entre os valores seja pequena (inferior a $5 \%$ ) para os parâmetros utilizados para a interface.

$\mathrm{Na}$ Tabela 4.2 são apresentados os resultados obtidos nas análises tensãodeformação. 
Tabela 4.2 - Resumo dos resultados obtidos nas análises tensão-deformação

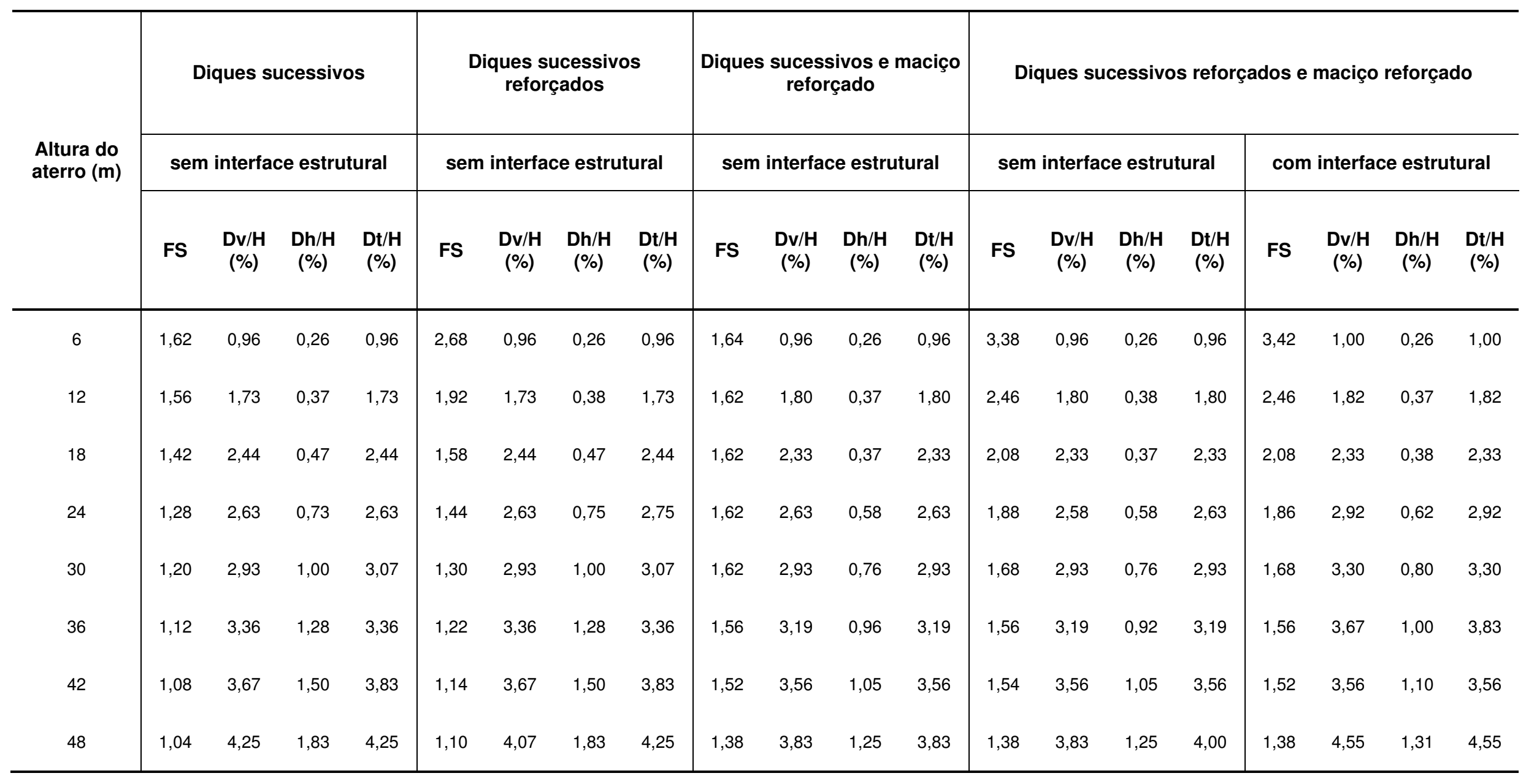




\subsection{CONSIDERAÇÕES ADICIONAIS}

O reforço de aterros sanitários por meio da inserção de geossintéticos no meio da massa de resíduos suscita algumas dúvidas no meio geotécnico:

- Como será o comportamento da geogrelha em meio a um material muito heterogêneo como o lixo?

- A que magnitude de deformações a geogrelha estará sujeita nos aterros sanitários?

- A geogrelha sofrerá alguma degradação adicional no meio dos RSU?

Com relação à primeira pergunta, relativa à interação entre a geogrelha e a massa de lixo, a imagem frequentemente associada é de uma geogrelha em meio a pneus, televisões, geladeiras, sofás e outros materiais de granulometrias diversas. No entanto, os resíduos dispostos nos aterros sanitários são compostos basicamente por lixo doméstico e público (de varrição e limpeza pública), cujos compostos possuem granulometria mais uniforme. Resíduos de construção e demolição, resíduos volumosos e pneus têm disposição específica. As diversas resoluções CONAMA nos últimos anos e a recente aprovação da Política Nacional de Resíduos Sólidos (BRASIL, 2010) têm conduzido a uma seleção do lixo a ser disposto nos aterros sanitários, que se intensificará no futuro próximo com a regulamentação da Lei Federal no 12.305/2010.

$\mathrm{Na}$ prática, para melhorar o entrosamento da geogrelha no interior do maciço sanitário, o método construtivo prevê a inserção dos reforços em meio a uma camada granular de areia (sanduíche), conforme as análises realizadas considerando a interface estrutural.

Para comprovar e permitir a obtenção de parâmetros fidedignos ao modelo analisado é interessante a realização de ensaios de arrancamento em maciço experimental, o que porém não faz parte do escopo deste trabalho.

Com relação às grandes deformações devidas a recalques diferenciais da massa subjacente de resíduos, vale lembrar que nas configurações apresentadas as geogrelhas são instaladas na base do aterro e a cada $6 \mathrm{~m}$ de altura, incluindo a base do dique subsequente.

Nos aterros sanitários a disposição dos resíduos é feita pelo preenchimento de células. A sobreposição das células (que corresponde à construção dos diques) é 
feita no mínimo após meses, garantindo-se a decomposição aeróbia dos RSU, e geralmente, dependendo da ocupação em aterros de grande porte, pode ocorrer depois de anos, quando se processou grande parte dos recalques devidos à decomposição anaeróbia acelerada. Sendo assim, no momento da instalação das geogrelhas do próximo nível, grande parte dos recalques já ocorreu. Esses recalques e seu desenvolvimento no tempo podem ser previstos por meio de diversos modelos como o Modelo Clássico, Modelo de Zimmerman et. al (1977), Meruelo, Simões e Campos (2003), Marques et al. (2002), entre outros.

Isto leva a outra questão: com a ocorrência dos recalques antes da instalação do reforço subsequente, um degrau pode se formar entre o dique de solo e a massa de resíduos. Neste caso, tanto a ancoragem da geogrelha como o comportamento da geogrelha podem ser alterados. Isto não foi analisado neste trabalho, que enfocou a avaliação preliminar da segurança estrutural das diversas configurações de alteamento. Os detalhes construtivos são importantes pontos de estudo para trabalhos subsequentes.

Sobre a última questão, há carência de dados sobre a sinergia de fatores que interferem na resistência e em outros parâmetros do reforço, como por exemplo, da degradação química, pela ação do lixiviado, e térmica, pela ação da temperatura na massa de resíduos, que pode chegar a $70^{\circ} \mathrm{C}$. Ensaios laboratoriais visando ao estudo da sinergia desses fatores podem trazer resultados aplicáveis ao projeto do maciço sanitário reforçado com geogrelhas. 


\section{CONCLUSÕES}

O presente trabalho apresentou um estudo para a verticalização de aterros sanitários por meio de reforço com geogrelhas e diques periféricos alteados pelo método de montante. O conceito de verticalização adotado visa o ganho de volume de disposição de resíduos sólidos urbanos pelo aumento da altura dos aterros sanitários, e não pelo aumento da inclinação dos taludes. No estudo foram realizadas análises de estabilidade utilizando métodos de equilíbrio limite e análises tensão-deformação.

As análises de estabilidade por métodos de equilíbrio limite mostraram que:

- A construção de alteamento das células com diques periféricos sucessivos de solo não aumentaria significativamente o fator de segurança de um aterro de até $48 \mathrm{~m}$ de altura, mantendo-se as características de largura das bermas e altura e espaçamento dos taludes. Isto se deve provavelmente ao aumento do peso próprio da seção mista sem contrapartida de aumento de resistência no círculo crítico, o qual passa pela massa de resíduos.

- A utilização de geogrelhas para reforço dos diques periféricos sucessivos promove o aumento dos fatores de segurança para alturas até $30 \mathrm{~m}$, sendo pouco significativa a variação no fator de segurança para alturas superiores.

- A utilização de geogrelhas no maciço sanitário aumenta consideravelmente o fator de segurança de aterros sanitários até $48 \mathrm{~m}$.

- As pressões neutras no interior da massa de resíduos, decorrentes da compactação, sobrecarga das camadas sobrejacentes, infiltração de águas pluviais e geração de lixiviado e gases, representadas conjuntamente pelo parâmetro de pressão neutra $r_{u}(0,0$ a 0,3), influenciam significativamente o fator de segurança dos aterros. Conforme a configuração, a variação de $r_{u}$ de 0,0 a 0,3 proporciona uma redução no fator de segurança de 7 a 24\%, evidenciando a importância do funcionamento adequado dos sistemas de drenagem interno e externo do aterro.

- O fator de segurança igual ou maior a 1,5 seria atendido, para as configurações normal de taludes e bermas, diques periféricos sucessivos não reforçados, diques periféricos sucessivos reforçados, diques periféricos sucessivos não reforçados e 
maciço reforçado, e diques periféricos sucessivos reforçados e maciço reforçado, com as alturas, respectivamente, de $12 \mathrm{~m}, 14 \mathrm{~m}, 18 \mathrm{~m}, 30 \mathrm{~m}$ e $30 \mathrm{~m}$. para $r_{u}=0,2$.

As análises tensão-deformação permitiram as seguintes conclusões:

- Os deslocamentos para as configurações estudadas são essencialmente verticais. Os deslocamentos horizontais representam em média cerca de $30 \%$ dos deslocamentos totais.

- As máximas deformações verticais são da ordem de 4\% para o aterro com 48m de altura, inferiores aos valores encontrados na bibliografia (10 a 30\%), os quais incluem a biodegradação da matéria orgânica que compõe o maciço e os recalques por "creep". Isso mostra que a maior parcela dos recalques são decorrentes da degradação anaeróbica da matéria orgânica presente nos resíduos e do "creep", mais do que do peso próprio das camadas sobrejacentes, e ocorrem ao longo do tempo.

- Os resultados das análises considerando a existência de uma interface estrutural (areia) entre o reforço no interior do maciço sanitário e as camadas adjacentes não diferiram significativamente dos fatores de segurança e das deformações obtidos sem a interface. Foram utilizados os valores de parâmetros (rigidez normal e rigidez cisalhante) "default" do "software". A obtenção de parâmetros reais dessa camada é interessante para confirmação dos resultados.

- Uma limitação da análise tensão-deformação é não permitir a consideração das pressões neutras diretamente, por exemplo, através do parâmetro $r_{u}$. As pressões neutras foram consideradas indiretamente nos parâmetros de resistência e deformabilidade dos materiais. Os parâmetros de deformabilidade utilizados nas simulações, por exemplo, foram obtidos de ensaios in situ realizados em aterros sanitários, nas condições de campo.

A comparação com os resultados das análises tensão-deformação e por métodos equilíbrio limite permite concluir que:

- As análises tensão-deformação para as configurações em diques sucessivos reforçados, diques sucessivos e maciço sanitário reforçado e diques sucessivos reforçados e maciço reforçado apresentam fatores de segurança compatíveis com os resultados obtidos nas análises equilíbrio-limite para $r_{\mathrm{u}}=0,1$. 
- Para ambas as metodologias, os resultados mostraram que o uso de reforços no interior do maciço sanitário proporciona um aumento no fator de segurança da ordem de $30 \%$, o que justifica a continuação deste estudo.

- A configuração em diques sucessivos e maciço sanitário reforçado mostrou-se, dentre as alternativas estudadas, a mais eficiente e eficaz para a configuração de aterro estudada, uma vez que permitiu obter o fator de segurança desejado sem a necessidade de reforço dos diques de solos.

- Os resultados também indicam que os taludes do aterro podem ser mais inclinados se forem utilizados reforços com maior resistência ou com o aumento da densidade de reforços, o que seria um aspecto adicional para acréscimo do volume de resíduos a ser disposto.

- Apesar de outros aspectos que devem ser incorporados para uma conclusão definitiva sobre a aplicação das geogrelhas como reforço de maciços sanitários, principalmente relacionados a aspectos construtivos e operacionais, as análises efetuadas forneceram uma avaliação preliminar positiva em termos de estabilidade estrutural da utilização de alteamento por diques periféricos sucessivos e, principalmente, do reforço dentro do maciço sanitário.

- É imprescindível que esses dados sejam validados por experimentos de campo com monitoramento dos deslocamentos. 


\section{SUGESTÕES PARA PESQUISAS FUTURAS}

Como sugestão para pesquisas futuras colocam-se os seguintes aspectos:

- Realização de ensaios de arrancamento de reforços em meio a uma camada de areia, a fim de obter parâmetros reais para a modelagem da interface estrutural entre os RSU e o reforço;

- Execução de um aterro experimental com dique periférico de solo compactado e reforço na massa de resíduos, com instrumentação capaz de mensurar os níveis de deformação em diferentes profundidades da massa de resíduos e dos reforços, em diversas etapas executivas;

- Realização de estudos para avaliar a verticalização dos aterros sanitários através da inclinação dos taludes;

- Realização de análises de sensibilidade para verificar qual a relação entre os parâmetros analisados e os fatores de segurança;

- Realização de ensaios de degradação combinada (química e térmica) dos reforços geossintéticos para verificar sua influência na resistência e deformabilidade dos reforços. 


\section{REFERÊNCIAS BIBLIOGRÁFICAS}

ABNT - Associação Brasileira de Normas Técnicas (1985). NBR-8849 Apresentação de Projetos de Aterros Controlados de Resíduos Sólidos Urbanos - Classificação.

ABNT - Associação Brasileira de Normas Técnicas (2004). NBR-10004 Resíduos Sólidos - Classificação.

ABNT - Associação Brasileira de Normas Técnicas (2004). NBR-10005 Procedimento para Obtenção de Extrato Lixiviado de Resíduos Sólidos.

ABNT - Associação Brasileira de Normas Técnicas (2004). NBR-10006 Procedimento para Obtenção de Extrato Solubilizado de Resíduos Sólidos.

ABNT - Associação Brasileira de Normas Técnicas (2004). NBR-10007 Amostragem de Resíduos Sólidos.

ABNT - Associação Brasileira de Normas Técnicas (2009). NBR-11682 Estabilidade de Taludes.

ABNT - Associação Brasileira de Normas Técnicas (2003). NBR-12553 Geossintéticos - Terminologia.

ABNT - Associação Brasileira de Normas Técnicas (2005). NBR-15226 Geossintéticos - Determinação do Comportamento em Deformação e na Ruptura, por Fluência sob Tração Não-Confinada.

ABNT - Associação Brasileira de Normas Técnicas (2010). NBR-15849 Aterros Sanitários de Pequeno Porte - Diretrizes para localização, Projeto, Implantação, Operação e Encerramento.

Abramento, M. (1995). Durabilidade e Comportamento de longo Prazo de Geossintéticos Parte 1: Propriedades mecânicas e Hidráulicas. In: II Simpósio Brasileiro sobre Aplicações de Geossintéticos, 1995, São Paulo, 1995.

Abramento, M. (1998). Geossintéticos em Estruturas de Contenção e Taludes Íngremes. Curso sobre Aplicações de Geossintéticos em Geotecnia e Meio Ambiente, 1. São Paulo, 1998, D1-D32. 
Abramento, M. (2002). Solos reforçados com geossintéticos, Mini-curso e palestra, São Paulo, 47 p.

Abreu, R.C. (2000). Compressibilidade de maciços sanitários, Dissertação de mestrado, Escola Politécnica, Universidade de São Paulo, 241 p.

Artieres, O., Goussé, F. \& Pringent, E. (1997). Laboratory-Ageing of Geomembranes in Municipal Landfill Leachates.

Azambuja, E., (1994). Investigação de Dano Mecânico em Geotêxteis Não Tecidos. Dissertação de mestrado, Universidade Federal do Rio Grande do Sul, UFRGSCPGEC.

Azevedo, R.F; Ribeiro, A.G.C.; Azevedo, I.D. (2006). Determination of municipal solid waste strength parameters using a large dimension lisimeter test, Simpósio Internacional de Tecnologia e Tratamento de Resíduos Sólidos - SITTRS, Rio de Janeiro, CD-ROM, 8 p.

Azevedo, R. F.; Zornberg J.G.; Nogueira, C.L. (1992). Utilização do Método dos Elementos Finitos no Cálculo de Estruturas de Solos Reforçados. Seminário sobre Aplicações de Geossintéticos em Geotecnia, Faculdade de Tecnologia, Universidade de Brasília.

Azevedo, J.; Nascimento, L.C.A e Mendes, O.F. (2006), Panorama dos problemas gerados pelos resíduos sólidos urbanos no Brasil.

Azevedo, J., (2000). Informações Estatísticas dos Resíduos Sólidos Urbanos no Brasil e em algumas das suas Capitais. XXII Congresso Associação Brasileira de Engenharia Sanitária. Vitória, Espírito Santo.

Babu, G.L.S.; Reddy, K. R.; Chousey, S.K.; (2010). Constitutive Model for MSW Considering Creep and Biodegradation Effects. $6^{\text {th }}$ Internation Congress on Environmental Geotechnics, 2010, New Delhi, India.

Becker, L.B. (2006). Comportamento de geogrelhas em muros de solo reforçado e em ensaios de arrancamento. Pontífica Universidade Católica do Rio de Janeiro (PUC-RIO), Rio de Janeiro. 
Becker, L.B. (2001). Fluência de Geotêxteis Confinados em Aterro Experimental. Dissertação de Mestrado. Pontífica Universidade Católica do Rio de Janeiro (PUC-RIO), Rio de Janeiro.

Benvenuto, C.; Cunha, M.A. (1991). Escorregamento em Massa de Lixo no Aterro Sanitário Bandeirantes em São Paulo, SP, Simpósio sobre Barragens de Rejeitos e Disposição de Resíduos - REGEO'91, Rio de Janeiro, p. 55-61.

Benvenuto, C.; Cipriano, M.A. (2010). Modelo Reológico de Comportamento de Resíduos e Aterros Sanitários, Segundo Critérios de Projeto e operação Atuais no Brasil. Revista Limpeza Pública, n.74. p.42 - 47.

Borgatto, A. V. A. (2006). Estudo do Efeito Fibra e da Morfologia na Estabilidade de Aterros de Resíduos Sólidos Urbanos. Dissertação de Mestrado. Universidade Federal do Rio de Janeiro (COPPE), Rio de Janeiro.157p.

Boscov, M.E.G.; Abreu, R.C. (2000). Aterros sanitários. Previsão de Desempenho x Comportamento Real, ABMS/NRSP, São Paulo, p. 7-44.

Boscov, M.E.G. (2008). Geotecnia Ambiental, Oficina de Textos, São Paulo, 248 p.

Boscov, M. E. G.; Campi, T. H. O ; Afonso, B. C. ; Tavares, J. A. M. ; Tercini, J. R. B.; Bergamo, L. D.; Ribeiro, M. W.; Juliano, R. A. P. (2011). Effects of pore pressure on slope stability of sanitary landfills. In: ICECE 2011 VII International Conference on Engineering and Computer Education, 2011. ICECE 2011 VII International Conference on Engineering and Computer Education,. p. 1-5.

Bonaparte, R., Ah-Line, C., Charron, R., Tisinger, L. (1988). Survivability and durability of a nonwoven geotextile. Geotechinical Special Publication no 18. Geosynthetics for soil improvement, ASCE, pp 68-91.

Brown, R. P. e Greenwood, J. H. (2002). Practical guide to the Assesment of Useful Life of Plastics. Era Technology Limited, UK. 183p.

Bueno, M. T. N. S. (2007). Análise da degradação de alguns geossintéticos em contato com fluídos agressivos. Tese de Doutorado. Faculdade de Tecnologia, Universidade de Brasília. Distrito Federal. 200 p.

Campi, T.M.O. (2011). Estimativa dos Parâmetros de Resistência ao Cisalhamento e do Módulo de Elasticidade dos Resíduos Sólidos Urbanos utilizando Resultados 
de Ensaios de Placa em Aterro Sanitário. Dissertação de mestrado. Escola Politécnica da Universidade de São Paulo, São Paulo.

Cardim, R. D. (2008). Estudo da Resistência de Resíduos Sólidos Urbanos por Meio de Ensaios de Cisalhamento Direto de Grandes Dimensões. Dissertação de Mestrado. Faculdade de Tecnologia, Universidade de Brasília, Distrito Federal, $91 \mathrm{p}$.

Cartier, G. \& Baldit, R.. (1983). Comportement Géotechnique dês Décharges de Résidus Urbains. Bulletin de Liaison dês Laboratoires dês Ponts et Chaussés, n. 128, p.55-64, Paris-França.

Carvalho, M. F. (1999). Comportamento Mecânico de Resíduos Sólidos Urbanos. Teses de doutorado. Escola de Engenharia de São Carlos, Universidade de São Paulo, 300p.

Carvalho, M. F.; Vilar, O.M. ; Kaimoto, L. S. (2000). Estudo da compressibilidade de resíduos sólidos urbanos. Solos e Rochas, São Paulo, v.23, n.1, p. 3-19.

Catapreta, C. A. A. (2008). Comportamento de um Aterro Sanitário Experimental: Avaliação da Influência do Projeto, Construção e Operação. Tese de Doutorado. Escola de Engenharia, Universidade Federal de Minas Gerais, 316 p.

Coelho, M. C. N. (2001). Impactos ambientais em áreas urbanas - teorias, conceitos e métodos de pesquisa. In: Guerra, A. J. T.; Cunha, S. B. C. (Org.) Impactos ambientais urbanos no Brasil. Rio de Janeiro: Bertrand Brasil, 2001. p.19-45.

Costa, C. M. L. (1999). Fluência de Geostêxteis. Dissertação de Mestrado. Escola de Engenharia de São Carlos, Universidade de São Paulo. São Carlos, 97 p.

Costa, C. M. L. (2004). Deformações Dependentes do Tempo em Muros de Solo Reforçado com Geotêxteis. Tese de Doutorado. Escola de Engenharia de São Carlos, Universidade de São Paulo. São Carlos, 330 p.

Comlurb (2009). Caracterização Gravimétrica e Microbiológica dos Resíduos Sólidos Domiciliares do Município do Rio de Janeiro, Rio de Janeiro.

Coumoulos, D.G.; Koryalos, T.P.; Metaxas, I.L.; Gioka, D.A. (1995). Geotechnical Investigation at the Main Landfill of Athens, Procedings Sardinia 95, Fifth International Landfill Symposium, S. Margherita di Pula, Cagliaria, Italy, October 
1995, p.885- 895 .

Cowland, J.W.; Koor, N.P. (1995). Stability Considerations for Steep Valley Landfills. Proceedings Sardinia 95, Fifth International Landfill Symposium, S. Margherita di Pula, Cagliari, Italy, October 1995, p.790 - 800.

Cowland, J.W.; Tang, K.Y.; Gabay, J. (1993). Density and Strength Properties of Hong Kong Refuse. Proceedings Sardinia 93, Fourth International Landfill Symposium, S. Margherita di Pula, Cagliari, Italy, October 1993, p.1433 - 1446.

Cruz, P.T. (1996). 100 Barragens Brasileiras: casos históricos, materiais de construção, projeto. $2^{\mathrm{a}}$ ed.. Oficina de Textos, São Paulo, 1996.

Dixon, N., Jones. D. R. V. (2005). Engeneering Properties of Municipal Solid Waste. Geotextiles and Geomembranes 23 (2005) 205-233.

Dixon N., Ngambi S., Jones D.R.V. (2004). Structural performance of a steep slope landfill lining system. Proc. of the Institution of Civil Engineers, Geotechnical Engineering, № 157, Issue GE3, p. 115 - 125.

Edincliler, A., Benson, C.H., and Edil, T.B. (1996). Shear Strength of Municipal Solid Waste. Interim Report - Year 1. Department of Civil and Environmental Engineering, University of Wisconsin, Madison, Wisc. Environmental Geotechnics Report 96-2.

Edil, T.B.; Ranguette, V.J.; Wuellner, W.W. (1990). Settlement of Municipal Refuse. Geotechnics of Waste Fills - Theory and Practice, ASTM STP 1070, Arvid Landva and G. David Knowles, Eds., American Society for Testing and Materials, Philadelphia, 1990, p.225-239.

Eid, H.T., Stark, T.D., Evans, W.D. and Sherry, P.E. 2000. Municipal solid waste slope failure - I: Waste and foundation soil properties. Journal of Geotechnical and Geoenvironmental Engineering, ASCE, 126(5): 397-407.

Ehrlich, M. \& Becker, L. (2009). Muros e Taludes de Solo Reforçado, Projeto e Execução. Oficina de Textos, São Paulo, 126 p.

Erlich, M.; Mitechell, J.K. (1994). Working Stress Design Method for Reinforced Soil Walls, Journal of Geotechnical Engineering, ASCE, Reston, Virginia, v.120, n.4, p.625-645, 1994. 
Elias, V.; Christopher, B.R.; Berg, R.R. (2001). Mechanically Stabilized Earth Walls and Reinforced Soil Slopes - Design and Construction Guidelines. Geotechnical Engineering, Washington, n. FHWA-NHI-00-043, p.394.

Fasset, J.B.; Leonards, G.A.; Repetto, P.C. (1994). Geotechnical properties of municipal solid wastes and their use in landfill design. In: Waste Technical Conference - Wastetech '94, 1994, Charleston, 32p.

Fucale, S.P. (2005). Influência dos componentes de reforço na resistência de resíduos sólidos urbanos. Tese de Doutorado, Centro de Tecnologia e Geociências, Universidade Federal de Pernambuco, Recife, Pernambuco, 215p.

Fucale, S.P., Jucá, J.F.T. (2002) Estudo da resistência à penetração dinâmica (SPT) em aterros de resíduos sólidos urbanos. Proc. XXVIII Congresso Interamericano de Engenharia Sanitária e Ambiental, Cancun, México.

Gandolla, M.; Dugnani, L.; Bressi, G.; Acaia, C. (1994). Determinação dos Efeitos do Recalque sobre os Depósitos de Lixo Solido Municipal. Simpósio Internacional de Destinação do Lixo, novembro, 1994, Salvador, p.191 - 211.

Girard, H.; Fischer, S.; Alonso, E. (1990). Problems of Friction Posed by Use of Geomembranes on Dam Slopes - Eexamples and Measurements. Geotextiles and Geomembranes, Vol.9, n.2, pp.129 - 143.

Giroud, J.P.; Swan, R.H.JR.; Richer, P.J.; Spooner, P.R. (1990). Geosynthetic Landfill Cap: Laboratory and Field testes, Design and Construction. Proceedings of the $4^{\text {th }}$ International Conference on Geotextiles, Geomembranes and Related Products, Vol.2, The Hague, Netherlands, Bakelma, Rotterdam, pp. 493 - 498.

Gomes C.M.B.C. (2008). Estudo do Comportamento de Aterros de Resíduos. Caracterização Física, Bioquímica e Mecânica dos Resíduos Sólidos Urbanos. Tese de Doutorado. Faculdade de Engenharia da Universidade do Porto (FEUP). $536 p$.

Grisolia, M.; Nopoleoni, Q.; Tancredi, G. (1995). Contribution to a Technical Classification of MSW. Proceedings Sardinia 95, Fifth International Landfill Symposium, S. Margherita di Pula, Cagliari, Italy. October 1995 p.705-710.

Grisolia, M.; Nopoleoni, Q. (1996). Geotechnical Characterization of Municipal Solid 
Waste: Choice of Design Parameter. Proc. Of The Second International Congress on Environmental Geotechnics, Osaka, Japan, A.A.Balkema, 5-8 november 1996, v.2,p. 641-646.

Hachich, W.C. (1978). Sobre a Segurança nos Projetos de Geotecnia. Dissertação de mestrado, Escola Politécnica, Universidade de São Paulo, São Paulo.

Hossain, M.S., Haque, M.A. (2009). Stability Analyses of Municipal Solid Waste Landfills with Decomposition. Geotech Geol Eng (2009) 27:659-666.

IBGE - Instituto Brasileiro de Geografia e Estatística (2010). Censo demográfico 2000. Características gerais da população: resultados da amostra. http://www.ibge.gov.br/home/estatistica/populacao/censo2000/populacao/tabela_b rasil.shtm, 8/2/2010.

IBGE - Instituto Brasileiro de Geografia e Estatística (2010). Dados históricos dos censos.

http://www.ibge.gov.br/home/estatistica/populacao/censohistorico/1940_1996.sht $\mathrm{m}, \mathrm{8} / 2 / 2010$.

IBGE - Instituto Brasileiro de Geografia e Estatística (2010). Pesquisa Nacional de Saneamento Básico. http://www.ibge.gov.br/home/estatistica/populacao/condicaodevida/pnsb2008/defa ulttabpdf_man_res_sol.shtm, 19/01/2012.

IBAM - Instituto Brasileiro de Administração Municipal (2001), Estatuto das Cidades, Rio de Janeiro, $60 \mathrm{p}$.

IPT - Instituto de Pesquisas Tecnológicas (2000). Lixo Municipal: manual de gerenciamento integrado, IPT/CEMPRE, 2a edição, IPT Publicação 2.622, São Paulo, $370 \mathrm{p}$.

Jessberger, H. L.; Kockel, R. (1993). Determination and Assessment of the Mechanical Properties os Waste Materials. Proceedings Sardinia 93, Fourth International Landfill Symposium, S. Margherita di Pula, Cagliari, Italy, October 1993, p. 1383-1392.

Jewell, R.A. (1996). Soil reinforcement with geotextiles. London, Ciria. Cap.2. p1530: Polymer and geotextile properties. 
Jewell, R.A.; Wroth, C.P. (1987). Direct Shear Tests on Reinforced Sand. Géotechnique, v. 37, Issue 1, p.53-68.

Kaimoto, L.S.A.; Cepollina, M. (1996). Considerações sobre alguns condicionantes e critérios geotécnicos de projeto e executivos de aterros sanitários, Simpósio Internacional de Qualidade Ambiental, Porto Alegre, p. 51-54.

Karpurapu, R.; Bathurst, R.J. (1995). Behaviour of Geosynthetic Reinforced Soil Retaining Walls Using the Finite Element Method. Computers And Geotechnics, n.17, p. $279-299$.

Kavazanjian, E.; Matasovic, N. (1995). Seismic Analysis of Solid Waste Landfills. Geoenviromental 2000. Geotechnical Special Publication n46, ASCE, vol.2, Ed. Yalcin B. Acar and David E. Daniel, New Orleans, p.1066 - 1080.

Knochenmus, G.; Wojnarowicz, M., Van Impe (1998). Stability of Municipal Solid Wastes. In: Proc. Of the Third International Congress on Environmental Geotechnics, Lisboa, Portugal, Sêco e Pinto (ed,.), Balkema, Rotterdam, p. 9771000.

Koerner, R.M. (1998). Designing with Geosynthetics. Prentice-Hall Inc., 4rd Ed., New Jersey, $761 \mathrm{pp}$.

Kolsch, F. (1995). Material Values for Some Mechanical Properties of Domestic Waste. Proceedings Sardinia 95, Fifth International Landfill Symposium, S. Margherita di Pula, Cagliari, Italy, October 1995, p.711-729.

Kolsch, F. (1993). The bearing behavior of domestic waste and related consequences for stability. In: International Landfill Symposium, 4., Cagliari, Sardinia. Proceedings. Cagliari: CISA, 1993.

Ling, H.I.; Leshchinsky, D.; Mohri, Y.; Kawabata, T. (1998). Estimation of Municipal Solid Waste Landfill Settlement. Journal of Geotechnical and Geoenvironmental Engineering, v.124, $\mathrm{n}^{\circ 1}$, January, 1998, ASCE, p.21-28.

Lopes, M.P e Lopes, M. L. (2009). A Durabilidade dos geossintéticos. FEUP Edições. 1ª edição. Porto, 295p.

Machado, S.L.; Carvalho, M.F.; Nascimento, J.C.F.; Dourado, K.A. (2005). Estudo do Comportamento Mecânico dos Resíduos Sólidos Urbanos sob a Influência da Biodegradabilidade. XXIII Congresso Brasileiro de Engenharia Sanitária e 
Ambiental, Campo Grande, Mato Grosso do Sul, 1-8.

Mahler, C.F. e Iturri, E.A.Z. (1998). The Finite Element Method applied to the study of solid waste landfills, Third International Congress on Environmental Geotechnics, Lisboa, vol. 1, p. 89-94.

Manassero, M.; Van Impe, W.F. \& Bouazza, ,A. (1996). Waste Disposal and Containment. In: Proc. Of The Second International Congresso n Environmental Geotechnics, Preprint of special lectures, Osaka, Japan, A. A. Balkema, ,v.3,p. $1425-1474$.

Mariano, M.O.H.; Jucá, J.F.T. (1998). Monitoramento de Recalques no aterro de Resíduos Sólidos de Muribeca. XI Congresso Brasileiro de Mecânica dos Solos e Engenharia Geotécnica, v.3, novembro 1988, Brasília. P.1671 - 1678.

Marques, A.C.M. (2001). Compactação e compressibilidade de resíduos sólidos urbanos. Tese de doutorado. Escola de Engenharia de São Carlos, Universidade de São Paulo, São Carlos.

Martins, H. L. (2006). Avaliação da Resistência de Resíduos Sólidos Urbanos pro Meio de Ensaios de Cisalhamento Direto em Equipamento de Grandes Dimensões. Dissertação de Mestrado. Programa de Pós-Graduação em Saneamento, Meio Ambiente e Recursos Hídricos, Universidade Federal de Minas Gerais, Minas Gerais, 116 p.

Marques, A.C.M. (2001). Compactação e Compressibilidade de Resíduos Sólidos Urbanos, Tese de Doutorado, Escola de Engenharia de São Carlos, Universidade de São Paulo, 408 p.

Matasovic, N., ,Kavazanjian E.Jr. (1998). Cyclic Characterization of Oll landfill solid Waste. Journal of Geotechnical and Geoenvironmental Engineering, ASCE, Vol.129, N4, p. $372-378$.

Matheus, E. (2002). Efeito do Envelhecimento Acelerado e do Dano Mecânico Induzido no Desempenho e Durabilidade de Alguns Geossintéticos. Tese de Doutorado. Publicação G.TD-010ª̂2, Departamento de Engenharia Civil e Ambiental, Universidade de Brasília, DF, 284p.

Miguel, P.A.; Margarida, P.L.; Maria de Lurdes. L. (2009). Effet of Damage During Instalation on Mechanical Behavior of a Woven Polyester Geogrid. In: $3^{\circ}$ Seminário Português sobre Geossintéticos. Combra, p.319 - 329. 
Ministério das Cidades (2003). Diagnóstico do Manejo de Resíduos Sólidos Urbanos - 2003. Sistema Nacional de Informações sobre Saneamento (SNIS) - Secretaria Nacional de Saneamento Ambiental. Brasília, 2005.

Mitchell, J.K.; Bray, J.D.; Mictchell, R.A. (1995). Material Interactions in Solid Waste Landfills. Geoenviromental 200. Geotechnical Special Publication n 06 , ASCE, vol.1, p.568 - 590. Ed. Yalcin B. Acar and David E. Daniel, New Orleans.

Moraes, C.M. (2002). Aterros Reforçados sobre Solos Moles - Análise Numérica e Analítica. Dissertação de Mestrado. Universidade Federal do Rio de Janeiro, Rio de Janeiro, $223 \mathrm{p}$.

Moravia, W. G. (2007). Estudos de caracterização, tratabilidade e condicionamento de lixiviados visando tratamento por lagoas. Dissertação de mestrado, EE/UFMG, Belo Horizonte, MG, Brasil.

Msouti, M.F.; Blivet, J.C.; Levacher, D. (1997). Comportement au fluage des géotextiles em reforcement mécanique. Études et recherches des laboratories des Ponts et Chaussées, GT n.63.

Nascimento, M.T. (2002). Avaliação de Dano Mecânico em Geossintéticos em Obras de Disposição de Resíduos. Dissertação de Mestrado. Faculdade de Tecnologia, Universidade de Brasília, Distrito Federal, 105 p.

Oliveira, D.A.F. (2002). Estabilidade de Taludes de Maciços de Resíduos Sólidos Urbanos. Dissertação de Mestrado, Universidade de Brasília, Distrito Federal, $143 p$.

Oliveira, G.A. (2006). Verificação da Influência da Rigidez do Reforço em Muro de Solo Reforçado em Modelos Físicos. Dissertação de Mestrado. Universidade Federal do Rio de Janeiro, Rio de Janeiro, 166 p.

Oweiss I.S. (1993). Stability of landfills. Chapter 11 of Geotechnical Pratice for Waste Disposal, edited by D.E. Daniel, Chapman \& Hall.

Ouvry, J.F.; Page, B. (2005). Settlement of waste package in chaffs in a domestic waste disposal. In: International Workshop Hydro - Physico - Mechanics Of Landfills, Grenoble, France, 2005. Proceedings. Grenoble: Grenoble University. 
Palmeira, E.M. (2011). Embankments. In: Sanjay K. Shukla. (Org.). Handbook of Geosynthetic Engineering. 2 ed. London: ICE-The Institution of Civil Engineers, 2011, v. 1, p. 1-55.

Palmeira, E.M. (1999). Utilização de Geossintéticos em Geotecnia Ambiental. Departamento de Engenharia Civil e Ambiental, Universidade de Brasília, Brasília, DF.

Palmeira, E.M. (2003). Fatores condicionantes do comportamento de filtros geotêxteis. REGEO'2003 - V Congresso Brasileiro de Geotecnia Ambiental / GEOSSINTÉTICOS'2003 - IV Simpósio Brasileiro de Geossintéticos, Porto Alegre, p. 49-67.

Paulson, J. N. (1990). Summary and evaluation of construction related damage to geotextiles in reforcing applications. Fouth International Conference on Geotextile, Geomembranes and Relateded Products, The Hague, 1990. Proceeding. Rotterdam, A.A. Balkema, v. 2, pp 615-619.

Pedroso, E.O. (2000). Estruturas de contenção reforçadas com geossintéticos. Dissertação de mestrado. Escola de Engenharia de São Carlos, Universidade de São Paulo, 74p.

Pinto, A. E. S. (2005). Aplicação de Geossintéticos em Linhas Férreas, Estudo Laboratorial dos Fenómenos de Danificação Durante a Instalação e Abrasão nos Materiais. Dissertação de Mestrado. Faculdade de Engenharia. Universidade do Porto, Porto, 168 p.

Ramirez, R.R.; Gourc, J.P.; Billet, P. (2002). Influence of the friction test conditions on the characterization of the geosynthetics interfaces - Geosynthetics $-7^{\text {th }}$ Gourc \& Girard (eds), 2002, Swets \& Zeitlinger, pp.591 - 594.

Reddy, K.R., Hettiarachchi, H., Gangathulasi, J., Bogner, J.E., (2011). Geotechnical Properties of Municipal Solid Waste at Different Phases of Biodegradation. Waste Management (2011).

Ribeiro, A.G.C. (2007). Determinação de Parâmetros de Resistência de Resíduos Sólidos Urbanos por Meio de Retro-Análises de Testes em Laboratório. Dissertação de Mestrado. Universidade Federal de Viçosa. Viçosa. p100.

Ribeiro, A.G.C. ; Azevedo, R. F (2008). Estimativa dos Parâmetros de Resistência de 
Resíduos Sólidos Urbanos da Cidade de Viçosa - MG por Meio de Ensaios Realizados em Laboratório. In: XIV Congresso Brasileiro de Mecânica dos Solos e Engenharia Geotécnica, 2008, Armação de Búzios. Anais do XIV Congresso Brasileiro de Mecânica dos Solos e Engenharia Geotécnica, 2008.

Salamoni, R.H.; Pinheiro, R.J.B. e Nummer, A.V. (2009). Processo operacional da Central de Tratamento de Resíduos da Caturrita - Santa Maria, RS, Teoria e Prática na Engenharia Civil, n.14, p. 43-50.

Santos, L.A.O.; Presa, E.P. (1995). Compressibilidade de aterros sanitários controlados, Terceiro Simpósio sobre Barragens de Rejeitos e Disposição de Resíduos - REGEO'95, Ouro Preto, Vol. 2, p. 577-591.

Sieira, A.C.C.F.; Gerscovich, D.M.S.; Sayão, A.S.F.J. (2005) . Maciços Reforçados com Geogrelhas: Mecanismos de Transferência de Carga.. In: Congresso Brasileiro de Estabilidade de Encostas - IV COBRAE, 2005, 2005, Salvador. Anais do IV COBRAE, 2005. v. 1. p. 671-680

Silveira, A. M. M. (2004). Estudo do Peso Específico de Resíduos Sólidos Urbanos. Dissertação de Mestrado, Universidade Federal do Rio de Janeiro, Rio de Janeiro, $101 \mathrm{p}$.

SMLU - Secretaria Municipal de Limpeza Urbana. Caracterização dos Resíduos Sólidos Domiciliares de Belo Horizonte. Belo Horizonte: SMLU, julho/2003.

Stark T. D, Eid, H., Evans W.D, Sherry P. (2000) Municipal solid waste slope failure i: waste and foundation soil properties. J Geotechn Geoenviron Eng ASCE 126(5):397-407.

Stark T.D., Huvaj-Sarihan, N., Li, G. (2009). Shear Strength of Municipal solid Waste for Stability Analyses, Environ Geol 57:1911 - 1923.

Souto, G. D'A.B., Povinelli, J. (2007). Características do lixiviado de aterros sanitários no Brasil. $24^{\circ}$ Congresso Brasileiro de engenharia Sanitária e Ambiental, Belo Horizonta, MG, Brasil.

Teixeira, S.H.C.. (2003). Estudo da interação solo-geogrelha em testes de arrancamento e sua aplicação na análise e dimensionamento de maciços reforçados. Tese de doutorado, Universidade de São Paulo, São Paulo. $214 f$. 
Tchobanoglous, G.; Theisen, H.; Vigil, S. (1993). Integrated Solid Waste Management Engineering Principles and Management Issues. MacGraw-hill, Inc., 1993, 978p.

Towhata, I., Kawano, Y., Yonai, Y., Koelsh, F., 2004. Laboratory tests on dynamic properties of municipal wastes. Proc. of 11th Conference on Soil Dynamics and Earthquake Engineering and 3rd International Conference on Earthquake Geotechnical Engineering, Vol.1, p. $688-693$.

UFA - Universidade federal de Alagoas. Gerenciamento integrado para transferência e destino final dos resíduos sólidos urbanos de Maceió. 256p. Maceió, 2004.

UFV - Universidade Federal de Viçosa. Relatórios Técnicos. Departamento de Engenharia Civil (DEC), Laboratório de Engenharia Sanitária e Ambiental (LESA), 1999.

US Army Corps of Engineers. Slope Stability. EM 1110-2-1902. Washington, 2003.

USEPA, 2006. Municipal Solid Waste in The United States: 2005 Facts and Figures. $<$ www.epa.gov>

Van Impe, W.F., Bouazza, A. (1996). Densification of Domestic Waste Fills by dynamic Compaction. In: Canadian Geotechnical Journal, v.33, p.879-887.

Van Impe, W.F. (1998). Environmental Geotechnics - ITC5 - Reports and Future Goals. Geotechnical Hazards, Maric, Lisac \& Szavits-Nossan (eds), Balkema, Rotterdam. p.127 - 156.

Van Meerten, J. J.; Sellmeijer, J. B. \& Pereboom, D, (1995). Prediction of Landfill Settlements. Proceedings Sardinia 95, Fifth International Landfill Symposium, S. Margherita di Pula, Cagliari, Italy, October 1995, p.823-831.

Vertematti, J. C., et al. (2004). Manual Brasileiro de Geossintéticos, ed. Edgard Blücher, São Paulo.

Viana, H.N.L. (2003). Estabilidade de Taludes de Áreas de Disposição de Resíduos Revestidos com Geossintéticos: Influência da Presença de Geogrelhas, Dissertação de Mestrado, Universidade de Brasília, 98p.

Vilar, O.M.; Marques, A.C.M.; Carvalho, M.F. e Machado, S.L. (2006). Some remarks on the mechanical properties and modeling of municipal solid waste. Simpósio 
Internacional de Tecnologias e Tratamento de Resíduos Sólidos - SITTRS, CDROM, Rio de Janeiro, p. 1-12.

Wall, D.K.; Zeiss, C. (1995). Municipal Landfill Biodegradation and Settlement. Journal of Environmental Engineering, ASCE, vol.121, n³, March, p.214-224.

Zeccos D.P. (2005). Evaluation of Static and Dynamic Properties of Municipal Solid Waste. Phd Thesis on Civil and Environmental Engineering, Universitu of California, Berkeley, 578p. 